\title{
Phase Transformation, Texture and Mechanical Anisotropy in Zirconium Alloys
}

\author{
by \\ Randy W.L. Fong, M.A.Sc., P.Eng. \\ A thesis submitted to The Faculty of Graduate Studies and Research in partial fulfillment \\ of the requirements for the degree of \\ Doctor of Philosophy
}

Ottawa-Carleton Institute of Mechanical and Aerospace Engineering

Department of Mechanical and Aerospace Engineering

Carleton University

Ottawa, Ontario

September 2013

(C) Randy W.L. Fong, 2013 
The undersigned recommend to

the Faculty of Graduate Studies and Research acceptance of the thesis

\section{Phase Transformation, Texture and Mechanical Anisotropy in Zirconium Alloys}

by

Randy W.L. Fong, M.A.Sc., P.Eng.

in partial fulfilment of the requirements

for the degree of Doctor of Philosophy

Dr. Ron Miller, Thesis Supervisor

Dr. Henry M.J. Saari, Thesis Co-Supervisor

Dr. Metin. I. Yaras

Chair, Department of Mechanical and Aerospace Engineering

Carleton University

September 2013 


\section{Abstract}

In $\mathrm{CANDU}^{\circledR 1}$ reactors, zirconium alloys are used for three tubing components. Zircaloy-4 is used for the fuel sheaths. $\mathrm{Zr}-2.5 \mathrm{Nb}$ alloy is used for the pressure tubes, and Zircaloy- 2 is used for the calandria tubes. These three tubes are manufactured using different processes, and they have different crystallographic textures and microstructures due to the different processes used to manufacture the tubes. These tubes normally operate at low temperatures $\left(<350^{\circ} \mathrm{C}\right)$. In a hypothetical loss-of-coolant accident (LOCA), these tubes may be subjected to high temperatures up to $1000^{\circ} \mathrm{C}$ or higher. During the temperature transient, a phase transformation occurs that changes the microstructure which affects the material's high-temperature deformation behaviour.

This thesis investigated the texture evolution, phase transformation and mechanical anisotropy in as-manufactured and two modifications ('A' and 'B') of CANDU Zr-2.5Nb pressure tube materials using neutron diffraction during heating up to $1050^{\circ} \mathrm{C}$ and on cooling. These investigations provided a further understanding of the anisotropic deformation behaviour observed in high temperature-ramped tensile deformation tests. The stable evolution of the hexagonal close-packed (hcp) $\alpha-Z r$ texture and changes in volume fraction of body-centered cubic (bcc) $\beta$-Zr, resulting from temperature changes during heating (or cooling) has provided key information to help explain the mechanical anisotropy response of as-manufactured pressure tube material. CANDU-type Zircaloy-4 fuel sheaths with as-manufactured and two simulated braze zone microstructures (one for the spacer location and the other simulating the heat-affect-

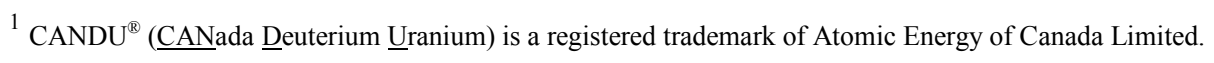


zone) were also investigated. An in-situ approach has been developed using SELFPOLY (a polycrystalline model) to determine the Kearns (texture) numbers and Hill's anisotropy factors with texture (Orientation Distribution Function) data obtained on fuel sheaths with previously known anisotropy factors measured using strain tests. The same approach was applied to the two modified $\mathrm{Zr}-2.5 \mathrm{Nb}$ pressure tube materials for comparison with the mechanical anisotropy of differently textured fuel sheaths. Further research work to validate the anisotropy factors are suggested using ballooning tests on fuel sheaths and high temperature-ramped tensile tests on the two modified pressure tube materials. 


\section{Preface}

This thesis is based on the following four manuscripts which are published in peer-reviewed journals or conference publication:

\section{Chapter 4}

R.W.L. Fong, R. Miller, H. Saari, and S.C. Vogel, Crystallographic texture and volume fraction of $\alpha$ and $\beta$ phases in as-received $\mathrm{Zr}-2.5 \mathrm{Nb}$ pressure tube material during heating and cooling, Metall. Mater. Trans.A, Vol. 43A, pp. 806-821, 2012

http://dx.doi.org/10.1007/s11661-011-0914-6

\section{Chapter 5}

R.W.L. Fong, Anisotropic deformation of $\mathrm{Zr}-2.5 \mathrm{Nb}$ pressure tube material at high temperatures, J. Nucl. Mater., Vol. 440, pp. 467-476, 2013

http://dx.doi.org/10.1016/j.jnucmat.2013.01.308

Chapter 6

R.W.L. Fong, Anisotropy factors from texture and mechanical strain in Zircaloy-4 fuel sheaths, J. Nucl. Mater., Vol. 440, pp. 288-297, 2013

http://dx.doi.org/10.1016/j.jnucmat.2013.04.089

\section{Chapter 7}

R.W.L. Fong, S. Vogel, R. Miller, and H. Saari, Characterization of the crystallographic textures and mechanical anisotropy factors in two modifications of $\mathrm{Zr}-2.5 \mathrm{Nb}$ pressure-tube materials, $8^{\text {th }}$ Pacific Rim International Conference on Advanced Materials and Processing (PRICM-8), Waikoloa, Hawaii, USA, August 4-9, 2013

The work presented in this thesis is original and my own with co-authors and supervisors in an advisory role.

The supervisor and co-supervisor of this thesis, hereby, attest that the information provided is accurate.

Dr. Ron Miller (Supervisor):

Dr. Henry M.J. Saari (Co-Supervisor): 


\section{Acknowledgements}

The author would like to express his sincere thanks and appreciation of the guidance and support received from Professors Ron Miller and Henry Saari of Carleton University. The author would also like to thank CANMET for cold-rolling of the samples used in this study. Thanks are due to Ken Kidd for the reversed bend samples of pressure tube and fuel sheaths, and Peter Moss for the vacuum encapsulation of the pressure tube samples in quartz tubes. Thanks are also due to Alan West and Gary Haacke for performing the high-temperature ramped tensile tests. I would also like to thank Steve Livingstone and Norm Lair for providing the samples of Zircaloy-4 fuel sheath materials used in this study. I would like to thank On Ting Woo for the TEM micrographs and Mark Seguin for the optical micrographs of the pressure tube and fuel sheath samples reported in this thesis. This work has benefited from the continuous support provided by Atomic Energy of Canada Limited. The author wishes to thank AECL management for their kind support of this research work. I would like to thank Kit Coleman (Researcher Emeritus), Brian Leitch, Thambiayah Nitheanandan, and Penny Neal for their reading and providing many useful comments - they are much appreciated. The assistance of Dimitry Sedaiko (NRC-Chalk River) with the neutron diffraction study is gratefully acknowledged. The many advice and support from Ian Swainson (NRC) are most appreciated.

This work has benefited from the use of the Manuel Lujan, Jr. Neutron Scattering Center at LANSCE, which is funded by the United States Department of Energy Office of Basic Energy Sciences. The author wishes to thank the staff scientists at LANSCE, in particular, Sven Vogel for his guidance and support with the HIPPO texture measurements. Many thanks are due to Xiahui $\mathrm{Yu}$ and Helmut Reiche for their assistance with the texture measurements performed at LANSCE.

Finally, I wish to express my appreciation of my life partner, Sylvie Pepin and my children, Allan and Naomi, for their countless support and encouragement to complete this thesis. 
In closing, I can iterate that what I have learned through this research is truly a reflection of this quote, and that is ... "The important thing in science is not so much to obtain new facts as to discover new ways of thinking about them”, by William Lawrence Bragg. 


\section{Table of Contents}

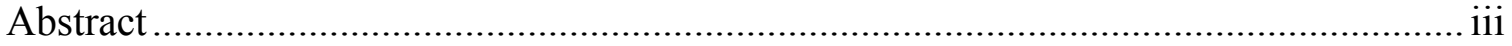

Preface

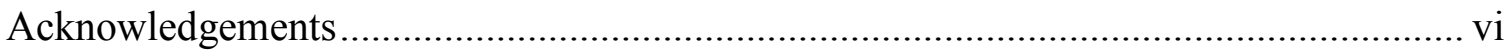

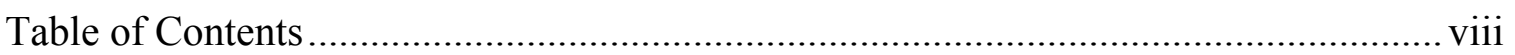

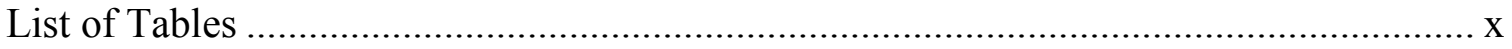

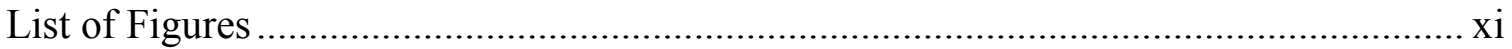

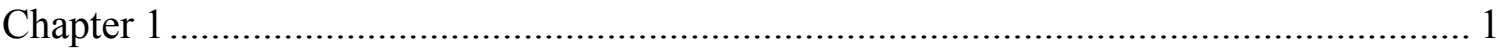

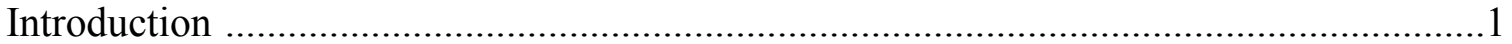

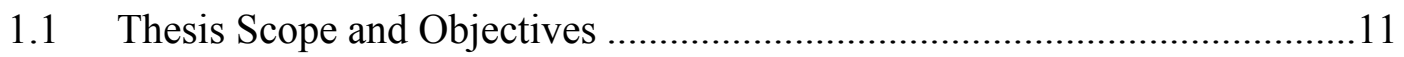

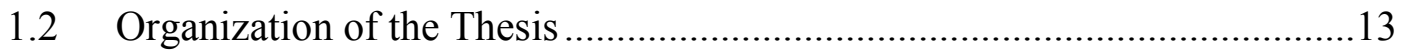

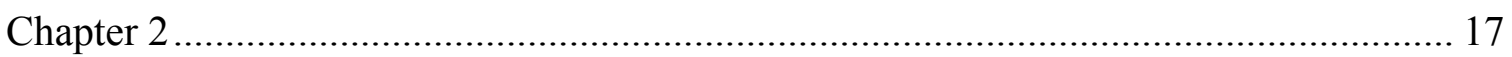

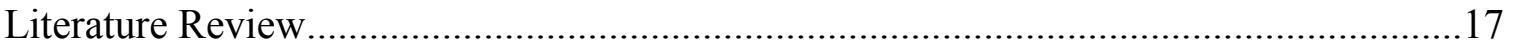

2.1. Phase Diagrams and Transformations in Zirconium Alloys........................ 17

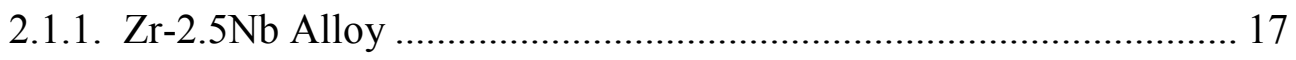

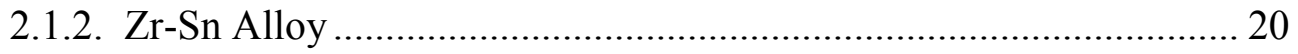

2.1.3. Investigations of Phase Transformations .......................................... 21

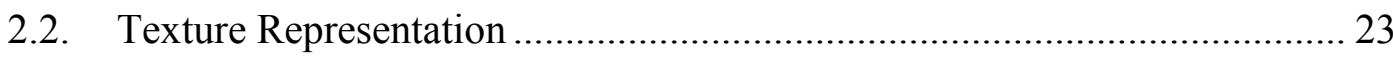

2.2.1 Direct pole figure............................................................................. 24

2.2.2 Inverse pole figure ........................................................................ 27

2.2.3 Orientation distribution function (ODF) ......................................... 28

2.2.4 Kearns (texture) numbers [2.37] .................................................... 40

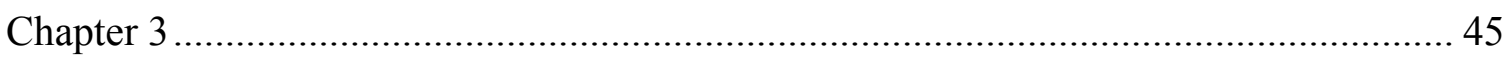

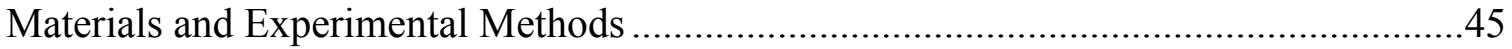

3.1 Zr-2.5Nb Pressure Tube Materials........................................................... 45

3.2 Zircaloy-4 Fuel Sheath Materials............................................................... 50

3.3 Neutron Diffraction Measurements ........................................................... 54 
Chapter 4

Crystallographic Texture and Volume Fraction of $\alpha$ - and $\beta$-Phase in $\mathrm{Zr}-2.5 \mathrm{Nb}$

Pressure Tube Material During Heating and Cooling...................................................64

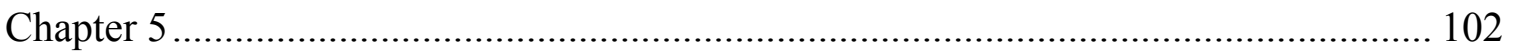

Anisotropic Deformation of Zr-2.5Nb Pressure Tube Material at High

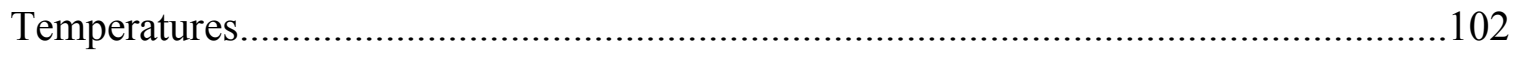

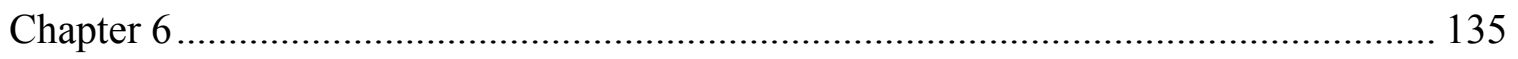

Anisotropy Factors from Texture and Mechanical Strain in Zircaloy-4 Fuel

Sheaths

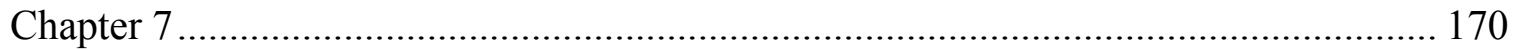

Characterization of the Crystallographic Textures and Mechanical Anisotropy

Factors in Two Modifications of Zr-2.5Nb Pressure Tube Materials............................170

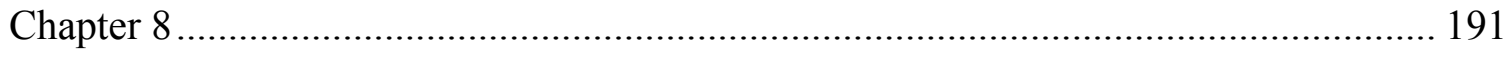

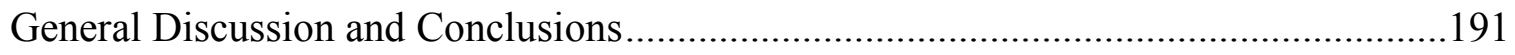

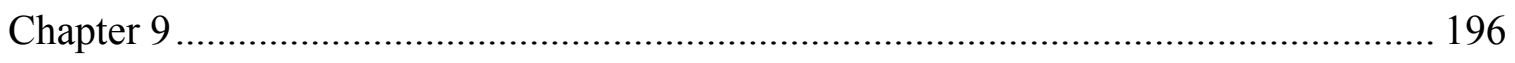

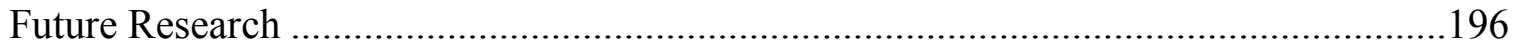

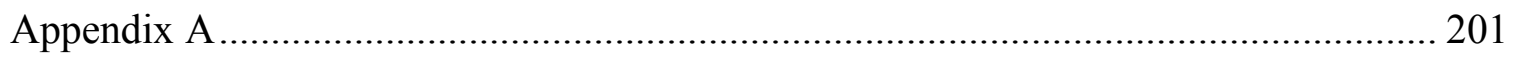

An example of MAUD analysis using the Rietveld method and EWIMV

algorithm used to calculate the orientation distribution function of crystallites using measured pole figures. 


\section{List of Tables}

Table 1.1 Typical chemical composition of Zirconium alloys $(\mathrm{wt} \%)$............................ 4

Table 3.1 A typical chemical composition of $\mathrm{Zr}-2.5 \mathrm{Nb}$ alloy pressure tube .................. 46

Table 3.2 Chemical specification of as-manufactured Zircaloy-4 fuel sheathing ........... 52

Table 4.1 Test temperatures, lattice parameter, volume fraction, unit cell volume, and history of $\alpha$ phase during heating and cooling. (The standard error in measurements of lattice parameter is expected to be less than $1 \%$ and for volume fraction to be in the order of $10-20 \%$.)

Table 7.1 Kearns numbers and Hill's anisotropy factors for differently-processed Zircaloy-4 fuel sheath materials.

Table 8.1 Kearns numbers and Hill's anisotropy factors calculated using ODF data 


\section{List of Figures}

Figure 1.1 Schematic diagram of a CANDU fuel channel .......................................... 2

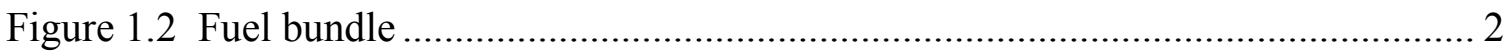

Figure 1.3 Elongated grain structure in $\mathrm{Zr}-2.5 \mathrm{Nb}$ pressure tube material ...................... 4

Figure $1.4(0002)$ and $(11 \overline{2} 0)$ pole figures for as-received $\mathrm{Zr}-2.5 \mathrm{Nb}$ pressure tube

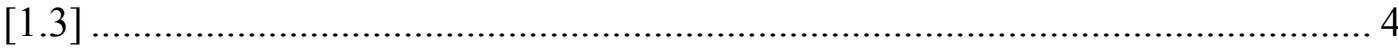

Figure 1.5 Equiaxed $\alpha-Z r$ grains in Zircaloy-2 calandria tube material ......................... 5

Figure 1.6 Basal pole figures of parent material in seamwelded $(a, b)$ and seamless

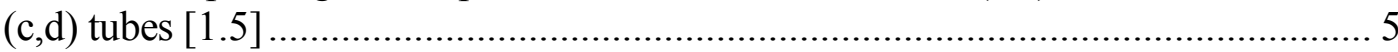

Figure 1.7 Variation of $0.2 \% \mathrm{YS}$ with neutron fluence at $23^{\circ} \mathrm{C}$ [1.7] .......................... 6

Figure 1.8 Typical manufacturing process used to produce fuel sheaths $[1.11] \ldots \ldots \ldots \ldots . . . .7$

Figure 1.9 Optical micrographs showing microstructures of Zircaloy-4 fuel sheaths: a) as-manufactured, b) braze-zone structure, and c) heat-affected zone structure

Figure 1.10 Basal pole figure of Zircaloy-2 fuel cladding tubes for BWR rods

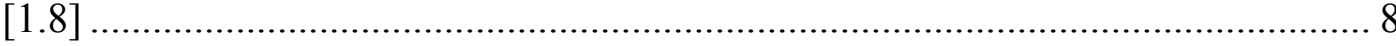

Figure 1.11 Flow surface diagrams (from Knoop hardness indentations) of different batches of Zircaloy-4 fuel cladding [1.14] ........................................ 9

Figure 1.12 Effect of neutron irradiation on resistance to plastic deformation

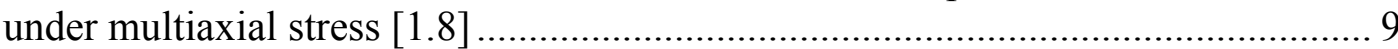

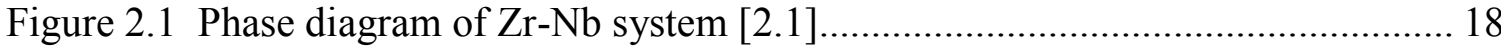

Figure 2.2 TTT-diagram for a $\mathrm{Zr}-2.5 \mathrm{wt} \% \mathrm{Nb}$ pressure tube. The numbers in

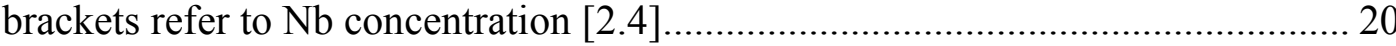

Figure 2.3 Phase diagram of Zr-Sn binary system [2.5] ......................................... 21

Figure 2.4 Orientation of the basal pole in a hexagonal crystal on the unit sphere with regard to an external reference frame described by two angles $\alpha$ and $\beta$ [2.24]

Figure 2.5 Illustration of a stereographic projection of $\{100\}$ planes in a cubic crystal with reference to the sample directions: (a) Crystal in unit sphere showing $\{100\}$ poles; (b) $\{100\}$ poles onto the equatorial plane; and (c) $\{100\}$ pole figure in stereographic projection [2.24]

Figure 2.6 [111] pole figure of 97\% cold-rolled Al with the definition of the pole

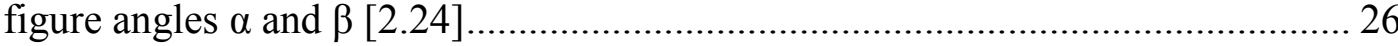

Figure 2.7 Diagram showing a stereographic and an equal-area projection [2.23] f...... 27 
Figure 2.8 Inverse pole figure of the extrusion axis of Ti deformed by extrusion [2.24]

Figure 2.9 Relationship between crystal and sample axis directions

Figure 2.10 Illustration showing the reference (a) and three rotations (b, c and d) of Euler angles $(\psi, \theta, \phi)$, in sequence, relating the HCP crystal lattice orientation with the tube sample coordinate system

Figure 2.11 Illustration showing crystal orientations described by Euler angles $(\Psi, \theta)$ for three constant- $\phi$ sections in relation to the sample axes: a) $\phi=0^{\circ}$, b) $\phi=30^{\circ}$ and c) $\phi=60^{\circ}$. 32

Figure 3.1 TEM micrographs showing elongated grain structure in $\mathrm{Zr}-2.5 \mathrm{Nb}$ pressure tube material a) longitudinal and $b$ ) transverse direction..

Figure 3.2 $\mathrm{Zr}-\mathrm{Nb}$ phase diagram [3.3]. The red dots correspond to the temperatures used in neutron measurements.

Figure 3.3 Photograph showing a stacked sample of pressure tube material used for neutron diffraction

Figure 3.4 Optical micrograph showing microstructure of Modification 'A' material.

Figure 3.5 Optical micrograph showing microstructure of Modification ' $\mathrm{B}$ ' material.

Figure 3.6 Optical micrographs showing microstructures of Zircaloy-4 fuel sheaths: a) as-received, b) simulated braze-zone structure, and c) simulated heat-affected zone structure

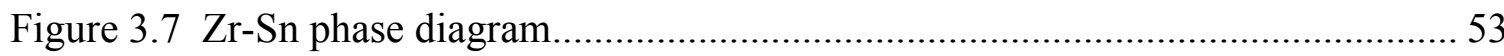

Figure 3.8 Photographs showing three samples used for neutron diffraction. 54

Figure 3.9 Schematic view of the HIPPO diffractometer used for crystallographic texture measurements with time-of-flight (TOF) neutrons at LANSCE [3.4], [3.5] 56

Figure 3.10 Coverage of pole figures by HIPPO's $40^{\circ}, 90^{\circ}$ and $150^{\circ}$ detectors for a single orientation (a) and 8 orientations (b) [3.4].

Figure 3.11 A schematic diagram showing a stacked sample of $\mathrm{Zr}-2.5 \mathrm{Nb}$ pressure tube material

Figure 3.12 Diagram showing the location of sample plates placed in a vacuum furnace used for neutron diffraction. 58

Figure 3.13 (a) Sample placed inside a vanadium basket. (b) Installation of sample holder in a vacuum furnace for texture measurements at LANSCE............58

Figure 4.1 TEM micrographs of as-received $\mathrm{Zr}-2.5 \mathrm{Nb}$ pressure tube showing elongated $\alpha-Z r$-grains containing a high density of dislocations and a thin 
layer of $\beta$-phase at the $\alpha$-grain boundaries viewing along: (a) longitudinal and (b) transverse (hoop) direction

Figure $4.2 \alpha$-phase (0002) and (11̄20) pole figures for as-received $\mathrm{Zr}-2.5 \mathrm{Nb}$ pressure tube at room temperature obtained from neutron diffraction measurements using a texture goniometer with a constant wavelength and well-resolved individual diffraction peaks [4.3].

Figure 4.3 $\mathrm{Zr}-\mathrm{Nb}$ phase diagram [4.2]. The vertical dashed line in the phase diagram corresponds to the $\mathrm{Zr}-2.5 \mathrm{Nb}$ composition where neutron measurements were performed at eight different temperatures traversing across different phase fields as shown by the points indicated along the temperature (dashed) line.

Figure 4.4 Diagrams showing Burgers orientation relationship between bcc and hcp phase lattice [4.9]: a) $(110)_{\mathrm{BCC}} / /(0002)_{\mathrm{HCP}}$ and b) $[\overline{1} 11]_{\mathrm{BCC}} / /[11 \overline{2} 0]_{\mathrm{HCP}} \cdot \ldots \ldots . . .71$

Figure 4.5 A schematic diagram showing a stacked sample consisting of two plates taken from the $\mathrm{Zr}-2.5 \mathrm{Nb}$ pressure tube material. The hoop direction of the sample is aligned with the furnace axis of rotation. The plates are held tightly together by spot-welded Zr-foils (not shown in the diagram).

Figure 4.6 TOF diffraction spectra from an as-received $\mathrm{Zr}-2.5 \mathrm{Nb}$ pressure tube sample on heating to eight different temperatures $\left[373 \mathrm{~K}\right.$ to $1323 \mathrm{~K}\left(100^{\circ} \mathrm{C}\right.$ to $\left.1050^{\circ} \mathrm{C}\right)$ ] and on cooling $\left[1173 \mathrm{~K}\right.$ and $823 \mathrm{~K}\left(900^{\circ} \mathrm{C}\right.$ and $\left.\left.550^{\circ} \mathrm{C}\right)\right]$.

Figure 4.7 The variation of unit cell volume of $\alpha$ and $\beta$ phase $\mathrm{Zr}$ in an as-received $\mathrm{Zr}-2.5 \mathrm{Nb}$ pressure tube at different heating and cooling temperatures.

Figure 4.8 Volume fraction of $\beta$-phase in as-received $\mathrm{Zr}-2.5 \mathrm{Nb}$ pressure tube material on heating at eight different temperatures $\left[373 \mathrm{~K}\right.$ to $1323 \mathrm{~K}\left(100^{\circ} \mathrm{C}\right.$ to $\left.\left.1050^{\circ} \mathrm{C}\right)\right]$ and also on cooling $\left[1173 \mathrm{~K}\right.$ and $823 \mathrm{~K}\left(900^{\circ} \mathrm{C}\right.$ and $\left.\left.550^{\circ} \mathrm{C}\right)\right]$.

Figure 4.9 Complete pole figures (equal-area projections) of $\alpha$ and $\beta$ phases in as-received $\mathrm{Zr}-2.5 \mathrm{Nb}$ pressure tube during heating $(\mathrm{g}, \mathrm{h})$ and cooling (i to 1$)$.

Figure 4.10 Pole figures of bcc $\beta$ and hcp $\alpha$ phase on heating at $823 \mathrm{~K}\left(550^{\circ} \mathrm{C}\right)$ (first two columns on left-hand side of diagram: a, b, d, e) and then on cooling at $823 \mathrm{~K}\left(550^{\circ} \mathrm{C}\right)$ after being heated to $1323 \mathrm{~K}\left(1050^{\circ} \mathrm{C}\right)$ (last two columns on right-hand side: $\mathrm{g}, \mathrm{h}, \mathrm{j}, \mathrm{k}$ ). The diagrams at the bottom of each column show the superimposed intensity peaks from pole figures of the two phases on an equal-area projection (Lambert net). An angular deviation of about $5^{\circ}$ is determined for a lattice correspondence between the bcc and hcp structure that on average essentially obeys the Burgers orientation relationship (Figure 4.4) during heating and cooling that involved a complete phase transformation sequence: $\mathrm{hcp} \rightarrow \mathrm{bcc} \rightarrow$ hcp.

Figure 4.11 Illustrations showing different crystal orientations described by Euler angles $(\Psi, \theta)$ for three constant- $\phi$ sections: a) $\phi=0^{\circ}$, b) $\phi=30^{\circ}$ and c) $\phi=60^{\circ}$, 
relating the crystallographic axes of the crystal to chosen axes in a sample (e.g., radial, hoop and longitudinal directions). Following Davies et al. [4.26] the crystallographic directions are assigned for [ $\overline{1} 2 \overline{1} 0]$ as hoop, [10 $\overline{1} 0]$ as longitudinal, and [0001] as radial directions, respectively.

Figure 4.12 ODF of hep $\alpha-\mathrm{Zr}$ crystallites in as-received $\mathrm{Zr}-2.5 \mathrm{Nb}$ pressure tube on heating to a) $823 \mathrm{~K}\left(550^{\circ} \mathrm{C}\right)$, b) $1073 \mathrm{~K}\left(800^{\circ} \mathrm{C}\right)$, c) $1123 \mathrm{~K}\left(850^{\circ} \mathrm{C}\right)$, d) $1173 \mathrm{~K}\left(900^{\circ} \mathrm{C}\right.$ ). ODF on cooling (from after being heated at $1323 \mathrm{~K}$ $\left(1050^{\circ} \mathrm{C}\right)$ ) are obtained at two temperatures: e) $1173 \mathrm{~K}\left(900^{\circ} \mathrm{C}\right)$ (cooling), and f) $823 \mathrm{~K}\left(550^{\circ} \mathrm{C}\right)$ (cooling). A previously unobserved strong $\alpha$-phase texture component is revealed on heating at $1173 \mathrm{~K}\left(900^{\circ} \mathrm{C}\right)$ (indicated by the arrows, labelled $\mathrm{A}$ in the $\mathrm{ODF})$. There is also a weak $\alpha$-phase texture component revealed on heating at $1173 \mathrm{~K}\left(900^{\circ} \mathrm{C}\right)$ (indicated by arrows, labelled $\mathrm{C}$ in the ODF). The labels Longitudinal and Hoop denote directions in the sample of pressure tube.

Figure 4.13 ODF of bec $\beta$-phase in as-received $\mathrm{Zr}-2.5 \mathrm{Nb}$ pressure tube on heating at: a) $823 \mathrm{~K}\left(550^{\circ} \mathrm{C}\right)$, b) $1073 \mathrm{~K}\left(800^{\circ} \mathrm{C}\right)$, c) $1123 \mathrm{~K}\left(850^{\circ} \mathrm{C}\right)$, d) $1173 \mathrm{~K}\left(900^{\circ} \mathrm{C}\right)$ and e) $1323 \mathrm{~K}\left(1050^{\circ} \mathrm{C}\right)$. ODF on cooling (after heating at $\left.1323 \mathrm{~K}\left(1050^{\circ} \mathrm{C}\right)\right)$ are obtained at two temperatures: f) $1173 \mathrm{~K}\left(900^{\circ} \mathrm{C}\right)$ (cooling) and g) $823 \mathrm{~K}\left(550^{\circ} \mathrm{C}\right)$ (cooling). The labels Longitudinal and Hoop denote the longitudinal and hoop directions in the sample. The arrows in the diagrams indicate where the volume fraction of crystallite orientations has changed on heating at different temperatures (with some disappearing - see arrows, labelled A; some appearing and disappear - see arrows, labelled B, and some had reoriented - see arrows, labelled C) 96

Figure 4.14 Optical micrographs of post-test sample of an as-received $\mathrm{Zr}-2.5 \mathrm{Nb}$ pressure tube after heating and cooling showing the through-wall microstructure (a) and at higher magnification showing prior $\beta$ grain boundaries and Widmanstätten $\alpha$ plates within the prior $\beta$ grains (b). 98

Figure 5.1 Schematic diagram of a CANDU fuel channel. .............................................. 104

Figure 5.2 TEM micrograph of as-received $\mathrm{Zr}-2.5 \mathrm{Nb}$ pressure tube ........................... 105

Figure $5.3 \alpha$-phase (0002) and (1120) pole figures for as-received $\mathrm{Zr}-2.5 \mathrm{Nb}$ pressure tube at room temperature [5.7] ........................................................... 106

Figure 5.4 $\mathrm{Zr}-\mathrm{Nb}$ phase diagram [5.12]. The red dots correspond to the temperatures used in neutron diffraction [5.11] ................................................ 108

Figure 5.5 Pole figures for alpha and beta phase measured on an as-manufactured $\mathrm{Zr}-2.5 \mathrm{Nb}$ pressure tube material during heating. The "arrow" label in the pole figure for (hcp) alpha at $900^{\circ} \mathrm{C}$ indicates a previously unobserved $\alpha$ phase texture component due to coarsening of the prior 'primary' $\alpha$-grains (taken from [5.11]). 
Figure 5.6 Volume fraction of $\beta$ phase obtained from neutron diffraction measurements on as-manufactured $\mathrm{Zr}-2.5 \mathrm{Nb}$ pressure tube material [5.11] ....... 110

Figure 5.7 Diagram showing a sectional and side view of the specimen with the locations of thermocouples and LVDT rods used for measuring the width and thickness on the same plane during the test [5.10].

Figure 5.8 Photographs showing the test setup for the start (a) and end (b) of test [5.10].

Figure 5.9 Tensile axial strain (stressing direction) and contractile strains (width and thickness directions) for transverse specimen tested at $25 \mathrm{MPa}$ and heating rate of $14^{\circ} \mathrm{C} / \mathrm{s}$.

Figure 5.10 Tensile axial strain (stressing direction) and contractile strains (width and thickness directions) for longitudinal specimen tested at $25 \mathrm{MPa}$ and heating rate of $14^{\circ} \mathrm{C} / \mathrm{s}$.

Figure 5.11 Variation of contractile strain ratio in transverse and longitudinal specimens

Figure 5.12 A plot of the temperature at $18 \%$ strain as a function of initial stress level.

Figure 5.13 Comparison of high-temperature creep properties between unirradiated offcuts and their irradiated Pickering 4 pressure tubes [5.10].

Figure 5.14 A superimposed plot of temperature and time data at $18 \%$ strain for $14-16^{\circ} \mathrm{C} / \mathrm{s}$ heating rate with the volume fraction of $\beta$ phase in $\mathrm{Zr}-2.5 \mathrm{Nb}$ pressure tube

Figure 5.15 A superimposed plot of temperature and time data at $18 \%$ strain for $29-37^{\circ} \mathrm{C} / \mathrm{s}$ heating rate with the volume fraction of $\beta$ phase in $\mathrm{Zr}-2.5 \mathrm{Nb}$ pressure tube

Figure 5.16 Illustration of the orientations of (hcp) $\alpha-\mathrm{Zr}$ crystals relative to the tensile axis in (a) transverse specimen, and (b) longitudinal specimen in $\mathrm{Zr}$ $2.5 \mathrm{Nb}$ pressure tube.

Figure 5.17 HCP lattice and axes (a) and planes and directions in HCP lattice for deformation by basal $<\mathrm{a}>$ slip (b), prism $<\mathrm{a}>$ slip (c), compressive pyramidal $<\mathrm{c}+\mathrm{a}>$ slip (d), tensile pyramidal $<\mathrm{c}+\mathrm{a}>$ twin (e and $\mathrm{f}$ ), compressive pyramidal $<\mathrm{c}+\mathrm{a}>$ twin $(\mathrm{g})$ [5.16].

Figure 5.18 Illustration of biaxial stressing of pressure tube and the contractile straining of the material being confined to the tube-radial direction.

Figure 6.1 Typical fuel sheathing fabrication schedule [6.1]. 138

Figure 6.2 Optical micrographs showing starting microstructures of Zircaloy-4 fuel sheathing used in neutron texture measurements: (a) as-manufactured, (b) transformed- $\beta$ in simulated braze zone, and (c) simulated heat-affectedzone. 
Figure 6.3 Diagram showing a stacked sample consisting of 18 plates from a Zircaloy-4 fuel sheath.

Figure 6.4 Basal (0002) and prism (11̄20) pole figures of $\alpha-\mathrm{Zr}$ phase in Zircaloy-4 fuel sheaths measured at $100^{\circ} \mathrm{C}$ : a) as-manufactured, b) $\alpha$-annealed (HAZ), and c) $\beta$-transformed structure

Figure 6.5 Pole figures of Zircaloy-4 fuel sheaths measured on heating at $500^{\circ} \mathrm{C}$ to $800^{\circ} \mathrm{C}$

Figure 6.6 Pole figuresof Zircaloy-4 fuel sheaths measured on heating at $850^{\circ} \mathrm{C}$ to $1000^{\circ} \mathrm{C}$

Figure 6.7 Pole figures of Zircaloy-4 fuel sheaths measured on cooling to near room temperature

Figure 6.8 Yield loci for differently processed Zircaloy-4 fuel sheath materials

Figure 6.9 Plot of anisotropy factors as a function of Kearns numbers, $\left[\left(f_{R}-f_{L}\right)^{2}+\left(f_{R}-f_{T}\right)^{2}+\left(f_{T}-f_{L}\right)^{2}\right]$, for Zircaloy-4 fuel sheaths, Zr-2.5Nb pressure tube and Zircaloy-2 seamless calandria tubes.

Figure 7.1 Elongated grain structures in as-manufactured pressure-tube (a) longitudinal, and (b) transverse direction

Figure 7.2 Pole figures of $\alpha$ - and $\beta$-phase in as-manufactured pressure tube at $100^{\circ} \mathrm{C}[7.2]$

Figure 7.3 Optical micrographs showing microstructures of two modified pressure-tube materials (a) 'A' and (b) 'B'

Figure 7.4 Diagram showing a stacked sample of pressure tube material 176

Figure 7.5 Pole figures of (a) Modification ' $A$ ' and (b) Modification ' $B$ ' of pressure tube material.

Figure 7.6 ODF plots (for $\phi=0^{\circ}$ ) of $\alpha$-phase in as-manufactured pressure tube and two modifications ('A' and 'B') materials. (Insert on right shows the crystal orientations)

Figure 7.7 Yield loci of $\mathrm{Zr}-2.5 \mathrm{Nb}$ pressure tube materials and Zircaloy-4 fuel sheaths

\section{APPENDICES}

Appendix A 


\section{Chapter 1}

\section{Introduction}

This thesis investigates the phase transformation, crystallographic texture and mechanical anisotropy of zirconium alloy tubes used in nuclear reactor applications with the objective to further the understanding of the behaviour of high temperature deformation. This subject is important as it provides useful information for manufacturing and application of the material. It also helps in gaining a theoretical understanding of the deformation mechanism of multiphase materials, i.e., the contribution of the second phase, the influences of texture and phase interactions on deformation, etc. The phase transformation and texture data obtained from this study is useful in evaluation and improvement of current and future polycrystalline deformation models. Using a polycrystalline deformation model (e.g., SELFPOLY), the texture data obtained is evaluated to correlate with the mechanical anisotropy factors measured on the tubing materials. This thesis also characterized the texture evolution of modified $\mathrm{Zr}-2.5 \mathrm{Nb}$ pressure tube materials in evaluating the mechanical anisotropic response of the material to determine whether the modifications of texture and microstructure of the materials would provide enhanced mechanical properties (e.g., fracture toughness, hightemperature deformation, etc.).

A CANDU ${ }^{\circledR 2}$ nuclear reactor essentially consists of a large vessel, which holds cool heavy-water moderator, penetrated horizontally by about 400 pairs of concentric tubes forming the fuel channels. Each fuel channel (Figure 1.1) consists of an inner

\footnotetext{
${ }^{2} \mathrm{CANDU}^{\circledR}$ (CANada Deuterium $\underline{\text { Uranium}}$ ) is a registered trademark of Atomic Energy of Canada Limited.
} 
$\mathrm{Zr}-2.5 \mathrm{Nb}$ alloy pressure tube containing the nuclear fuel bundles (Figure 1.2) and the hot pressurized heat transport fluid (heavy water, $\mathrm{D}_{2} \mathrm{O}$ ). The fuel is clad using thin-walled sheathing made of Zircaloy-4 material. A Zircaloy-2 calandria tube surrounds the pressure tube, and isolates it from the cool heavy-water moderator. The two tubes are separated using spacers, and the annulus space is filled with dry $\mathrm{CO}_{2}$ at atmospheric pressure. During normal operation the calandria tubes are loaded at about $70^{\circ} \mathrm{C}$ in bending by the weight of the pressure tube and its contents. The pressure tubes normally operate at about $300^{\circ} \mathrm{C}$, and contain the pressurized coolant flow over the fuel elements and transports the fission heat produced by the fuel to the heat exchangers and steam turbines to generate electricity.

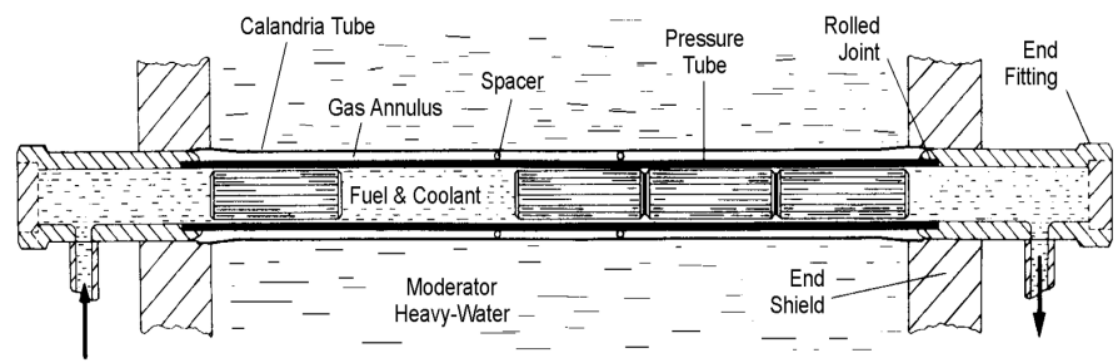

Figure 1.1 Schematic diagram of a CANDU fuel channel

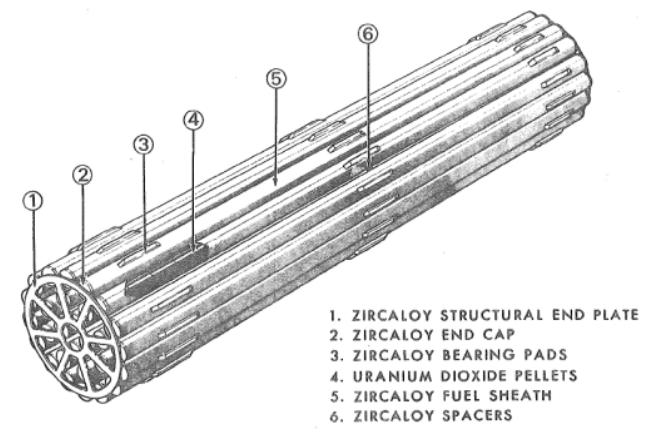

Figure 1.2 Fuel bundle 
Table 1.1 lists the typical chemical compositions of the three reactor fuel channel components (calandria tube, fuel sheath and pressure tube). The fabrication of pressure tubes involves the following processing steps: quadruple melt ingot; forge to bar; machine hollow billets; preheat billets to $815^{\circ} \mathrm{C}$ and extrude into tubes; cold-draw $25-30 \%$ (in two wall thickness reductions); and stress relieve in steam-autoclave for $24 \mathrm{hr}$ at $400^{\circ} \mathrm{C}$ (which also introduces a protective oxide layer on the inside and outside surface of the pressure tube) [1.1]. The resulting microstructure consists of elongated hcp $\alpha-\mathrm{Zr}$ grains containing a high dislocation density, and a thin layer of bec $\beta$ phase at the $\alpha$-grain boundaries (Figure 1.3). Small quantities of meta- stable $\omega$ phase (space group P6/mmm) may also exist in the material, depending on the thermo-mechanical history. At room temperature, a typical $\mathrm{Zr}-2.5 \mathrm{Nb}$ pressure tube material contains mostly $\alpha$-phase $\mathrm{Zr}$ with about $1 \mathrm{wt} \% \mathrm{Nb}$ and a small portion of $\mathrm{Nb}$-stabilized $\beta$ phase with about $20 \mathrm{wt} \% \mathrm{Nb}$, corresponding to the monotectoid composition in the $\mathrm{Zr}-\mathrm{Nb}$ phase diagram [1.2]. As a result of the manufacturing process used to produce the pressure tubes, the as-manufactured pressure tube material shows a pronounced crystallographic texture of $\alpha-\mathrm{Zr}$ grains with most of the basal poles aligned along the transverse (hoop) direction (Figure 1.4). In this thesis work, the phase transformation and evolution of texture in an as-manufactured pressure-tube material were evaluated in detail during heating and cooling using neutron diffraction to provide useful insights and benchmarking for further evaluation of the modified microstructures and textures of the $\mathrm{Zr}-2.5 \mathrm{Nb}$ pressure tube materials. The measured texture data were analyzed and used to determine the response to mechanical anisotropy of these materials. 
Table 1.1 Typical chemical composition of Zirconium alloys (wt\%)

\begin{tabular}{|c|c|c|c|}
\hline \hline Element & $\begin{array}{c}\text { Zircaloy-2 } \\
\text { (calandria tube) }\end{array}$ & $\begin{array}{c}\text { Zircaloy-4 } \\
\text { (fuel sheath) }\end{array}$ & $\begin{array}{c}\text { Zr-2.5Nb } \\
\text { (pressure tube) }\end{array}$ \\
\hline \hline Tin & $1.20-1.70$ & $1.20-1.70$ & - \\
\hline Iron & $0.07-0.20$ & $0.18-0.24$ & $<650 \mathrm{ppm}$ \\
\hline Chromium & $0.05-0.15$ & $0.07-0.13$ & $<100 \mathrm{ppm}$ \\
\hline Nickel & $0.03-0.08$ & - & $<35 \mathrm{ppm}$ \\
\hline Niobium & - & - & $2.5-2.8$ \\
\hline Oxygen & 1400 ppm max. & 1400 ppm max. & $1000-1300 \mathrm{ppm}$ \\
\hline Balance & \multicolumn{3}{|c}{ Zirconium plus impurities } \\
\hline
\end{tabular}

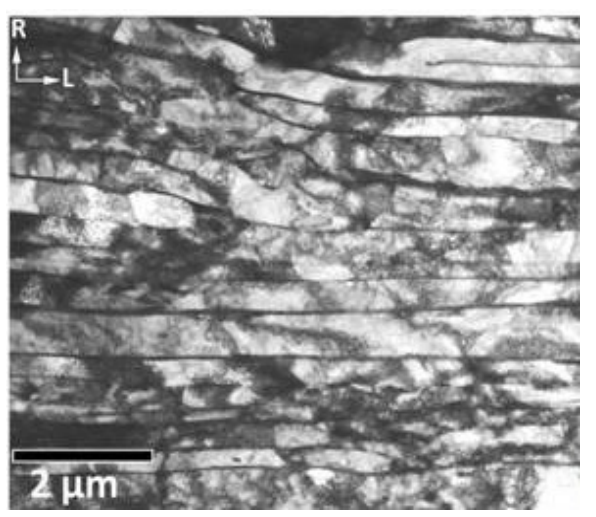

Figure 1.3 Elongated grain structure in $\mathrm{Zr}-2.5 \mathrm{Nb}$ pressure tube material
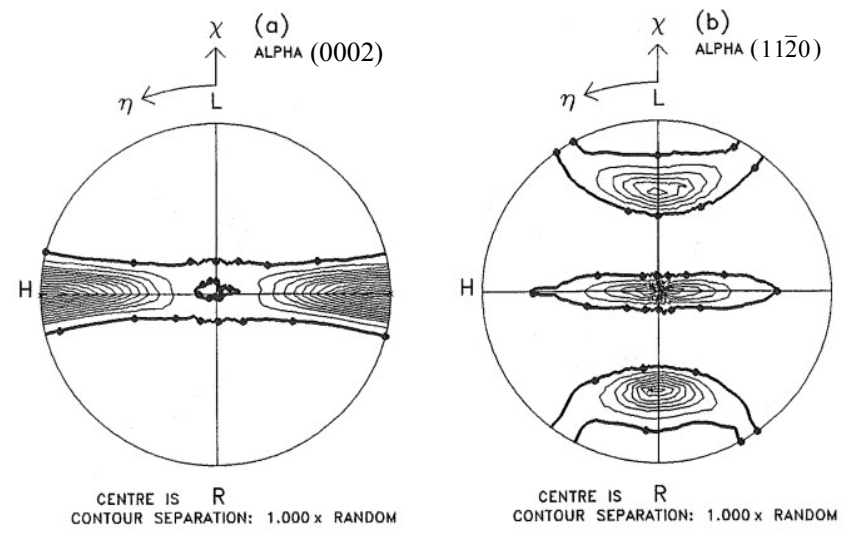

Figure $1.4(0002)$ and $(11 \overline{2} 0)$ pole figures for as-received $\mathrm{Zr}-2.5 \mathrm{Nb}$ pressure tube [1.3] 
For calandria tubes, the fabrication involves processing by brake-forming and seamwelding of annealed and recrystallized Zircaloy-2 strips [1.4]. The seamwelds on the tubes are welded longitudinally. The parent material in a finished calandria tube has an equiaxed $\alpha-\mathrm{Zr}$ grain structure (Figure 1.5), whereas the seamweld material is composed of a complicated microstructure. Two types of welded calandria tubes have been used in reactor applications. The textures of the parent materials differed slightly between these two types of welded tubes (Figure 1.6a and Figure 1.6b).

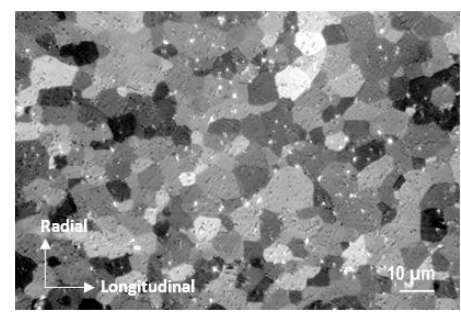

Figure 1.5 Equiaxed $\alpha$-Zr grains in Zircaloy-2 calandria tube material

Figure 1.6 Basal pole figures of parent material in seamwelded $(a, b)$ and seamless $(\mathrm{c}, \mathrm{d})$ tubes [1.5]

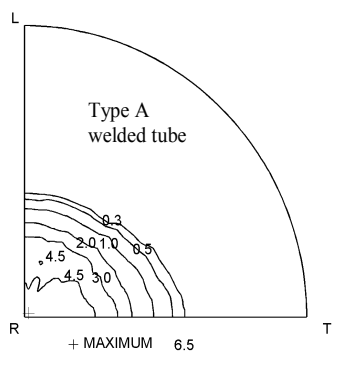

a)

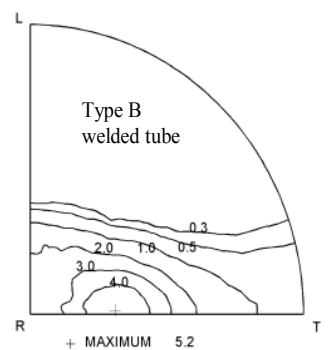

b)
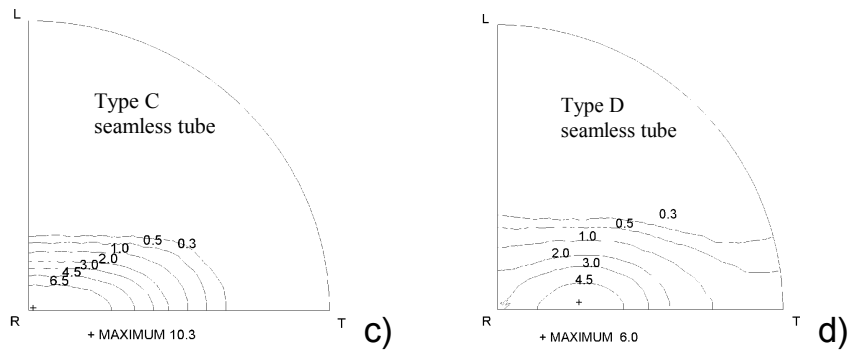
Improvements in burst strength and creep rupture of calandria tubes have been achieved by eliminating the seam-weld (i.e., making the tubes seamless) and increasing the radial basal texture component of the Zircaloy-2 materials [1.6]. The two types of textures in seamless calandria tubes manufactured using two different processes (rollextrusion and tube reduction) are shown in Figure 1.6c and Figure 1.6d [1.6]. Recent work showed that the effect of neutron irradiation on the mechanical anisotropy of calandria tube material due to texture appears to decrease with high fluence [1.7]. The magnitude of plastic anisotropy decreases with increasing neutron fluence (dose), and the mechanical properties of Zircaloy-2 calandria tube materials have a tendency to become isotropic at high fluence (Figure 1.7) [1.7]. As a part of this thesis investigation, the mechanical anisotropy of the two type of seamless calandria tubes are evaluated using plastic strain test data previously reported [1.6] for comparison with the tubes having different textures.

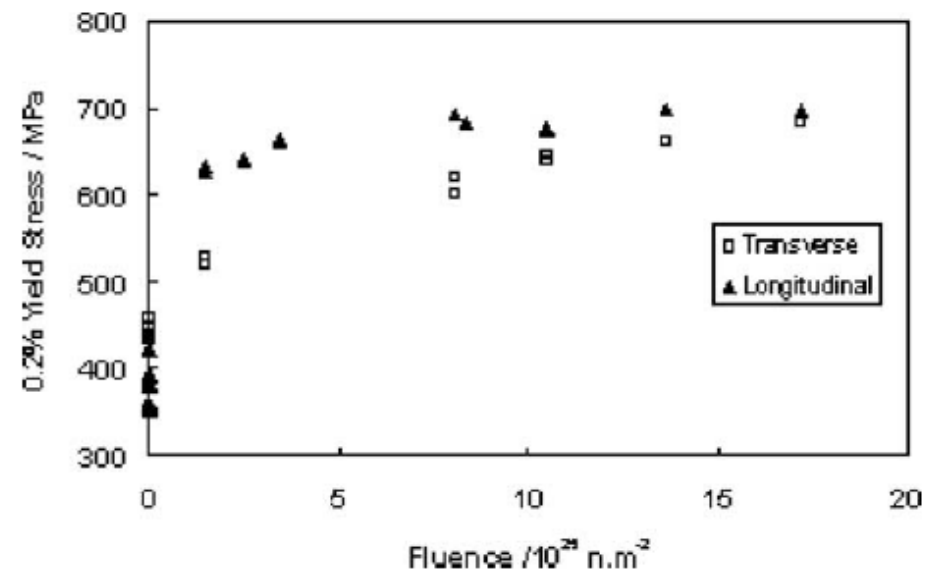

Figure 1.7 Variation of $0.2 \% \mathrm{YS}$ with neutron fluence at $23^{\circ} \mathrm{C}$ [1.7] 
For fuel sheathing, a typical fabrication schedule involves several hot and cold working steps, Figure 1.8 [1.11]. The microstructure of a finished ('as-fabricated') fuel cladding material is in the cold-worked and stress-relieved condition (Figure 1.9a). Depending on how the fuel sheath is fabricated, a typical texture of a fuel sheath would be similar to that shown in Figure 1.10.

\begin{tabular}{ll}
\hline Starting Materials: & Zircaloy-4 ingot \\
& $\downarrow$ \\
& Forge to bar \\
& $\downarrow$ \\
& Machine billet \\
& $\downarrow$ \\
& $\downarrow$ \\
& Extrude tube shell \\
& $\downarrow$ \\
& Anneal \\
& \\
& $\downarrow$ \\
Number of cold reductions & Cold-work \\
and intermediate anneals & $\downarrow$ \\
depends on size of tube shell & Anneal \\
& $\downarrow$ \\
& \\
& Cold-work (40-70\% reduction) \\
& $\downarrow$ \\
& Stress relieve \\
& $\downarrow$ \\
& Final sizing (<3\% reduction) \\
\hline
\end{tabular}

Figure 1.8 Typical manufacturing process used to produce fuel sheaths [1.11]

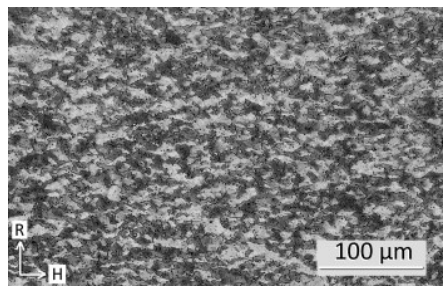

a)

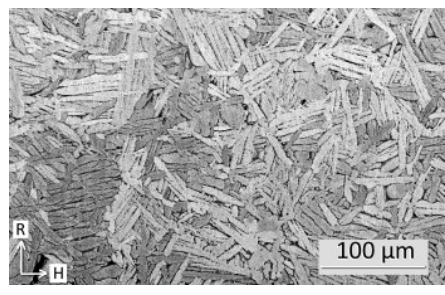

b)

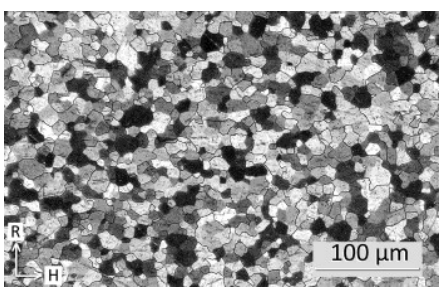

Figure 1.9 Optical micrographs showing microstructures of Zircaloy-4 fuel sheaths: a) as-manufactured, b) braze-zone structure, and c) heatc) affected zone structure 


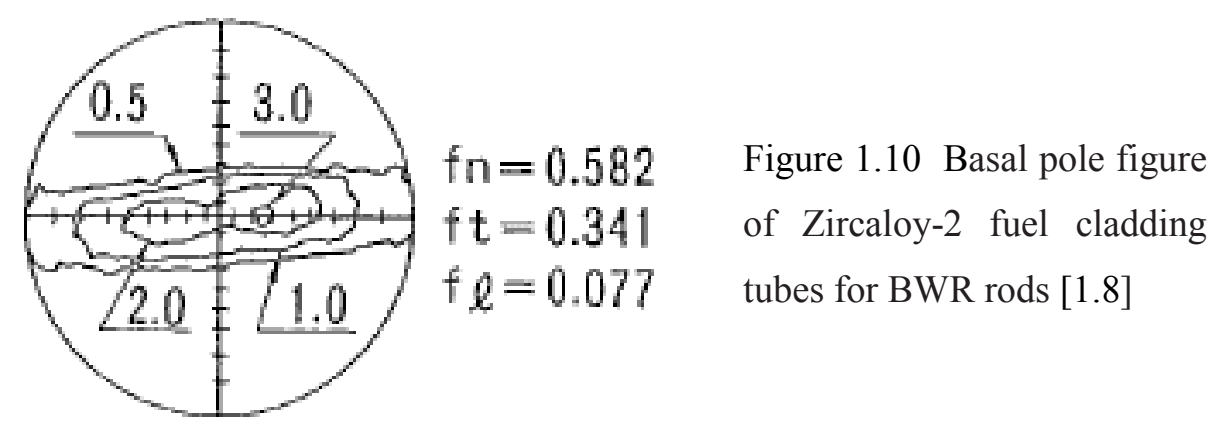

Induction brazing is used to attach appendages (bearing and spacer pads) on to the thin-walled fuel cladding [1.12]. The brazing metal used in Canada is a eutectic alloy, $\mathrm{Zr}-5 \mathrm{wt} \% \mathrm{Be}$ [1.13], with a melting point of $965^{\circ} \mathrm{C}$. It was selected as a brazing metal mainly because of its good wetting properties and high mechanical strength [1.13]. The brazing cycle (40-60 seconds) involves heating the attachments in a glass vacuum chamber to temperatures in excess of $1000^{\circ} \mathrm{C}$ and then cooling by an inert atmosphere [1.12]. The microstructures of the fuel cladding are modified locally by the brazing process. Examples of microstructures in the brazed-zone and heat-affected zone materials are shown in Figure $1.9 \mathrm{~b}$ and Figure 1.9c, respectively. The effect of brazing on the mechanical anisotropy of Zircaloy-4 fuel cladding has been measured by Knoop hardness indentations [1.14]. It was found that short brazing times $(1 \mathrm{~min})$ at temperatures $>1050^{\circ} \mathrm{C}$ reduced the degree of anisotropy, and an anneal treatment of $1 \mathrm{~h}$ at $850^{\circ} \mathrm{C}$ gave the highest degree of mechanical isotropy, Figure 1.11 [1.14]. A similar effect of irradiation on mechanical anisotropy has also been observed in results from Knoop hardness test data, Figure 1.12 [1.8] and thermal creep data for irradiated Zircaloy cladding [1.10]. 


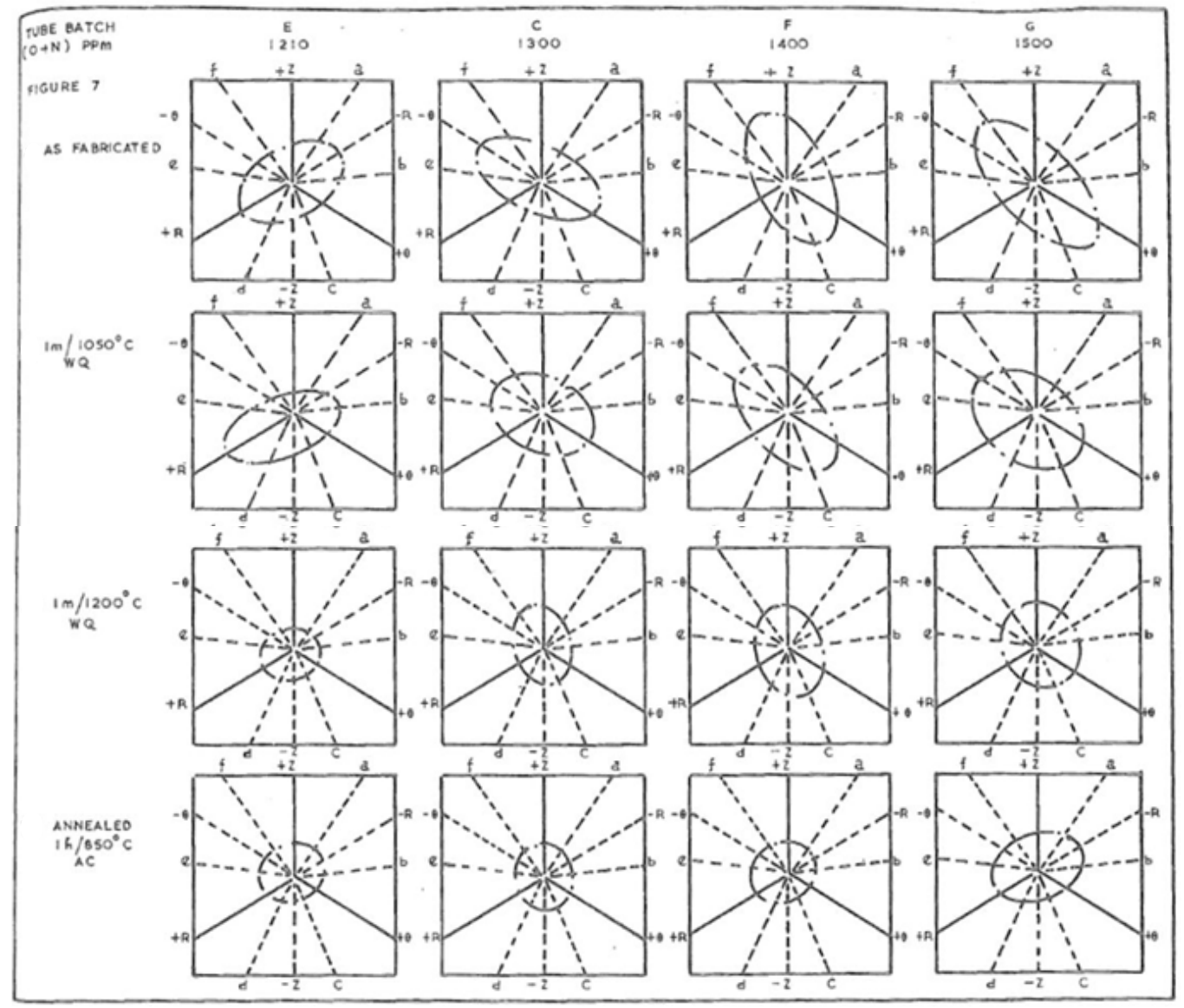

Figure 1.11 Flow surface diagrams (from Knoop hardness indentations) of different batches of Zircaloy-4 fuel cladding [1.14]

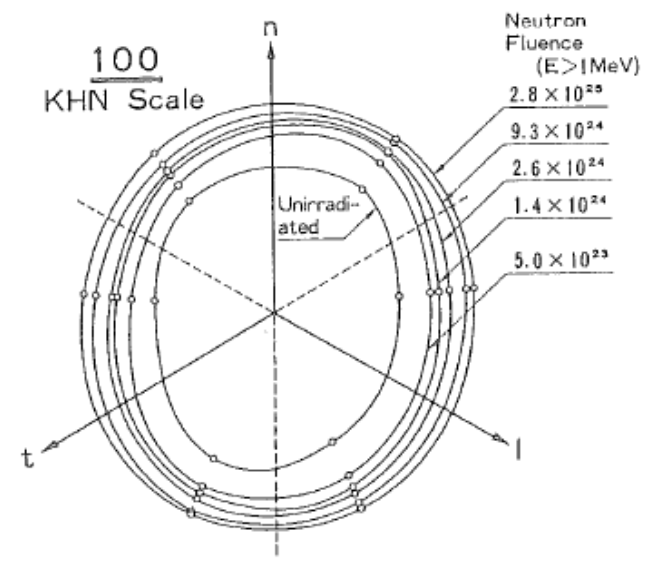

Figure 1.12 Effect of neutron irradiation on resistance to plastic deformation under multiaxial stress [1.8] 
During a hypothetical loss-of-coolant accident (LOCA), the zirconium alloy tubing materials can be heated to high temperatures above $1000^{\circ} \mathrm{C}$. For Zircaloys at low temperatures (below $\approx 875^{\circ} \mathrm{C}$ ), the microstructure consists of hexagonal close-packed (hcp) $\alpha$ phase zirconium with second phase particles [1.14], [1.15], [1.16]. The hcp crystallites of $\alpha-Z r$ have anisotropic properties (e.g., elastic properties, thermal conductivity, diffusion characteristics). The microstructure of the alloy will change accordingly with the changes in temperature and time. At high temperatures, the material will evolve with different volume fractions of the $\alpha$ - and $\beta$-phases and it is important to characterize the changes in phase transformation and to relate them to their hightemperature mechanical behaviour. For Zircaloy fuel cladding, the $\alpha-\beta$ phase transformation characteristics is considered to be one of the most important model parameters used to describe the thermo-mechanical behaviour of the sheathing under LOCA conditions [1.17], [1.18], [1.19]. Similarly, the high-temperature parameters related to phase transformation characteristics for the texture and volume fraction of the phase constituents during heating and cooling are also important considerations for $\mathrm{Zr}-2.5 \mathrm{Nb}$ pressure tube materials. Previous studies have investigated changes in $\alpha \rightarrow \beta \rightarrow \alpha$ phase transformation textures in Zircaloy-2 and Zircaloy-4 during heating and cooling [1.20], [1.21], [1.22]. Since the solvus lines for Zircaloys (a dilute Zr-Sn system [1.23]) are different from those for $\mathrm{Zr}-2.5 \mathrm{Nb}$ alloy [1.2], differences in volume fraction changes of $\alpha$ and $\beta$ phases between the two alloy systems can be expected during heating and cooling, although the lattice transformation processes can be similar. Hence, the 
microstructural information obtained on Zircaloys would not be entirely applicable to $\mathrm{Zr}-2.5 \mathrm{Nb}$ pressure tube material.

This thesis investigates the effects of phase transformation and texture on the mechanical anisotropy of fuel sheath and pressure tube materials. In-situ experimental measurements are used to determine the phase transformations and textures of these two different nuclear reactor materials employed in CANDU reactors. The changes in volume fraction of $\beta$-phase material in $\mathrm{Zr}-2.5 \mathrm{Nb}$ pressure tube material were evaluated systematically with changes in heating and cooling temperatures. The purpose of this thesis investigation is to further the understanding of the deformation behaviour of $\mathrm{Zr}-2.5 \mathrm{Nb}$ alloy and Zircaloys at high temperatures through the study of the influence of texture and microstructure. Modifications of existing $\mathrm{Zr}-2.5 \mathrm{Nb}$ pressure tube materials through high temperature annealing and with or without subsequent cold-working are also investigated for their changes in texture and microstructure to see if they would enhance the properties of the material (e.g., fracture toughness and high-temperature deformation).

\subsection{Thesis Scope and Objectives}

The objectives of this thesis work include:

1. To study, by in-situ neutron diffraction, the phase transformation and evolution of texture in as-received $\mathrm{Zr}-2.5 \mathrm{Nb}$ pressure tube material during heating and cooling.

2. To understand the influence of texture and the contribution of $\beta$-phase material to the high-temperature anisotropic deformation behaviour of as-received $\mathrm{Zr}-2.5 \mathrm{Nb}$ pressure tube material. 
3. To determine the effect of texture on the mechanical anisotropy of Zircaloy-4 fuel sheaths using measured texture data that correlated with the anisotropy factors obtained earlier using mechanical strain data.

4. To characterize the texture and microstructure in two modifications of as-received $\mathrm{Zr}-2.5 \mathrm{Nb}$ pressure tube materials and evaluate their effect on mechanical anisotropy for further improvement in mechanical properties of the $\mathrm{Zr}-2.5 \mathrm{Nb}$ alloy material (e.g., high-temperature deformation, fracture toughness, etc.).

The work reported in this thesis is in manuscript form. Chapter 2 gives a general review of previous work relevant to this study and also some background knowledge and experimental techniques used to obtain texture data. The texture data are used and analyzed using a polycrystalline model (SELFPOLY [1.24], [1.25]) to determine the Kearns (texture) numbers [1.26] and the mechanical anisotropy factors using Hill's yield criterion [1.27]. Chapter 3 provides the experimental details on the $\mathrm{Zr}$-alloy materials and measurement techniques used in this thesis work. Chapter 4 studies the in-situ phase transformation and texture evolution in as-received $\mathrm{Zr}-2.5 \mathrm{Nb}$ pressure tube material during heating and cooling using neutron diffraction. Chapter 5 investigates the anisotropic deformation of $\mathrm{Zr}-2.5 \mathrm{Nb}$ pressure tube material using the obtained texture data from Chapter 4 to help understand the high-temperature deformation behaviour. Chapter 6 investigates the texture data obtained by neutron diffraction on Zircaloy-4 fuel sheath materials with different simulated braze-zone microstructures and the evaluation of the texture data using SELFPOLY to determine the Kearns numbers and Hill's anisotropy factors that are correlated with earlier anisotropy factors determined using 
mechanical strain data. Chapter 7 gives the characterization of the texture and its evolution in two modified $\mathrm{Zr}-2.5 \mathrm{Nb}$ pressure tube materials during heating and cooling to high temperatures. The texture data obtained are also analyzed using SELFPOLY based on the correlated analysis reported in Chapter 6 to calculate the Kearns numbers and the Hill's anisotropy factors. Chapter 8 gives a general discussion and concluding remarks on this thesis. Chapter 9 proposes future research work.

\subsection{Organization of the Thesis}

Because the thesis is a collection of manuscripts that have been reproduced in their published forms, there is necessarily some overlap between the chapters. As such, the following "road-map" shows which chapters are already peer-reviewed and also where redundant materials are in the various chapters. The reader may choose to skip some of this redundant material without losing the flow of ideas.

- Chapters 4, 5, and 6 are manuscripts published in journals and thus have been peer-reviewed.

- Chapter 7 is a manuscript which is submitted for publication in a conference proceeding.

- Redundant materials are contained in the Introduction and Experimental sections in Chapters 4, 6, and 7, that the readers can skip reading if desired.

\section{References}

[1.1] B.A. Cheadle, The development of $\mathrm{Zr}-2.5 \mathrm{Nb}$ pressure tubes for CANDU reactors, J. ASTM International, Vol. 7, No. 8, pp. 1-15, 2010 
[1.2] J.P. Abriata and J.C. Bolcich, The Nb-Zr system, Bull. Alloy Phase Diagrams, Vol. 3, No. 1, pp. 34-44, 1982

[1.3] P. Gangli, J. Root, and R. Fong, Investigation of texture and interfaces in a $\mathrm{Zr}-2.5 \mathrm{Nb}$ alloy with zirconium hydrides, Canadian Metallurgical Quarterly, Vol. 34, No. 3, pp. 211-218, 1995

[1.4] E.G. Price, and P.J. Richinson, Thin-walled large-diameter Zirconium alloy tubes in CANDU reactors, Atomic Energy of Canada Ltd. Report, AECL-6345, 1978

[1.5] R.W.L. Fong and C.R. Fraser, Evaluation of ductility of Zircaloy-2 materials using a small ellipsoidal-shaped punch, Small Specimen Test Techniques, ASTM STP 1329, American Society for Testing and Materials, 1998 (Also in AECL-11968)

[1.6] C.E. Coleman and R.W.L. Fong, Strengthening CANDU calandria tubes by crystallographic texture, Can. Metall. Conference, Ottawa, Canada, August 20-23, 2000

[1.7] X. Wei, J. R. Theaker, and M. Griffiths, Deformation anisotropy of annealed Zircaloy-2 as a function of fast neutron fluence, J. ASTM International, Vol. 5, No. 1, pp. 11, 2008

[1.8] M. Nakatsuka and M. Nagai, Reduction of plastic anisotropy of Zircaloy cladding by neutron irradiation, (I) Yield loci obtained from Knoop hardness", J. Nucl. Sci. Technol., Vol. 24 [10], pp. 832-838, 1987

[1.9] L.K. Murty and S.T. Mahmood, Effects of recrystallization and neutron irradiation on creep anisotropy of Zircaloy Cladding, Zirconium in the Nuclear Industry: 9th International Symposium, ASTM STP 1132, C. M. Eucken and A. M. Garde, Eds., ASTM International, West Conshohocken, PA, pp. 198-217, 1991

[1.10] H. Tsai and M.C. Billone, Thermal creep of irradiated Zircaloy cladding, J. ASTM International, Vol. 3, No. 1, pp. 1-19, January 2006

[1.11] R.A. Holt, W. Evans and B.A Cheadle, The role of zirconium alloy metallurgy in the fabrication of CANDU fuel, Atomic Energy of Canada Ltd. Report AECL-5107, 1975

[1.12] D.G. Hardy and N.A. Graham, The performance, strength, and corrosion resistance of brazed joints on CANDU fuel bundles, Trans. Am. Nucl. Soc., 19:122-123, 1974

[1.13] K.T. Bates, Brazing of Zircaloy in nuclear fuel, Paper presented at NUCLEX '66 International Nuclear Industries Fair and Technical Meetings on "Brazing of Zircaloy in Nuclear Fuel, Basle, Switzerland, September 1966 
[1.14] D.O. Northwood and W.L. Fong, Effect of brazing on the mechanical anisotropy of Zircaloy-4 nuclear fuel cladding, Canadian Metallurgical Quarterlv, Vol. 22, pp. 411-419, 1983

[1.15] W.L. Fong and D.O. Northwood, Identification of second-phase particles in Zircaloy-4 nuclear fuel sheathing, Metallography, 15:27-41, 1982

[1.16] VO Quach and D.O. Northwood, Influence of the phosphorus impurity content on the microstructure of Zircaloy-4 air cooled from the high temperature beta phase region, Metallography, 17:191-201, 1984

[1.17] H.E. Sills and R.A. Holt, Predicting high-temperature transient deformation from microstructural models, Zirconium in the nuclear Industry: $4^{\text {th }}$ Conf. ASTM STP 681 , pp. 325-341, 1979

[1.18] H.E. Sills and R.A. Holt, NIRVANA, a high-temperature creep model for Zircaloy fuel sheathing, Atomic Energy of Canada Ltd. Report AECL-6412, 1979

[1.19] T. Forgeron, J.C. Brachet, F. Barcelo, A. Castaing, J. Hivroz, J.P. Mardon, and C .Bernaudat, Experiment and modeling of advanced fuel rod cladding behaviour under LOCA conditions: alpha-beta phase transformation kinetics and EDGAR methodology, Zirconium in the nuclear Industry: $12^{\text {th }}$ Int. Symp. ASTM STP 1354, pp. 256-278, 2000

[1.20] J. Romero, M. Preuss and J. Quinta Da Fonseca, Texture memory and variant selection during phase transformation of a zirconium alloy, Acta Mater., Vol.. 57, Issue 8, pp. 5501-5511, 2009

[1.21] H.R. Wenk, I. Lonardelli and D. Williams, Texture changes in the hcp $\rightarrow$ bcc $\rightarrow$ hcp transformation of zirconium studied in situ by neutron diffraction, Acta Mater., Vol. 52, pp. 1899-1907, 2004

[1.22] N. Gey, E. Gautier, M. Humbert, A. Cerqueira, J.L. Bechade and P.J. Archambault, Study of the $\alpha / \beta$ phase transformation of Zy-4 in presence of applied stresses at heating: analysis of the inherited microstructures and textures, J. Nucl. Mater., 302:175-184, 2002

[1.23] J.P. Abriata, J.C. Bolcich and D. Arias: Bull. Alloy Phase Diagrams, 4(2), pp. 2087-2089, 1983

[1.24] C.N. Tomé, C.B. So and C.H. Woo, Self-consistent calculation of steady-state creep and growth in textured zirconium, Phil. Mag A, Vol. 67, pp. 917-930, 1993 
[1.25] P.A. Turner, C.N Tomé, N. Christodoulou, C.H. Woo, A self-consistent model for polycrystals undergoing simultaneous irradiation and thermal creep, Phil. Mag. A, Vol. 79(10), pp. 2505-2524, 1999

[1.26] J.J. Kearns, Thermal expansion and preferred orientation in Zircaloy, WAPD-TM-472, 1965

[1.27] R. Hill, A theory of the yielding and plastic flow of anisotropic metals, Proc. Roy. Soc. A, 193, London, 281, 1948 


\section{Chapter 2}

\section{Literature Review}

This chapter contains a summarized literature review of previous studies on topics that are relevant to this thesis project.

The topics briefly reviewed here relate to the phase diagrams of $\mathrm{Zr}-\mathrm{Nb}$ and $\mathrm{Zr}-\mathrm{Sn}$ alloys, zirconium phase transformation, and various representations of crystallographic texture. Some of the literature reviews are used for reference and discussion that are included in the manuscripts contained in Chapter 4 through to Chapter 7.

\subsection{Phase Diagrams and Transformations in Zirconium Alloys}

\subsubsection{Zr-2.5Nb Alloy}

The $\mathrm{Zr}-2.5 \mathrm{Nb}$ alloy used for the pressure tubes in CANDU reactors are produced from an ingot with a chemical composition specification typically of 2.5 to 2.8 weight percent $\mathrm{Nb}, 1000$ to 1300 ppm O, <650 ppm Fe, and balance $\mathrm{Zr}$ (Table 1.1). Oxygen is an $\alpha$-phase stabilizer, and $\mathrm{Nb}$ and Fe stabilize the $\beta$ phase. Figure 2.1 shows the phase diagram of the $\mathrm{Zr}-\mathrm{Nb}$ alloy system [2.1], which is basically a eutectoid with a miscibility gap region (usually described as a monotectoid). The effect of niobium addition to zirconium is to stabilize the high-temperature bcc $\beta$ phase of zirconium $\left(\beta_{\mathrm{Zr}}\right)$. A continuous series of solid solutions exist between $\beta_{\mathrm{Zr}}$ at the zirconium-rich end and $\beta_{\mathrm{Nb}}$ at the niobium-rich end. The major points of discussion and experiment have been the solid solubility limit of $\mathrm{Nb}$ in the $\alpha-\mathrm{Zr}$ phase and the monotectoid composition. The data for 
CANDU Zr-2.5Nb pressure tube material containing typically $1000-1500$ ppm oxygen indicates that the maximum solubility limit of niobium in zirconium is $0.8 \mathrm{wt} \% \mathrm{Nb}$ and that the monotectoid composition is just above $21 \mathrm{wt} \% \mathrm{Nb}[2.2]$.

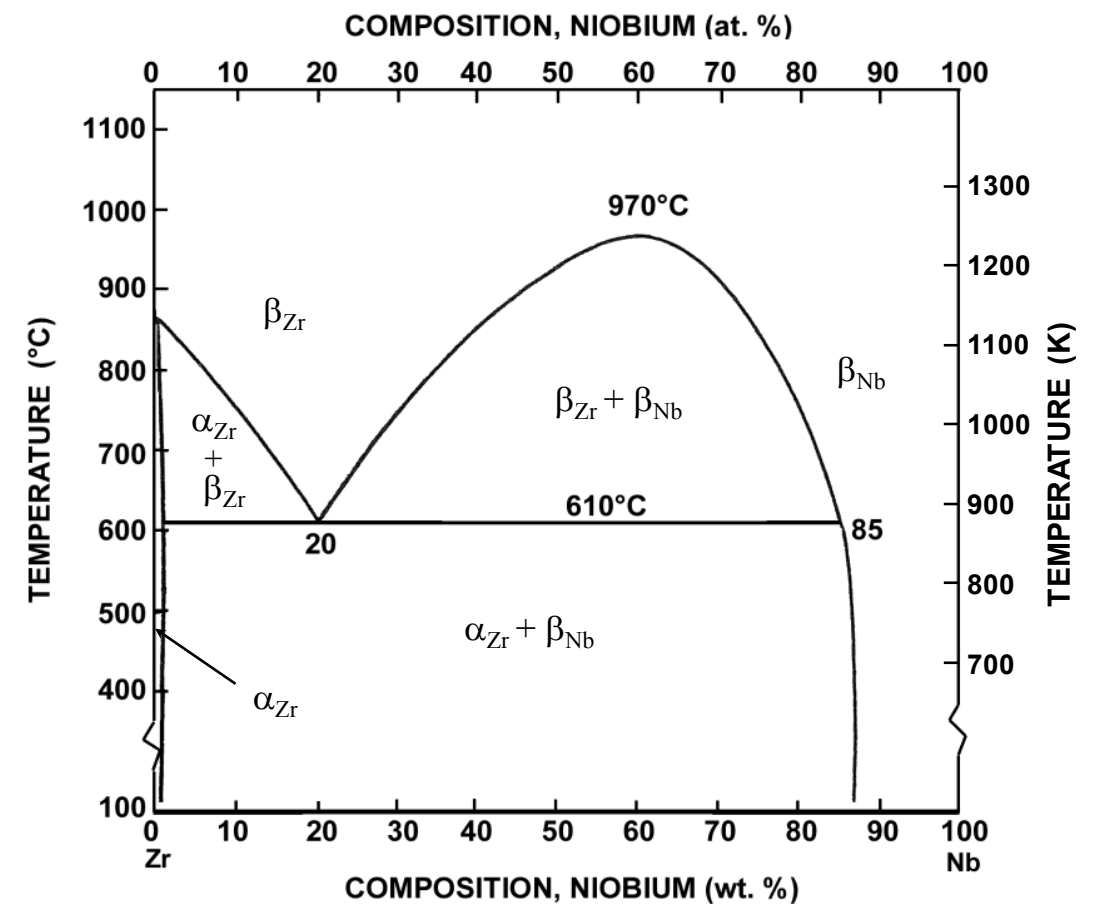

Figure 2.1 Phase diagram of $\mathrm{Zr}-\mathrm{Nb}$ system [2.1]

The $\mathrm{Zr}-2.5 \mathrm{Nb}$ alloy in the equilibrium condition at room temperature is in the two-phase $\left(\alpha+\beta_{\mathrm{Nb}}\right)$ region. This will change to a $\left(\alpha+\beta_{\mathrm{Zr}}\right)$ region on heating to above $610^{\circ} \mathrm{C}$ (i.e., monotectoid temperature), but below the $\left(\alpha+\beta_{\mathrm{Zr}}\right) / \beta_{\mathrm{Zr}}$ phase boundary. The position of the $\left(\alpha+\beta_{\mathrm{Zr}}\right) / \beta_{\mathrm{Zr}}$ phase boundary is strongly affected by oxygen content; this boundary is at about $870^{\circ} \mathrm{C}$ (Figure 2.1). The extrusion temperature of $\mathrm{Zr}-2.5 \mathrm{Nb}$ pressure tubes at $815^{\circ} \mathrm{C}$, is within the $\left(\alpha+\beta_{\mathrm{Zr}}\right)$ phase region. On air cooling the extrusion to room 
temperature, the $\left(\alpha+\beta_{\mathrm{Zr}}\right)$ structure does not transform to the equilibrium $\left(\alpha+\beta_{\mathrm{Nb}}\right)$ structure, but rather remains as $\left(\alpha+\beta_{\mathrm{Zr}}\right)$. The stress relief treatment at $400^{\circ} \mathrm{C}$ for $24 \mathrm{~h}$ given to the manufactured pressure tube material, partially decomposes the as-fabricated metastable $\beta_{\mathrm{Zr}}$ formed during the hot extrusion and air-cooling to room temperature, into the stable $\beta_{\text {Nb }}$ phase, via the following reactions [2.3]

$$
\begin{aligned}
& \beta_{\mathrm{Zr}} \rightarrow \omega+\beta_{\mathrm{enr}} \\
& \beta_{\mathrm{enr}} \rightarrow \omega+\beta_{\mathrm{Nb}} \\
& \omega \rightarrow \alpha_{\mathrm{Zr}}+\beta_{\mathrm{Nb}}
\end{aligned}
$$

combining Eqns. 2.2.1.1, 2.2.1.2 and 2.2.1.3 gives,

$$
\beta_{\mathrm{Zr}} \rightarrow \alpha_{\mathrm{Zr}}+\beta_{\mathrm{Nb}}
$$

$\beta_{\text {enr }}$ is enriched in niobium, and $\omega$ is a metastable hexagonal close-packed phase. The breakdown of the $\beta_{\mathrm{Zr}}$ phase (containing about $20 \% \mathrm{Nb}$ ) occurs at temperatures below about $525^{\circ} \mathrm{C}$. However, the stable $\beta_{\mathrm{Nb}}$ phase may not be achieved under practical terms, since the temperature-time-transformation (TTT) diagram developed for the $\beta$-phase in $\mathrm{Zr}-2.5 \mathrm{Nb}$ pressure tubes (Figure 2.2 ), indicates that the metastable $\beta_{\mathrm{Zr}}$ is most likely to transform into a $\beta_{\text {enr }}$ phase [2.4]. 


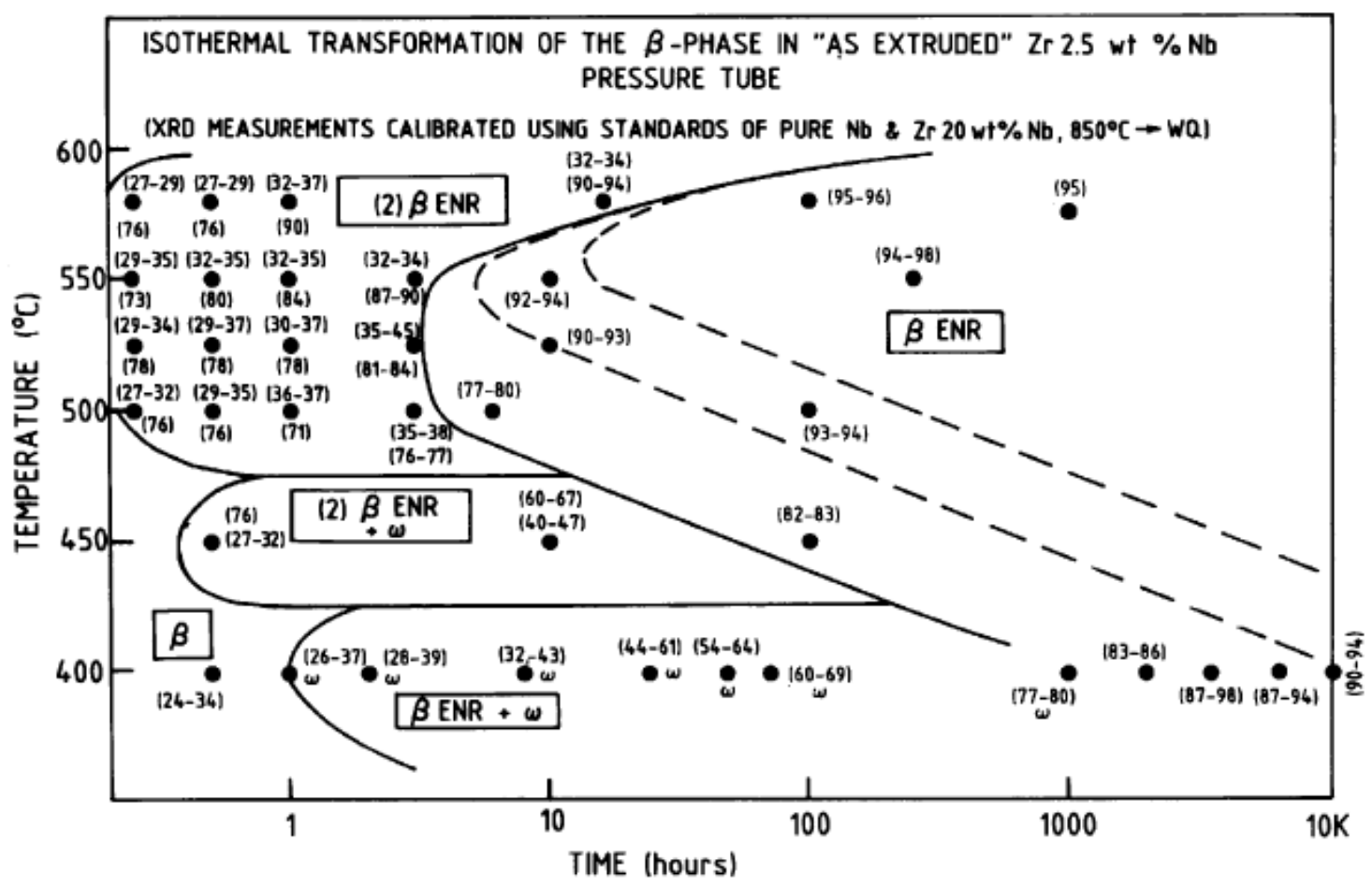

Figure 2.2 TTT-diagram for a $\mathrm{Zr}-2.5 \mathrm{wt} \% \mathrm{Nb}$ pressure tube. The numbers in brackets refer to $\mathrm{Nb}$ concentration [2.4]

\subsubsection{Zr-Sn Alloy}

The fuel sheath and calandria tube materials are made from Zircaloy-4 and Zircaloy-2, respectively, which is basically a dilute Zr-Sn system. The phase diagram of a Zr-Sn system is shown in Figure 2.3 [2.5]. The chemical compositions of the fuel sheath and calandria tube materials (Table 1.1) indicate that the Zircaloy materials contain about 1.2 to $1.7 \mathrm{wt} \% \mathrm{Sn}$. Except for the nickel content in Zircaloy-2, the chemical compositions of both Zircaloy-2 and Zircaloy-4 are essentially the same. The fuel sheaths and calandria tubes at room temperature are composed of a single $\alpha$-phase material with a hexagonal-close-packed (hcp) structure and various types of second phase 


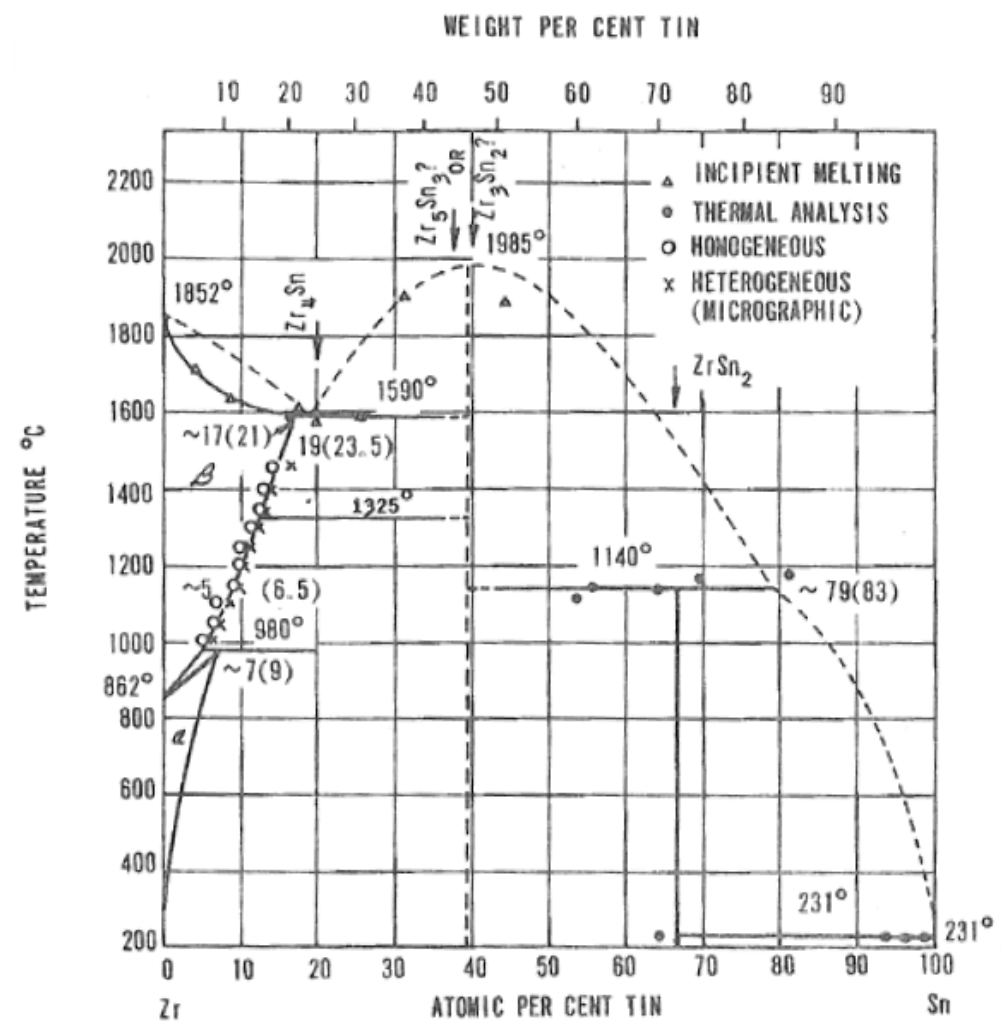

Figure 2.3 Phase diagram of Zr-Sn binary system [2.5]

particles [2.6]-[2.11]. The $\alpha$-phase transforms to the body-centered cubic (bcc) $\beta$-phase on heating to above the $\alpha /\left(\alpha+\beta_{\mathrm{Zr}}\right)$ phase boundary, the position of this phase boundary is about $810-825^{\circ} \mathrm{C}[2.11]$ and the second phase particles dissolve on heating at $\sim 800^{\circ} \mathrm{C}$ [2.11]. Further heating to above $\sim 975^{\circ} \mathrm{C}$ (i.e., $\left(\alpha+\beta_{\mathrm{Zr}} / \beta_{\mathrm{Zr}}\right)$ phase boundary [2.11]) transforms the material into a single bcc $\beta$-phase structure.

\subsubsection{Investigations of Phase Transformations}

Various investigations of phase transformation and volume fractions of the two phases in $\mathrm{Zr}$ alloys have been primarily performed using indirect techniques that include 
dilatometry and calorimetry [2.11],[2.12],[2.13], and electrical resistivity [2.12],[2.14]. The calorimetry studies of phase transformations in zirconium alloys such as Zircaloys and $\mathrm{Zr}-1 \mathrm{Nb}$, found that the $\alpha-\beta$ transition is also dependent on the rate of heating of the sample material, and thus resulted in varying volume fractions of the two phases [2.11], [2.13]. A direct method of investigation includes metallographic examinations of 'transformed' microstructures at room temperature [2.15],[2.16]. In-situ studies using Scanning Electron Microscopy Electron Backscattered Diffraction (SEM-EBSD) have also provided insights into the nucleation and growth stages in Ti during the phase transformation process [2.17]. $\mathrm{Zr}$ behaves much the same way as in $\mathrm{Ti}$, as these two elements occupy the same valence (4) in the Periodic Table. Hence the observations on Ti would be also applicable to Zr. High-temperature X-ray diffraction has also been used to study phase transformation in titanium alloys [2.18],[2.19]. Neutron diffraction has also been applied to study the kinetics of phase transformation in titanium alloys [2.20] and also in-situ texture changes in $\mathrm{hcp} \rightarrow \mathrm{bcc} \rightarrow \mathrm{hcp}$ transformation in a hot-rolled Zircaloy-4 plate [2.21] and Zr-2.5 [2.22].

In this thesis investigation, neutron diffraction experiments are used to study the equilibrium phase structure and volume fraction on heating and cooling the as-received $\mathrm{Zr}-2.5 \mathrm{Nb}$ pressure tube sample materials. The kinetics of phase transformations are not studied as it occurs much too fast at the higher temperatures to allow meaningful texture measurements to be obtained for analysis. Similarly, the evolution of textures resulting from phase transformations in modified $\mathrm{Zr}-2.5 \mathrm{Nb}$ pressure tube materials during heating and cooling is also investigated by neutron diffraction techniques. 


\subsection{Texture Representation}

Texture is a description of an assembly of discrete orientations or a distribution that is represented by intensity values in cells in orientation space or pole space which is commonly obtained and used in practice. For general mathematical considerations, such distributions are represented as continuous functions. The volume fraction of orientations within a certain region $\Delta \Omega$ of orientation space is

$$
\frac{\Delta V}{V}=\frac{\int_{\Delta \Omega} f(g) d g}{\int_{\Omega_{0}} f(g) d g}
$$

where $\Omega_{0}$ is the total volume of the orientation space (total of $8 \pi^{2}$ ) [2.23] The equation (2.3.1) as defined need not itself be normalized (by $8 \pi^{2}$ ); common practice is to set $\mathrm{f}(\mathrm{g}) \equiv 1$ for uniform density. This is often called the orientation density 'in multiples of a random distribution', mrd. Orientations with densities above $1 \mathrm{mrd}$ indicate that more lattice planes are aligned in those directions than in a random sample, and vice versa.

In pole space, the total pole density from crystals with the $h k l$ planes satisfying Bragg's law (after normalization) is given by [2.24]

$$
I_{\text {norm }}(\alpha, \beta)=\frac{1}{N} \cdot I_{\text {corr }}(\alpha, \beta)
$$

where $N=\int_{i}(\alpha, \beta) \sin \alpha_{i} / \int_{i} \sin \alpha_{i}$. Here, the integral over the full pole figure becomes 1 , which means that the pole figure of a randomly oriented standard sample would be 1 at all points. Pole figures are usually normalized such that pole densities are 
given in units of mrd (multiples of random distribution). A pole figure of a random standard sample would be "x1" mrd for all points in the pole figure.

The representation of texture can be presented in several ways: i) direct pole figure, ii) inverse pole figure, iii) orientation distribution function (ODF), and iv) Kearns numbers.

\subsubsection{Direct pole figure}

A direct pole figure is used to describe the distribution of a chosen crystal pole

(i.e., plane normals of an assigned (hkl) plane) with the surface of a reference sphere. For convenience, the density of the poles on the reference sphere surface is mapped onto a plane surface as a continuous function. Poles are projected from the reference sphere onto a pole figure as follows. The position of a given pole on the sphere is usually defined by the polar and azimuthal angles $(\alpha, \beta)$. The angle $\alpha$ describes the azimuth of the pole, where $\alpha=0^{\circ}$ is the north pole of the unit sphere, and the angle $\beta$ is the rotation of the pole around the polar axis starting from a specified reference direction (Figure 2.4).

A pole figure is a projection that is often represented as a stereographic projection, showing the distribution of a particular lattice plane in a crystal oriented in relation to the sample reference directions, Figure 2.5. Figure 2.6 shows an example of a pole figure with the definition of the pole figure angles $\alpha$ and $\beta$. 


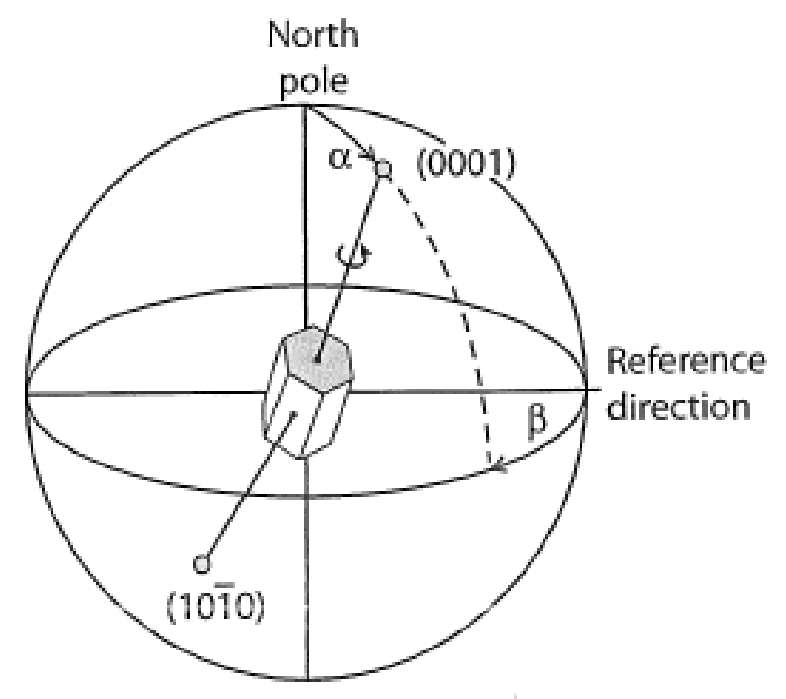

Figure 2.4 Orientation of the basal pole in a hexagonal crystal on the unit sphere with regard to an external reference frame described by two angles $\alpha$ and $\beta[2.24]$
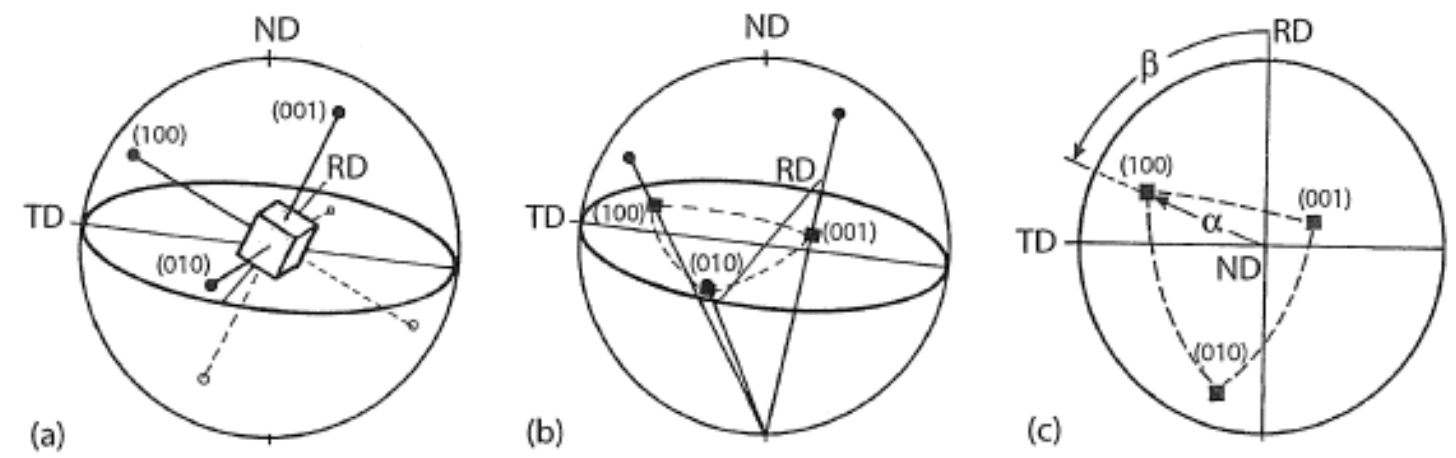

Figure 2.5 Illustration of a stereographic projection of $\{100\}$ planes in a cubic crystal with reference to the sample directions: (a) Crystal in unit sphere showing $\{100\}$ poles; (b) $\{100\}$ poles onto the equatorial plane; and (c) $\{100\}$ pole figure in stereographic projection [2.24] 


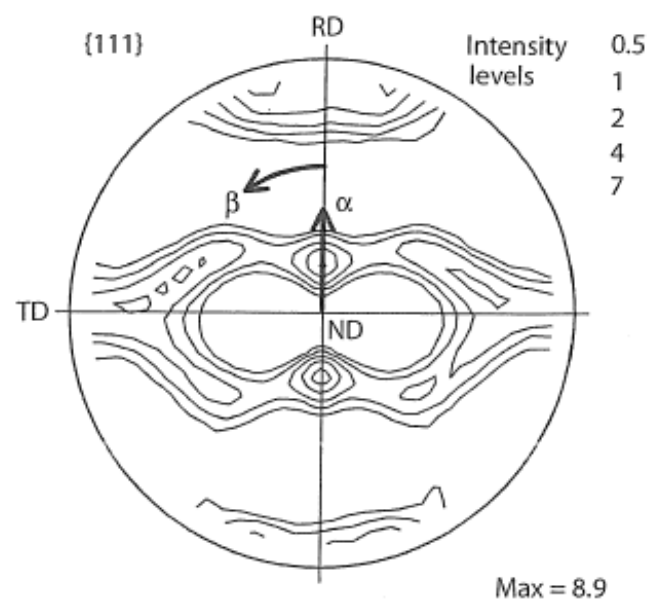

Figure 2.6 [111] pole figure of $97 \%$ cold-rolled Al with the definition of the pole figure angles $\alpha$ and $\beta$ [2.24]

A pole figure can also be represented as an equal-area projection showing the distribution of the same particular lattice plane in a crystal oriented in relation to the same referenced directions in the sample. The definitions for these two different projections (stereographic and equal-area) are illustrated in Figure 2.7. A Wulff net is commonly used for mapping of angles between different poles in a stereographic projection, Figure 2.7a [2.25]. For the equal-area projection, a Lambert net is used to determine the angles between the poles Figure 2.7b [2.26].

In this thesis work, the pole figures of the crystals in the $\mathrm{Zr}-2.5 \mathrm{Nb}$ pressure tube and Zircaloy-4 fuel sheath samples are measured using diffraction techniques with neutrons. The total intensity of diffracted neutrons that is measured for a given $(h k l)$ plane, corresponding to some point on the pole figure defined by the polar and azimuthal angles $(\alpha, \beta)$, originates from all the crystals in the sample that satisfy the Bragg's law. 
(A)

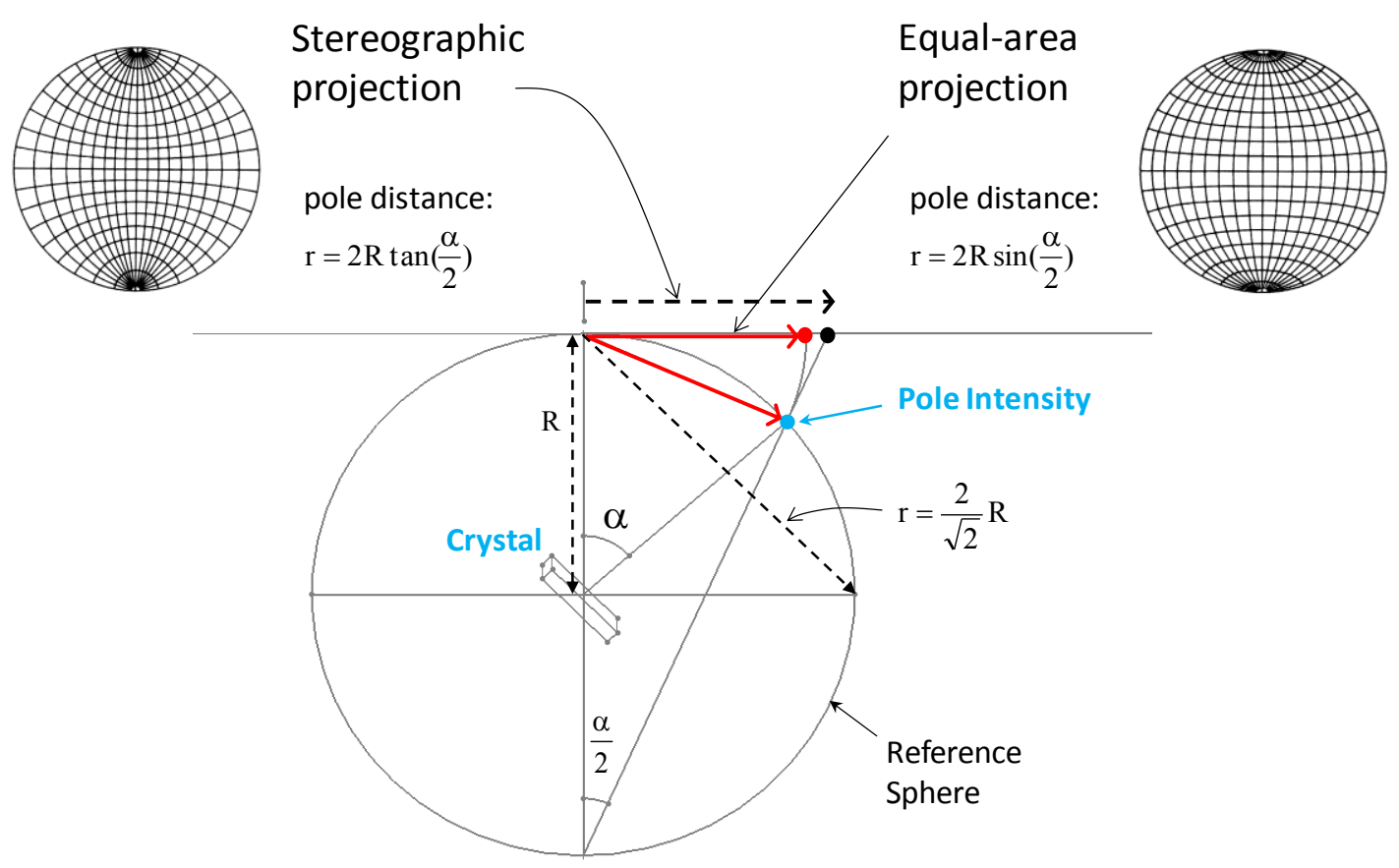

Figure 2.7 Diagram showing a stereographic and an equal-area projection [2.23]

\subsubsection{Inverse pole figure}

Texture can also be represented in an inverse pole figure, as shown in Figure 2.8. The inverse pole figure shown in the figure is for the extrusion axis of titanium, which has been plotted with iso-intensity lines in the hexagonal standard triangle formed by the

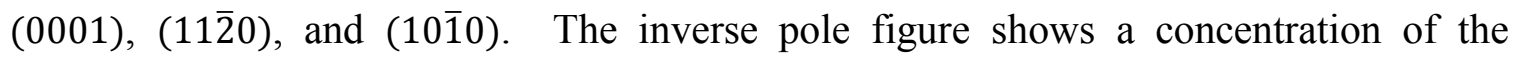
extrusion axis in the vicinity of $(10 \overline{1} 0)$, which means that the basal plane normals are perpendicular to the extrusion axis. This is a common texture of hexagonal materials deformed by extrusion. This inverse pole figure only shows the orientation of one reference axis of the sample, whereas rotations about this reference axis are not 
considered. Thus, for a complete representation of the 3-D orientation distribution, the orientations of two other reference axes are required.

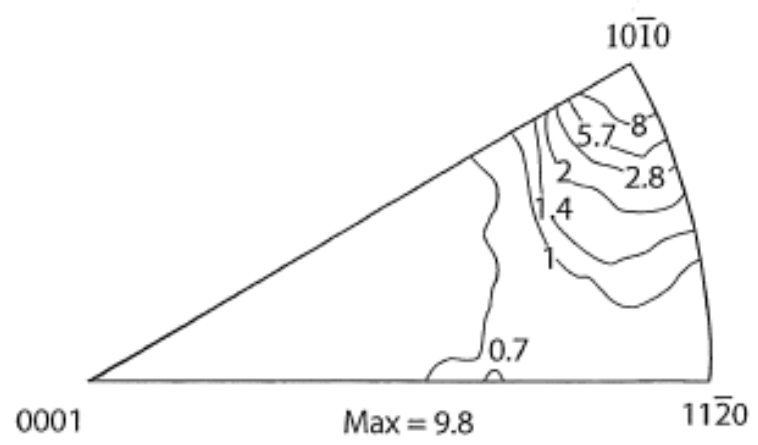

Figure 2.8 Inverse pole figure of the extrusion axis of Ti deformed by extrusion [2.24]

\subsubsection{Orientation distribution function (ODF)}

A complete description of texture is given by an orientation distribution function (ODF). The ODF is calculated using measured pole figure data. For crystals with a hep lattice that has a lower symmetry than a cubic system, at least four pole figures are needed. In pole figures for hcp crystals, as in the case of the $\alpha$-Zr phase material in zirconium and zirconium-based alloys, usually the plane normals of (0001), (1010), $(11 \overline{2} 0)$ and $(11 \overline{2} 2)$ are measured. For cubic crystals, as in the case of the $\beta$-phase material in zirconium and its alloys, only three pole figures from three hkl planes such as (001), (111), and (110) would be sufficient for input data to calculate the ODF. 
To specify the crystal orientation, $\mathbf{g}$, of the crystal coordinate axes $(\mathbf{x}, \mathbf{y}, \mathbf{z})$ with respect to the sample axes $(\mathbf{X}, \mathbf{Y}, \mathbf{Z})$, requires three angles such as the Euler angles $(\psi, \theta, \phi)$ for rotation of one of the two coordinate axes with respect to the other coordinate system. Before starting of the rotations, the crystallographic directions of the hcp $\alpha-\mathrm{Zr}$ crystal lattice are assigned to be aligned with the reference directions in the sample, as shown in Figure 2.9 for a tube sample defined by the longitudinal direction (L), the hoop direction $(\mathrm{H})$ and the radial direction $(\mathrm{R})$. Following Davies et al. [2.27], $\mathbf{X}=[\overline{1} 2 \overline{1} 0]$ as hoop, $\mathbf{Y}=[10 \overline{1} 0]$ as the longitudinal, and $\mathbf{Z}=[0001]$ as the radial direction of the tube sample. In an extruded (or a cold-drawn) tube, the longitudinal direction is normally aligned with the direction of extrusion (or drawing). Similarly, for a flat-rolled sample (e.g., plate or sheet), the reference directions of the axes in the sample are defined as the rolling direction (RD), transverse direction (TD) and normal direction (ND).

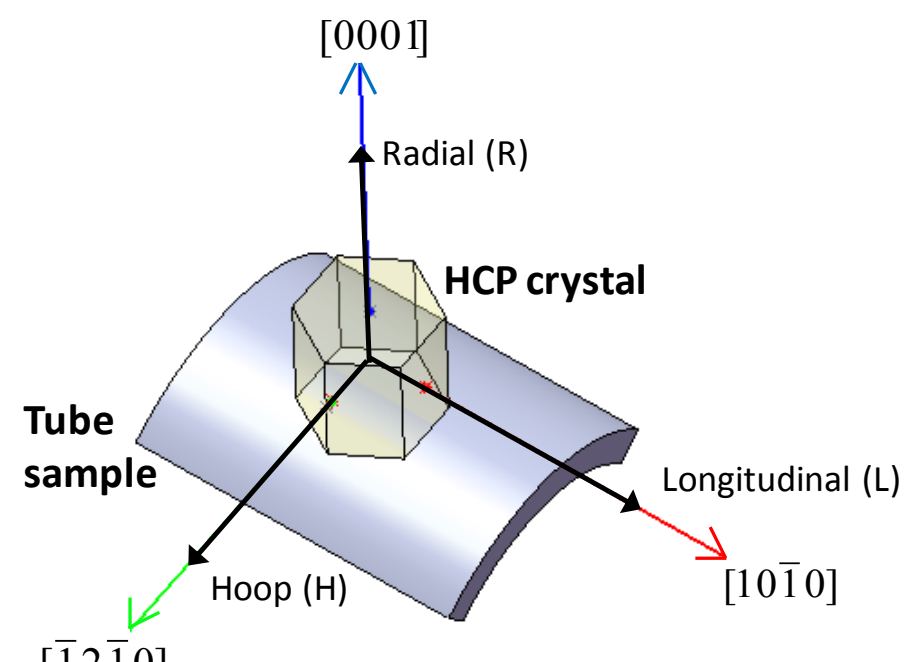

Figure 2.9 Relationship between crystal and sample axis directions 
The Euler angles relate the crystal coordinate axes with the specimen principal axes. The three rotations of the three Euler angles, in sequence, transform the crystal lattice orientations into the sample frame (i.e., tube coordinate system) as illustrated in Figure 2.10. The distribution of crystal orientations over a suitable space defined by the three Euler angles then describes the orientation distribution of the crystals in the reference sample. For convenience, the density of the crystal orientations is usually plotted as a continuous function of the Euler angles. Figure 2.11 shows illustrations of different crystal orientations described by Euler angles $(\Psi, \theta)$ for three constant- $\phi$ sections: a) $\phi=0^{\circ}$, b) $\phi=30^{\circ}$ and c) $\phi=60^{\circ}$, relating the crystallographic axes of the crystal to chosen axes in a sample (e.g., radial, hoop and longitudinal directions). There are other methods to represent crystallite orientations in Euler space such as that proposed by by Bunge [2.28], where the sample frame is rotated into the crystal frame. These representations are not illustrated here, but they are equivalent. 

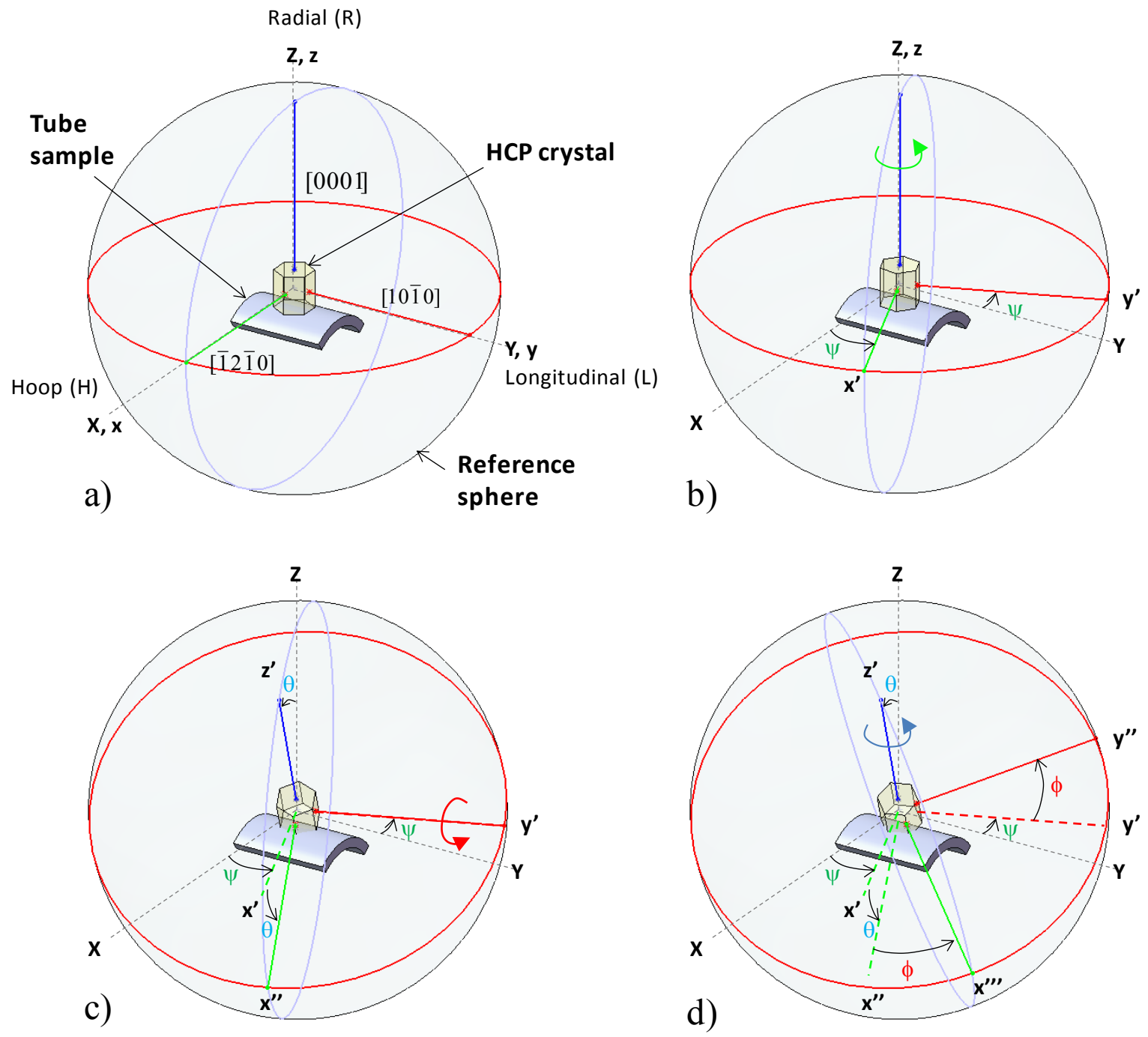

Figure 2.10 Illustration showing the reference (a) and three rotations (b, c and d) of Euler angles $(\psi, \theta, \phi)$, in sequence, relating the $\mathrm{HCP}$ crystal lattice orientation with the tube sample coordinate system 


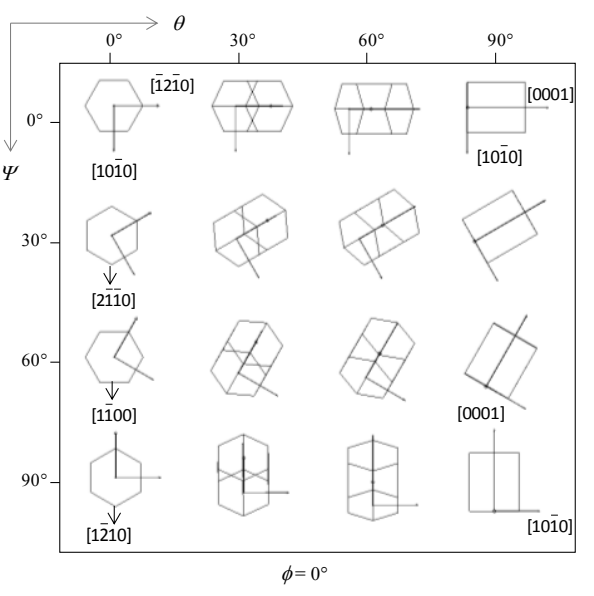

a)

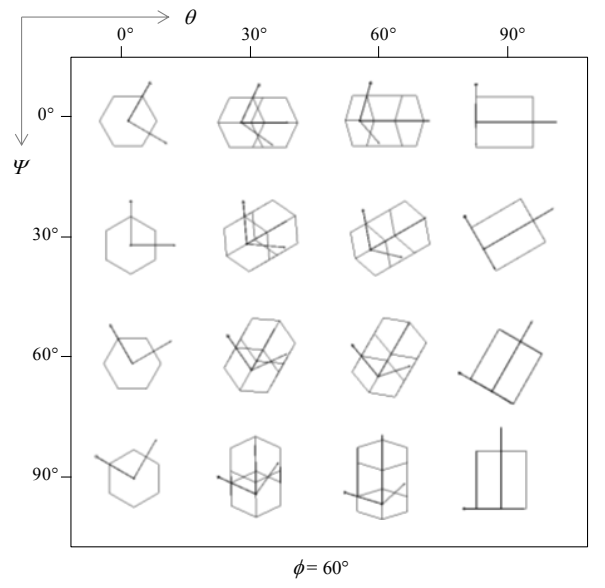

c)

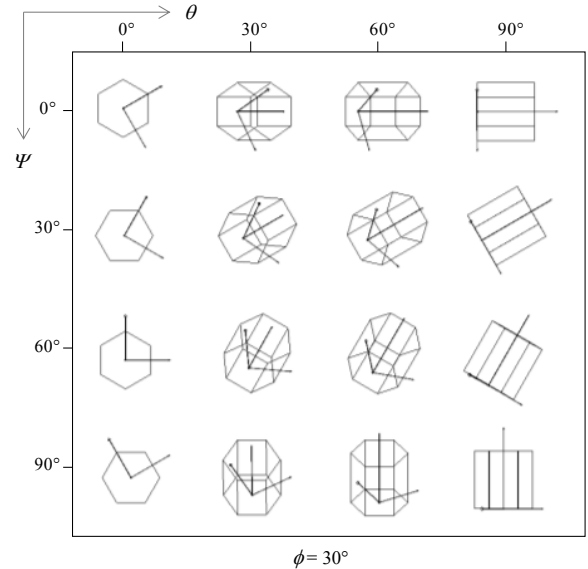

b)

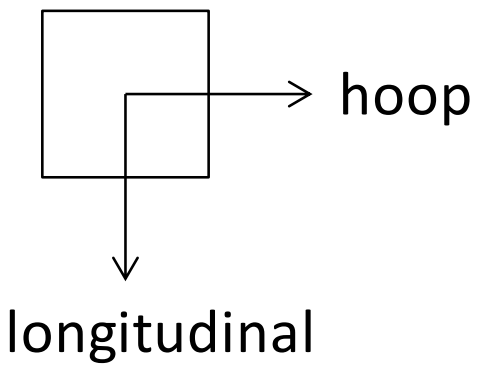

Figure 2.11 Illustration showing crystal orientations described by Euler angles $(\Psi, \theta)$ for three constant $\phi$ sections in relation to the sample axes: a) $\phi=0^{\circ}$, b) $\phi=30^{\circ}$ and c) $\phi=60^{\circ}$

Mathematical models have been developed to calculate the orientation distribution function (ODF) of the crystals in a sample using input data from a set of pole figures obtained from experimental measurements for a set of lattice (hkl) planes. The most widely used models for calculating the ODF are those proposed independently by Roe [2.29] and by Bunge [2.28], using generalized spherical harmonics functions to 
represent the orientation distribution of crystals in a sample. Other models used to calculate the ODF are the Direct or Discrete methods. The ODF calculations using the Harmonic method are performed in Fourier space, whereas in the Direct or Discrete methods the computations are performed in orientation space. The two different methods (Harmonic and Direct) are briefly discussed as follows.

\section{$\underline{\text { Harmonic Method }}$}

In the Harmonic method, the basic premise is the assumption that both the measured pole figures and the orientation distribution can be fitted by a series expansion with suitable mathematical functions. The appropriate functions to use in a spherical coordinate system are the "spherical harmonics functions" (just as sines and cosines are used in Fourier analysis of linearly periodic functions). Spherical functions form an orthogonal set over the range $0 \leq \alpha<\pi, 0 \leq \beta<2 \pi$ on the surface of a sphere which is used for pole figures. Roe [2.29] developed a procedure by which the ODF, $\omega(\Psi, \theta, \phi)$, can be deduced from the set of plane-normal distributions obtained experimentally. The ODF is expressed using a series of generalized spherical harmonics:

$$
\omega(\Psi, \theta, \phi)=\sum_{l=0}^{\infty} \sum_{m=-l}^{l} \sum_{n=-l}^{l} W_{l m n} Z_{l m n}(\cos \theta) e^{i m \Psi} e^{i n \phi}
$$

where $W_{l m n}$ are the series expansion coefficients and $Z_{l m n}(\cos \theta)$ is a generalization of the associated Legendre functions, also called the augmented Jacobi polynomials [2.29]. This probability function $\omega(\Psi, \theta, \phi)$ is known as the ODF, and $(\Psi, \theta, \phi)$ are Euler angles 
relating the crystal coordinate axes with the specimen principal axes. The input data for the harmonic series method consists of a set of pole figure measurements, with the intensities, $I(\alpha, \beta)$, also expressed as a series of spherical harmonic as in eqn. 2.3.3.2 [2.23]:

$$
I(\alpha, \beta)=\sum_{l=0}^{\infty} \sum_{m=-l}^{l} Q_{l m} P_{l}^{m}(\cos \alpha) e^{i m \beta}
$$

where $Q_{l m}$ are the coefficients to solve for $P_{l}^{m}(\cos \alpha) e^{i m \beta}$ in the series of spherical harmonics, and $l$ and $m$ govern the shape of the function. In this series, $l$ represents the 'order' of the spherical harmonic function. This is an infinite series; a truncation at some finite value of $l$ is necessary in practice, limited by the number of data points measured. Because these functions are orthogonal, the $Q_{l m}$ coefficients are obtained from experimental data by integration, given in eqn. 2.3.3.3 [2.23]:

$$
Q_{l m}=\int_{0}^{\pi} \int_{0}^{\pi} p(\alpha, \beta)(\cos \alpha) e^{-i m \beta} \sin \alpha d \beta d \alpha
$$

The problem then becomes one of finding the relation that will transform between the unknown $W_{l m n}$ and experimentally accessible $Q_{l m}$, The transformation relation is given in eqn. (2.3.3.4) [2.23]:

$$
Q_{l m}=\sum_{n=-1}^{l} W_{l m n} P_{l}^{n}(\cos \xi) e^{-i n \eta}
$$

where $\xi$ and $\eta$ are the polar coordinates of the (hkl) pole in the crystal coordinate system. 
Equation (2.3.3.4) is a linear equation relating the pole figure coefficients with the ODF coefficients. By measuring several pole figures from geometrically independent poles, one obtains a set of linear simultaneous equations that can be solved for the $W_{l m n}$ coefficients. The $W_{l m n}$ values are then substituted in eqn. (2.3.3.1) to obtain the ODF, which can be used to recalculate any pole figure, even those that are not measured. The pole figures calculated using spherical harmonic functions are usually presented in a symmetrized representation.

In the generalized spherical functions developed by Bunge [2.28], the three Euler angles employed to describe the crystal orientations are $\varphi_{1}, \Phi$ and $\varphi_{2}$. The Bunge and Roe methods are conceptually identical. The relationships between the Euler angles used by Bunge and by Roe, are [2.23]:

$$
\varphi_{1}=\frac{\pi}{2}-\Psi ; \quad \Phi=\theta ; \quad \varphi_{2}=\frac{\pi}{2}-\phi
$$

In the fitting refinement of the harmonic function to the data, a common pitfall is the potential for overfitting of the data by refining to too high of an order, $l$. A simple rule of thumb is to select $l$, given in eqn. (2.3.3.6) [2.30].

$$
\operatorname{Order}(l)=\frac{360}{b}
$$

where $b$ is equal to the angular resolution of the detector [2.30]. 


\section{Direct Method}

In the direct method, the ODF is calculated in orientation space to deal with the problem of 'ghosting' produced by the shape and mathematical procedure of the harmonic method. In the formulation of the direct method, both the pole figure and ODF are represented by discrete values, usually obtained by producing a regular grid of cells and subdividing these domains and solving the ODF [2.23]. Although there are many different direct algorithms used, the EWIMV algorithm is applied for all the texture analysis reported this thesis.

The EWIMV algorithm was derived from the WIMV (Williams-Imhof-MatthiesVinel) method [2.30] that allows data to be entered at arbitrary positions (rather than the conventional $5^{\circ} \times 5^{\circ} \times 5^{\circ}$ grid) [2.31]. For the EWIMV algorithm, 'projection paths' relating cells in the ODF grid with cells on various pole figure grids are established by consideration of the crystal geometry. The value in each pole figure cell $\left(P_{h}\right)$ is the average of the values in the ODF cells (weighted by the cell size) along the corresponding project line(s) through eqn. (2.3.3.7).

$$
P_{h}(y)=\frac{1}{N} \sum_{i=1}^{N} f\left(y \Leftarrow g_{i}\right)
$$

where $g$ represents the crystal orientation (i.e., three Euler angles), and $y$ represents a point on the pole figure of the crystal pole $h$. The computation in this direct method is an iterative process. The computation to find a solution starts with making an initial 
estimate $\left(f_{o}\right)$ of the ODF by placing in each ODF cell the geometric mean of the values in the associated experimental pole figure cells:

$$
f_{0}(g)=N_{o} \prod_{j=1}^{I} \prod_{m_{i}=1}^{M_{i}} P_{h_{i}}^{e x p}\left(y_{m_{i}}\right)^{\frac{1}{I M_{i}}}
$$

where $I$ is the number of measured pole figures, $M_{i}$ is the multiplicity of the $i$ th pole figure, and $N_{o}$ is the normalization. If the initial estimate were that the ODF is random, then the operation of the following eqn. (2.3.3.9) would lead to the same result as eqn. (2.3.3.8) after the first iteration. In eqn. (2.3.3.8) the pole figure cell values of zeros will lead automatically to corresponding zeros in the $f_{o}$ as required. The ODF is refined by a series of 'inner iterations', as follows. If $P_{h_{i}}^{n}$ is the recalculated pole figure after the $n$th iteration step, for each cell of the ODF, a correction factor for each ODF cell is derived as the ratio of the geometric mean of the corresponding cells in the experimental pole figure $\left(=\mathrm{f}_{0}(\mathrm{~g})\right)$ to the corresponding one in the recalculated pole figure cells. The next estimate $((n+1))$ is then derived from the $n$th by multiplying with this correction factor:

$$
f_{n+1}(g)=N_{n} f_{n}(g) \frac{f_{0}(g)}{\prod_{j=1}^{I} \prod_{m_{i}=1}^{M_{i}} P_{h_{i}}^{\exp }\left(y_{m_{i}}\right)^{\frac{1}{I M_{i}}}}
$$

If the initial ODF estimate in a cell is too large, then the corresponding recalculated pole figure values will also be too large, and the correction factor will be less 
than unity. The ODF estimate for that cell will then be reduced in the next iteration, as required. In practice, the algorithm converges rapidly, and a satisfactory agreement is found between the experimental data and recalculated pole figures, typically after 10-12 iterations [2.23].

Additionally, an optimal 'outer iteration' may be imposed, to limit the maximum value of the ODF to $f(g) \geq f(g)_{\min }$, thus raising the 'phon' or isotropic background. By this way, any potential negative ghost holes or valleys will be filled, which in turn reduces the corresponding positive ghosts as well.

Eqn. (2.3.3.7) represents a system of linear equations, and its solution requires the inversion of a large, though sparse, matrix. In general, insufficient experimental data will be available to give a unique solution. Additionally, the ghost problem manifests itself in a different form, regardless of the amount of data available, so a solution is not possible without additional conditions. Applying different explicit or implied conditions could lead to different solutions within the solution range.

The EWIMV algorithm is an improvement of the WIMV method, and provides a better integration between the Rietveld method [2.32] and the texture computation. The main differences of EWIMV relative to WIMV are: (a) the ODF cell path for each individual measurement and reflection is computed explicitly for the true measurement angles, no longer requiring a regularly-space grid coverage and interpolation, (b) it uses a 2-D 'tube cell' projection of the paths which improves smoothness of the ODF, (c) it uses a modified iteration algorithm based on an entropy principle that increases the speed and 
convergence, and (d) different cell sizes can be selected for the texture computation [2.33].

The EWIMV algorithm is implemented in the Los Alamos texture software package popLA [2.34] as well as the Berkeley texture package BEARTEX [2.23]. In a recent addition, the EWIMV has also been implemented in the MAUD (materials analysis using diffraction) program [2.35] to combine with the Rietveld method (also implemented in MAUD) for analyzing the HIPPO diffraction data obtained at LANSCE. MAUD uses the Rietveld method that was originally developed to determine crystal structures from powder samples and to fit the complete measured diffraction spectra by refining the instrument, phase, and sample parameters.

The use of the MAUD program as a method for analysing the HIPPO diffraction data is described in [2.35]. Tutorial examples on the use of MAUD for texture analysis are found in [2.36]. It is important to have a benchmark pole figure that has been well characterized at room temperature available for analysis of the neutron data using the MAUD program as a way to 'calibrate' the computation parameters (e.g., values set for sample orientation in relation to the direction of the incident neutron beam direction on the sample). Once the appropriate sample orientation set values are determined to give a matching comparison of pole figure with the benchmark, then the analyses of the neutron data obtained at all other elevated temperatures should use the same set of values for calculating the ODF.

In this thesis investigation, all pole figures reported are reproduced from the ODF obtained using the Rietveld method and EWIMV (direct method for texture computation) 
as implemented in the MAUD program. Details of the procedure for MAUD are described in [2.35]. The ODF data can also be used to calculate the Kearns (texture) numbers [2.36] to represent texture based on the distribution of resolved fraction of basal plane normals in the principal directions in the sample.

\subsubsection{Kearns (texture) numbers [2.37]}

The Kearns numbers, $\left(f_{R}, f_{T}\right.$, and $\left.f_{L}\right)$, defined as a weighted average of the intensity of the basal plane normals oriented with respect to the sample's principal direction, are calculated using eqn. (2.3.4.1).

$$
f_{d}=\left[\sum_{\alpha_{d}} V_{f}\left(\alpha_{d}, \beta\right) \sin \alpha_{d} \cos ^{2} \alpha_{d}\right] /\left[\sum_{\alpha_{d}} V_{f}\left(\alpha_{d}, \beta\right) \sin \alpha_{d}\right]
$$

Here $d$ stands for $R$ (radial), $T$ (transverse) or $L$ (longitudinal) direction of the original tube sample. $V_{f}\left(\alpha_{d}, \beta\right)$ is the volume fraction of grains with basal poles oriented at a given polar and azimuthal angles $\alpha_{d}$ and $\beta$ in the pole figure for the sample, respectively. Normally, the sum of the three Kearns numbers must equal to 1 (eqn. 2.3.4.2).

$$
f_{R}+f_{T}+f_{L}=1
$$

The Kearns numbers only relate to the resolved fraction of basal plane normals in the principal directions of a sample and this texture representation is not as complete as the ODF. To compute the Kearns numbers only the basal pole figure needs to be measured either using X-ray or neutron diffraction. The Kearns numbers are commonly used for comparison in relation to differences in anisotropic behaviour of hcp materials. 
In this thesis investigation, the Kearns numbers are computed using the ODF data derived from neutron diffraction measurements performed on the HIPPO time-of-flight diffractometer at LANSCE. The calculations are obtained using the SELPOLY code with the ODF data as input.

\section{References:}

[2.1] J.P. Abriata and J.C. Bolcich, The Nb-Zr system, Bull. Alloy Phase Diagrams, Vol. 3, No. 1, pp. 34-44, 1982

[2.2] D.O. Northwood and D.C. Gillies, A determination of the $\alpha /(\alpha+\beta)$ and $(\alpha+\beta) / \beta$ phase boundaries in the zirconium-niobium system, Microstruc. Sci., 7:123-132, 1979

[2.3] S.A. Aldridge and B.A. Cheadle, Age hardening of $\mathrm{Zr}-2.5 \mathrm{wt} \% \mathrm{Nb}$ slowly cooled from the $(\alpha+\beta)$ phase field, J. Nucl. Mater., 42:32-42, 1972

[2.4] M. Griffiths, J.E. Winegar and A. Buyers, The transformation behaviour of the $\beta$-phase in Zr-2.5Nb pressure tubes, J. Nucl. Mater. 383:28-33, 2008

[2.5] J.P. Abriata, J.C. Bolcich and D. Arias: Bull. Alloy Phase Diagrams, 4(2), pp. 2087-2089, 1983

[2.6] G. Okvist and K. Kallstrom, The effect of zirconium carbide on the $\beta \rightarrow \alpha$ transformation structure in Zircaloy, J. Nucl. Mater., Vol. 35, pp. 316-321, 1970

[2.7] R.A. Holt, The beta to alpha phase transformation in Zircaloy-4, J. Nucl. Mater., Vol. 35, pp. 322-334, 1970

[2.8] J.B Vander Sande and A..L. Bement, An investigation of second phase particles in Zircaloy-4 alloys, J. Nucl. Mater., Vol. 52, pp. 115-118, 1974

[2.9] E. Vitikainen and P. nenonen, Transmission electron microscopy studies on intermetallics in some zirconium alloys, J. Nucl. Mater., Vol. 78, pp. 362-373, 1978

[2.10] W.L. Fong and D.O. Northwood, Identification of Second-Phase Particles in Zircaloy-4 Nuclear Fuel Sheathing, Metallography 15:27-41, 1982 
[2.11] T. Forgeron, J.C. Brachet, F. Barcelo, A. Castaing, J. Hivroz, J.P. Mardon and C. Bernaudat, Experiment and modeling of advanced fuel rod cladding behaviour under LOCA conditions: Alpha-Beta Phase Transformation Kinetics and EDGAR Methodology, Zirconium in the Nuclear Industry: $12^{\text {th }}$ International Symposium, ASTM STP 1354, G.P. Sabol and G.D. Moan, Eds., ASTM, West Conshohocken, PA, pp. $256-278,2000$

[2.12] D. Kaddour, S. Frechinet, A.F. Gourgues, J.C. Brachet, L. Portier, A. Pineau, Experimental determination of creep properties of Zirconium alloys together with phase transformation, Scripta Materialia, Vol. 51, pp. 515-519, 2004

[2.13] C. Toffolon-Masclet, T. Guilbert, and J.C. Brachet, Study of secondary intermetallic phase precipitation/dissolution in $\mathrm{Zr}$ alloys by high temperature-high sensitivity calorimetry, J. Nucl. Mater. 372:367-378, 2008

[2.14] S. Malinov, P. Markovsky, W. Sha, and Z. Guo, Resistivity study and computer modelling of the isothermal transformation kinetics of Ti-6Al-4V and Ti-6Al-2Sn-4Zr2Mo-0.08Si alloys, J. Alloys and Compounds, 314:181-192, 2001

[2.15] I.T. Bethune and C.D. Williams, The $\alpha /(\alpha+\beta)$ boundary in the Zr-Nb system, J. Nucl. Mater. Vol. 29, pp. 129-132, 1968

[2.16] C.K. Chow, Y. Liner, and G.L. Rigby, A model for growth of beta-phase particles in zirconium-2.5 wt\% niobium, Atomic Energy of Canada Ltd. Report AECL-7821, 1984

[2.17] G.G. Seward, S. Celotto, D.J. Prior, J. Wheeler, and R.C. Pond, In situ SEM-EBSD observations of the hep to bcc phase transformation in commercially pure titanium, Acta Mater. 52:821-832, 2004

[2.18] Z.S. Zhu, J.L. Gu, R.Y. Liu, N.P. Chen and M.G. Yan, Variant selection and its effect on phase transformation textures in cold rolled titanium sheet, Mat. Sci. \& Engr. A280, pp. 199-203, 2000

[2.19] J.W. Elmer, T.A. Palmer, S.S. Babu and E.D. Specht, In situ observations of lattice expansion and transformation rates of $\alpha$ and $\beta$ phases in Ti-6Al-4V, Mater. Sci. A, Vol. 391, pp. 104-113, 2005

[2.20] B.K. Damkroger, D. Juul Jensen and G.R. Edwards, In-situ measurement of phase transformation kinetics using neutron diffraction, Scripta Mater. Vol. 22, pp. 287-291, 1988 
[2.21] H-R Wenk, I. Lonardelli and D. Williams, Texture changes in the hcp $\rightarrow$ bcc $\rightarrow h c p$ transformation of zirconium studied in situ by neutron diffraction, Acta Mater. Vol. 52, pp. 1899-1907, 2004

[2.22] M.R. Daymond, R.A. Holt, S. Cai, P. Mosbrucker and S.C. Vogel: Acta Mater., 2010, 58:4053-4066

[2.23] U.F. Kocks, C. N. Tomé, and H.-R. Wenk, Texture and Anisotropy: Preferred orientations in polycrystals and their effect on material properties, Cambridge University Press, 1998

[2.24] O. Engler and V. Randle, Introduction to texture analysis: Macrotexture, macrotexture, and orientation mapping, CRC Press, 2010

[2.25] B.D. Cullity, Elements of X-ray diffraction, Addison-Wesley Publishing Co. Inc., 1978

[2.26] H.R. Wenk: Preferred Orientation in Metals and Rocks, H.-R. Wenk, ed., Academic Press, pp. 11-47, 1985

[2.27] G.J. Davies, D.J. Goodwill and J.S. Kallend, Charts for analysing crystallite orientation distribution function plots for hexagonal materials, J. Appl. Crystallogr., Vol. 4, pp. 193-196, 1970

[2.28] H.J. Bunge: Z. Metallk., Vol. 56, pp. 872-74, 1965

[2.29] R. Roe, Description of crystallite orientation in polycrystalline materials. III. General solution to pole figure inversion, J. Appl. Phys., Vol. 36, pp. 2024-2031, 1965

[2.30] S. Matthies, J. Pehl, H. R. Wenk, L. Lutterotti, , and S. C. Vogel, Quantitative texture analysis with the HIPPO neutron TOF diffractometer, J. Appl. Crystallogr., Vol. 38, pp. $462-475,2005$

[2.31] S. Matthies and G. Vinel, Phys. Status Solidi B, Vol. 112, pp. 111-120, 1982

[2.32] H.M. Rietveld, J. Appl. Crystallogr., Vol. 2, pp. 65-71, 1969

[2.33] H.-R. Wenk, L. Lutterotti and S.C. Vogel, Texture analysis with the new HIPPO TOF diffractometer, Nucl. Instrum. Methods Phys. Res., A515, pp. 575-588, 2003

[2.34] J.S. Kallend, U.F. Kocks, A.D. Rollett and H.,-R. Wenk, Operational texture analysis, Mater. Sci. Eng. A, Vol. 132, pp. 1-11, 1991

[2.35] H.R. Wenk, L. Lutterotti and S.C. Vogel, Rietveld texture analysis from TOF neutron diffraction data, J. Powder Diffraction, Vol. 25, No. 3 pp. 283-296, 2010

[2.36] Tutorial on using MAUD program for texture analysis using HIPPO neutron diffraction data (http://eps.berkeley.edu/ wenk/TexturePage/MAUD.htm) 
[2.37] J.J. Kearns, Thermal expansion and preferred orientation in Zircaloy, WAPD-TM-472, 1965 


\section{Chapter 3}

\section{Materials and Experimental Methods}

This chapter describes the preparation of $\mathrm{Zr}-2.5 \mathrm{Nb}$ pressure tube and Zircaloy-4 fuel sheath materials used in this thesis investigation for experimental measurements of texture and phase transformations using neutron diffraction.

\subsection{Zr-2.5Nb Pressure Tube Materials}

The investigation was performed on CANDU $\mathrm{Zr}-2.5 \mathrm{Nb}$ pressure tube materials with three different metallurgical conditions.

The three $\mathrm{Zr}-2.5 \mathrm{Nb}$ pressure tube materials evaluated were:

1) As-manufactured $\mathrm{Zr}-2.5 \mathrm{Nb}$ pressure tube (No. RX 119), (reported in Chapter 4).

2) Modification ' $\mathrm{A}$ ' of as-manufactured $\mathrm{Zr}-2.5 \mathrm{Nb}$ pressure tube material (reported in Chapter 7).

3) Modification ' $\mathrm{B}$ ' of as-manufactured $\mathrm{Zr}-2.5 \mathrm{Nb}$ pressure tube material (reported in Chapter 7).

The as-manufactured $\mathrm{Zr}-2.5 \mathrm{Nb}$ pressure tube material used in this thesis investigation had been fabricated from a quadruple- melted ingot where the billet had been hot-extruded at about $815^{\circ} \mathrm{C}$ into a tube which was then cold-worked $25-30 \%$ and 
Table 3.1 A typical chemical composition of $\mathrm{Zr}-2.5 \mathrm{Nb}$ alloy pressure tube

\begin{tabular}{|c|c|c|c|}
\hline Element & $\begin{array}{c}\text { ppm }(\mathrm{wt} \%) \\
\text { Max. }\end{array}$ & Element & $\begin{array}{c}\text { ppm }\left(w t^{\%}\right) \\
\text { Max. }\end{array}$ \\
\hline $\mathrm{Al}$ & 75 & $\mathrm{Nb}$ & 2.5 to $2.8 \mathrm{wt} \%$ \\
$\mathrm{~B}$ & 0.5 & $\mathrm{Ni}$ & 35 \\
$\mathrm{C}$ & 125 & $\mathrm{O}$ & 1000 to 1500 \\
$\mathrm{Cd}$ & 0.5 & $\mathrm{P}$ & 12 \\
$\mathrm{Co}$ & 20 & $\mathrm{~Pb}$ & 50 \\
$\mathrm{Cr}$ & 100 & $\mathrm{Si}$ & 100 \\
$\mathrm{Cu}$ & 50 & $\mathrm{Sn}$ & 100 \\
$\mathrm{Fe}$ & 370 & $\mathrm{Ta}$ & 100 \\
$\mathrm{H}$ & $<5.0$ & $\mathrm{Ti}$ & 50 \\
$\mathrm{Hf}$ & 50 & $\mathrm{U}$ & 3.5 \\
$\mathrm{Mg}$ & 1 & $\mathrm{~V}$ & 50 \\
$\mathrm{Mn}$ & 50 & $\mathrm{~W}$ & 50 \\
$\mathrm{Mo}$ & 50 & $\mathrm{Zr}$ & Balance \\
$\mathrm{N}$ & 65 & & \\
\hline
\end{tabular}

given a final stress-relief at $400^{\circ} \mathrm{C}$ for $24 \mathrm{~h}$. The stress relief treatment partially decomposes the as-fabricated metastable $\beta_{\mathrm{Zr}}$ phase (containing about $20 \% \mathrm{Nb}$ ) into a $\beta_{\text {enr }}$ phase enriched in $\mathrm{Nb}$ content [3.1], [3.2]. Table 3.1 gives a typical chemical composition of $\mathrm{Zr}-2.5 \mathrm{Nb}$ pressure tube materials. Figure 3.1 shows a typical starting microstructure of an as-manufactured pressure tube material, consisting of elongated hcp $\alpha-\mathrm{Zr}$ grains containing a high dislocation density, and a thin layer of bcc $\beta$ phase at the $\alpha$-grain boundaries. Small quantities of meta-stable $\omega$ phase (space group P6/mmm) may also exist in the material, depending on the thermo-mechanical history. At room temperature, a typical $\mathrm{Zr}-2.5 \mathrm{Nb}$ pressure tube material contains mostly $\alpha$-phase $\mathrm{Zr}$ containing about $1 \mathrm{wt} \% \mathrm{Nb}$ and a small portion of $\mathrm{Nb}$-stabilized $\beta$ phase with about $20 \mathrm{wt} \% \mathrm{Nb}$, corresponding to the monotectoid composition in the $\mathrm{Zr}-\mathrm{Nb}$ phase diagram (Figure 3.2). 


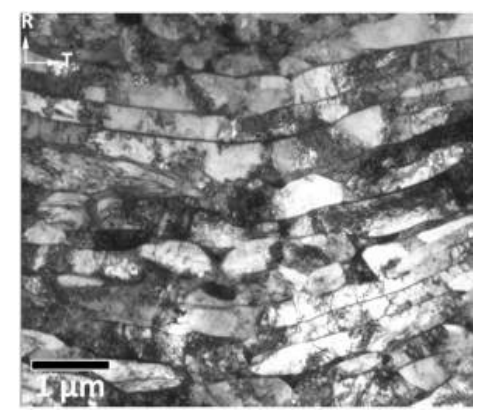

a)

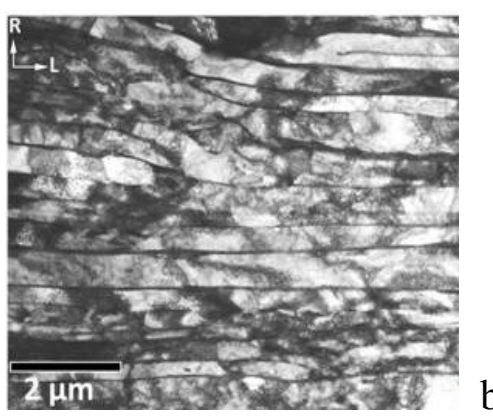

b)

Figure 3.1 TEM micrographs showing elongated grain structure in $\mathrm{Zr}-2.5 \mathrm{Nb}$ pressure tube material a) longitudinal and b) transverse direction. (This Figure 1a first appeared in Figure 1.3)

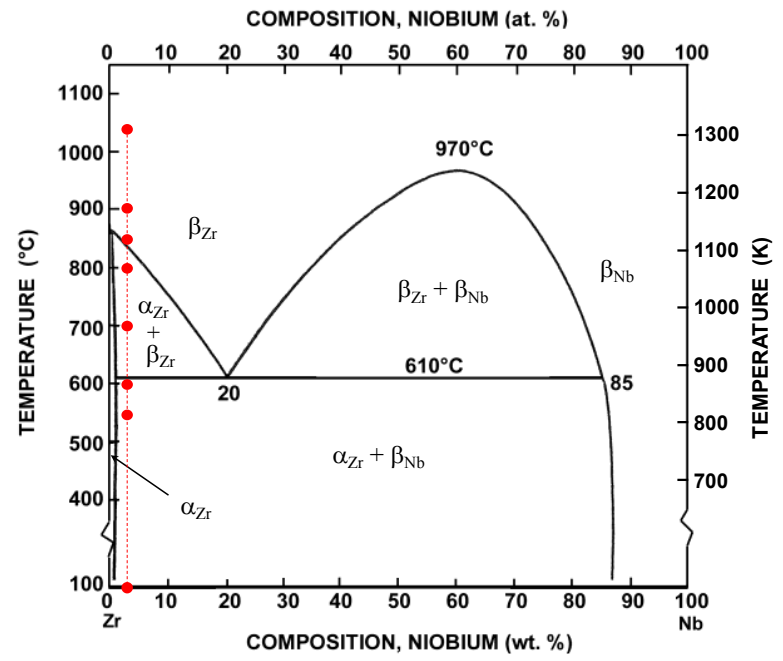

Figure 3.2 Zr-Nb phase diagram [3.3]. The red dots correspond to the temperatures used in neutron measurements. (This figure first appeared in Figure 2.1)

For the neutron diffraction experiments (Chapter 4, Chapter 6, and Chapter 7), a suitably-sized sample was prepared by stacking together two or more plates that were cut from the pressure tube material, Figure 3.3. To increase the sampling volume and thus improve the neutron measurements, the overall dimension of the stacked sample was made into approximately $10 \mathrm{~mm}$ tall x $8 \mathrm{~mm}$ wide $\times 8 \mathrm{~mm}$ thick. To obtain the two 
plates, a slit ring was first cut from the pressure tube and then reverse bent to obtain a flat strip which was cut into plates with the desired dimensions. The reverse bending of the strip is expected to introduce residual stresses and dislocations in the sample, in addition to the prior cold-worked and stress-relieved condition that would also affect the lattice parameters of the two phases. On heating at elevated test temperatures (e.g., at $550^{\circ} \mathrm{C}$ and higher) the sample would then be stress-relieved. To improve thermal conduction between the two plates, the small curvature and the autoclaved oxide on the inside surfaces of the two plates were mechanically polished, then cleaned with acetone and held tightly stacked together by spot-welding on a thin Zr-foil on both sides of the stacked sample. The neutron scattering from the thin $\mathrm{Zr}$ foils is expected to be minor since the volume of the stacked sample (volume being probed) is much larger than that of the foil, and hence they would not significantly alter the diffraction profile obtained from the stacked sample. The sample was ultrasonically cleaned with acetone before using it for the neutron diffraction measurements. The experimental method for neutron diffraction and the texture data analysis used in this thesis work are briefly described in Section 3.4 .

Figure 3.3 Photograph showing a stacked sample of pressure tube material used for neutron diffraction

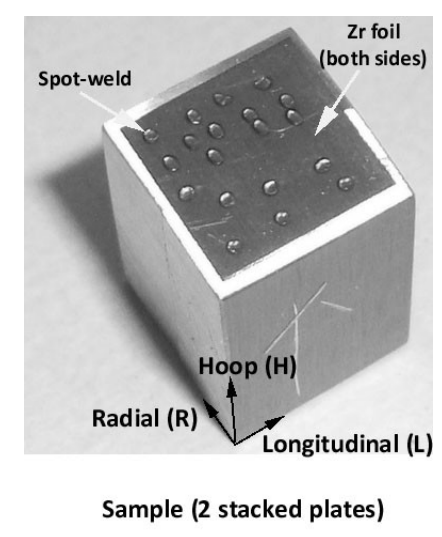


Modification 'A' pressure tube material was accomplished by a high-temperature annealing of as-manufactured pressure tube material at $875^{\circ} \mathrm{C}$ under vacuum for 17 days and then slowly cooled. To prepare a sample of the Modification 'A' material for neutron measurement, a slit ring ( 25-mm wide) was first cut from an as-manufactured $\mathrm{Zr}-2.5 \mathrm{Nb}$ pressure tube and then reverse bent to obtain a flat strip. The strip material was encapsulated in a quartz tube under vacuum, and given a high-temperature annealing at $875^{\circ} \mathrm{C}$ for 17 days and then cooled slowly back to room temperature. The sample was retrieved by breaking the glass tube. Figure 3.4 shows the microstructure of the Modification 'A' $\mathrm{Zr}-2.5 \mathrm{Nb}$ pressure tube sample, composed of large equiaxed primary $\alpha-Z r$ grains within a matrix of Widmanstätten $\alpha-Z r$ platelets transformed from prior $\beta-Z r$ grains. Optical micrographs showing the microstructures of the samples were obtained using standard metallographic procedures

A stacked sample of this Modification 'A' material was prepared for neutron diffraction measurements to characterize the change in texture as a result of the hightemperature annealing treatment. The evolution of texture on heating the Modification 'A' material to high temperatures was also investigated using neutron diffraction.

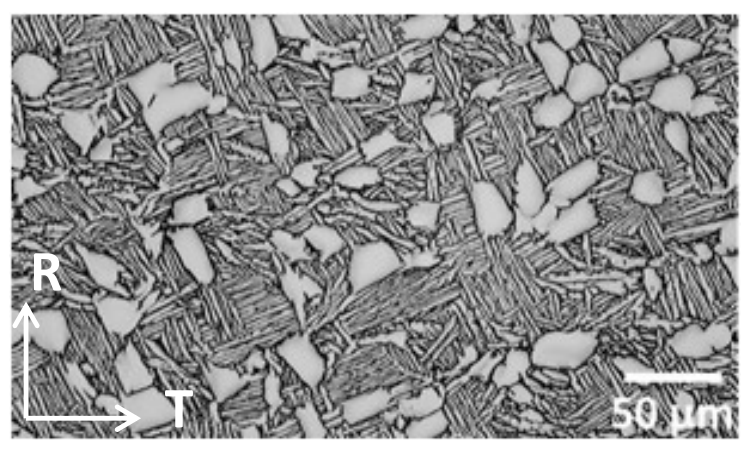

Figure 3.4 Optical micrograph showing microstructure of Modification 'A' material 
The Modification 'B' material was achieved by cold-rolling with 3 passes on the Modification ' $A$ ' material to obtain about $60 \%$ of cold work (in wall thickness reductions). The cold rolling of the Modification ' $A$ ' material was performed along the transverse direction of the strip material. The cold-rolling operation was accomplished at CANMET Materials Technology Laboratory. Figure 3.5 shows the microstructure of the Modification ' $\mathrm{B}$ ' material, composed of elongated primary $\alpha-\mathrm{Zr}$ grains and deformed Widmanstätten $\alpha-Z r$ platelets.

A stacked sample of this Modification 'B' material was prepared for neutron diffraction measurements to characterize the texture changes that resulted from the coldrolling process. The evolution of texture in this material during heating to high temperatures was also investigated using neutron diffraction.

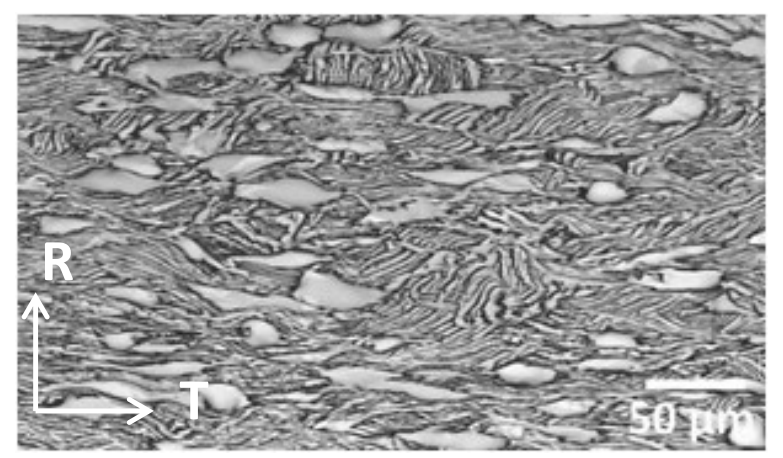

Figure 3.5 Optical micrograph showing microstructure of

Modification ' $\mathrm{B}$ ' material

\subsection{Zircaloy-4 Fuel Sheath Materials}

This thesis investigation was performed on CANDU Zircaloy-4 fuel sheath materials with three different metallurgical conditions. Table 3.2 gives a typical 
chemical composition of Zircaloy-4 fuel sheath materials. The Zircaloy-4 fuel sheath materials evaluated comprised:

1) As-manufactured fuel sheath (parent) material.

2) As-manufactured fuel sheath after simulated brazing at $1050^{\circ} \mathrm{C}$ for $40-60 \mathrm{~s}$, in argon atmosphere (simulated material corresponding to the brazed spacer/bearing pad location).

3) As-manufactured fuel sheath after simulated brazing cycle at $\sim 815^{\circ} \mathrm{C}$ for 40-60 s, in argon atmosphere (simulated material corresponding to the heat-affected-zone (HAZ) location near the spacer).

The microstructure of as-manufactured fuel sheath material, shown in Figure 3.6a, shows a cold-worked and stress-relieved $\alpha-Z r$ grain structure. The microstructure of the fuel sheath material after given a simulated brazing treatment $\left(1050^{\circ} \mathrm{C}\right.$ for $\left.40-60 \mathrm{~s}\right)$ shown in Figure 3.6b, shows a basketweave structure of $\beta$-transformed Widmanstätten $\alpha-\mathrm{Zr}$ platelets. The heating of the Zircaloy-4 fuel sheath material to $1050^{\circ} \mathrm{C}$ changes the roomtemperature hcp $\alpha-\mathrm{Zr}$ phase into a full $\beta$-Zr phase material (Figure 3.7). In the simulated brazing treatment at $\sim 815^{\circ} \mathrm{C}$ for $40-60 \mathrm{~s}$ to simulate a heat-affected-zone (HAZ), the microstructure obtained is an $\alpha$-annealed $\alpha-\mathrm{Zr}$ grain structure as shown in Figure 3.6c, consistent with the Zr-Sn phase diagram (Figure 3.7). 
Table 3.2 Chemical specification of as-manufactured Zircaloy-4 fuel sheathing

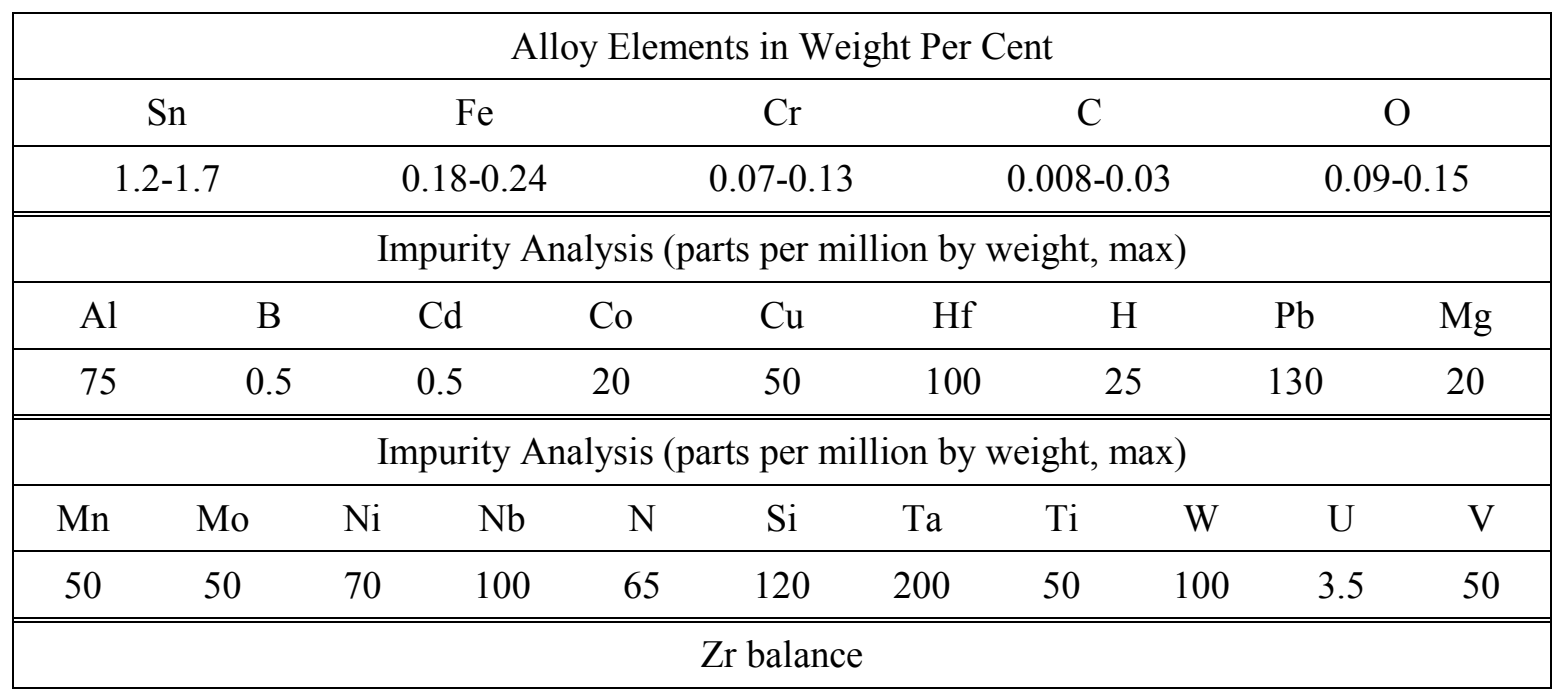

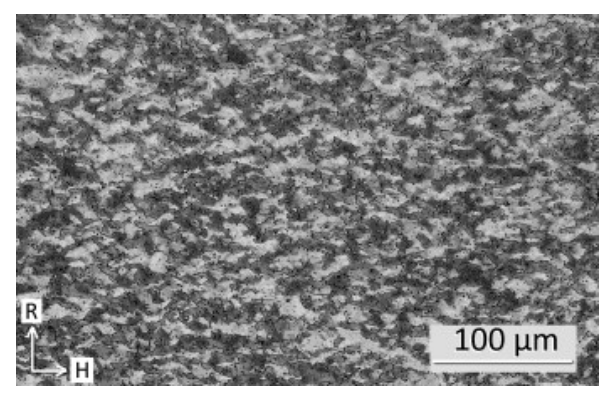

a)

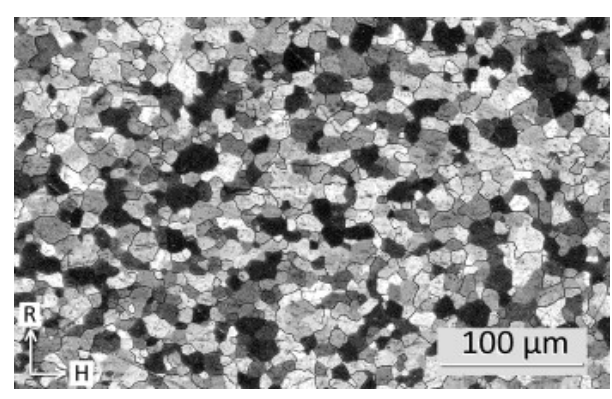

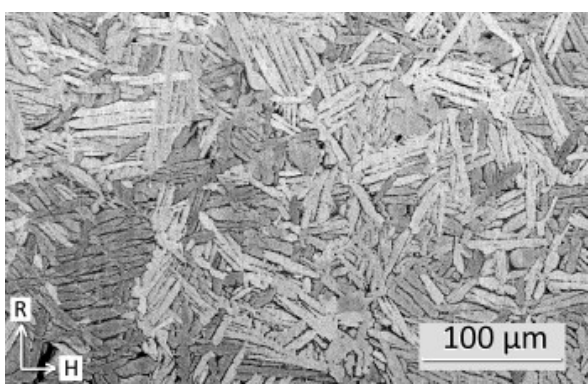

b)

Figure 3.6 Optical micrographs showing microstructures of Zircaloy-4 fuel sheaths: a) as-received, b) simulated braze-zone structure, and c) simulated heat-affected zone structure. (This figure first appeared in Figure 1.9) 


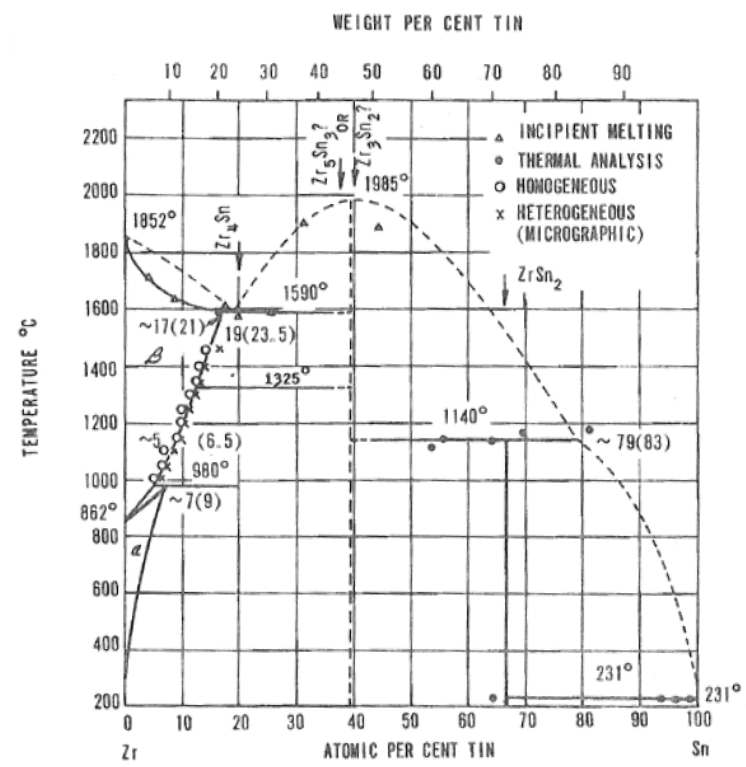

Figure 3.7 Zr-Sn phase diagram. (This figure first appeared in Figure 2.3)

To prepare stacked samples for neutron texture measurements, a slit ring was cut from the fuel sheathing and then reverse bent to obtain a flat strip. The strip material was cut into small plates with approximate desired dimensions, which were then held together by welding on vanadium straps around the stacked plates. Figure 3.8 shows the photographs of the three stacked samples of fuel sheath materials used in the neutron diffraction measurements of texture. The texture data obtained were used to calculate the Kearns (texture) numbers and the Hill's mechanical anisotropy factors. These results are reported in Chapter 6. 


\subsection{Neutron Diffraction Measurements}

The investigation of phase transformation and texture measurements on the samples prepared from the $\mathrm{Zr}-2.5 \mathrm{Nb}$ pressure tube and Zircaloy-4 fuel sheath materials described earlier (Sections 3.1 and 3.2) were performed on the time-of-flight (TOF) HIPPO difftractometer at the Los Alamos Neutron Science Center (LANSCE). Figure 3.9 shows a schematic view of the HIPPO diffractometer equipped with $1360{ }^{3} \mathrm{He}$ detector tubes arranged on 50 detector panels positioned on five rings of constant

\begin{tabular}{|c|c|c|c|}
\hline $\begin{array}{c}\text { Fuel Sheathing } \\
\text { Sample }\end{array}$ & $\begin{array}{c}\text { (as-mfg'd) } \\
\text { (cold-worked and } \\
\text { stress-relieved) }\end{array}$ & $\begin{array}{c}(\alpha \text {-annealed }) \\
\left(\sim 815^{\circ} \mathrm{C} / 40-60 \mathrm{~s}\right)\end{array}$ & $\begin{array}{r}(\beta \text {-transformed }) \\
\left(1050^{\circ} \mathrm{C} / 40-60 \mathrm{~s}\right)\end{array}$ \\
\hline $\begin{array}{c}\text { View in radial } \\
\text { direction }\end{array}$ & 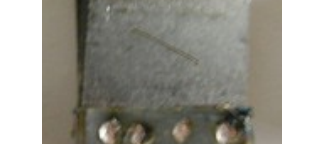 & & \\
\hline $\begin{array}{c}\text { View in hoop } \\
\text { direction }\end{array}$ & & & \\
\hline $\begin{array}{c}\text { View in axial } \\
\text { direction }\end{array}$ & & & \\
\hline
\end{tabular}

Figure 3.8 Photographs showing three samples used for neutron diffraction 
diffraction angles for crystallographic texture measurements. The pole-figure coverage with the 140, 90 and $40^{\circ}$ banks of detector panels is shown in Figure 3.10.

For the texture measurements obtained in this thesis work, only the $150^{\circ}$ bank ( 7 of 8 detector panels), the $90^{\circ}$ bank ( 8 of 10 detector panels) and the $40^{\circ}$ bank ( 11 of 12 detector panels) were used as they cover a wide range of diffraction angles. The large detector coverage in combination with the TOF technique, recording multiple diffraction peaks for the same diffraction vector simultaneously, allows sufficient collection of diffracted neutrons that one can determine the orientation distribution function (ODF) after rotating the sample around a single axis. A single axis of rotation on the sample allows the vacuum furnace to be held in a fixed position relative to the neutron beam while the sample can be rotated about the axis of the furnace (Figure 3.11).

To perform the HIPPO texture measurements in this study, the sample (Figure 3.11) was placed in a vanadium basket (Figure 3.13) inside a vacuum furnace with vanadium heating elements and heat shields (Figure 3.12). Vanadium produces no coherent scattering, and therefore the diffraction spectra show only peaks from the sample. For texture measurement, an incident beam of polychromatic thermal neutrons collimated to $10 \mathrm{~mm}$ in beam diameter was directed at the sample. When the sample was placed in the vanadium basket, the transverse direction of the sample (or the tube hoop direction) was aligned with the vertical axis of the furnace, and the sample radial direction was initially approximately aligned along the direction of the incident neutron beam. Two thermocouples, located in the furnace with one at about $70 \mathrm{~mm}$ above the sample within the $200 \mathrm{~mm}$ high hot zone, were used to control and record the temperature 
of the sample during heating and cooling. The uncertainty in the sample temperature for the furnace used in this study is expected to be less than $\pm 5 \mathrm{~K}\left(5^{\circ} \mathrm{C}\right)$.

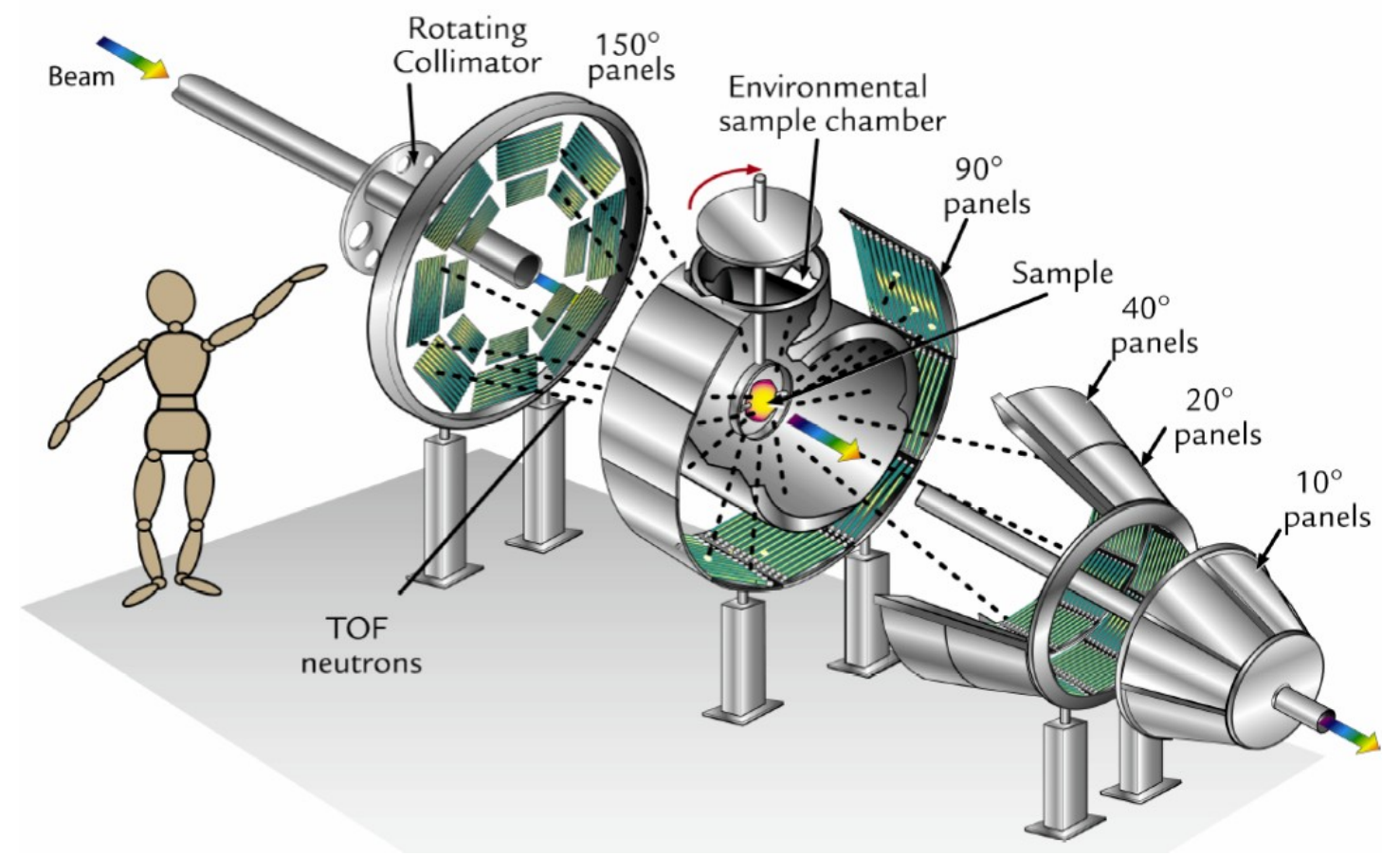

Figure 3.9 Schematic view of the HIPPO diffractometer used for crystallographic texture measurements with time-of-flight (TOF) neutrons at LANSCE [3.4], [3.5] 


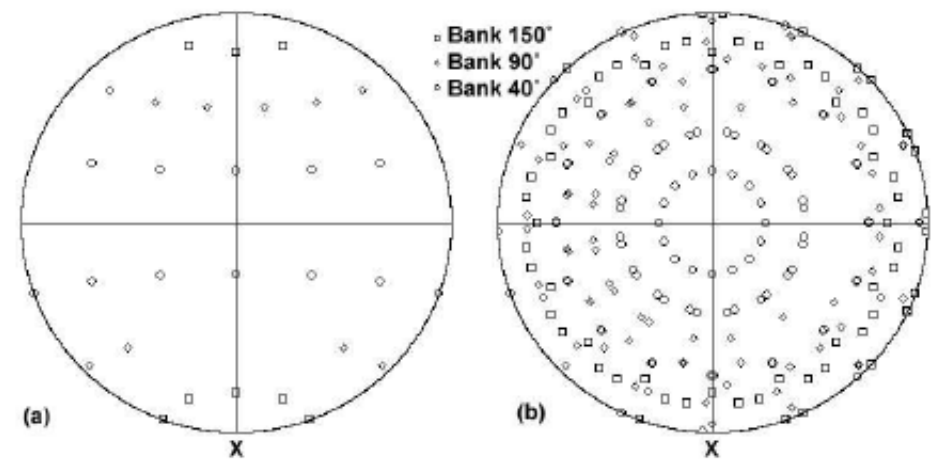

Figure 3.10 Coverage of pole figures by HIPPO's $40^{\circ}, 90^{\circ}$ and $150^{\circ}$ detectors for a single orientation (a) and 8 orientations (b) [3.4]

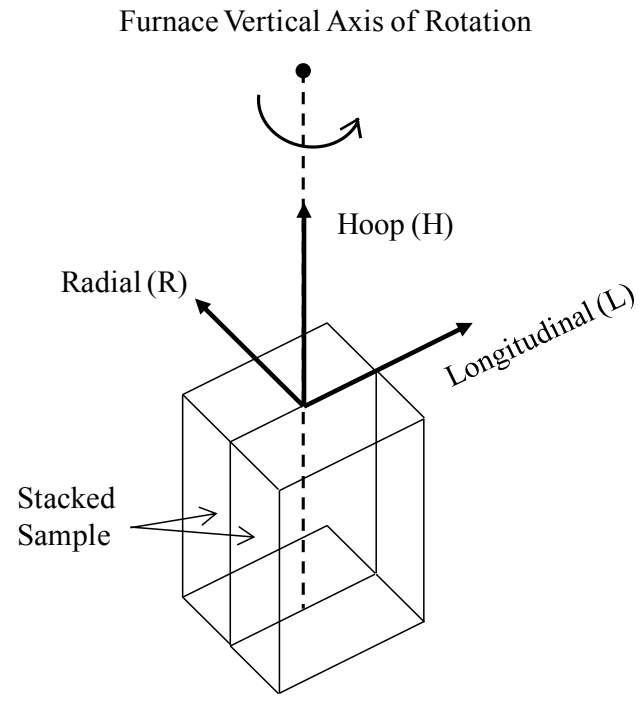

Figure 3.11 A schematic diagram showing a stacked sample of $\mathrm{Zr}-2.5 \mathrm{Nb}$ pressure tube material 


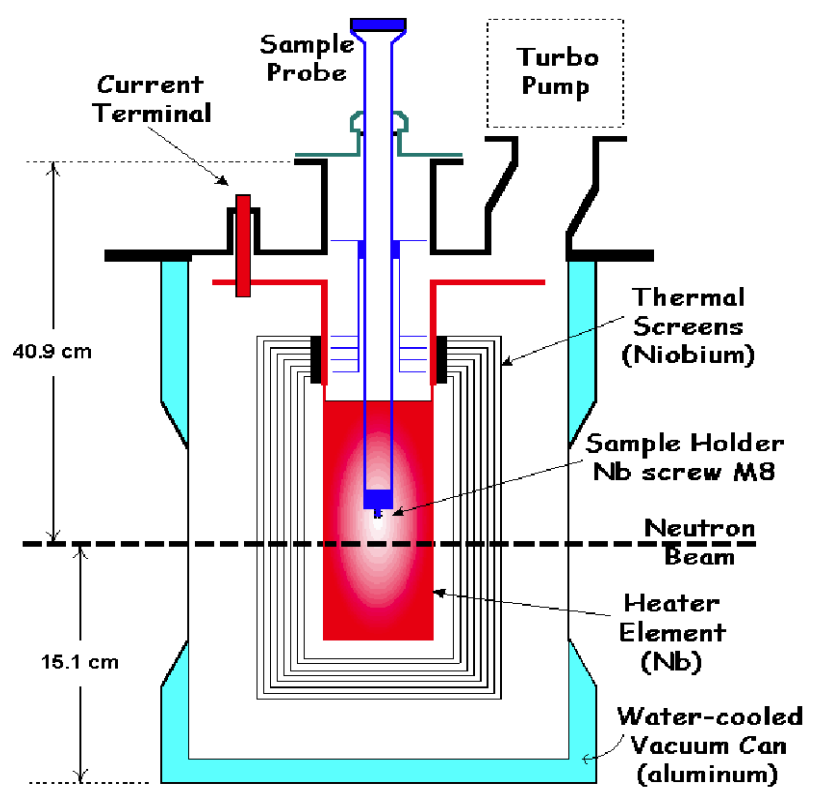

Figure 3.12 Diagram showing the location of sample plates placed in a vacuum furnace used for neutron diffraction

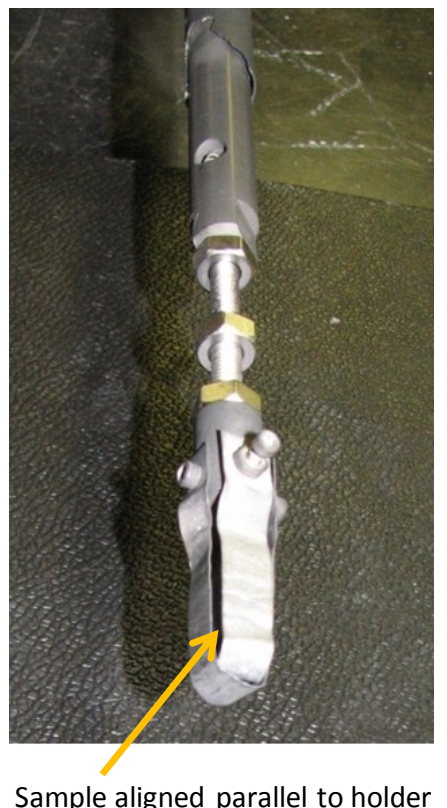

Sample aligned parallel to holder a)

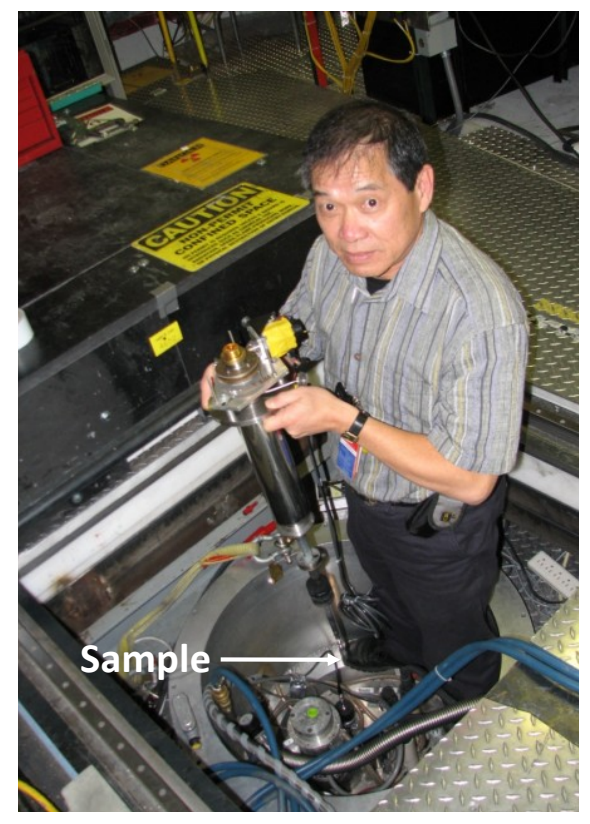

b)

Figure 3.13 (a) Sample placed inside a vanadium basket. (b) Installation of sample holder in a vacuum furnace for texture measurements at LANSCE 
For the as-manufactured $\mathrm{Zr}-2.5 \mathrm{Nb}$ pressure tube sample, the pole figures and volume fractions of $\alpha$ and $\beta$ phases were measured during heating of the sample at eight different temperatures and on cooling at two different temperatures. The sample was heated and cooled at the rate of $20 \mathrm{~K} / \mathrm{min}\left(20^{\circ} \mathrm{C} / \mathrm{min}\right)$. The chosen temperatures correspond to neutron measurements obtained in the $\alpha$-phase field, just straddling the $\alpha /(\alpha+\beta)$ transus $\left(\approx 610^{\circ} \mathrm{C}\right)$, within the $(\alpha+\beta)$ field, near the $(\alpha+\beta) / \beta$ transus $\left(\approx 850^{\circ} \mathrm{C}\right)$. The $(\alpha+\beta) / \beta$ transus temperature increases with increasing concentration of $\alpha$-phase stabilizers, just inside the $\beta$-phase field, and finally after the reversed $\beta$ to $\alpha$ transformation within the $(\alpha+\beta)$ field and inside the $\alpha$-phase field, as illustrated in $\mathrm{Zr}-\mathrm{Nb}$ phase diagram shown in Figure 3.2.

For texture measurement on the $\mathrm{Zr}-2.5 \mathrm{Nb}$ pressure tube samples at each temperature, the stacked sample (Figure 3.11) was rotated around the furnace axis in three different rotations $\left(0^{\circ}, 45^{\circ}\right.$ and $\left.90^{\circ}\right)$. For the Zircaloy-4 fuel sheath samples measured at each temperature, the stacked sample was rotated around the furnace axis also in three rotations $\left(-45^{\circ}, 0^{\circ}\right.$ and $\left.45^{\circ}\right)$. Diffraction data were collected at each of the three rotations for a period of 18 minutes which was deemed sufficient to obtain the orientation distribution function to reconstruct pole figures for many different planes. The total time for each temperature interval was about $1 \mathrm{~h}$ (including time for data readout and rotation). The pole intensities measured with the three panels of detectors $\left(150^{\circ}\right.$ bank, $90^{\circ}$ bank, and $40^{\circ}$ bank) were used to extract texture information using the Rietveld method, as implemented in the MAUD (뜨aterial $\underline{\text { Analysis }}$ Using $\underline{\text { Diffraction) }}$ 
program [3.6] for analyzing HIPPO diffraction data. An example of the texture analysis of HIPPO diffraction data analyses using Rietveld method and EWIMV algorithm implemented in the MAUD program is included in Appendix A.

In addition to extracting texture information, the volume fractions and lattice parameters for the $\alpha$ and $\beta$ phases were also obtained with the Rietveld refinement within the MAUD program, for the sample from the as-manufactured $\mathrm{Zr}-2.5 \mathrm{Nb}$ pressure tube material. For all the other samples (Modification ' $\mathrm{A}$ ' and ' $\mathrm{B}$ ' of $\mathrm{Zr}-2.5 \mathrm{Nb}$ pressure tube materials, and Zircaloy-4 fuel sheath materials), the volume fractions were not evaluated for this thesis work.

\subsubsection{Analysis of HIPPO diffraction data}

The HIPPO diffraction data for each test temperature consisted of a total of 78 histograms, all of which were analyzed simultaneously using the Rietveld method as implemented in MAUD [3.7],[3.8]. The data are refined taking into account the HIPPO instrument parameters and background, then crystallographic and microstructural parameters, and finally all parameters, including the texture and volume fractions of the phases present in the sample. In general, the scattering cross-section for Bragg scattering is proportional to $\mathrm{N} / \mathrm{V}$, where $\mathrm{N}$ is the number of unit cells contributing to the scattering and $\mathrm{V}$ is the unit cell volume. The scale factor $(\mathrm{S})$ obtained in the Rietveld analysis for the calculated intensities that best scaled with the observed measurements, is directly proportional to N/V. The scale factor and the unit cell volume of the phase are obtained from the Rietveld analysis to derive the volume fraction of that phase using $V_{p}=\left(S V^{2}\right)_{p} /$ 
$\Sigma\left(\mathrm{S} \mathrm{V}^{2}\right)_{\mathrm{i}}$, where $\mathrm{V}_{\mathrm{p}}$ is the volume fraction of that phase $\mathrm{p}$, and the summation in the denominator accounts for all crystalline phases in the sample.

MAUD uses the Rietveld method [3.9] that was originally developed to determine crystal structures from powder samples, and to fit the complete measured diffraction spectra by refining the instrument, phase and sample parameters. Since the whole spectra are analyzed, the Rietveld analysis can account for overlapping peaks. The texture is refined inside the least-squares Rietveld refinement procedure at each separate cycle of iteration, and calculating the orientation distribution function (ODF) using a modified WIMV (Williams-Imhof-Matties-Vinel) algorithm, called 'EWIMV' in MAUD that allows data to be entered at arbitrary pole figure positions [3.8], [3.10].

The HIPPO diffraction data (consisting of a total of 78 histograms) were taken as input in MAUD, though only the information within the computational range for d-spacing of $0.5-3.0 \AA$ was used. A $10^{\circ} \times 10^{\circ} \times 10^{\circ}$ grid was used for calculating the ODF of the sample for each test temperature. No sample symmetry was imposed on the calculations. The complete pole figures for both $\alpha$ and $\beta$ phases were reconstructed from the calculated ODFs. All the reconstructed pole figures in this thesis report are presented on a Lambert equal-area projection [3.11].

In this thesis on the texture measurements and analyses (reported in Chapter 4, Chapter 6, and Chapter 7), the complete pole figures at each temperature are presented using only the diffracting planes for hep and bcc lattice structures relevant to the Burgers orientation relationship $[3.12]$ (i.e., $(110)_{B C C} / /(0002)_{H C P}$ and $\left.[\overline{1} 11]_{B C C} / /[11 \overline{2} 0]_{H C P}\right)$. For an hcp lattice, pole figures for the (0002) plane normals and a prism plane normals 
$(11 \overline{2} 0)$ are sufficient to define the orientation of the crystal lattice relative to the sample reference orthogonal axes (e.g., Radial-R, Longitudinal-L and Hoop-H directions in a tube). These two hep planes are relevant to the Burgers orientation relationship [3.12] and they are used to evaluate the lattice correspondence with the bcc phase by examining the angular deviations of superimposed intensity peaks of the poles on an equal-area projection (see Chapter 4).

Also, selected ODFs determined for the as-manufactured $\mathrm{Zr}-2.5 \mathrm{Nb}$ pressure tube sample were examined to evaluate all the crystallite orientations during the $\alpha$ - and $\beta$-phase transformations that occurred on heating into the $\beta_{\mathrm{Zr}}$-phase field and then cooling to within the $\left(\alpha+\beta_{Z \mathrm{Zr}}\right)$ phase field and in the $\left(\alpha+\beta_{\mathrm{Nb}}\right)$ phase field. The results are reported in Chapter 4. In addition, the lattice parameters and volume fraction for the $\alpha$ and $\beta$ phase obtained from the texture analysis in MAUD (EWIMV) were also evaluated for as-manufactured $\mathrm{Zr}-2.5 \mathrm{Nb}$ pressure tube sample, also reported in Chapter 4.

\section{References}

[3.1] M. Griffiths, J.E. Winegar and A. Buyers, The transformation behaviour of the $\beta$-phase in $\mathrm{Zr}-2.5 \mathrm{Nb}$ pressure tubes, J. Nucl. Mater. Vol. 383, pp. 28-33, 2008

[3.2] S.A. Aldridge and B.A. Cheadle, Age hardening of Zr-2.5 wt\% Nb slowly cooled from the $(\alpha+\beta)$ phase field, J. Nucl. Mater., 42:32-42, 1972 J. Nucl. Mater., Vol. 42, pp. 32-42, 1972

[3.3] J.P. Abriata and J.C. Bolcich, The Nb-Zr system, Bull. Alloy Phase Diagrams, Vol. 3, No. 1, pp. 34-44, 1982 
[3.4] S.C. Vogel, C. Hartig, L. Lutterotti, R.B. Von Dreele, H.R. Wenk and D.J. Williams, Texture measurements using the new neutron diffractometer HIPPO and their analysis using the Rietveld method, International Centre for Diffraction Data, Advances in X-ray Analysis, Vol. 47, pp. 431-436, 2004

[3.5] H.R. Wenk, L. Lutterotti and S.C. Vogel, Texture analysis with the new HIPPO TOF diffractometer, Nucl. Instrum. Methods Phys. Res., A515, pp. 575-588, 2003

[3.6] H.R. Wenk, L. Lutterotti and S.C. Vogel, Rietveld texture analysis from TOF neutron diffraction data, J. Powder Diffraction, Vol. 25, No. 3 pp. 283-296, 2010

[3.7] S. Matthies, L. Lutterotti and H.R. Wenk, Advances in texture analysis from diffraction Spectra, J. Appl. Crystallogr., Vol. 30, pp. 31-42, 1997

[3.8] S. Matthies, J. Pehl, H.R. Wenk and S. Vogel, Quantitative texture analysis with the HIPPO neutron TOF diffractometer, J. Appl. Crystallogr., Vol. 38, pp. 462-475, 2005

[3.9] H.M. Rietveld, J. Appl. Crystallogr., Vol. 2, pp. 65-71, 1969

[3.10] L. Lutterotti, D. Chateigner, S. Ferrari and J. Ricote: Thin Solid Films, Vol. 450, p. 34, 2004

[3.11] H.R. Wenk: Preferred Orientation in Metals and Rocks, H.-R. Wenk, ed., Academic Press, pp. 11-47, 1985

[3.12] W.G. Burgers, On the process of transition of the cubic-body-centered modification inot the hexagonal-close-packed modification of zirconium, Physica I, pp. 561-586, 1934 


\section{Chapter 4}

\section{Crystallographic Texture and Volume Fraction of $\alpha$ - and $\beta$-Phase in $\mathrm{Zr}-2.5 \mathrm{Nb}$ Pressure Tube Material During Heating and Cooling}

(Manuscript published in Metall. Trans. A, Vol. 43A, 2012, 806-821)

http://dx.doi.org/10.1007/s11661-011-0914-6

Cover Introduction: This manuscript presents the results of a detailed in-situ neutron diffraction study of the evolution of texture and phase transformations in an as-manufactured $\mathrm{Zr}-2.5 \mathrm{Nb}$ pressure tube material during heating at eight different temperatures $\left(100^{\circ} \mathrm{C}\right.$ to $\left.1050^{\circ} \mathrm{C}\right)$ and cooling. The pole figures for $\alpha$ and $\beta$ phases were measured using the time-of-flight (TOF) neutron diffraction technique on the HIPPO texture diffractometer at the Los Alamos Neutron Science Center (LANSCE). The texture measurements were used to calculate the orientation distribution function (ODF) of the $\alpha$ - and $\beta$-phase crystallites in the samples for each test temperature. The results of the $\alpha$ and $\beta$ phase textures during heating and cooling involving the phase transformations of $\alpha \rightarrow \beta \rightarrow \alpha$ were shown to obey Burgers orientation relationship of $(110)_{\mathrm{BCC}} / /(0002)_{\mathrm{HCP}}$ and $[\overline{1} 11]_{\mathrm{BCC}} / /[11 \overline{2} 0]_{\mathrm{HCP}}$. The ODF provided information on a previously unobserved $\alpha-\mathrm{Zr}$ texture component during heating at $900^{\circ} \mathrm{C}$; the appearance of this strong texture component at high temperature is due to the coarsening of prior 'primary' $\alpha$-Zr grains that were initially present in the as-manufactured pressure tube material as a result of the tube fabrication processes used to manufacture the tube. The volume fraction of $\beta$-phase was obtained during heating and cooling at different temperatures. These 
results provided a benchmark data on texture and microstructural parameters that can be used to improve polycrystalline models and account for the mechanical anisotropy response of the material during heating to high temperatures in relation to hightemperature manufacturing processes, or to some postulated high-temperature transient during a hypothetical loss-of-coolant accident (LOCA) scenario. The data from this work has been used to explain and further understand the anisotropic deformation behaviour that has been observed in high temperature-ramped tensile deformation tests on as- manufactured pressure tube materials (reported in Chapter 5).

\footnotetext{
$\underline{\text { Abstract }}$

The phase transformations in an as-received $\mathrm{Zr}-2.5 \mathrm{Nb}$ pressure tube material have been characterized in detail by neutron diffraction. The texture and volume fraction of $\alpha-$ and $\beta$-phase were measured on heating at eight different temperatures $[373 \mathrm{~K}$ to $1323 \mathrm{~K}\left(100^{\circ} \mathrm{C}\right.$ to $\left.\left.1050^{\circ} \mathrm{C}\right)\right]$ traversing across the $\alpha /(\alpha+\beta)$ and $(\alpha+\beta) / \beta$ solvus lines, and also upon cooling $\left[1173 \mathrm{~K}\right.$ and $823 \mathrm{~K}\left(900^{\circ} \mathrm{C}\right.$ and $\left.\left.550^{\circ} \mathrm{C}\right)\right]$. The results indicate that the $\alpha$-phase texture is quite stable, with little change in the $\{0002\}$ and $\{11 \overline{2} 0\}$ pole figures during heating to $1123 \mathrm{~K}\left(850^{\circ} \mathrm{C}\right)$. The $\beta$-phase volume fraction increased while a slight change in texture was observed until heating reached $973 \mathrm{~K}\left(700^{\circ} \mathrm{C}\right)$. On further heating to $1173 \mathrm{~K}\left(900^{\circ} \mathrm{C}\right)$, there appears a previously unobserved $\alpha$-phase texture component due to coarsening of the prior 'primary' $\alpha$-grains; meanwhile the transformed $\beta$-phase
} 
texture evolved markedly. At $1323 \mathrm{~K}\left(1050^{\circ} \mathrm{C}\right)$, the $\alpha$-phase disappeared with only $100 \% \beta$-phase remaining but with a different texture than that observed at lower temperatures. On cooling from the full $\beta$-phase regime, a different cool-down transformed $\alpha$-phase texture was observed, with no resemblance of the original texture observed at $373 \mathrm{~K}\left(100^{\circ} \mathrm{C}\right)$. The transformed $\alpha$-phase texture shows that the $\{0002\}$ plane normals are within the radial-longitudinal plane of the pressure tube following the Burgers orientation relationship of $(110)_{\mathrm{BCC}} / /(0002)_{\mathrm{HCP}}$ and $[\overline{1} 11]_{\mathrm{BCC}} / /[11 \overline{2} 0]_{\mathrm{HCP}}$ with a memory of the precursor texture of the primary $\alpha$-grains observed on heating at $1173 \mathrm{~K}$ $\left(900^{\circ} \mathrm{C}\right)$

\subsection{Introduction}

$\mathrm{Zr}-2.5 \mathrm{Nb}$ alloy is used for the pressure tubes in CANDU reactors. The pressure tubes are fabricated by a processing route involving the following steps: quadruple melt ingot; forge to bar; machine hollow billets; preheat billets to $1088 \mathrm{~K}\left(815^{\circ} \mathrm{C}\right)$ and extrude into tubes; cold-draw 25-30\% (in two wall thickness reductions); and stress relieve in steam-autoclave for $24 \mathrm{hr}$ at $673 \mathrm{~K}\left(400^{\circ} \mathrm{C}\right)$ (which also introduces a protective oxide layer on the inside and outside surface of the tube) [4.1]. The resulting microstructure consists of elongated hcp $\alpha-Z r$ grains containing a high dislocation density, and a thin layer of bec $\beta$ phase at the $\alpha$-grain boundaries (Figure 4.1). Small quantities of meta-stable $\omega$ phase (space group P6/mmm) may also exist in the material, depending on the thermo-mechanical history. At room temperature, a typical $\mathrm{Zr}-2.5 \mathrm{Nb}$ pressure tube 
material contains mostly $\alpha$-phase $\mathrm{Zr}$ containing about $1 \mathrm{wt} \% \mathrm{Nb}$ and a small portion of $\mathrm{Nb}$-stabilized $\beta$ phase with about $20 \mathrm{wt} \% \mathrm{Nb}$, corresponding to the monotectoid composition in the $\mathrm{Zr}-\mathrm{Nb}$ phase diagram [4.2]. The deformed hcp $\alpha-\mathrm{Zr}$ grains exhibit a strong crystallographic texture with a large concentration of the basal (0002) plane normals aligned in the hoop $(\mathrm{H})$ direction of the tube, and the prism $(11 \overline{2} 0)$ poles oriented in the tube's radial direction, Figure 4.2 [4.3]. The crystallographic textures are developed primarily during the high-temperature extrusion of the billet to form the pressure tube. As a result of the strong crystallographic texture of the $\alpha$-phase developed during manufacturing, the pressure tube material exhibits anisotropic mechanical behaviour [4.1].

Figure 4.1 TEM micrographs of as-received $\mathrm{Zr}-2.5 \mathrm{Nb}$ pressure tube showing elongated $\alpha$-Zr-grains containing a high density of dislocations and a thin layer of $\beta$-phase at the $\alpha$-grain boundaries viewing along: (a) longitudinal and

(b) transverse (hoop) direction. (This figure first appeared in Figure 3.1)
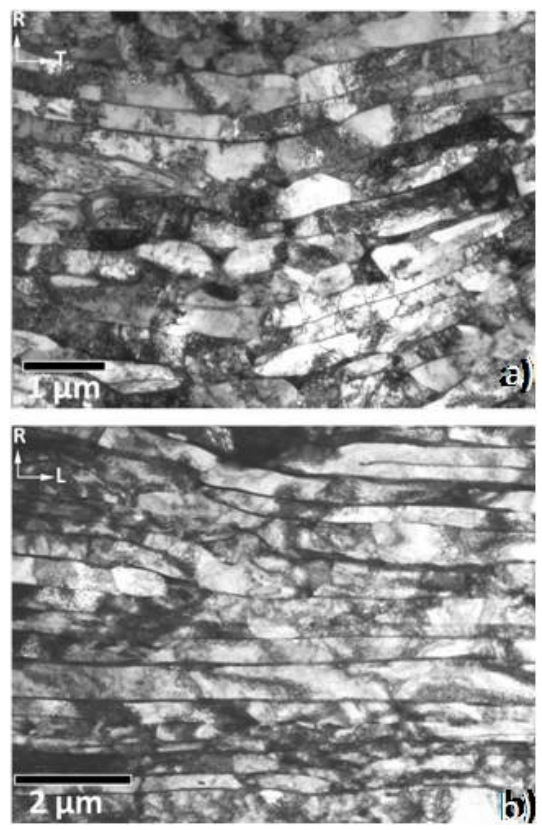

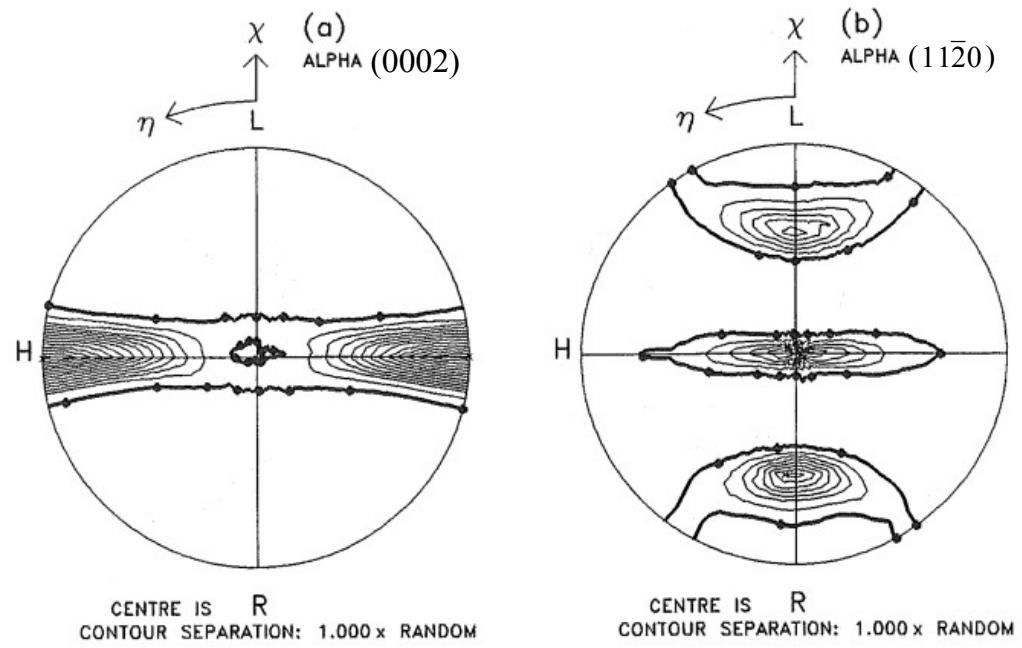

Figure $4.2 \alpha$-phase (0002) and (1120) pole figures for as-received $\mathrm{Zr}-2.5 \mathrm{Nb}$ pressure tube at room temperature obtained from neutron diffraction measurements using a texture goniometer with a constant wavelength and well-resolved individual diffraction peaks [4.3]. (This figure first appeared in Figure 1.4)

In reactor, the pressure tubes normally operate at about $573 \mathrm{~K}\left(300^{\circ} \mathrm{C}\right)$. In the event of a hypothetical loss-of-coolant accident (LOCA), the pressure tube may be subjected to a high-temperature transient up to $1473 \mathrm{~K}\left(1200^{\circ} \mathrm{C}\right)$. During a hightemperature excursion, a phase transformation occurs that changes the textures and proportions of the $\alpha$ - and $\beta$-phase. Such changes can affect the material's deformation behaviour, and thus control its high-temperature deformation properties under some hypothetical LOCA scenarios. A detailed characterization of changes in texture and volume fraction of the two phases with temperature changes provides useful microstructural data for modelling of high-temperature deformation behaviour. Previous studies have investigated changes in $\alpha \rightarrow \beta \rightarrow \alpha$ phase transformation textures in Zircaloy-2 and Zircaloy-4 during heating and cooling [4.4],[4.5], [4.6]. Since the solvus 
lines for Zircaloys (a dilute $\mathrm{Zr}$-Sn system [4.7]) are different from those for $\mathrm{Zr}-2.5 \mathrm{Nb}$ alloy [4.2], differences in volume fraction changes of $\alpha$ and $\beta$ phases between the two alloy systems can be expected during heating and cooling, although the lattice transformation processes can be similar. Hence, the microstructural information obtained on Zircaloys would not be entirely applicable to $\mathrm{Zr}-2.5 \mathrm{Nb}$ pressure tube material. In a recent work on $\mathrm{Zr}-2.5 \mathrm{Nb}$ pressure tube material [4.8], the texture changes were evaluated at two temperatures (heating to $898 \mathrm{~K}\left(625^{\circ} \mathrm{C}\right)$ and $1248 \mathrm{~K}\left(975^{\circ} \mathrm{C}\right)$, and cooling back down to $\left.898 \mathrm{~K}\left(625^{\circ} \mathrm{C}\right)\right)$ mainly to study the effect of repeated thermal cycling on texture evolution, however no information on volume fraction of the $\beta$ or $\alpha$ phase was available. Thus, it is useful to obtain a complete characterization of the texture and volume fraction of the $\alpha$ and $\beta$ phase to provide the microstructural data as inputs and benchmarking for modelling of pressure tube materials under some LOCA scenarios.

In this paper, an extensive study of phase transformations in a sample of as-received CANDU $\mathrm{Zr}-2.5 \mathrm{Nb}$ pressure tube material has been undertaken by neutron diffraction at the Los Alamos Neutron Science Center. The textures and volume fractions of $\alpha$ - and $\beta$-phase in the sample have been measured on heating at eight different temperatures $\left[373 \mathrm{~K}\right.$ to $1323 \mathrm{~K}\left(100^{\circ} \mathrm{C}\right.$ to $\left.\left.1050^{\circ} \mathrm{C}\right)\right]$ and on cooling at two temperatures [1173 $\mathrm{K}$ and $823 \mathrm{~K}\left(900^{\circ} \mathrm{C}\right.$ and $\left.\left.550^{\circ} \mathrm{C}\right)\right]$, traversing across the two solvus lines along the $\mathrm{Zr}-2.5 \mathrm{Nb}$ composition as indicated in Figure 4.3. The lattice parameters of the two phases were also determined from the diffraction spectra for each temperature. This study reveals a previously unobserved $\alpha$-phase texture component that appears during heating to $900^{\circ} \mathrm{C}$, likely due to coarsening of the prior 'primary' $\alpha$-Zr grains. This 
$\alpha$-phase texture component is shown to be responsible for changing the evolution of the transformed $\beta$-phase texture when the 'primary' $\alpha-Z r$ grains are completely transformed into the $\beta$-phase structure on further heating at $1323 \mathrm{~K}\left(1050^{\circ} \mathrm{C}\right)$ in the full $\beta$-phase field. On cool-down after heating in the $\beta$-phase field, the reverse phase transformation textures $(\beta \rightarrow \alpha)$ approximately followed the Burgers orientation relationship: $(110)_{\mathrm{BCC}} / /(0002)_{\mathrm{HCP}}$ and $[\overline{1} 11]_{\mathrm{BCC}} / /[11 \overline{2} 0]_{\mathrm{HCP}}[4.9]$ (Figure 4.4). The texture and volume fraction of the two phases, including changes in their lattice parameters discussed in terms of their volumetric expansion that occurred during heating and cooling, are presented and evaluated.

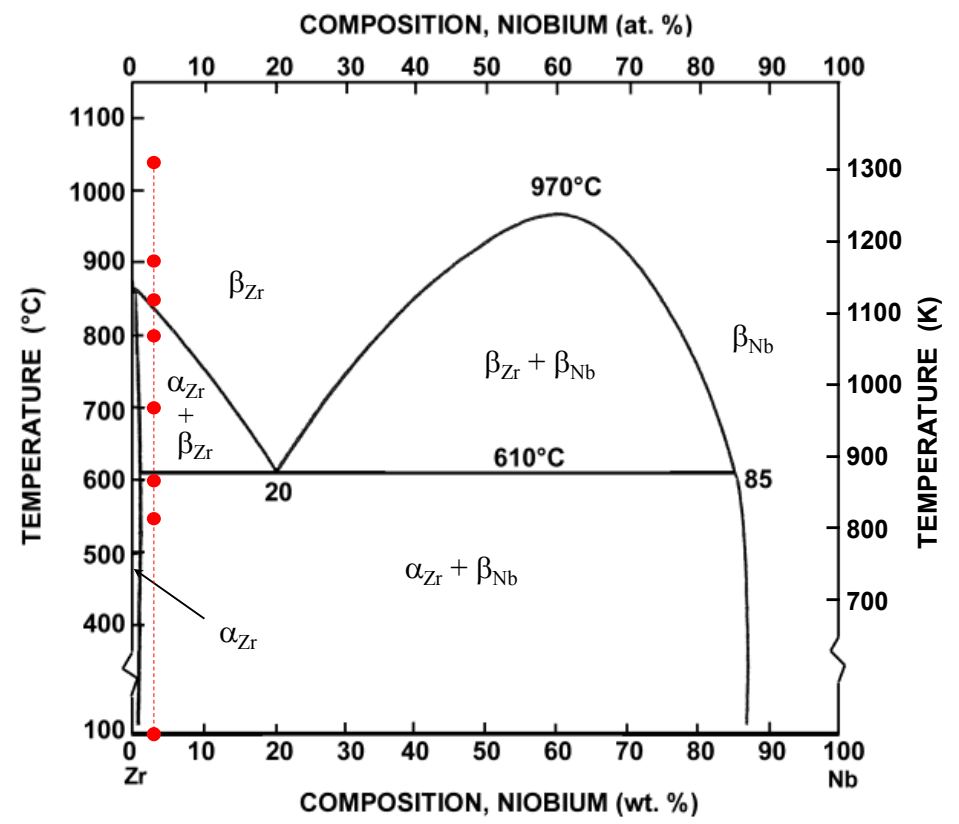

Figure 4.3 $\mathrm{Zr}-\mathrm{Nb}$ phase diagram [4.2]. The vertical dashed line in the phase diagram corresponds to the $\mathrm{Zr}-2.5 \mathrm{Nb}$ composition where neutron measurements were performed at eight different temperatures traversing across different phase fields as shown by the points indicated along the temperature (dashed) line. (This figure first appeared in Figure 3.2) 


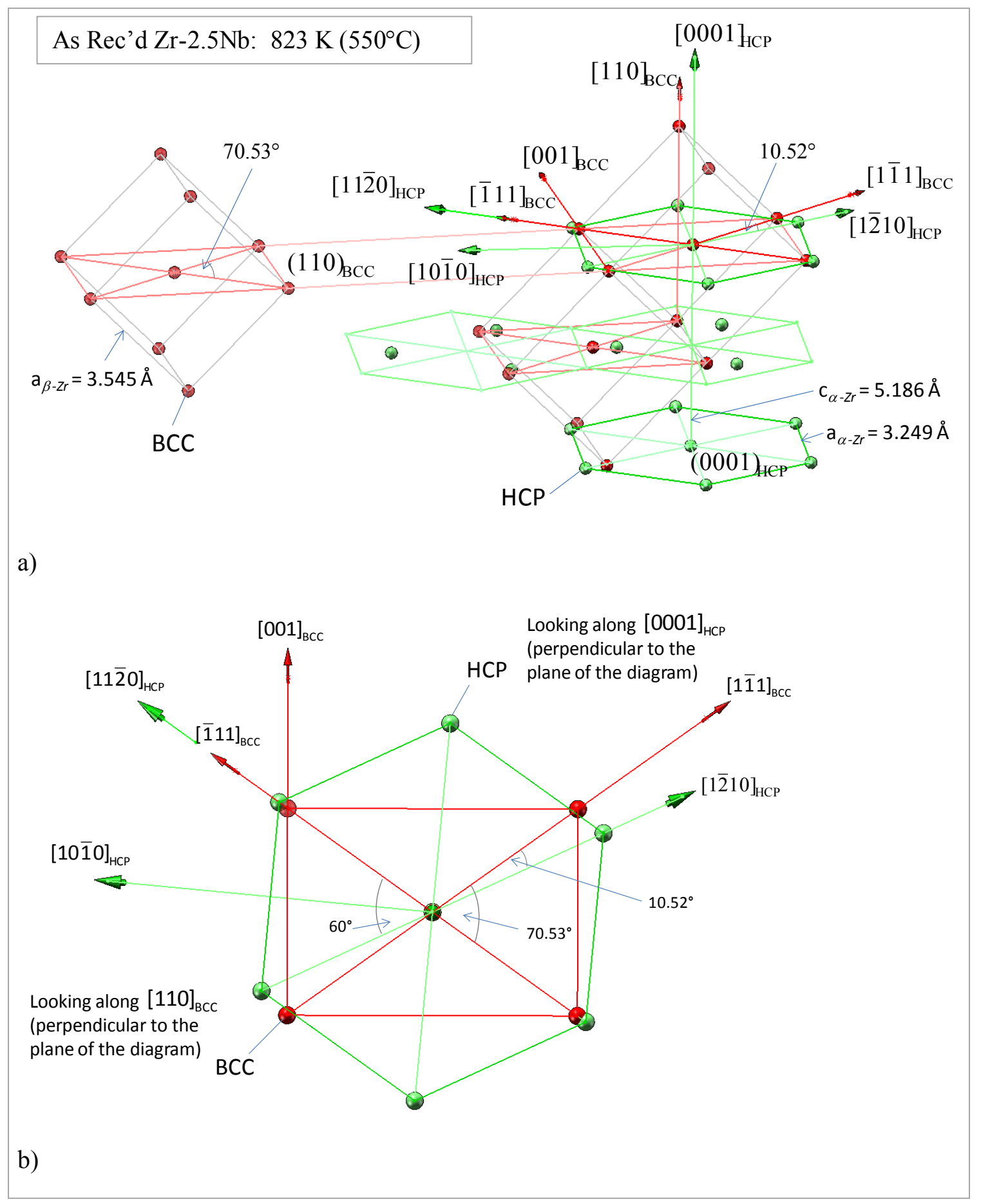

Figure 4.4 Diagrams showing Burgers orientation relationship between bcc and hcp phase lattice [4.9]: a) $(110)_{\mathrm{BCC}} / /(0002)_{\mathrm{HCP}}$ and b) $[\overline{1} 11]_{\mathrm{BCC}} / /[11 \overline{2} 0]_{\mathrm{HCP}}$. 


\subsection{Experimental}

\subsubsection{Material and sample preparation:}

The sample used in this study was taken from an as-received CANDU $\mathrm{Zr}-2.5 \mathrm{Nb}$ pressure tube that had been fabricated from a quadruple-melted ingot where the billet had been hot-extruded at about $1088 \mathrm{~K}\left(815^{\circ} \mathrm{C}\right)$ into a tube which was then cold-worked $25-30 \%$ and given a final stress-relief at $673 \mathrm{~K}\left(400^{\circ} \mathrm{C}\right)$ for $24 \mathrm{~h}$. The stress relief treatment partially decomposes the as-fabricated metastable $\beta_{\mathrm{Zr}}$ phase (containing about $20 \% \mathrm{Nb}$ ) into a $\beta_{\mathrm{enr}}$ phase enriched in $\mathrm{Nb}$ content [4.10], [4.11]. The chemical composition specification of the ingot used to manufacture this pressure tube is $2.52-2.57$ $\mathrm{wt} \% \mathrm{Nb}, 1190-1220 \mathrm{ppm} \mathrm{O}, 350-410 \mathrm{ppm} \mathrm{Fe}$ and the balance is Zr. Oxygen is a $\alpha$-phase stabilizer, and $\mathrm{Nb}$ and Fe stabilize the $\beta$-phase. The actual concentration of oxygen in the sample was 1004-1040 ppm.

To increase the sampling volume and thus improve the neutron measurements, the sample was prepared by stacking together two plates that were cut from the pressure tube (Figure 4.5). The overall dimension of the stacked sample is approximately $10 \mathrm{~mm}$ tall $\mathrm{x}$ $8 \mathrm{~mm}$ wide $\times 8 \mathrm{~mm}$ thick. To obtain the two plates, a slit ring was first cut from the pressure tube and then reverse bent to obtain a flat strip which was cut into plates with the desired dimensions. The reverse bending of the strip is expected to introduce residual stresses and dislocations in the sample, in addition to the prior cold-worked and stressrelieved condition that would also affect the lattice parameters of the two phases. On heating at elevated test temperatures (e.g., at $823 \mathrm{~K}\left(550^{\circ} \mathrm{C}\right)$ and higher) the sample would then be stress-relieved. To improve thermal conduction between the two plates, 
the small curvature and the autoclaved oxide on the inside surfaces of the two plates were mechanically polished, then cleaned with acetone and held tightly stacked together by spot-welding on a thin Zr-foil on both sides of the stacked sample. The neutron scattering from the thin $\mathrm{Zr}$ foils is expected to be minor since the volume of the stacked sample (volume being probed) is much larger than that of the foil, and hence they would not significantly alter the diffraction profile obtained from the stacked sample.

The starting microstructure of the sample is typical of that shown in Figure 4.1. The neutron diffraction measurements were performed on the sample at eight different temperatures on heating, and at two different temperatures on cooling (Table 4.1). These temperatures are located within the $\mathrm{Zr}-2.5 \mathrm{Nb}$ alloy phase diagram traversing across the different phase fields as shown in Figure 4.3. After high-temperature neutron measurements, the post-test sample was prepared for light microscopy using standard techniques to examine the reversed $\beta$ to $\alpha$ transformation microstructure.

\subsubsection{Neutron diffraction measurements:}

The texture measurements were performed on the Time-Of-Flight (TOF) HIghPressure Preferred Orientation (HIPPO) diffractometer at the Los Alamos Neutron Science Center. The HIPPO diffractometer is equipped with a large number of detector panels positioned on rings at five different diffraction angles and each detector probes a different sample direction [4.12], [4.13]. For these measurements, only the $150^{\circ}$ bank (7 of 8 detector panels), the $90^{\circ}$ bank ( 8 of 10 detector panels) and the $40^{\circ}$ bank (11 of 12 detector panels) were used as they cover a wide range of diffraction angles. The large 
detector coverage in combination with the TOF technique, recording multiple diffraction peaks for the same diffraction vector simultaneously, allows sufficient collection of diffracted neutrons that one can determine the orientation distribution function after rotating the sample around a single axis. A single axis of rotation on the sample allows the furnace to be held in a fixed position relative to the neutron beam while the sample can be rotated about the axis of the furnace (Figure 4.5).

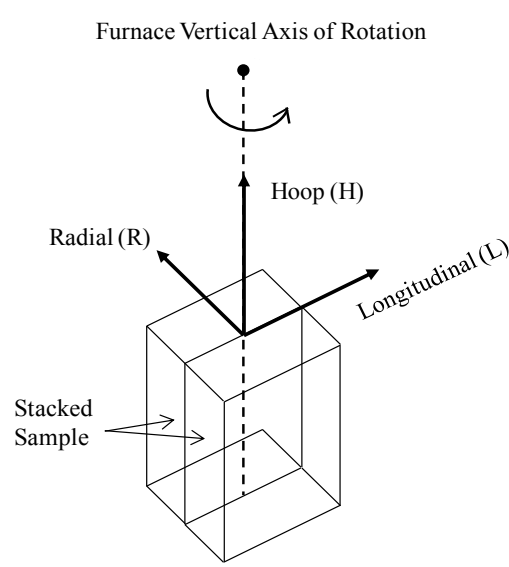

Figure 4.5 A schematic diagram showing a stacked sample consisting of two plates taken from the $\mathrm{Zr}-2.5 \mathrm{Nb}$ pressure tube material. The hoop direction of the sample is aligned with the furnace axis of rotation. The plates are held tightly together by spot-welded Zr-foils (not shown in the diagram). (This figure first appeared in Figure 3.11)

To perform the HIPPO texture measurements in this study, the sample (Figure 4.5) was placed in a vanadium basket inside a vacuum furnace with vanadium heating elements and heat shields. Vanadium produces no coherent scattering, and therefore the diffraction spectra show only peaks from the sample. For this texture measurement, an incident beam of polychromatic thermal neutrons collimated to $10 \mathrm{~mm}$ in beam diameter 
was directed at the sample. When the sample was placed in the vanadium basket, the transverse direction of the sample (or the tube hoop direction) was aligned with the vertical axis of the furnace, and the sample radial direction was initially approximately aligned along the direction of the incident neutron beam. Two thermocouples, located in the furnace with one at about $70 \mathrm{~mm}$ above the sample within the $200 \mathrm{~mm}$ high hot zone, were used to control and record the temperature of the sample during heating and cooling. The uncertainty in the sample temperature for the furnace used in this study is expected to be less than $\pm 5 \mathrm{~K}\left(5^{\circ} \mathrm{C}\right)$.

The pole figures and volume fractions of $\alpha$ and $\beta$ phases were measured during heating of the sample at eight different temperatures and on cooling at two different temperatures (Table 4.1). The sample was heated and cooled at the rate of $20 \mathrm{~K} / \mathrm{min}$ $\left(20^{\circ} \mathrm{C} / \mathrm{min}\right)$. The temperatures listed in Table 4.1 were chosen with guidance from earlier results obtained from a differential scanning calorimetry (DSC) study [4.14]. The chosen temperatures correspond to neutron measurements obtained in the $\alpha$-phase field, just straddling the $\alpha /(\alpha+\beta)$ transus $\left(\approx 883 \mathrm{~K}\left(610^{\circ} \mathrm{C}\right)\right)$, within the $(\alpha+\beta)$ field, near the $(\alpha+\beta) / \beta$ transus $\left(\approx 1123 \mathrm{~K}\left(850^{\circ} \mathrm{C}\right)\right)$, this temperature increases with increasing concentration of $\alpha$-phase stabilizers), just inside the $\beta$-phase field, and finally after the reversed $\beta$ to $\alpha$ transformation within the $(\alpha+\beta)$ field and inside the $\alpha$-phase field, as illustrated in Figure 4.3. 
Table 4.1 Test temperatures, lattice parameter, volume fraction, unit cell volume, and history of $\alpha$ phase during heating and cooling. (The standard error in measurements of lattice parameter is expected to be less than $1 \%$ and for volume fraction to be in the order of $10-20 \%$.)

\begin{tabular}{|c|c|c|c|c|c|c|c|c|c|c|}
\hline \multirow[t]{2}{*}{$\begin{array}{l}\mathrm{Zr}-2.5 \mathrm{Nb} \text { sample } \\
\text { (As-received) }\end{array}$} & \multicolumn{8}{|c|}{$\begin{array}{c}\text { On Heating }(\mathrm{K}) \\
{\left[{ }^{\circ} \mathrm{C}\right]}\end{array}$} & \multicolumn{2}{|c|}{$\begin{array}{c}\text { On Cooling } \\
\begin{array}{c}(\mathrm{K}) \\
{\left[{ }^{\circ} \mathrm{C}\right]}\end{array}\end{array}$} \\
\hline & $\begin{array}{l}373 \\
{[100]}\end{array}$ & $\begin{array}{l}823 \\
{[550]} \\
\end{array}$ & $\begin{array}{l}873 \\
{[600]}\end{array}$ & $\begin{array}{l}973 \\
{[700]}\end{array}$ & $\begin{array}{l}1073 \\
{[800]}\end{array}$ & $\begin{array}{l}1123 \\
{[850]}\end{array}$ & $\begin{array}{l}1173 \\
{[900]}\end{array}$ & $\begin{array}{l}1323 \\
{[1050]}\end{array}$ & $\begin{array}{l}1173 \\
{[900]}\end{array}$ & \begin{tabular}{|l|}
823 \\
{$[550]$}
\end{tabular} \\
\hline $\begin{aligned} \text { hcp } \alpha \text {-phase: } & \text { a }(\AA) \\
& \text { c }(\AA)\end{aligned}$ & $\begin{array}{l}3.242 \\
5.162\end{array}$ & $\begin{array}{l}3.249 \\
5.186\end{array}$ & $\begin{array}{l}3.249 \\
5.189\end{array}$ & $\begin{array}{l}3.252 \\
5.197\end{array}$ & $\begin{array}{l}3.254 \\
5.204\end{array}$ & $\begin{array}{l}3.256 \\
5.211\end{array}$ & $\begin{array}{l}3.261 \\
5.216\end{array}$ & $\begin{array}{l}- \\
-\end{array}$ & $\begin{array}{l}3.252 \\
5.200\end{array}$ & $\begin{array}{l}3.247 \\
5.185\end{array}$ \\
\hline bcc $\beta$-phase: a $(\AA)$ & 3.545 & 3.545 & 3.534 & 3.580 & 3.602 & 3.610 & 3.618 & 3.627 & 3.621 & 3.538 \\
\hline $\begin{array}{l}\text { Volume fraction of } \\
\beta \text {-phase: }\end{array}$ & 0.02 & 0.03 & 0.04 & 0.20 & 0.37 & 0.66 & 0.85 & 1.00 & 0.79 & 0.12 \\
\hline \multicolumn{11}{|l|}{ Volume of unit cell: } \\
\hline$\alpha$-phase: $\quad V_{\text {hcp }}\left(\AA^{3}\right)$ & 46.98 & 47.41 & 47.44 & 47.60 & 47.72 & 47.84 & 48.04 & - & 47.63 & 47.34 \\
\hline$\beta$-phase: $V_{b c c}\left(\AA^{3}\right)$ & 44.55 & 44.55 & 44.14 & 45.88 & 46.73 & 47.05 & 47.36 & 47.71 & 47.48 & 44.29 \\
\hline History of $\alpha$-phase: & $\chi_{\mathrm{Zr}}+\beta_{\mathrm{enr}}$ & $x_{\mathrm{Zr}}+\beta_{\mathrm{enr}}$ & $x_{\mathrm{Zr}}+\beta_{\mathrm{enr}}$ & $x_{Z r}+\beta_{Z r}$ & $x_{Z r}+\beta_{Z r}$ & $x_{Z r}+\beta_{Z r}$ & $x_{Z r}+\beta_{Z r}$ & $\beta_{\mathrm{Zr}}$ & $\alpha_{\mathrm{Zr}}+\beta_{\mathrm{Zr}}$ & $\alpha_{Z \mathrm{rr}}+\beta_{\mathrm{Zr}}$ \\
\hline
\end{tabular}

Notes: (1) $\beta_{\mathrm{enr}}$ is enriched in niobium with regard to the metastable $\beta_{\mathrm{Zr}}$ phase at low temperatures (below $873 \mathrm{~K}\left(600^{\circ} \mathrm{C}\right)$ ).

For texture measurement at each temperature, the sample was rotated around the furnace axis in three different rotations $\left(0^{\circ}, 45^{\circ}\right.$ and $\left.90^{\circ}\right)$, Figure 4.5. Diffraction data were collected at each of the three rotations for a period of 18 minutes which was deemed sufficient to obtain the orientation distribution function to reconstruct pole figures for many different planes. The total time for each temperature interval was about $1 \mathrm{~h}$ (including time for data readout and rotation). The pole intensities measured with the three panels of detectors $\left(150^{\circ}\right.$ bank, $90^{\circ}$ bank, and $40^{\circ}$ bank $)$ were used to extract texture information using the Rietveld method, as implemented in the MAUD (ㅍaterial $\underline{\text { Analysis }}$

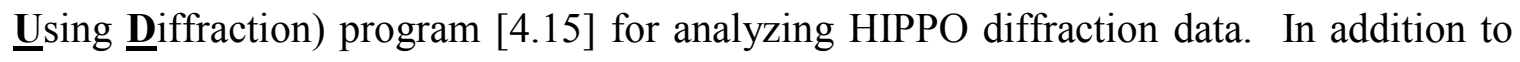
extracting texture information, the volume fractions and lattice parameters for the $\alpha$ and $\beta$ phases were also obtained with the Rietveld refinement within the MAUD program. 


\subsection{Data Analysis}

The HIPPO diffraction data for each test temperature consisted of a total of 78 histograms, all of which were analyzed simultaneously using the Rietveld method as implemented in MAUD [4.16], [4.17]. The data are refined taking into account the HIPPO instrument parameters and background, then crystallographic and microstructural parameters, and finally all parameters, including the texture and volume fractions of the phases present in the sample. In general, the scattering cross-section for Bragg scattering is proportional to $\mathrm{N} / \mathrm{V}$, where $\mathrm{N}$ is the number of unit cells contributing to the scattering and $\mathrm{V}$ is the unit cell volume. The scale factor $(\mathrm{S})$ obtained in the Rietveld analysis for the calculated intensities that best scaled with the observed measurements, is directly proportional to $\mathrm{N} / \mathrm{V}$. The scale factor and the unit cell volume of the phase are obtained from the Rietveld analysis to derive the volume fraction of that phase using $V_{p}=\left(S^{2}\right)_{p} /$ $\Sigma\left(\mathrm{S} \mathrm{V}^{2}\right)_{\mathrm{i}}$, where $\mathrm{V}_{\mathrm{p}}$ is the volume fraction of that phase $\mathrm{p}$, and the summation in the denominator accounts for all crystalline phases in the sample.

MAUD uses the Rietveld method that was originally developed to determine crystal structures from powder samples, and to fit the complete measured diffraction spectra by refining the instrument, phase and sample parameters. Since the whole spectra are analyzed, the Rietveld analysis can account for overlapping peaks. The texture is refined inside the least-squares Rietveld refinement procedure at each separate cycle of iteration, and calculating the orientation distribution function (ODF) using a modified WIMV (Williams-Imhof-Matties-Vinel) algorithm, called 'EWIMV' in MAUD that allows data to be entered at arbitrary pole figure positions [4.17], [4.18]. 
The HIPPO diffraction data (consisting of a total of 78 histograms) were taken as input in MAUD, though only the information within the computational range for d-spacing of $0.5-3.0 \AA$ was used. A $10^{\circ} \times 10^{\circ} \times 10^{\circ}$ grid was used for calculating the ODF of the sample for each test temperature. No sample symmetry was imposed on the calculations. The complete pole figures for both $\alpha$ and $\beta$ phases were reconstructed from the calculated ODFs. All the reconstructed pole figures in this paper are presented on a Lambert equal-area projection [4.19].

In this paper, the complete pole figures at each temperature are presented using only the diffracting planes for hcp and bcc lattice structures relevant to the Burgers orientation relationship [4.9] (i.e., $(110)_{\mathrm{BCC}} / /(0002)_{\mathrm{HCP}}$ and $\left.[\overline{1} 11]_{\mathrm{BCC}} / /[11 \overline{2} 0]_{\mathrm{HCP}}\right)$. For an hcp lattice, pole figures for the (0002) plane normals and a prism plane normals (11 $\overline{2} 0)$ are sufficient to define the orientation of the crystal lattice relative to the sample reference orthogonal axes (e.g., Radial-R, Longitudinal-L and Hoop-H directions in a tube). These two hcp planes are relevant to the Burgers orientation relationship (Figure 4.4) that is used to evaluate the lattice correspondence with the bcc phase. The lattice correspondence between the bcc and hcp phases were evaluated using two sets of pole figures as an illustration, by examining the angular deviations of superimposed intensity peaks of the poles on an equal-area projection.

Also, selected ODFs were examined to evaluate all the crystallite orientations during the $\alpha$ - and $\beta$-phase transformations that occurred on heating into the $\beta_{\mathrm{Zr}}$-phase field and then cooling to within the $\left(\alpha+\beta_{\mathrm{Zr}}\right)$ phase field and in the $\left(\alpha+\beta_{\mathrm{Nb}}\right)$ phase field. 
The lattice parameters and volume fraction for the $\alpha$ and $\beta$ phase obtained from the texture analysis in MAUD (EWIMV) are also evaluated in this study.

\subsection{Results and Discussion}

4.4.1 TOF diffraction spectra and lattice parameters as a function of test temperatures:

Figure 4.6 shows a segment of the spectra obtained on heating [373 K to $1323 \mathrm{~K}$ $\left(100^{\circ} \mathrm{C}\right.$ to $\left.\left.1050^{\circ} \mathrm{C}\right)\right]$ and on cooling $\left[1173 \mathrm{~K}\right.$ and $823 \mathrm{~K}\left(900^{\circ} \mathrm{C}\right.$ and $\left.\left.550^{\circ} \mathrm{C}\right)\right]$. The $\alpha(\mathrm{hcp})$ and $\beta$ (bcc) diffraction peaks are indexed, and they were used in the analysis for texture, lattice parameters and volume fraction for the $\alpha$ and $\beta$ phase. Also, the figure shows the relative diffraction intensity changes in $\alpha$ (hcp) and $\beta$ (bcc) diffraction peaks due only to $\alpha-\beta$ phase transformations that occur during heating and cooling. The volume fraction of the phases is related to the intensity of the peaks.

Table 4.1 lists the results for lattice parameters of the two phases at each temperature. The lattice parameters obtained in this study are consistent and relatively larger by about $0.5 \%$ than those of single crystal of $\mathrm{Zr}$ values reported in the literature [4.20], [4.21], [4.22].

Using the lattice parameters for hcp and bcc phase obtained in this study, a unit cell volume was calculated for each temperature (Table 4.1). The results are compared with those from the literature in Figure 4.7. As seen in Figure 4.7, the volumetric thermal expansion of the hcp lattice increased linearly on heating up to about $1023 \mathrm{~K}\left(750^{\circ} \mathrm{C}\right)$ (and also extended to the larger volume obtained from cooling at $1173 \mathrm{~K}\left(900^{\circ} \mathrm{C}\right)$ after 
being heated at $1323 \mathrm{~K}\left(1050^{\circ} \mathrm{C}\right)$ in the full $\beta$-phase regime). Heating to temperatures above $1023 \mathrm{~K}\left(750^{\circ} \mathrm{C}\right)$ gave a larger linear expansion up to $1173 \mathrm{~K}\left(900^{\circ} \mathrm{C}\right)$. This increase of linear expansion at the higher temperatures can be attributed to segregation of

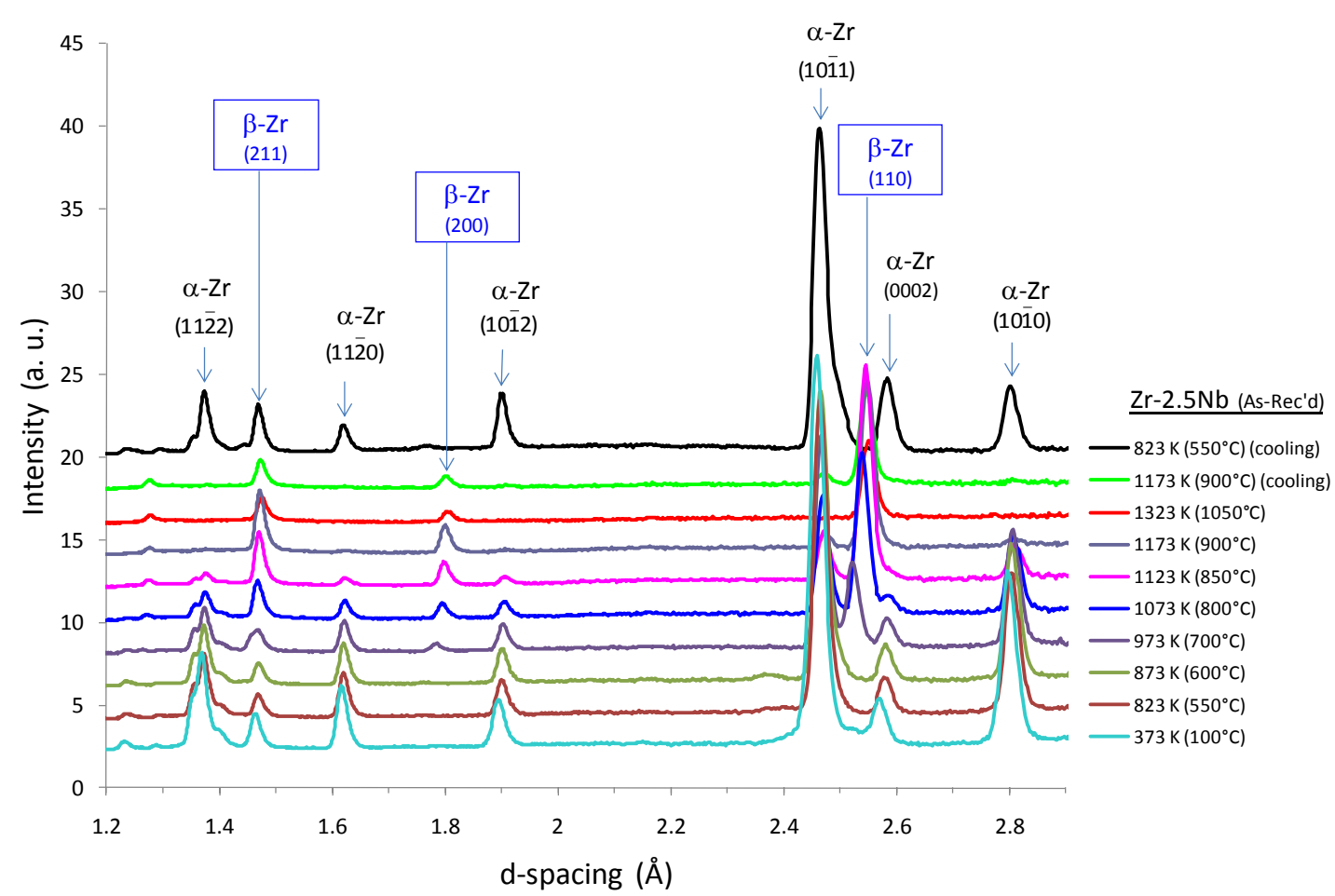

Figure 4.6 TOF diffraction spectra from an as-received $\mathrm{Zr}-2.5 \mathrm{Nb}$ pressure tube sample on heating to eight different temperatures $\left[373 \mathrm{~K}\right.$ to $1323 \mathrm{~K}\left(100^{\circ} \mathrm{C}\right.$ to $\left.\left.1050^{\circ} \mathrm{C}\right)\right]$ and on cooling $\left[1173 \mathrm{~K}\right.$ and $823 \mathrm{~K}\left(900^{\circ} \mathrm{C}\right.$ and $\left.\left.550^{\circ} \mathrm{C}\right)\right]$.

oxygen in the 'primary' $\alpha-Z r$ grains [4.23], occupying the interstitial sites of the hcp structure which is known to increase the lattice parameters. In general, the linear expansion behaviour of $\alpha$-phase $\mathrm{Zr}$ found in this study is shown to be consistent with Goldak's values for pure Zr [4.21], Figure 4.7, although the absolute values are slightly larger than literature values. A possible cause for this discrepancy can be attributed to the 
presence of alloying and impurity elements (interstitial types such as oxygen and nitrogen).

For the $\beta$-phase material, Figure 4.7 shows three linear volumetric expansion characteristics. On heating below the monotectoid temperature $\left(\approx 883 \mathrm{~K}\left(610^{\circ} \mathrm{C}\right)\right)$, there is little change in volume expansion with temperature, due to the transformation of the metastable $\beta_{\mathrm{Zr}}$ phase (containing about $20 \% \mathrm{Nb}$ ) into a $\beta_{\text {enr }}$ phase enriched in $\mathrm{Nb}$ content [4.10], [4.11] that contracts the lattice parameter in combination with the linear thermal expansion of the lattice.

On heating through the intermediate range of temperatures from about $873 \mathrm{~K}$ to $1173 \mathrm{~K}\left(600^{\circ} \mathrm{C}\right.$ to $\left.900^{\circ} \mathrm{C}\right)$, there is a sharp increase in linear volumetric expansion of the $\beta$-phase structure and, this behaviour can be related to the combined changes in the niobium content in the transformed $\beta_{\mathrm{Zr}}$ phase and the dependence of lattice parameter on temperature.

On heating at temperatures above $1173 \mathrm{~K}\left(900^{\circ} \mathrm{C}\right)$ and traversing into the full $\beta$-phase field, there is a decline in the linear volumetric expansion of the $\beta$-phase structure which is simply due to the linear temperature dependence of the lattice parameter. The linear volumetric expansion behaviour evaluated in this study is consistent with the literature for pure bcc $\mathrm{Zr}$ [4.22] although the determined lattice parameters are slightly larger. This discrepancy may also be due to alloying and impurity elements present in the $\mathrm{Zr}-2.5 \mathrm{Nb}$ pressure tube in comparison to the pure single crystal material used in earlier studies. 


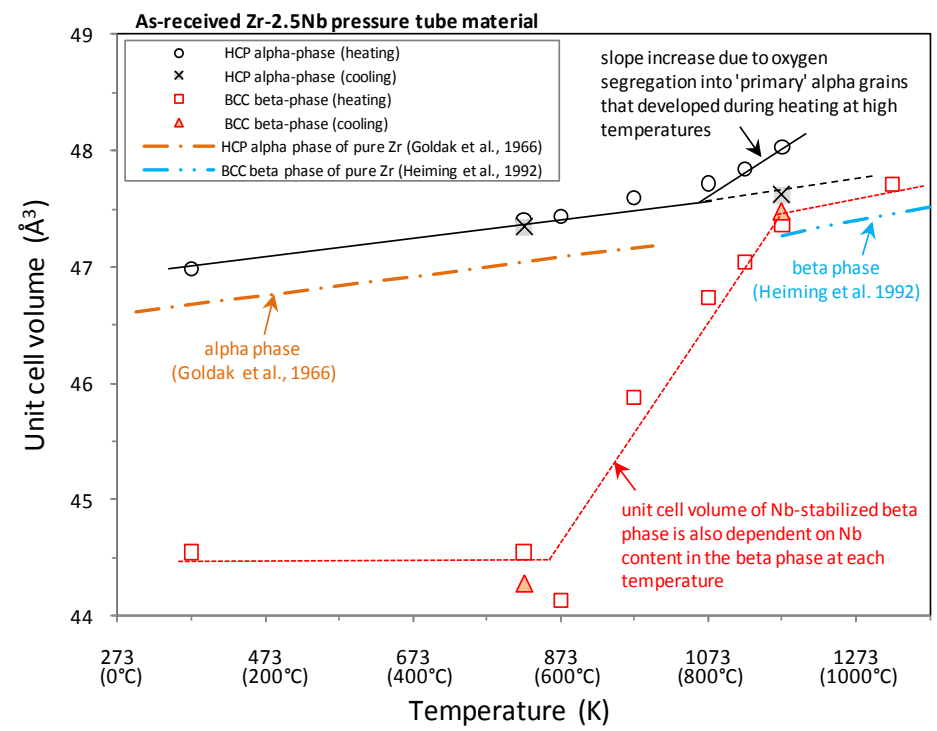

Figure 4.7 The variation of unit cell volume of $\alpha$ and $\beta$ phase $\mathrm{Zr}$ in an as-received $\mathrm{Zr}-2.5 \mathrm{Nb}$ pressure tube at different heating and cooling temperatures.

\subsubsection{Volume fraction of $\beta$-phase on heating and on cooling:}

Table 4.1 lists the volume fractions of $\beta$-phase measured in the sample on heating and on cooling. Figure 4.8 shows the $\beta$-phase volume fraction plotted as a function of temperature, where the amount of transformed $\beta$-phase increases sharply as the temperature goes just above the $\alpha /(\alpha+\beta)$ transus estimated from the fit to the neutron data to be at about $883 \mathrm{~K}\left(610^{\circ} \mathrm{C}\right)$. At about $1083 \mathrm{~K}\left(810^{\circ} \mathrm{C}\right)$ there is an equal proportion of $\beta$ and $\alpha$ phase, and the $(\alpha+\beta) / \beta$ transus is estimated from the fit to be at about $1233 \mathrm{~K}$ $\left(960^{\circ} \mathrm{C}\right)$. The solvus temperatures for $\alpha /(\alpha+\beta)$ and $(\alpha+\beta) / \beta$ phase boundaries are indicated by dashed arrows separating the different phase fields shown in the figure. The values for volume fraction and solvus lines for an as-received $\mathrm{Zr}-2.5 \mathrm{Nb}$ pressure tube sample are found to be consistent with those in literature [4.24], [4.25]. 


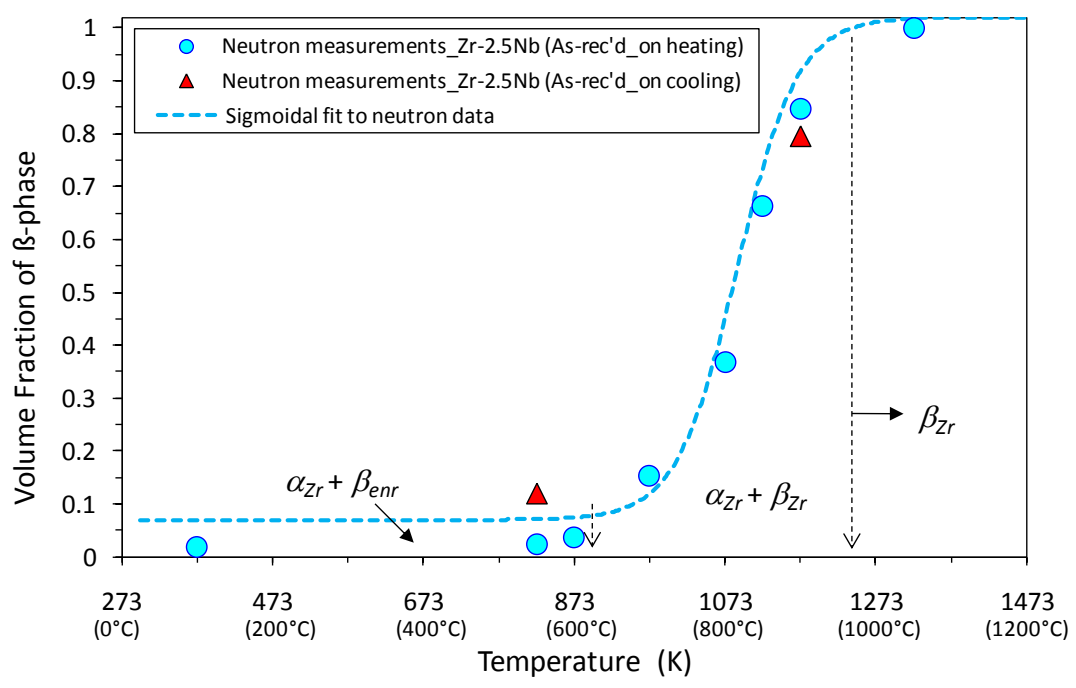

Figure 4.8 Volume fraction of $\beta$-phase in as-received $\mathrm{Zr}-2.5 \mathrm{Nb}$ pressure tube material on heating at eight different temperatures $\left[373 \mathrm{~K}\right.$ to $1323 \mathrm{~K}\left(100^{\circ} \mathrm{C}\right.$ to $\left.\left.1050^{\circ} \mathrm{C}\right)\right]$ and also on cooling [1173 $\mathrm{K}$ and $823 \mathrm{~K}\left(900^{\circ} \mathrm{C}\right.$ and $\left.\left.550^{\circ} \mathrm{C}\right)\right]$.

\subsubsection{Pole figures from an as-received $\mathrm{Zr}$-2.5Nb pressure tube sample on heating and cooling:}

Figure 4.9 shows complete pole figures for the $\alpha$ - and $\beta$-phase in the sample of as-received $\mathrm{Zr}-2.5 \mathrm{Nb}$ pressure tube measured at each temperature during heating and cooling. Only the plane normals for the two phases relevant to the Burgers orientation relationship (i.e., $(110)_{\mathrm{BCC}} / /(0002)_{\mathrm{HCP}}$ and $\left.[\overline{1} 11]_{\mathrm{BCC}} / /[11 \overline{2} 0]_{\mathrm{HCP}}\right)$ are shown in the figure. From examination of Figure 4.9, the $\alpha$-phase texture is found to be quite stable, with little change in the $\{0002\}$ and $\{11 \overline{2} 0\}$ pole figures during heating to $1123 \mathrm{~K}\left(850^{\circ} \mathrm{C}\right)$. It can be seen that the $\alpha$-phase $\{0002\}$ and $\{11 \overline{2} 0\}$ pole figures at $373 \mathrm{~K}\left(100^{\circ} \mathrm{C}\right)$ and up to 973 $\mathrm{K}\left(700^{\circ} \mathrm{C}\right)$ are much the same as those measured at room temperature in a earlier study [4.3] (Figure 4.2). By comparison, the $\alpha$ and $\beta$ phase textures obtained between $373 \mathrm{~K}$ 
and $873 \mathrm{~K}\left(100^{\circ} \mathrm{C}\right.$ and $\left.600^{\circ} \mathrm{C}\right)$ in this study are similar to but showing a much sharper texture than those previously measured on a cold-worked $\mathrm{Zr}-2.5 \mathrm{Nb}$ tube that was initially heated at $898 \mathrm{~K}\left(625^{\circ} \mathrm{C}\right)$ before being heated to $1248 \mathrm{~K}\left(975^{\circ} \mathrm{C}\right)$ and cooled back down to $898 \mathrm{~K}\left(625^{\circ} \mathrm{C}\right)[4.8]$.

A further examination of the $\alpha$-phase $\{11 \overline{2} 0\}$ pole figures at heating temperatures up to $973 \mathrm{~K}\left(700^{\circ} \mathrm{C}\right)$ indicates that there is no rotation of these poles, suggesting that the previously deformed $\alpha$ grains did not recrystallize during heating. Unlike cold-worked Zircaloys which exhibit a grain recrystallization (when heated between $873 \mathrm{~K}$ and 1023 $\mathrm{K}\left(600^{\circ} \mathrm{C}\right.$ and $\left.750^{\circ} \mathrm{C}\right) \alpha$-phase field $)$ there is a texture change by rotation of $\{11 \overline{2} 0\}$ poles of approximately $30^{\circ}$ about the c-axis of the crystals [4.4]), cold-worked $\mathrm{Zr}-2.5 \mathrm{Nb}$ material does not recrystallize when heated at these temperatures [4.25] and hence no rotation of these poles were observed (Figure 4.9c and Figure 4.9d).

Examination of the transformed $\beta$-phase texture measured in this study showed that there is a slight change on heating up to $973 \mathrm{~K}\left(700^{\circ} \mathrm{C}\right)$.

On further heating to $1173 \mathrm{~K}\left(900^{\circ} \mathrm{C}\right)$, there appears to be a new $\alpha$-phase texture component (see arrow insert in Figure 4.9g); meanwhile the transformed $\beta$-phase texture evolved markedly. By comparison, this $\alpha$-phase texture component was not observed in cold-worked (as-received) $\mathrm{Zr}-2.5 \mathrm{Nb}$ pressure tube material in a previous study that evaluated the effect of thermal cycling on texture evolution between two test temperatures (at $898 \mathrm{~K}\left(625^{\circ} \mathrm{C}\right)$ - just above the $(\alpha+\beta) / \beta$ transus, and at $1248 \mathrm{~K}\left(975^{\circ} \mathrm{C}\right)$ in the full $\beta$-phase regime) [4.8]. 
At $1323 \mathrm{~K}\left(1050^{\circ} \mathrm{C}\right)$, the $\alpha$-phase had disappeared, only $100 \% \beta$-phase was observed with a different texture than that observed at lower temperatures. A further observation of the $\beta$-phase $\{110\}$ and $\{222\}$ pole figures on heating from $973 \mathrm{~K}$ to $1323 \mathrm{~K}\left(700^{\circ} \mathrm{C}\right.$ to $1050^{\circ} \mathrm{C}$ ) (Figure $4.9 \mathrm{~d}$ to Figure $4.9 \mathrm{~g}$ ) indicates that the $\beta$-phase texture had evolved basically three times. It appears that the first two texture evolutions on heating up to $1123 \mathrm{~K}\left(850^{\circ} \mathrm{C}\right)$ may have not strictly followed the Burgers orientation relationship suggesting that there could be a shape change of the $\beta$-phase $\mathrm{Zr}$ grains due to an increasing volumetric expansion (Figure 4.7) and the resulting increase in volume fraction of the transformed $\beta$-phase material with increasing temperatures (Figure 4.8), as noted earlier in this study.

On cooling from the full $\beta$-phase regime, a cool-down transformed $\alpha$-phase texture was observed with no resemblance of its initial low-temperature texture (e.g., comparing Figure 4.9k: $823 \mathrm{~K}\left(550^{\circ} \mathrm{C}\right)$ (cooling) with Figure $4.9 \mathrm{~b}: 823 \mathrm{~K}\left(550^{\circ} \mathrm{C}\right)$ (heating)). This new transformed $\alpha$-phase texture due only to the phase transformation shows that the $\{0002\}$ plane normals have aligned within the radial-axial plane of the pressure tube (see Figure 4.9k and Figure 4.91). By comparison, the previous study showed that the cool-down transformed $\alpha$-phase texture at $898 \mathrm{~K}\left(625^{\circ} \mathrm{C}\right)$ after first heating to $1248 \mathrm{~K}\left(975^{\circ} \mathrm{C}\right)$ had only a partial texture reorientation (from hoop to longitudinal) as some of the original texture had remained in the hoop direction of the tube [4.8].

It will be shown in the subsequent analysis that the reversed $\beta$ to $\alpha$ transformation follows the Burgers orientation relationship (Figure 4.4). In addition, the complete 
orientations for all crystallites can be better evaluated using the ODFs to clearly reveal all the crystal orientations of the high-temperature texture developed during heating at $1173 \mathrm{~K}\left(900^{\circ} \mathrm{C}\right)$.

\subsubsection{Analysis of lattice orientation relationship between $\alpha$ and $\beta$ phases:}

The lattice orientation correspondence between the $\alpha$ - and $\beta$-phase, Figure 4.10, is determined from the angular deviation of the superimposed pole intensity peaks from two sets of pole figures on an equal-area projection (i.e., a Lambert net). This analysis shows that on average there is an angular deviation of about $5^{\circ}$ between the plane normals of the hcp and bcc lattices for the two phases for the two temperatures shown (heating to $823 \mathrm{~K}\left(550^{\circ} \mathrm{C}\right)$, and cooling to $823 \mathrm{~K}\left(550^{\circ} \mathrm{C}\right)$, after being heated to $1323 \mathrm{~K}$ $\left.\left(1050^{\circ} \mathrm{C}\right)\right)$. This $5^{\circ}$ angular deviation is within the Burgers orientation relationship (i.e., $(110)_{\mathrm{BCC}} / /(0002)_{\mathrm{HCP}}$ and $[\overline{1} 11]_{\mathrm{BCC}} / /[11 \overline{2} 0]_{\mathrm{HCP}}$, Figure 4.4), and follows the Burgers orientation relationship.

\subsubsection{Examination of the ODFs of $\alpha$ and $\beta$ phases:}

To reveal a complete description of orientations of all crystallites within the sample, plots of the orientation distribution functions (ODF) of $\alpha$ and $\beta$ phases for selected test temperatures during heating and cooling are presented. The ODFs gives a complete map of the distribution of orientations of the crystallites ( $\alpha$ or $\beta$ phase) in the sample. 


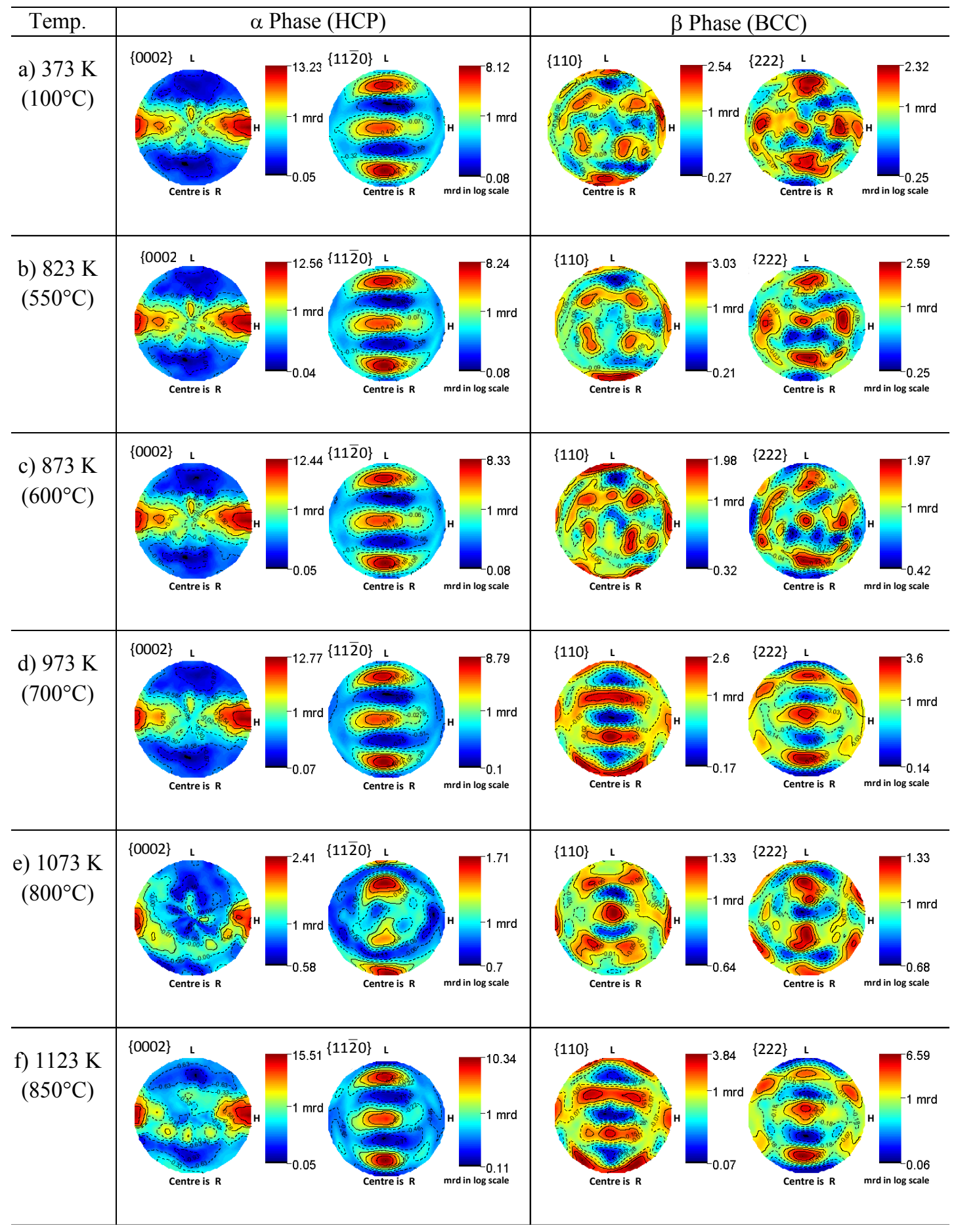

Figure 4.9 Complete pole figures (equal-area projections) of $\alpha$ and $\beta$ phases in as-received $\mathrm{Zr}-2.5 \mathrm{Nb}$ pressure tube during heating $(\mathrm{g}, \mathrm{h})$ and cooling (i to $\mathrm{l}$ ). 


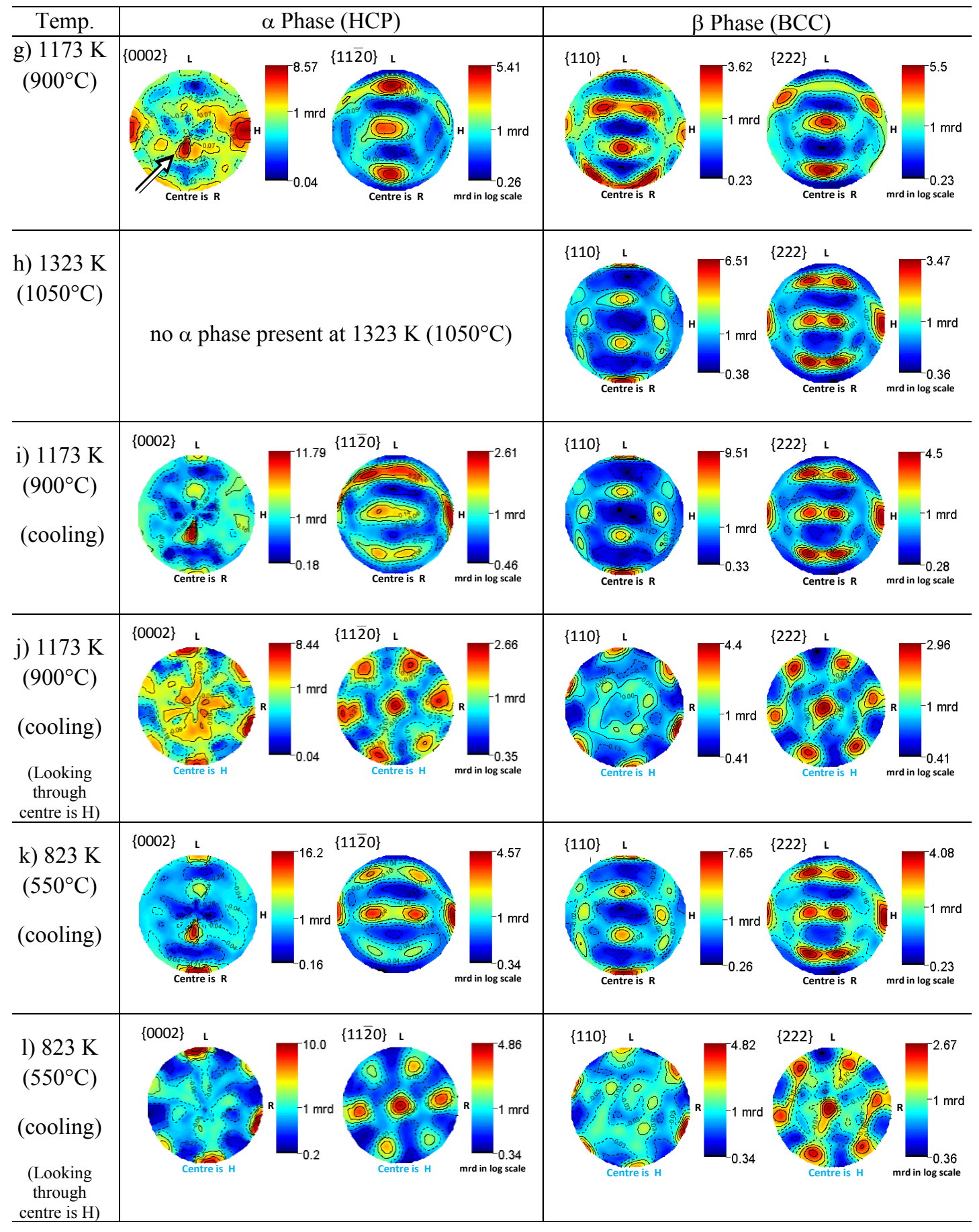

Figure 4-9 (cont'd): Complete pole figures (equal-area projections) of $\alpha$ and $\beta$ phases in as-received $\mathrm{Zr}-2.5 \mathrm{Nb}$ pressure tube during heating ( $\mathrm{g}, \mathrm{h}$ ) and cooling ( $\mathrm{i}$ to 1 ). 


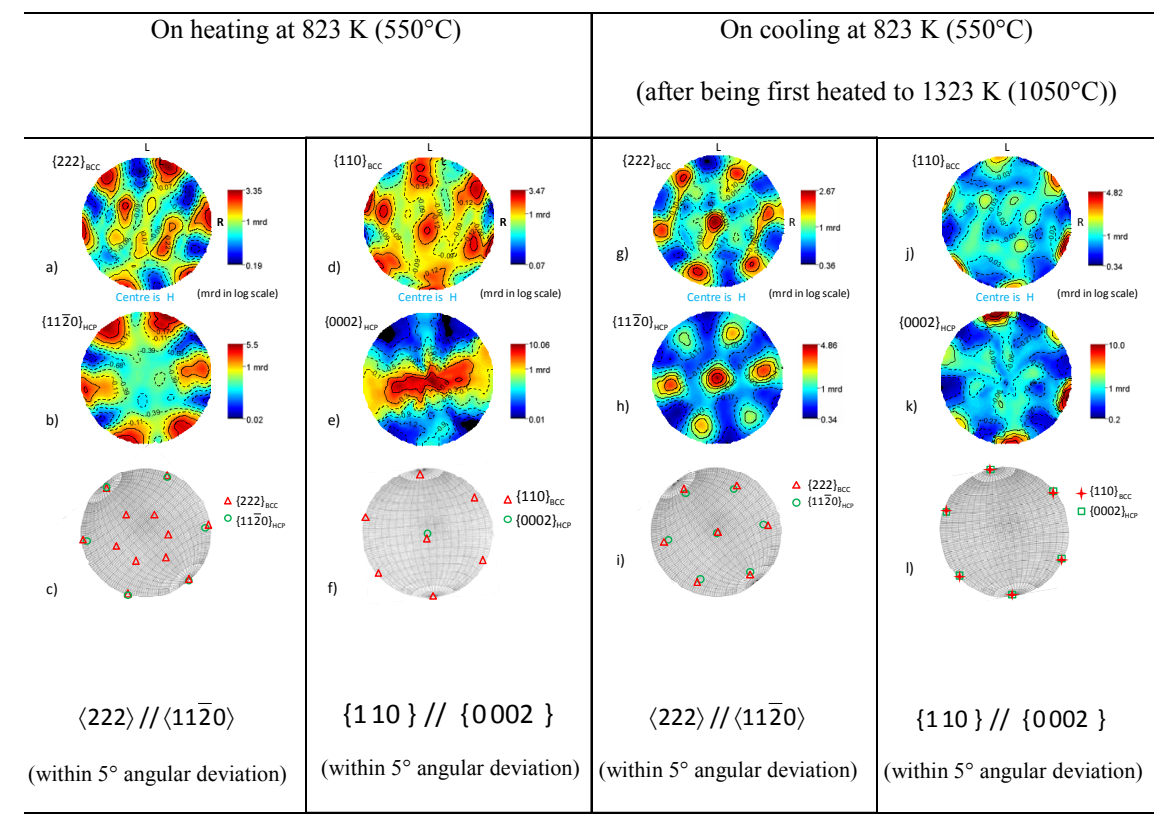

Figure 4.10 Pole figures of bcc $\beta$ and hcp $\alpha$ phase on heating at $823 \mathrm{~K}\left(550^{\circ} \mathrm{C}\right)$ (first two columns on left-hand side of diagram: a, b, d, e) and then on cooling at $823 \mathrm{~K}\left(550^{\circ} \mathrm{C}\right)$ after being heated to $1323 \mathrm{~K}\left(1050^{\circ} \mathrm{C}\right)$ (last two columns on right-hand side: $\left.\mathrm{g}, \mathrm{h}, \mathrm{j}, \mathrm{k}\right)$. The diagrams at the bottom of each column show the superimposed intensity peaks from pole figures of the two phases on an equal-area projection (Lambert net). An angular deviation of about $5^{\circ}$ is determined for a lattice correspondence between the bcc and hcp structure that on average essentially obeys the Burgers orientation relationship (Figure 4.4) during heating and cooling that involved a complete phase transformation sequence: $\mathrm{hcp} \rightarrow \mathrm{bcc} \rightarrow \mathrm{hcp}$.

The orientation of a crystal axes in relation to the sample reference orthogonal axes is defined by Euler angles $(\Psi, \theta, \phi$ - these are rotation angles on the crystal that relates its orientation to the referenced axes of the sample), thus the ODF of a sample is usually presented in 3-D Euler space. To define the Euler angles, one starts with the 
crystal orthogonal axes $(X, Y, Z)$ and sample axes $(x, y, z)$ coincident. Following Davies et al. [4.26], angle $\Psi$ is the first rotation of the crystal about the $\mathrm{Z}$ axis, $\theta$ is the subsequent rotation of the crystal about its $\mathrm{Y}$ axis and $\phi$ is the subsequent rotation of the crystal about its $\mathrm{Z}$ axis. To assist with evaluating the ODFs, Figure 4.11 shows an illustration for the different orientations of a crystal described by a set of Euler angles $(\Psi, \theta, \phi)$ relating to the sample axes. In the figure, the crystallographic directions of the hcp $\alpha-Z r$ crystal lattice are assigned (following Davies et al. [4.26]) with $X=[\overline{1} 2 \overline{1} 0]$ as hoop, $\mathrm{Y}=[10 \overline{1} 0]$ as longitudinal and $\mathrm{Z}=[0001]$ as radial directions of the sample, respectively. For the bcc $\beta-\mathrm{Zr}$ phase, the coincident axes of the cubic crystal lattice should be aligned with the sample axes that follows the Burgers orientation relationship with the hep $\alpha-\mathrm{Zr}$ crystal, Figure 4.4, (i.e., $\mathrm{X}=[001]$ as hoop, $\mathrm{Y}=[\overline{1} \overline{1} 0]$ as longitudinal and $\mathrm{Z}=[110]$ as radial directions in the sample, respectively).

In this study the ODFs are plotted for the selected ODFs of $\alpha$ and $\beta$ phase as shown in Figure 4.12 and Figure 4.13, respectively. The ODFs of the $\alpha$ phase texture are evaluated with corresponding assistance from Figure 4.11. Similarly, the $\beta$ phase ODFs can be evaluated using the lattice correspondence with the $\alpha$ phase through the Burgers orientation relationship established from Figure 4.10.

Figure 4.12 presents a selected set of ODFs, showing a comparison of changes in volume fraction of orientations of the $\alpha$ phase crystallites that evolved during the heating and cooling texture measurements. The ODFs are shown for $\phi=0^{\circ}$ to $\phi=60^{\circ}$ at $10^{\circ}$ 
interval, and since the hcp lattice has 3-fold plane symmetry about the c-axis, the ODF plot for $\phi=60^{\circ}$ is essentially a repetition of the ODF plot for $\phi=0^{\circ}$ (Figure 4.11).

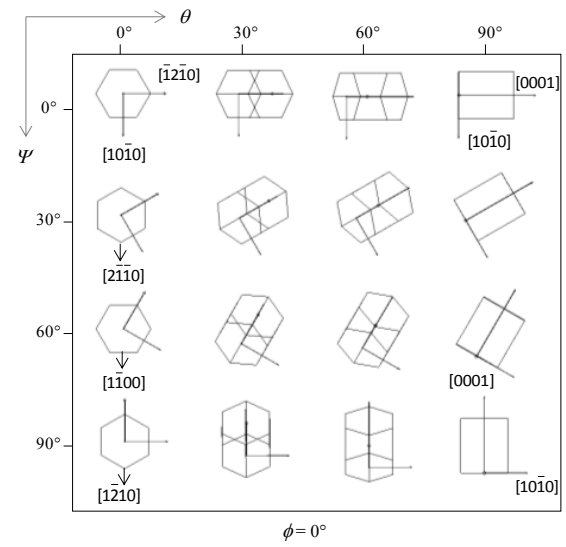

a)

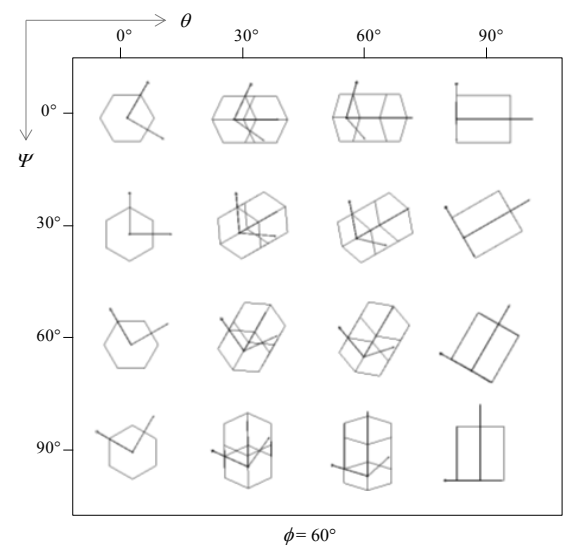

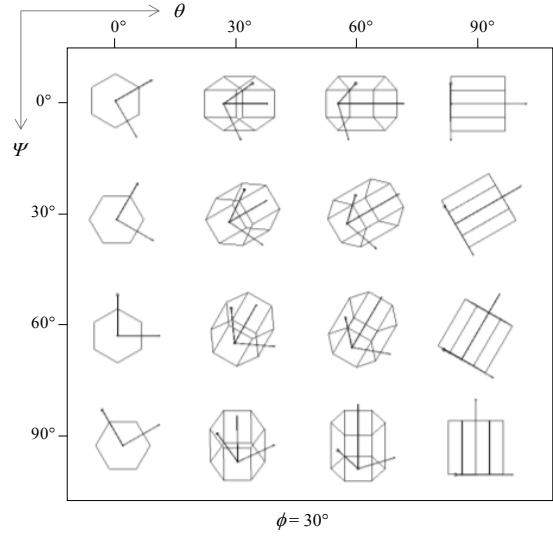

b)

c)

Figure 4.11 Illustrations showing different crystal orientations described by Euler angles $(\Psi, \theta)$ for three constant $\phi$ sections: a) $\phi=0^{\circ}$, b) $\phi=30^{\circ}$ and c) $\phi=60^{\circ}$, relating the crystallographic axes of the crystal to chosen axes in a sample (e.g., radial, hoop and longitudinal directions).

Following Davies et al. [4.26] the crystallographic directions are assigned for [ $[\overline{1} 2 \overline{1} 0]$ as hoop, [10 $\overline{1} 0]$ as longitudinal, and [0001] as radial directions, respectively. (This figure first appeared in Figure 2.11)

An examination of the ODF at $823 \mathrm{~K}\left(550^{\circ} \mathrm{C}\right)$ (Figure $\left.4.12 \mathrm{a}\right)$ showed that there is only one pronounced texture component, defined by the Euler angles $\left(\Psi=0^{\circ}, \theta=45-90^{\circ}\right.$, 
and $\phi=0^{\circ}$ ) and indicated by arrows, labelled B in the ODFs. There is also a weak texture component observed at $823 \mathrm{~K}\left(550^{\circ} \mathrm{C}\right)$ (as indicated by arrows, labelled A in the ODFs). The ODF of the pronounced texture component indicates that the (0002) poles are mainly aligned in the sample hoop direction. Whereas the ODF for the weak texture component shows that this set of $\alpha$ phase crystallites have their (0002) poles aligned along the radial direction. The two texture components observed in this study (Figure 4.12a) are consistent with earlier examinations on as-received 'production' $\mathrm{Zr}-2.5 \mathrm{Nb}$ pressure tube materials using transmission electron microscopy [4.27]. Three types of grains were identified in the earlier study [4.27]: (i) Type ' $\mathrm{A}$ ' grains are large and appear equiaxed when viewed along the tube's longitudinal direction; Type 'B' grains are platelets between $0.2-1 \mu \mathrm{m}$ thick that tend to be aligned within the plane of the tube; and Type ' $\mathrm{C}$ ' grains are small aligned platelets $<0.2 \mu \mathrm{m}$ thick that are clustered in discrete regions. The Type-A grains tend to have their c-axes oriented towards the radial direction and Type-B grains tend to have their c-axes oriented in the transverse (hoop) direction. The Type-C grains are always associated with an increase of basal texture component in the longitudinal direction. The Type-A and Type-B grains make up the bulk of the material.

In comparison to the $\mathrm{ODF}$ at $823 \mathrm{~K}\left(550^{\circ} \mathrm{C}\right)$ (Figure 4.12a), Type-A grains would correspond to the ODF intensity (labelled A) of a small set of crystallites defined by Euler angles $\left(\Psi=50-60^{\circ}, \theta=0-10^{\circ}\right.$, and $\phi=0^{\circ}$ to $\left.\phi=60^{\circ}\right)$ as these are the prior 'primary' $\alpha-\mathrm{Zr}$ grains that are present during and after the extrusion of the pressure tube material. Similarly, the Type-B grains would correspond to the ODF intensity (labelled B in the ODF plots) for the large set of crystallites that are defined by Euler angles ( $\Psi=0^{\circ}, \theta=45$ - 
$90^{\circ}$, and $\phi=0-10^{\circ}$ and $\phi=50-60^{\circ}$ ), and these grains developed the pronounced $\alpha$-phase texture observed as a result of $\beta \rightarrow \alpha$ after the extrusion during cool down.

The pronounced texture component (i.e., mainly showing the (0002) poles aligned in the sample hoop direction) is seen to dominate to higher heating temperatures up to $1173 \mathrm{~K}\left(900^{\circ} \mathrm{C}\right)$ (Figure $\left.4.12 \mathrm{~d}\right)$, although the maximum value of ODF intensity has decreased to 40 , suggesting that this large set of $\alpha-\mathrm{Zr}$ grains (labelled B in the ODF plots) had increasingly transformed into the $\beta$-phase structure. Consequently, the ODF intensity for the prior 'primary' $\alpha-Z r$ grains has increased as a result of their relative increase in volume fraction and their grain growth during heating at $1173 \mathrm{~K}\left(900^{\circ} \mathrm{C}\right)(\mathrm{see}$ Figure $4.12 \mathrm{~d}$ - as indicated by the arrows, labelled A in the ODF plot). The orientations of these coarsened 'primary' $\alpha-\mathrm{Zr}$ grains are defined by the Euler angles $\left(\Psi=80-90^{\circ}\right.$, $\theta=15-20^{\circ}$, and $\phi$ for all angles from 0 to $60^{\circ}$ ). In Figure $4.12 \mathrm{~d}$, another small set of weak texture component (labelled $\mathrm{C}$ in the ODF plot) is observed that would correspond to the Type-C grains with a basal texture component in the longitudinal direction [4.27] as discussed earlier.

A further heating to $1323 \mathrm{~K}\left(1050^{\circ} \mathrm{C}\right)$ showed there was no $\alpha$ phase present, therefore no $\alpha$-phase ODF is shown here; however on cooling back to $1173 \mathrm{~K}\left(900^{\circ} \mathrm{C}\right)$ the previously predominant texture at $373 \mathrm{~K}\left(100^{\circ} \mathrm{C}\right)$ did not re-appear. Instead the newly nucleated $\alpha$ crystallites (when transformed from the full $\beta$ phase field) are shown to have the same orientations as the 'primary' $\alpha-Z r$ grains before they were completely transformed into $\beta$ (see Figure 4.12e) suggesting a "memory" effect of the precursory 
texture of the 'primary' $\alpha-Z r$ grains. This $\alpha$ texture, as transformed from the $\beta$ phase, remained dominant when the sample was cooled to a lower temperature at $823 \mathrm{~K}\left(550^{\circ} \mathrm{C}\right)$ (Figure 4.12f).

\subsection{6 $\quad \beta$-phase ODFs:}

Figure 4.13 shows selected ODFs of the $\beta$ phase determined from the neutron measurements during the heating and cooling experiments. From examination of the figure, there are three texture components (as indicated by the labelled arrows) that evolved at the different temperatures.

The low-temperature texture component at $823 \mathrm{~K}\left(550^{\circ} \mathrm{C}\right)$ (indicated by arrows, labelled $\mathrm{A}$ in Figure 4.13a) defined by the Euler angles $\left(\Psi=10-30^{\circ}, \theta=0-20^{\circ}\right.$, and $\phi$ at 10 , 20 and $30^{\circ}$ ) had disappeared on heating to higher temperatures. On cooling after heating at $1323 \mathrm{~K}\left(1050^{\circ} \mathrm{C}\right)$, none of these crystal orientations re-appeared (Figure $4.13 \mathrm{f}$ and Figure $4.13 \mathrm{~g})$.

During heating to $1073 \mathrm{~K}\left(800^{\circ} \mathrm{C}\right)$, there is a new texture component that appeared (arrow, labelled B in Figure 4.13b) defined by the Euler angles $\left(\Psi=80-90^{\circ}\right.$, $\theta=50-70^{\circ}$, and $\phi=40^{\circ}$ ). The texture component remained unchanged on further heating to $1173 \mathrm{~K}\left(900^{\circ} \mathrm{C}\right)$ (Figure $\left.4.13 \mathrm{~d}\right)$ and then disappeared on heating to $1323 \mathrm{~K}\left(1050^{\circ} \mathrm{C}\right)$ (arrow, labelled B in Figure 4.13e) and remained absent on cooling to lower temperatures. Heating at $1323 \mathrm{~K}\left(1050^{\circ} \mathrm{C}\right)$ also resulted in relocation of some texture components (arrows, labelled $\mathrm{C}$ in Figure 4.13e) from one orientation to another orientation. The relocations can be defined by changes in the Euler angles from $\left(\Psi=20^{\circ}\right.$, 
$\left.\theta=45^{\circ}, \phi=50^{\circ}\right)$ to $\left(\Psi=0^{\circ}, \theta=40^{\circ}, \phi=50^{\circ}\right)$ for one texture component and for the other by changing ( $\left(\Psi=80^{\circ}, \theta=60^{\circ}, \phi=50^{\circ}\right)$ to $\left(\Psi=60^{\circ}, \theta=50^{\circ}, \phi=50^{\circ}\right)$.

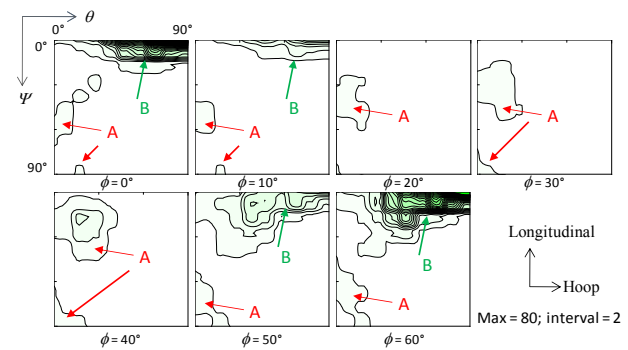

a) $823 \mathrm{~K}\left(550^{\circ} \mathrm{C}\right)$

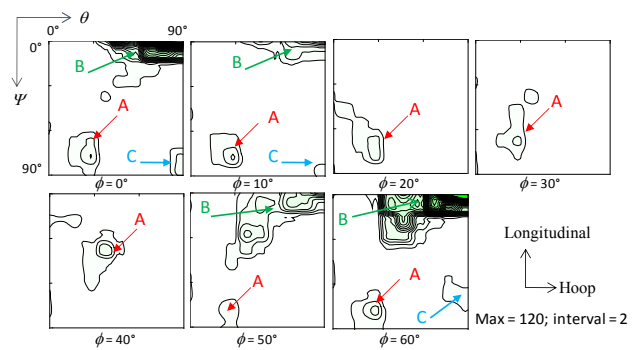

c) $1123 \mathrm{~K}\left(850^{\circ} \mathrm{C}\right)$

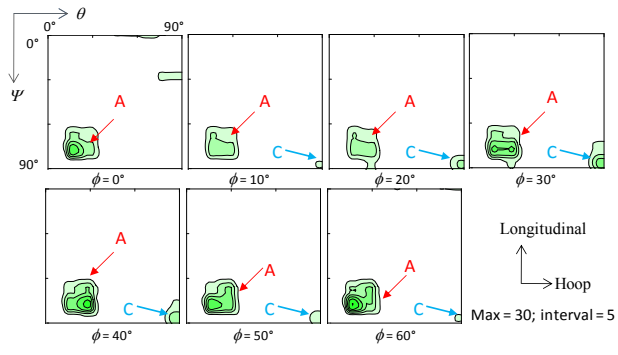

e) $1173 \mathrm{~K}\left(900^{\circ} \mathrm{C}\right)$ (cooling)

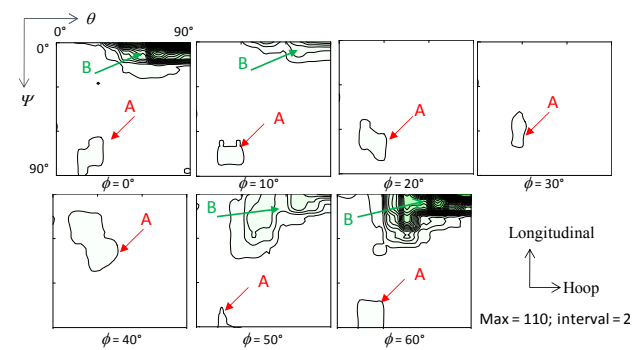

b) $1073 \mathrm{~K}\left(800^{\circ} \mathrm{C}\right)$

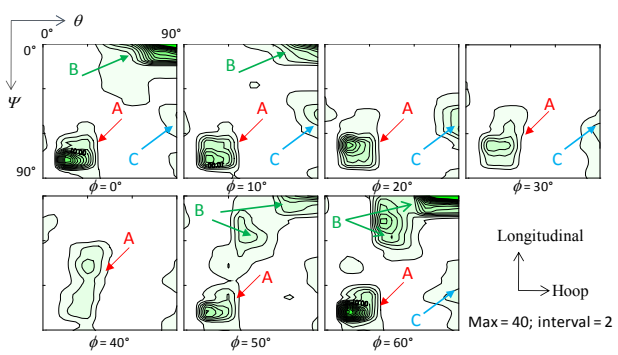

d) $1173 \mathrm{~K}\left(900^{\circ} \mathrm{C}\right)$

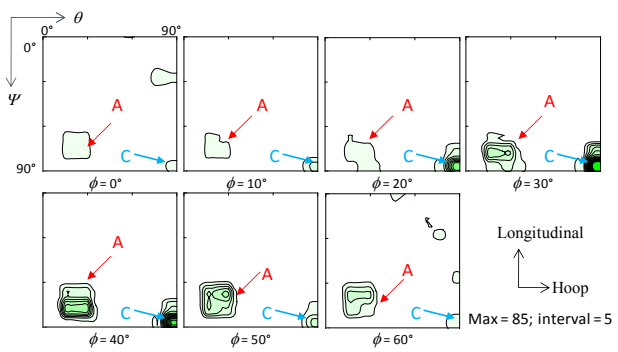

f) $823 \mathrm{~K}\left(550^{\circ} \mathrm{C}\right)$ (cooling)

Figure 4.12 ODF of hcp $\alpha-\mathrm{Zr}$ crystallites in as-received $\mathrm{Zr}-2.5 \mathrm{Nb}$ pressure tube on heating to a) $823 \mathrm{~K}\left(550^{\circ} \mathrm{C}\right)$, b) $1073 \mathrm{~K}\left(800^{\circ} \mathrm{C}\right)$, c) $1123 \mathrm{~K}\left(850^{\circ} \mathrm{C}\right)$, d) $1173 \mathrm{~K}\left(900^{\circ} \mathrm{C}\right)$. ODF on cooling (from after being heated at $1323 \mathrm{~K}\left(1050^{\circ} \mathrm{C}\right)$ ) are obtained at two temperatures: e) $1173 \mathrm{~K}$ $\left(900^{\circ} \mathrm{C}\right)$ (cooling), and f) $823 \mathrm{~K}\left(550^{\circ} \mathrm{C}\right)$ (cooling). A previously unobserved strong $\alpha$-phase texture component is revealed on heating at $1173 \mathrm{~K}\left(900^{\circ} \mathrm{C}\right)$ (indicated by the arrows, labelled A in the ODF). There is also a weak $\alpha$-phase texture component revealed on heating at $1173 \mathrm{~K}$ $\left(900^{\circ} \mathrm{C}\right.$ ) (indicated by arrows, labelled $\mathrm{C}$ in the $\mathrm{ODF}$ ). The labels Longitudinal and Hoop denote directions in the sample of pressure tube. 


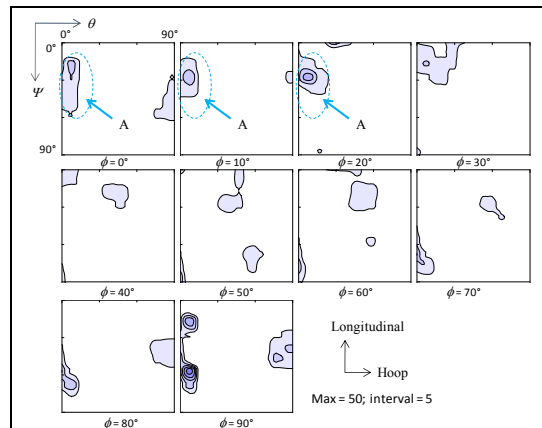

a) $823 \mathrm{~K}\left(550^{\circ} \mathrm{C}\right)$

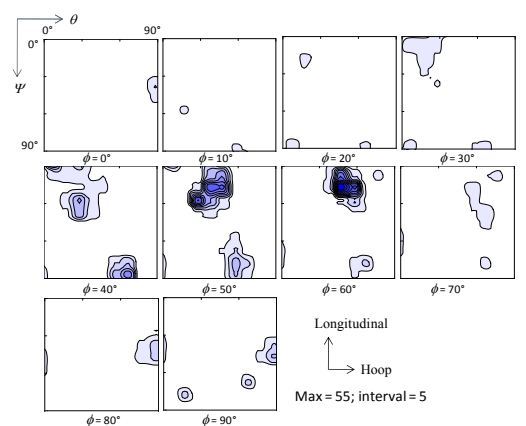

c) $1123^{\phi=80^{\circ}} \mathrm{K}\left(850^{\circ} \mathrm{C}\right)$

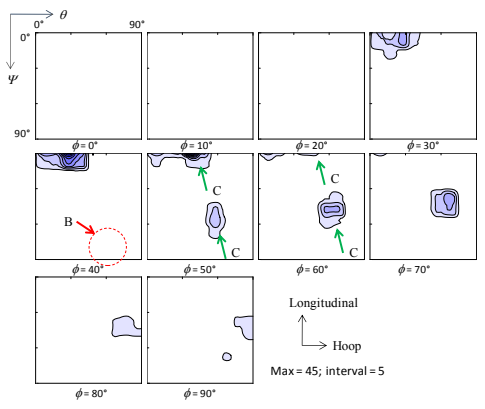

e) $1323 \mathrm{~K}\left(1050^{\circ} \mathrm{C}\right)$

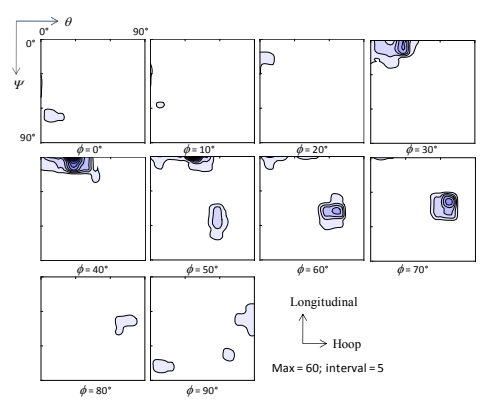

g) $823 \stackrel{\mathrm{K}}{\mathrm{K}}\left(550^{\circ} \mathrm{C}\right)$ (cooling)

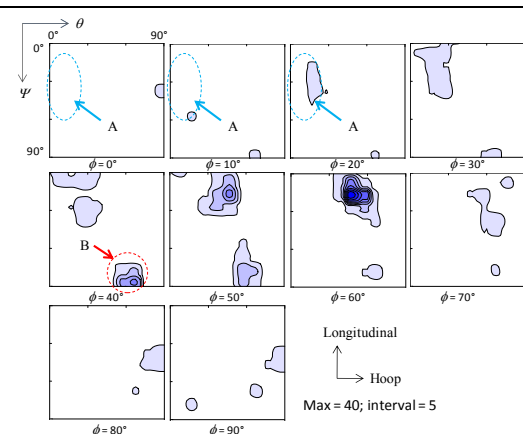

b) $1073 \mathrm{~K}\left(800^{\circ} \mathrm{C}\right)$

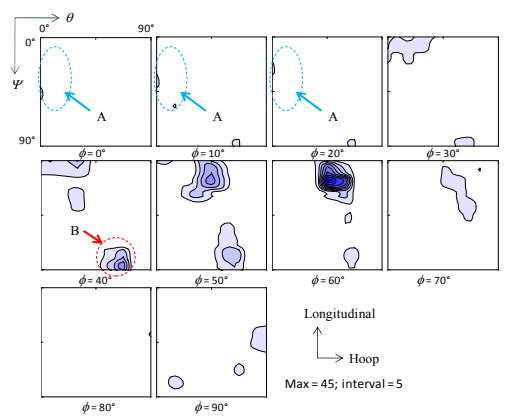

d) $1173 \mathrm{~K}\left(900^{\circ} \mathrm{C}\right)$

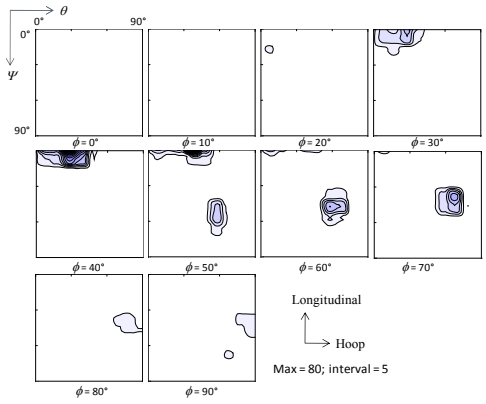

f) $1173^{\phi=80^{\circ}} \mathrm{K}\left(900^{\circ} \mathrm{C}\right)$ (cooling)

Figure 4.13 ODF of bcc

$\beta$-phase in as-received

$\mathrm{Zr}-2.5 \mathrm{Nb}$ pressure tube on heating at: a) $823 \mathrm{~K}\left(550^{\circ} \mathrm{C}\right)$,

b) $1073 \mathrm{~K}\left(800^{\circ} \mathrm{C}\right)$, c $) 1123$

$\left.\mathrm{K}\left(850^{\circ} \mathrm{C}\right), \mathrm{d}\right) 1173 \mathrm{~K}$ $\left(900^{\circ} \mathrm{C}\right)$ and e) $1323 \mathrm{~K}$ $\left(1050^{\circ} \mathrm{C}\right)$. ODF on cooling (after heating at $1323 \mathrm{~K}$ $\left.\left(1050^{\circ} \mathrm{C}\right)\right)$ are obtained at two temperatures: f) $1173 \mathrm{~K}$ $\left(900^{\circ} \mathrm{C}\right)$ (cooling) and g) 823 $\mathrm{K}\left(550^{\circ} \mathrm{C}\right)$ (cooling). The labels Longitudinal and Hoop denote the longitudinal and hoop directions in the sample. The arrows in the diagrams indicate where the volume fraction of crystallite orientations has changed on heating at different temperatures (with some disappearing - see arrows, labelled A; some appearing and disappear - see arrows, labelled B, and some had reoriented - see arrows, labelled C). 


\subsubsection{Post-test microstructure after first heating and cooling:}

Figure 4.14 shows the post-test grain structure in the as-received $\mathrm{Zr}-2.5 \mathrm{Nb}$ pressure tube sample that had completed the neutron diffraction measurements during heating at eight different temperatures $\left[373 \mathrm{~K}\right.$ to $1323 \mathrm{~K}\left(100^{\circ} \mathrm{C}\right.$ to $\left.\left.1050^{\circ} \mathrm{C}\right)\right]$ and cooling [1173 $\mathrm{K}$ and $823 \mathrm{~K}\left(900^{\circ} \mathrm{C}\right.$ and $\left.\left.550^{\circ} \mathrm{C}\right)\right]$. Since the heating and cooling of the sample was done at a rate of $20 \mathrm{~K} / \mathrm{min}\left(20^{\circ} \mathrm{C} / \mathrm{min}\right)$, the resulting microstructure on cooling is composed of Widmanstätten $\alpha$ plates, as expected. As seen in Figure $4.14 \mathrm{~b}$, the $\alpha$ platelets appeared to have been nucleated at the prior $\beta$-grain boundaries. The resulting texture and multiplicity of orientation of the $\alpha$-platelets (Figure 4.14b) following the $\alpha \rightarrow$ $\beta \rightarrow \alpha$ transformation is dependent on the variant selection mechanism occurring during the phase transformation on cooling [4.4],[4.8],[4.28]. There are 24 rotational symmetry elements for a bcc $\beta$ lattice, giving 24 variants, and the variants are reduced to 12 distinct variants when the Burgers orientation relationship is taken into account. A shape change also occurs as a result of lattice transformation from $\beta \rightarrow \alpha$ with a small contraction $(\sim 2 \%)$ along the c-axis of the hep $\alpha-\mathrm{Zr}$, and about $10 \%$ contraction along the $<10 \overline{1} 0>$ and about $10 \%$ expansion along the $\langle 11 \overline{2} 0\rangle$ direction; the strains are reversed with the transformation of $\alpha$ to $\beta$ [4.8],[4.28]. A macroscopic observation of the prior $\beta$ grains as shown in Figure 4.14a, suggests that they are about $300 \mu \mathrm{m}$ in diameter. 

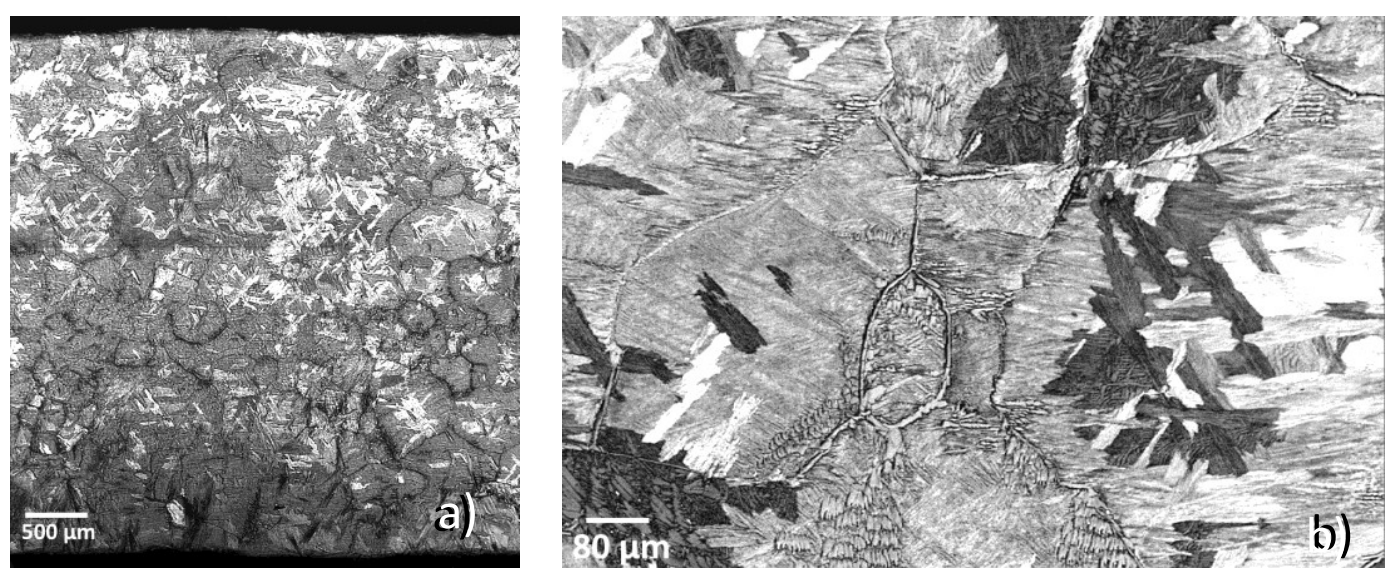

Figure 4.14 Optical micrographs of post-test sample of an as-received $\mathrm{Zr}-2.5 \mathrm{Nb}$ pressure tube after heating and cooling showing the through-wall microstructure (a) and at higher magnification showing prior $\beta$ grain boundaries and Widmanstätten $\alpha$ plates within the prior $\beta$ grains (b).

\subsection{Conclusions}

The main conclusions drawn from this study are:

1. The volume fraction of $\beta$ phase estimated from this study showed that the volume fraction started to increase sharply on heating above $883 \mathrm{~K}\left(610^{\circ} \mathrm{C}\right)$ and reached $100 \%$ at an estimated temperature of about $1233 \mathrm{~K}\left(960^{\circ} \mathrm{C}\right)$.

2. When an as-received $\mathrm{Zr}-2.5 \mathrm{Nb}$ pressure tube material is initially heated to high temperatures consisting of full $\beta$-phase regime, a previously unobserved strong $\alpha$-phase texture component appears during heating at $1173 \mathrm{~K}\left(900^{\circ} \mathrm{C}\right)$ due to coarsening of prior 'primary' $\alpha-\mathrm{Zr}$ grains, as the texture intensity of the remaining $\alpha$-phase had decreased. 
3. The pole figure at $1173 \mathrm{~K}\left(900^{\circ} \mathrm{C}\right)$ shows the appearance of the new $\alpha$-phase texture component. The complete description of the orientations of the prior 'primary' $\alpha$-phase texture component is clearly revealed in the ODF plots.

4. The transformation of bcc $\beta$-phase to the hep $\alpha$-phase upon cooling from $1323 \mathrm{~K}$ $\left(1050^{\circ} \mathrm{C}\right.$ ) (in the full $\beta$ phase regime) approximately followed the Burgers orientation relationship. The transformed $\alpha$-phase texture appears to show a "memory" of the precursor texture of the 'primary' $\alpha-\mathrm{Zr}$ grains before they were completely transformed to the $\beta$ phase when heated to $1323 \mathrm{~K}\left(1050^{\circ} \mathrm{C}\right)$.

5. The $\beta$-phase goes through three evolutions of texture during heating that can be attributed to an increasing volume fraction of the transformed $\beta$ phase, the cusping of the (transformed) $\beta$-phase as the $\beta$ phase cusps penetrate into the $\alpha / \alpha$ grain boundaries to develop equiaxed-shaped 'primary' $\alpha-\operatorname{Zr}$ grains and then evolve again as the 'primary' $\alpha-\mathrm{Zr}$ grains transformed completely into $\beta$-phase when heating continued into the full $\beta$-phase field.

\section{References}

[4.1] B.A. Cheadle: Journal of ASTM International, 2010, Vol. 7, No. 8, Paper ID JAI103057

[4.2] J.P. Abriata and J.C. Bolcich: Bull. Alloy Phase Diagrams, 1982, Vol. 3, No. 1, pp. 34-44.

[4.3] P. Gangli, J. Root and R. Fong: Can. Metall. Quart., 1995, 34:211-218.

[4.4] J. Romero, M. Preuss and J. Quinta Da Fonseca: Acta Mater., 2009, 57:5501-5511.

[4.5] H.R. Wenk, I. Lonardelli and D. Williams: Acta Mater., 2004, 52:1899-1907. 
[4.6] N. Gey, E. Gautier, M. Humbert, A. Cerqueira, J.L. Bechade and P.J. Archambault: J. Nucl. Mater., 2002, 302:175-184.

[4.7] J.P. Abriata, J.C. Bolcich and D. Arias: Bull. Alloy Phase Diagrams, 1983, 4(2), pp. 2087-2089.

[4.8] M.R. Daymond, R.A. Holt, S. Cai, P. Mosbrucker and S.C. Vogel: Acta Mater., 2010, 58:4053-4066.

[4.9] W.G. Burgers: Physica I, 1934, pp. 561-586.

[4.10] M. Griffiths, J.E. Winegar and A. Buyers: J. Nucl. Mater., 2008, 383:28-33.

[4.11] S.A. Aldridge and B.A. Cheadle: J. Nucl. Mater., 1972, 42:32-42.

[4.12] S.C. Vogel, C. Hartig, L. Lutterotti, R.B. Von Dreele, H.R. Wenk

and D.J. Williams: International Centre for Diffraction Data, Advances in X-ray Analysis, 2004, 47:431-436.

[4.13] H.R. Wenk, L. Lutterotti and S.C. Vogel: Nucl. Instrum. Methods Phys. Res., 2003, A515, pp. 575-588.

[4.14] R.W.L. Fong, H. Saari, R. Miller, J. Teutsch and S.C. Vogel: presented at Thermec'2011 conference, Quebec City, 2011 August 1-5.

[4.15] H.R. Wenk, L. Lutterotti and S.C. Vogel: J. Powder Diffraction, 2010, Vol. 25, No. 3 (14 pp.).

[4.16] S. Matthies, L. Lutterotti and H.R. Wenk: J. Appl. Crystallogr., 1997, 30: 31-42.

[4.17] S. Matthies, J. Pehl, H.R. Wenk and S. Vogel: J. Appl. Crystallogr., 2005, 38:462-475.

[4.18] L. Lutterotti, D. Chateigner, S. Ferrari and J. Ricote: Thin Solid Films, 2004, 450:34.

[4.19] H.R. Wenk: Preferred Orientation in Metals and Rocks, H.-R. Wenk, ed., Academic Press, 1985, pp. 11-47.

[4.20] D.L. Douglass: The Metallurgy of Zirconium, Atomic Energy Review Supplement 1997, International Atomic Energy Agency, Vienna.

[4.21] J. Goldak, L.T. Lloyd and C.S. Barrett: Physical Review, 1966, Vol. 144, No. 2, pp. 478-484.

[4.22] A. Heiming, W. Petry, J. Trampenau, W. Miekeley and J. Cockcroft: J. Phys., Condens. Mater., 1992, 4, pp. 727-733.

[4.23] R. Choubey and J.A. Jackman: Metall. and Mater. Trans A, 1996, Vol. 27A, pp. 431-440.

[4.24] I.T. Bethune and C.D. Williams: J. Nucl. Mater., 1968, 29:129-132.

[4.25] D.O. Northwood and W.L. Fong: Metallography, 1980, 13:97-115. 
[4.26] G.J. Davies, D.J. Goodwill and J.S. Kallend: J. Appl. Crystallogr., 1970, 4:193-196.

[4.27] M. Griffiths, R.A. Holt, J. Li, S. Saimoto: Microstruct. Sci., 1999, ASM Int. 26:293-302.

[4.28] M. Humbert and N. Gey, Elasticity-based model of the variant selection observed in the $\beta$ to $\alpha$ phase transformation of a Zircalloy-4 sample, Acta Mater., 2003, 51:4783-4790. 


\section{Chapter 5}

\section{Anisotropic Deformation of $\mathrm{Zr}-2.5 \mathrm{Nb}$ Pressure Tube Material at High Temperatures}

(Manuscript of paper is in press, J. Nucl. Mater., 2013)

http://dx.doi.org/10.1016/j.jnucmat.2013.01.308)

Cover Introduction: This manuscript presents the results of an evaluation to help further understand how the stable texture evolution and the changes in volume fraction of the $\beta$-phase observed in the as-manufactured $\mathrm{Zr}-2.5 \mathrm{Nb}$ pressure tube material during heating to high temperatures up to $1050^{\circ} \mathrm{C}$ (Chapter 4) account for the anisotropic deformation behaviour that has been observed in high temperature-ramped tensile tests obtained on as-manufactured pressure tube materials.

\footnotetext{
$\underline{\text { Abstract }}$

$\mathrm{Zr}-2.5 \mathrm{Nb}$ alloy is used for the pressure tubes in $\mathrm{CANDU}^{\circledR}$ reactor fuel channels. In reactor, the pressure tube normally operates at $300^{\circ} \mathrm{C}$ and experiences a primary coolant fluid internal pressure of approximately $10 \mathrm{MPa}$. Manufacturing and processing procedures generate an anisotropic state in the pressure tube which makes the tube stronger in the hoop (transverse) direction than in the axial (longitudinal) direction. This anisotropy condition is present for temperatures less than $500^{\circ} \mathrm{C}$. During postulated accident conditions where the material temperature could reach $1000^{\circ} \mathrm{C}$, it might be
} 
assumed that the high temperature and subsequent phase change would reduce the inherent anisotropy, and thus affect the deformation behaviour (ballooning) of the pressure tube. From constant-load, rapid-temperature-ramp, uniaxial deformation tests, the deformation rate in the longitudinal direction of the tube behaves differently than the deformation rate in the transverse direction of the tube. This anisotropic mechanical behaviour appears to persist at temperatures up to $1000^{\circ} \mathrm{C}$. This paper presents the results of high-temperature deformation tests using longitudinal and transverse specimens taken from as-received $\mathrm{Zr}-2.5 \mathrm{Nb}$ pressure tubes. It is shown that the anisotropic deformation behaviour observed at high temperatures is largely due to the stable crystallographic texture of the $\alpha-\mathrm{Zr}$ phase constituent in the material that was previously observed by neutron diffraction measurements during heating at temperatures up to $1050^{\circ} \mathrm{C}$. The deformation behaviour is also influenced by the phase transformation occurring at high temperatures during heating. The effects of texture and phase transformation on the anisotropic deformation of as-received $\mathrm{Zr}-2.5 \mathrm{Nb}$ pressure tube material are discussed in the context of the tube ballooning behaviour. Because of the high temperatures in postulated accident scenarios, any irradiation damage will be annealed from the pressure tube material and thus the un-irradiated material results presented in this paper are also applicable to irradiated pressure tubes. 


\subsection{Introduction}

$\mathrm{Zr}-2.5 \mathrm{Nb}$ alloy is used for the pressure tubes in $\mathrm{CANDU}^{\circledR 3}$ reactor fuel channels. The fuel channels are horizontal. Each channel has an inner $\mathrm{Zr}-2.5 \mathrm{Nb}$ pressure tube containing the nuclear fuel and pressurized heavy water coolant, and an outer Zircaloy-2 calandria tube that isolates it from the cool heavy water moderator. The two tubes are separated using spacers and the annulus space is filled with dry circulating $\mathrm{CO}_{2}$ (Figure 5.1) $[5.1]$

The $\mathrm{Zr}-2.5 \mathrm{Nb}$ pressure tubes are fabricated using the following manufacturing steps: quadruple melt ingot; forge to bar; machine hollow billets; preheat billets to $815^{\circ} \mathrm{C}$ and extrude into tubes; cold-draw 25-30\% (in two wall-thickness reductions); and stress relieve in steam-autoclave for $24 \mathrm{hr}$ at $400^{\circ} \mathrm{C}$ (which also introduces a protective oxide layer on the inside and outside surface of the tube) [5.2]. The microstructure of the finished pressure tube consists of elongated hexagonal close-packed (hcp) $\alpha$-Zr grains containing a high dislocation density and a thin layer of body-centred cubic (bcc) $\beta$ phase at the $\alpha$-grain boundaries (Figure 5.2) [5.2]. Small quantities of meta-stable $\omega$ phase may

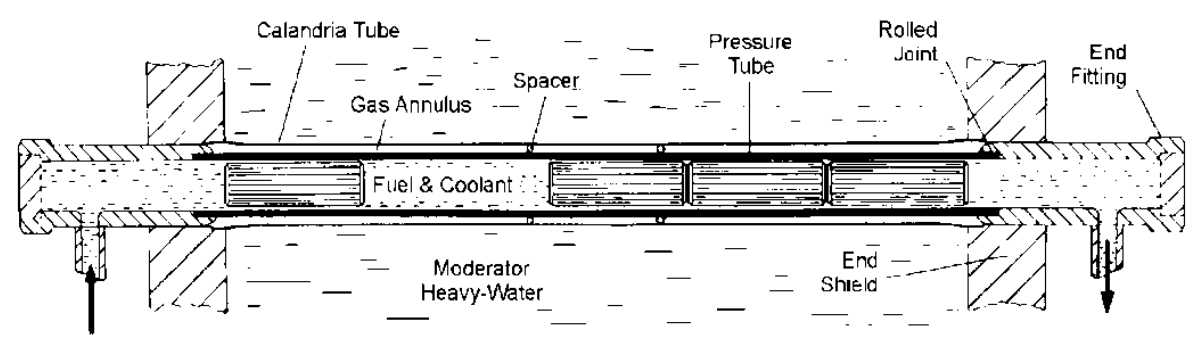

Figure 5.1 Schematic diagram of a CANDU fuel channel. (This figure first appeared in Figure 1.1)

${ }^{1} \mathrm{CANDU}^{\circledR}$ (CANada Deuterium $\left.\underline{\text { Uranium}}\right)$ is a registered trademark of Atomic Energy of Canada Limited. 
also exist in the material, depending on the thermo-mechanical history [5.3],[5.4]. The fabrication procedures used to produce the pressure tubes generate a strong crystallographic texture (Figure 5.3), and results in anisotropic mechanical properties in the pressure tube materials [5.2],[5.5],[5.6]. The crystallographic texture of the deformed $\alpha-\mathrm{Zr}$ grains exhibits a large concentration of the basal (0002) plane normals aligned in the hoop $(\mathrm{H})$ direction of the tube, and with the prism $(11 \overline{2} 0)$ poles oriented in the tube's radial $(\mathrm{R})$ direction [5.7]. The crystallographic textures are developed mainly during high-temperature extrusion of the billet to form the pressure tube [5.2].

In the reactor, the pressure tube normally operates at $300^{\circ} \mathrm{C}$ with a primary coolant fluid internal pressure of about $10 \mathrm{MPa}$. During a hypothetical loss-of-coolant accident (LOCA), the pressure tube may overheat to $1000^{\circ} \mathrm{C}$ and, during heating deform

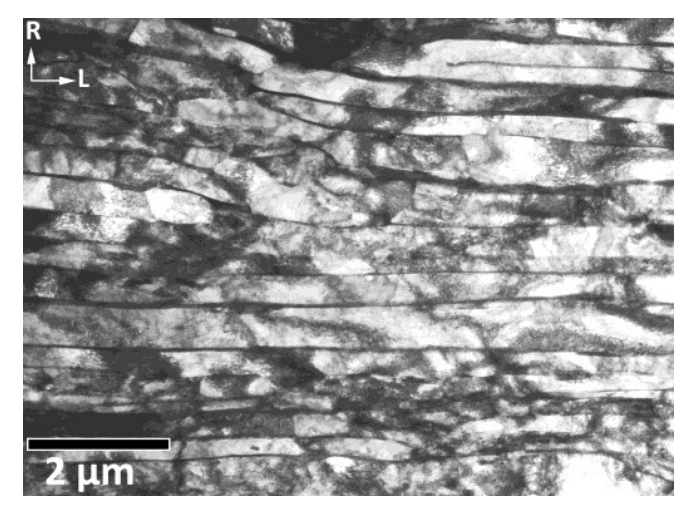

Figure 5.2 TEM micrograph of as-received $\mathrm{Zr}-2.5 \mathrm{Nb}$ pressure tube. (This figure first appeared in Figure 1.3) 
Figure $5.3 \alpha$-phase (0002) and (112̄0) pole figures for as-received $\mathrm{Zr}-2.5 \mathrm{Nb}$ pressure tube at room temperature [5.7]. (This figure first appeared in Figure 1.4)
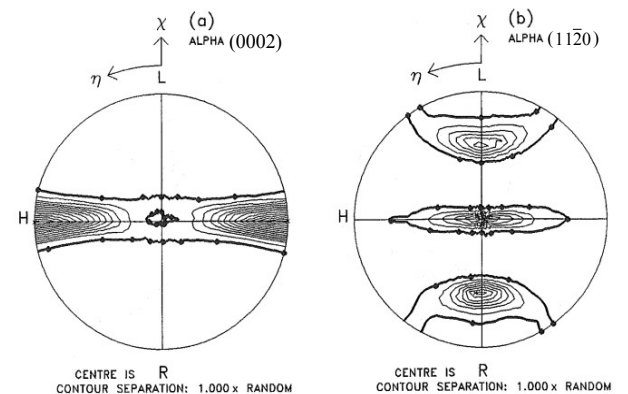

by ballooning into contact with its surrounding moderator-cooled calandria tube. During contact the excess heat is safely transferred into the moderator heat sink. The small annulus gap between the pressure tube and calandria tube allows a uniformly deforming pressure tube to quickly come into contact with its calandria tube at nearly $18 \%$ circumferential strain. The ballooning deformation of the pressure tube occurs under a residual internal pressure during a LOCA. The pressure tube deformation occurs biaxially, and most of the deformation occurs in the circumferential (hoop) direction of the tube [5.8].

As a result of the anisotropic state in an as-manufactured pressure tube at room temperature, predominantly due to its crystallographic texture [5.3], the tube material is much stronger in the hoop (circumferential) direction than in the axial (longitudinal) direction [5.2],[5.5],[5.6]. The strength of the pressure tubes is also increased with operating exposure to fast neutrons in a reactor [5.9]. When a pressure tube is heated to high temperatures the microstructure of the material (i.e., crystallographic texture, volume fraction of the phase constituents, and their grain shape and structure) evolves with the temperature changes. The microstructural changes occurring during the hightemperature heating are expected to influence the material's deformation behaviour. The 
room-temperature crystallographic texture and mechanical anisotropy in the pressure tube material is expected to be present during deformation under rapid-temperature-ramp excursions for some LOCA scenarios.

This paper presents experimental data obtained separately for high-temperature characterization of phase transformation and uniaxial deformation in $\mathrm{Zr}-2.5 \mathrm{Nb}$ pressure tube materials. The previous results compared the deformation of irradiated pressure tubes and their unirradiated pressure tube materials [5.10] are also discussed in this paper. The results for crystallographic texture and beta-phase fraction previously obtained at high temperatures have been incorporated in this paper to provide explanations for the anisotropic deformation behaviour observed in uniaxial testing of longitudinal and transverse tensile specimens.

\subsection{Crystallographic texture and volume fraction of $\alpha$ and $\beta$ phase in $\mathrm{Zr}-2.5 \mathrm{Nb}$ pressure tube material [5.11]}

The phase transformations in an as-manufactured $\mathrm{Zr}-2.5 \mathrm{Nb}$ pressure tube material have been characterized in detail previously by neutron diffraction at the Los Alamos Neutron Science Center [5.11]. The textures and volume fractions of $\alpha$ - and $\beta$-phase were measured on heating at eight different temperatures $\left(100^{\circ} \mathrm{C}\right.$ to $\left.1050^{\circ} \mathrm{C}\right)$ and also upon cooling $\left(900^{\circ} \mathrm{C}\right.$ and $\left.550^{\circ} \mathrm{C}\right)$, traversing across the $\alpha /(\alpha+\beta)$ and $(\alpha+\beta) / \beta$ solvus lines along the $\mathrm{Zr}-2.5 \mathrm{Nb}$ composition ([5.4]).

The sample examined in this study was from an as-received standard $\mathrm{Zr}-2.5 \mathrm{Nb}$ pressure tube. The chemical composition specification for this pressure tube is $2.52-2.57$ 
wt $\% \mathrm{Nb}, 1190-1220 \mathrm{ppm} \mathrm{O,} \mathrm{350-410} \mathrm{ppm} \mathrm{Fe} \mathrm{and} \mathrm{the} \mathrm{balance} \mathrm{Zr.} \mathrm{The} \mathrm{sample} \mathrm{volume}$ evaluated by neutron diffraction was approximately $640 \mathrm{~mm}^{3}$. Details of the measurements and analysis of texture and volume fraction for $\alpha$ and $\beta$ phases are described in [5.11] for the anisotropic deformation behaviour observed in $\mathrm{Zr}-2.5 \mathrm{Nb}$ pressure tube materials during high-temperature deformation tests. Figure 5.5 shows the heating portion of the texture results. As previously evaluated [5.11], the results indicate that the $\alpha$-phase texture is quite stable, with little change observed in the $\{0002\}$ and $\{11 \overline{2} 0\}$ pole figures during heating to $850^{\circ} \mathrm{C}$. Further heating to $900^{\circ} \mathrm{C}$ revealed a previously unobserved $\alpha$-phase texture component due to coarsening of the prior 'primary' $\alpha$-grains, while the transformed $\beta$-phase texture evolved markedly. The $\alpha$-phase disappeared on further heating to $1050^{\circ} \mathrm{C}$, resulting in a $100 \% \beta$ phase.

Figure $5.4 \mathrm{Zr}-\mathrm{Nb}$ phase diagram [5.12]. The red dots correspond to the temperatures used in neutron diffraction

[5.11]. (This figure first appeared in Figure 3.2)

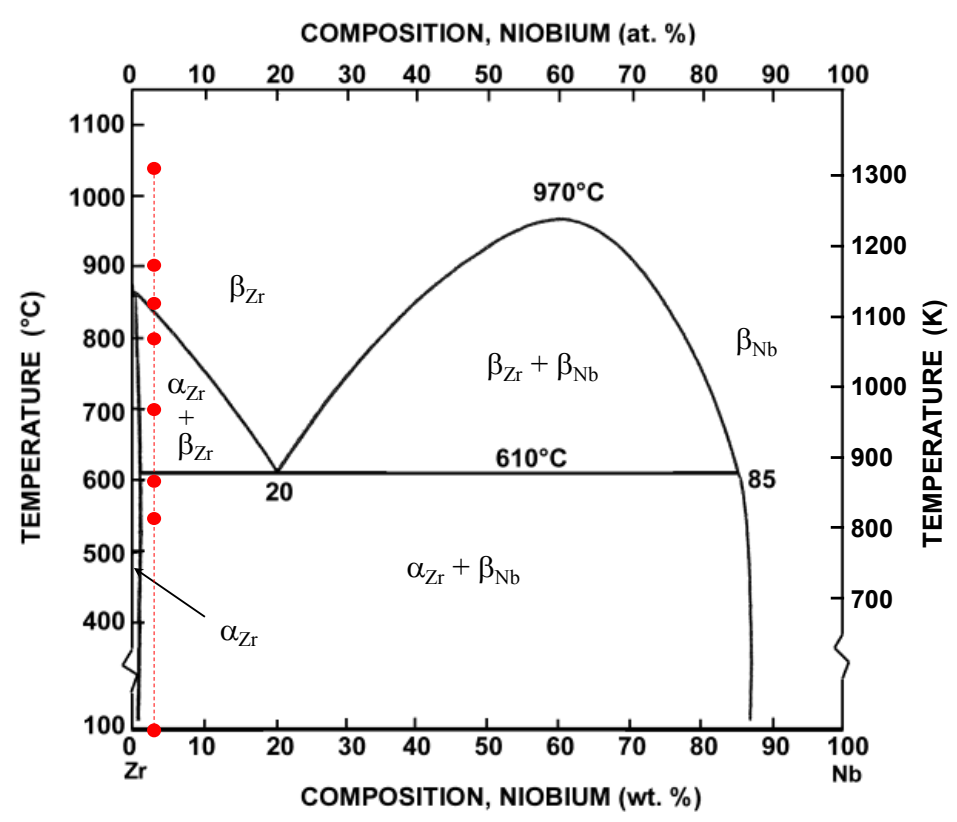




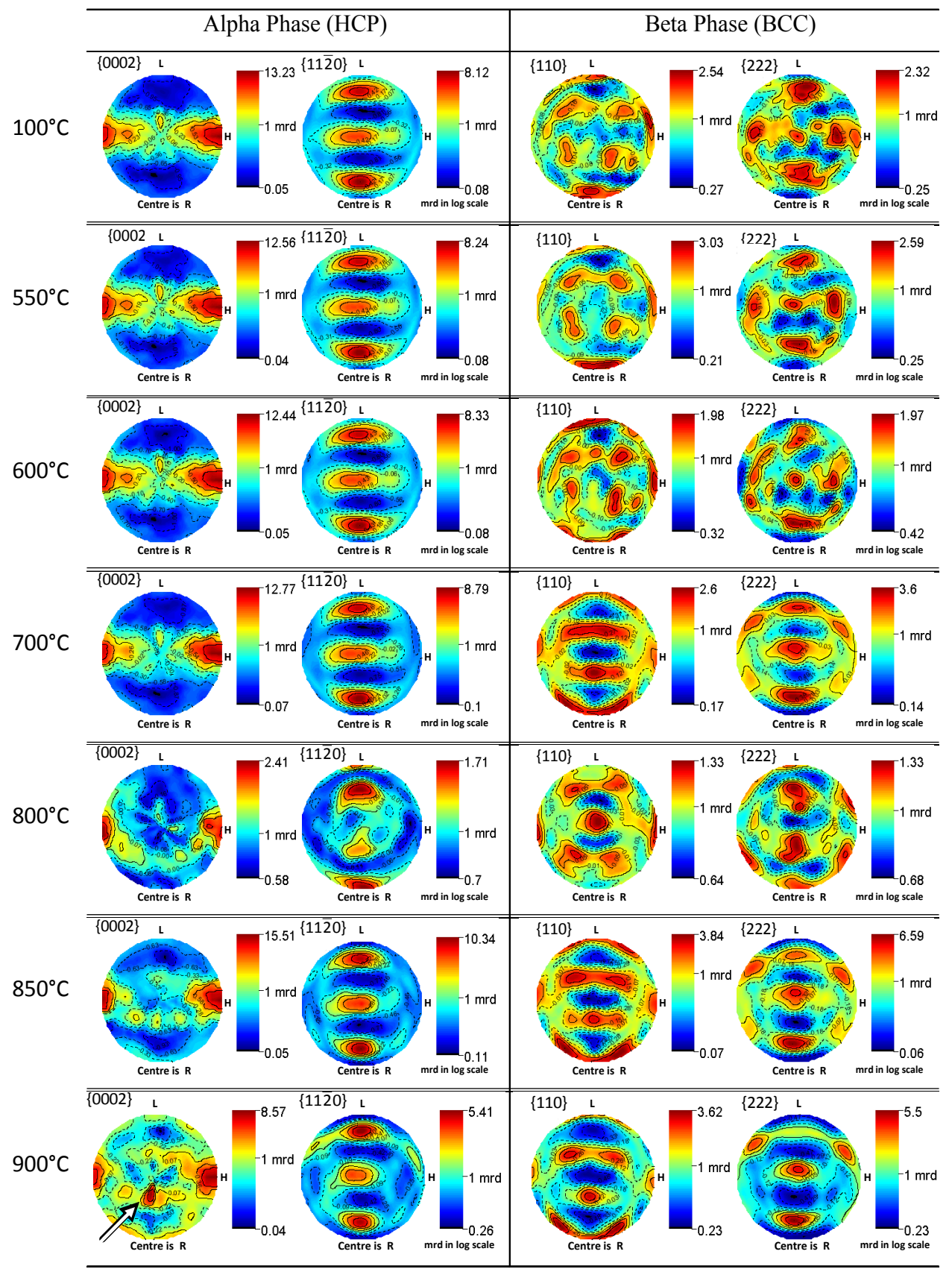

Figure 5.5 Pole figures for alpha and beta phase measured on an as-manufactured $\mathrm{Zr}-2.5 \mathrm{Nb}$ pressure tube material during heating. The "arrow" label in the pole figure for (hcp) alpha at $900^{\circ} \mathrm{C}$ indicates a previously unobserved $\alpha$-phase texture component due to coarsening of the prior 'primary' $\alpha$-grains (taken from [5.11]). (This figure first appeared in Figure 4.9) 
Figure 5.6 shows the $\beta$-phase volume fraction, where the amount of transformed $\beta$-phase increases sharply as the temperature goes just above the $\alpha /(\alpha+\beta)$ transus estimated at $610^{\circ} \mathrm{C}$. At about $810^{\circ} \mathrm{C}$ there is an equal proportion of $\beta$ and $\alpha$ phase, and the $(\alpha+\beta) / \beta$ transus is estimated from the fit to be at about $960^{\circ} \mathrm{C}$.

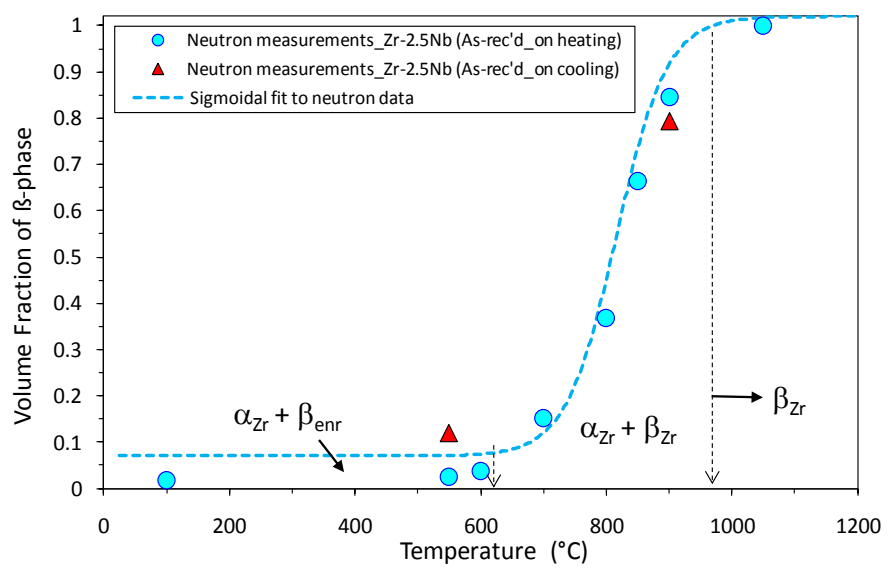

Figure 5.6 Volume fraction of $\beta$ phase obtained from neutron diffraction measurements on as-manufactured $\mathrm{Zr}-2.5 \mathrm{Nb}$ pressure tube material [5.11].

(This figure first appeared in Figure 4.8)

\subsection{Constant-load, rapid-temperature-ramp deformation tests}

Uniaxial tensile specimens were cut from the pressure tube in both the transverse and longitudinal directions of the tube. No straightening of the pressure tube is required to obtain the specimens, and this avoids changing the microstructure of the material. The gauge section of the specimens was $10 \mathrm{~mm}$ long x $6 \mathrm{~mm}$ wide x $3.5 \mathrm{~mm}$ (wall) thickness.

The mid-plane of the specimen was instrumented with two Type-K thermocouples (TC1 and TC2), Figure 5.7, that were spot-welded on the wide face of the specimen 
[5.10]. It has been observed that the spot-welded thermocouples do not preferentially produce a localization of necking of the tensile specimen during the test. The thermocouples were attached on the same plane as the linear variable displacement transducer (LVDT) extension rods so that the temperature and strains at the same locations could be measured simultaneously. The specimen was heated rapidly by passing an AC current through it. One of the thermocouples was used for temperature control to obtain a linearly-ramped temperature on the specimen. The instantaneous average temperature of the specimen was calculated from the two thermocouples and was used to calculate the heating rate of the specimen and the temperature of the specimen at $18 \%$ strain. The thermocouple wires were $0.2-\mathrm{mm}$ in diameter, Teflon insulated, Type-K (chromel-alumel) supplied by OMEGA Engineering Company. These thermocouple wires were "special limits of error" grade with a guaranteed error limit of $\pm 1.1^{\circ} \mathrm{C}$ or $\pm 0.4 \%$ (whichever is greater). The maximum uncertainty at $800^{\circ} \mathrm{C}$ was estimated to be $\pm 6.3^{\circ} \mathrm{C}$, including instrumentation uncertainty and positioning uncertainty. 
Figure 5.7 Diagram showing a sectional and side view of the specimen with the locations of thermocouples and LVDT rods used for measuring the width and thickness on the same plane during the test [5.10].

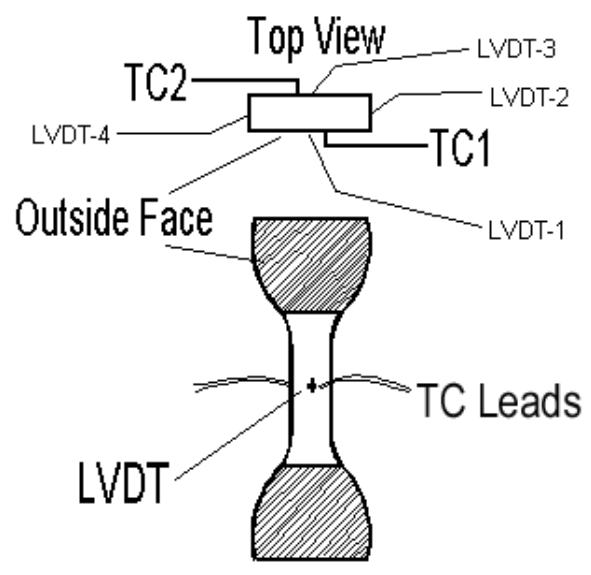

Figure 5.8 shows the set-up used for constant-load, rapid-temperature-ramp deformation tests. The apparatus is mounted on a MTS tensile testing machine which is programmed to apply and maintain a constant tensile load on the specimen. The MTS machine was able to maintain a constant load on the specimen up to $30 \%$ axial strain. The grips were constructed so that the centreline axis of the specimen coincides with the centre of the pull rod to eliminate bending of the specimen during the test. The misalignment of the broken specimen, as seen in Figure 5.8 is a result of the contact pressure from the LVDT rods, pushing on broken sample and causing it to be deflected. 
Figure 5.8 Photographs showing the test setup for the start (a) and end (b) of test [5.10].

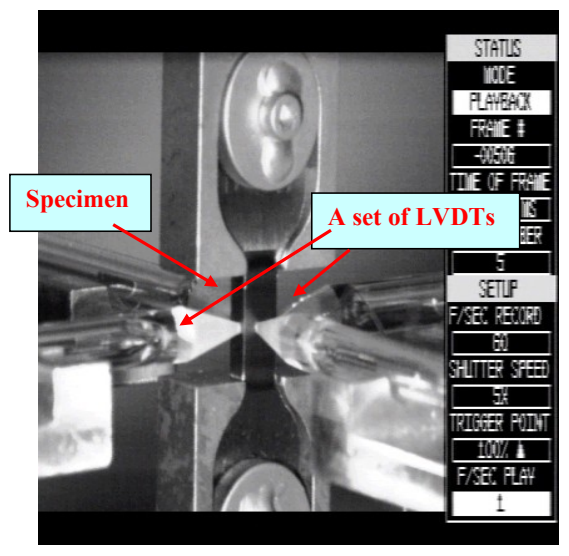

a) At start of high temperature ramp test.

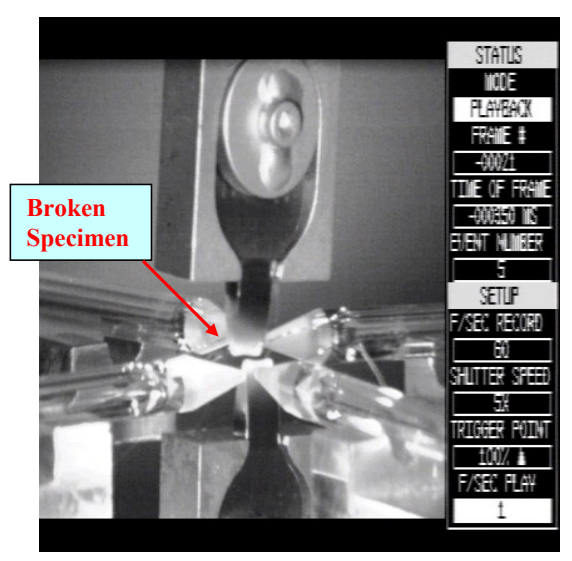

b) At end of test.

The strains in the two principal directions perpendicular to the tensile direction of the specimen were measured using two sets of LVDTs, developed by Shewfelt et al. [5.8]. Four quartz rods, with low thermal expansion coefficient and low thermal conductivity, were used as the LVDTs extensions that were in contact with the specimen. The tips of the quartz rods were narrowed to $1 \mathrm{~mm}$ in diameter. A slight air pressure (10 psi) held the rods on the specimen surface without deforming the specimen. The signals from the LVDTs were fed to the data acquisition system and converted to distance travelled by the LVDT core. The uncertainty in the displacement measurement was $\pm 0.01 \mathrm{~mm}$. 
The true strains in each of the principal directions were calculated using:

$$
\varepsilon_{l}=\ln \left(l / l_{o}\right)
$$

where $l$ and $l_{o}$ are the instantaneous dimension and the original dimension in that direction, respectively.

For the transverse specimen, the axial strain in the tensile direction, assuming constant volume, is calculated using:

$$
\varepsilon_{\text {trans }}=-\left(\varepsilon_{r}+\varepsilon_{l}\right)
$$

where $\varepsilon_{r}$ and $\varepsilon_{l}$ are strains in the radial and longitudinal direction of the pressure-tube, respectively. These strains are the thickness strain $\left(e_{T}\right)$ and width strain $\left(e_{w}\right)$ in the longitudinal specimen.

For the longitudinal specimen, the axial strain in the tensile direction, assuming constant volume, is calculated using:

$$
\varepsilon_{\text {long }}=-\left(\varepsilon_{r}+\varepsilon_{t}\right)
$$

where $\varepsilon_{r}$ and $\varepsilon_{t}$ are strains in the radial and transverse direction of the pressure-tube, respectively. These strains are the thickness strain $\left(e_{T}\right)$ and width strain $\left(e_{W}\right)$ in the transverse specimen.

The contractile strain ratio (CSR), indicates the response of mechanical anisotropy which is related to the texture, is defined as:

$$
C S R=e_{W} / e_{T}
$$


A high CSR value (>>1) indicates a pronounced mechanical anisotropy which indicates a strong texture. A CSR value of close to unity (1) suggests that there is little or no mechanical anisotropy to be expected.

\subsection{Results of deformation tests for transverse and longitudinal specimens}

Figure 5.9 shows results for the width and thickness (contractile) strains measured in a transverse specimen and the tensile axial strains calculated using the contractile strains (Eqn. 5.2). Also plotted in the same figure are the instantaneous contractile strain ratio (Eqn. 5.4) and the temperature-ramp history for the specimen.

Contractile strains were detected as the temperature started to exceed $650^{\circ} \mathrm{C}$, and these contributed to increasing the axial strain in the tensile direction of the specimen. The width and thickness strain both increased gradually. On heating to about $815^{\circ} \mathrm{C}$, the contractile strain ratio increased up to a maximum value of about 3.3 at about $8 \%$ axial strain and decreased to a value of 2.9 at $18 \%$ axial strain. The width and thickness strain had increased further with the width strain increasing much faster than the thickness strain. Consequently, the increase in axial strain had occurred with an increased rate. At $18 \%$ axial strain the specimen had reached a ramp-temperature of $849^{\circ} \mathrm{C}$. The time to reach the temperature at $18 \%$ axial strain starting from $300^{\circ} \mathrm{C}$ was determined to be 43.6 s. Similarly, the results for longitudinal specimen (tested under same test conditions as those used in the transverse specimen) are shown Figure 5.10 The instantaneous contractile strain ratio and the rapid-temperature-ramp history are also 
shown in the same figure. When the specimen temperature started to exceed $650^{\circ} \mathrm{C}$, contractile strains were detected contributing to increasing values for the tensile axial strain and contractile strain ratio. The width and thickness strain both increased gradually. On heating to about $790^{\circ} \mathrm{C}$, the contractile strain ratio increased to a maximum value of 1.9 at about $1 \%$ axial strain, and with further heating the value decreased gradually to about 1.0 at $893^{\circ} \mathrm{C}$ for $18 \%$ axial strain. The width and thickness strain both continued to increase gradually and with little difference in magnitude between the two. Consequently, the increase in axial strain had occurred at a slow rate. The time to reach the temperature at $18 \%$ axial strain starting from $300^{\circ} \mathrm{C}$ was determined for the longitudinal specimen to be $46.9 \mathrm{~s}$.

Figure 5.9 Tensile axial strain (stressing direction) and contractile strains (width and thickness directions) for transverse specimen tested at 25 $\mathrm{MPa}$ and heating rate of $14^{\circ} \mathrm{C} / \mathrm{s}$.

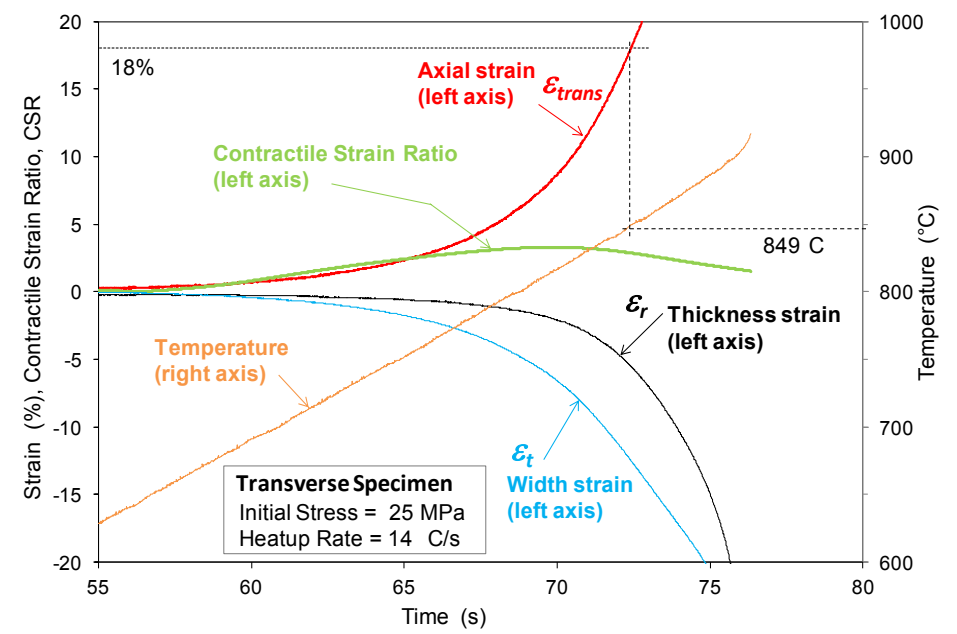


Figure 5.10 Tensile axial strain

(stressing direction) and contractile strains (width and thickness directions) for longitudinal specimen tested at 25 $\mathrm{MPa}$ and heating rate of $14^{\circ} \mathrm{C} / \mathrm{s}$.

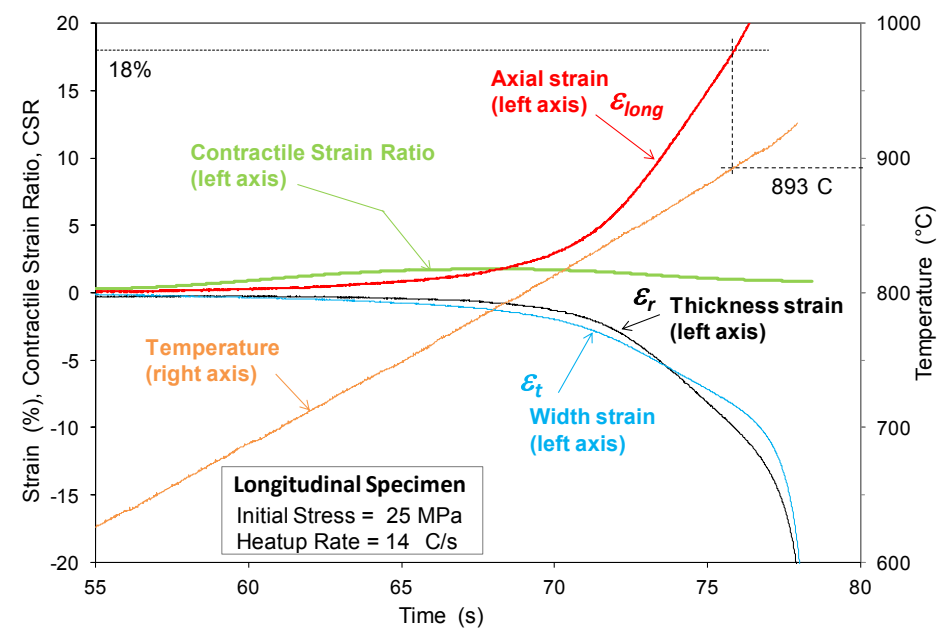

\subsubsection{Contractile strain ratio (CSR) and ramp-temperature as a function of tensile axial strain}

Figure 5.11 shows a different plot for the contractile strain ratio (CSR) as a function of tensile axial strain in the transverse and longitudinal specimens (tested with same conditions of initial stress and heating rate). The ramp-temperature history for the specimen tested is also plotted as a function of their axial-strain history in the same figure. As shown in Figure 5.11, the CSR value for transverse specimen increased from small initial tensile deformation to $2 \%$ axial strain. The CRS then continued to slowly increase to about $8 \%$ axial strain, and with further increase in axial strain the CSR gradually decreased to a value of 2.9 at $18 \%$ axial strain. At $18 \%$ axial strain, the specimen had reached $849^{\circ} \mathrm{C}$, also shown in Figure 5.9. In comparison, the CSR value for the longitudinal specimen increased to a maximum value of 1.9 with small initial axial strain $(1 \%)$ at about $790^{\circ} \mathrm{C}$. With further increase in axial strain, the CSR decreased 
gradually to a value of 1.8 , the same value for the transverse specimen which showed an opposite (increasing) trend for CSR with increasing axial strain to $1.5 \%$. On further axial straining to $18 \%$, the longitudinal specimen CSR values decrease monotonically to nearly 1.0, indicating primarily isotropic behaviour (Figure 5.11). At 18\% axial strain the longitudinal specimen reached $893^{\circ} \mathrm{C}$ much higher than the temperature of $849^{\circ} \mathrm{C}$ reached by the transverse specimen.

\subsubsection{Temperature data at $18 \%$ axial strain as a function of initial stress}

Using the temperature data at $18 \%$ strain from the longitudinal and transverse specimens tested using different heating rates and initial stress levels (constant load), the results can also be presented as a function of the initial stress, as shown in Figure 5.12. It can be seen from the figure that the longitudinal specimens showed higher temperatures than the transverse specimens for a given same set of initial stress level and heating rate. The lines shown in Figure 5.12 illustrate the effect of heating rate on the temperature predicted using Shewfelt's creep equation [5.8] for $18 \%$ strain with different initial stresses.

It is clear from the figure that increasing the heating rate results in an increasingly higher temperature attained for $18 \%$ strain especially when the material is being deformed at low initial-stress levels (i.e., a low-stress regime, $<30 \mathrm{MPa}$ ). 
Figure 5.11 Variation of contractile strain ratio in transverse and longitudinal specimens
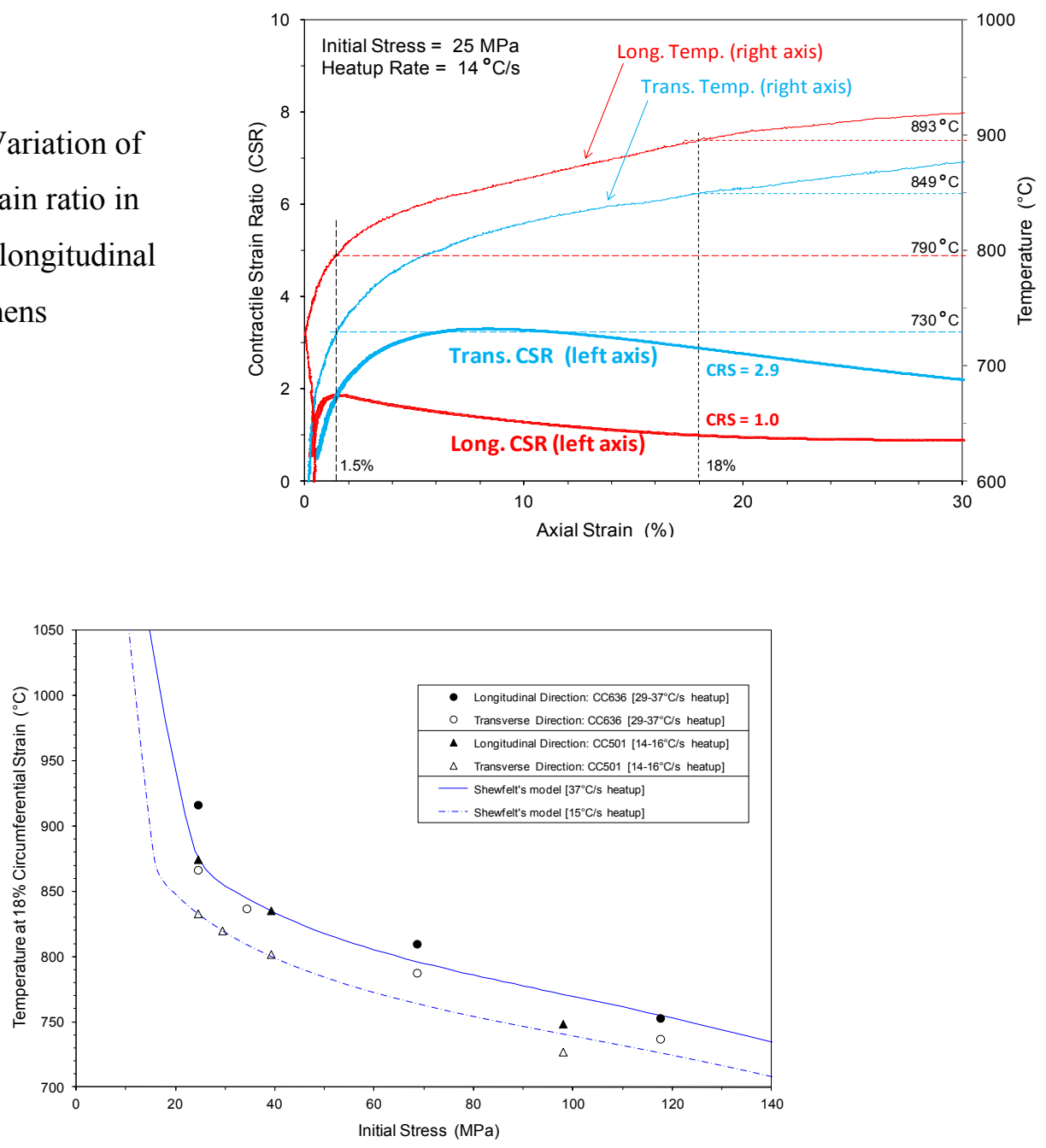

Figure 5.12 A plot of the temperature at $18 \%$ strain as a function of initial stress level.

\subsection{Effect of neutron irradiation on the material's temperature at $18 \%$ strain}

Previous studies have been conducted that evaluated the effect of neutron irradiation on the rapid-temperature-ramp uniaxial strain behaviour of $\mathrm{Zr}-2.5 \mathrm{Nb}$ pressure tubes removed from CANDU electrical power-generation reactors [5.10]. The results are compared to their unirradiated pressure tubes obtained using the offcut materials taken from the same pressure tubes before they were installed in the reactor. 
Figure 5.13 shows the comparison for "contact temperature" (i.e., temperature at $18 \%$ strain, similar to Figure 5.12) between irradiated and unirradiated pressure tube materials; all of the tests shown were obtained using transverse specimens. The irradiated pressure tube materials had received a range of fluence from $0.6-7.7 \times 10^{26}$ $\mathrm{n} / \mathrm{m}^{2}, \mathrm{E}>1 \mathrm{MeV}$. From a statistical analysis of the data [5.10], it was shown that there was little or no effect of irradiation on the rapid-temperature-ramp uniaxial deformation of $\mathrm{Zr}-2.5 \mathrm{Nb}$ pressure tube materials. As can be expected, the heating of the material to such high temperatures quickly anneals out any irradiation damage that had been accumulated from reactor operation. As shown in previous work on irradiated $\mathrm{Zr}-2.5 \mathrm{Nb}$ pressure tube materials [5.13], the post-irradiation annealing performed at temperatures $\geq 400^{\circ} \mathrm{C}$ effectively removes the hardening effect from irradiation exposure. Hence, the un-irradiated material results presented earlier in this paper are also applicable to irradiated pressure tubes. Much of the variability is attributed mainly to the initial differences in microstructure (mainly grain size and crystallographic texture) and also from tube-to-tube variations in chemical composition, rather than due to irradiation exposure. 
Figure 5.13 Comparison of hightemperature creep properties between unirradiated offcuts and their irradiated Pickering 4 pressure tubes $[5.10]$.

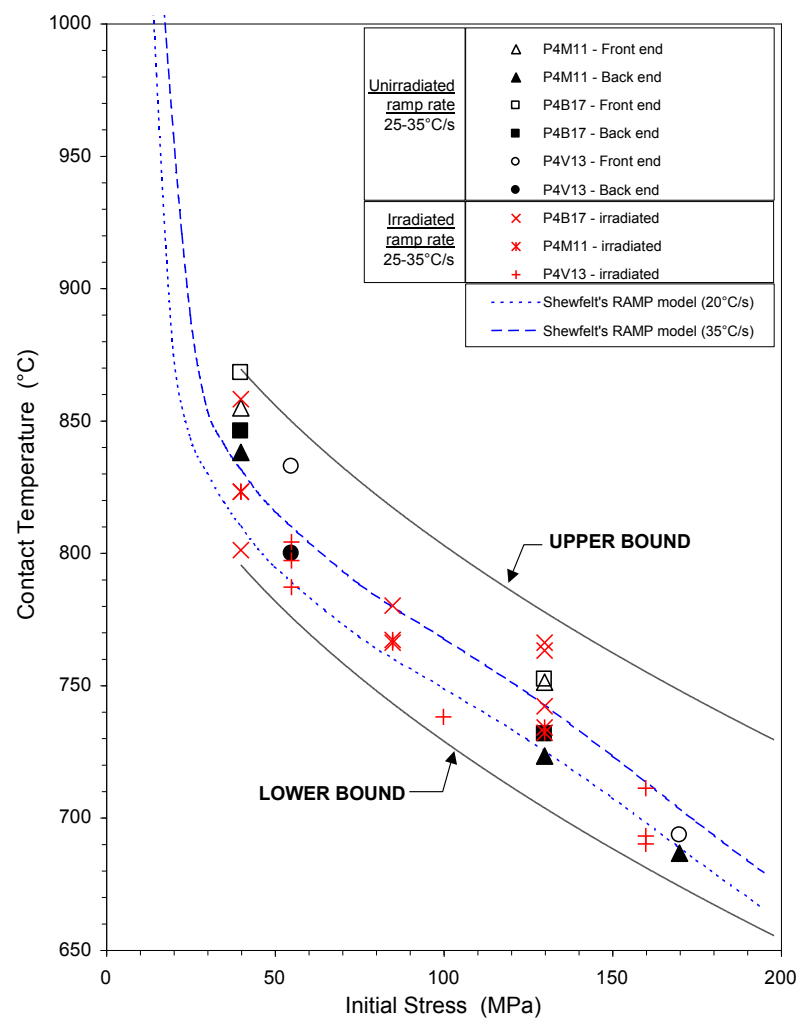

\subsection{Temperature-time at $\mathbf{1 8 \%}$ tensile strain and volume fraction of $\beta$ phase}

Using the volume fraction of $\beta$ phase measured at different temperatures under isothermal conditions, the results for temperature and time data at $18 \%$ tensile axial strain for longitudinal and transverse specimens tested using different heating rates and initial stresses are plotted as a function of temperature and superimposed onto the data for the $\beta$-phase volume fraction. Figure 5.14 shows the superimposed data for the longitudinal and transverse specimens tested at a heating rate of $14-16^{\circ} \mathrm{C} / \mathrm{s}$. It can be seen in the figure that the deformation results from the temperature-ramp tests show a correspondence to the amount of $\beta$ phase material transforming during heating (or cooling) of the material. Shown in Figure 5.14 are three sets of data for the three 
different initial stress (constant load) levels used in the tests, where it is observed that the longitudinal specimens generally took longer to reach $18 \%$ strain and therefore reached a higher temperature than the transverse specimens which underwent a faster deformation. The difference in time between the longitudinal and transverse specimens is reduced with increasing initial stress levels, suggesting that increasing stress (i.e., deformation rate) tends to favour isotropic deformation. The results also suggest that the anisotropic behaviour associated with slower deformation rates (i.e., at lower stress levels) could be attributed to the stable crystallographic texture of the $\alpha$-phase material even as the $\alpha$-phase material transforms into an increasing volume fraction of $\beta$-phase material during heating of the specimen to high temperatures. A similar result is also seen for tests with a faster heating rate of $29-37^{\circ} \mathrm{C} / \mathrm{s}$, Figure 5.15 .

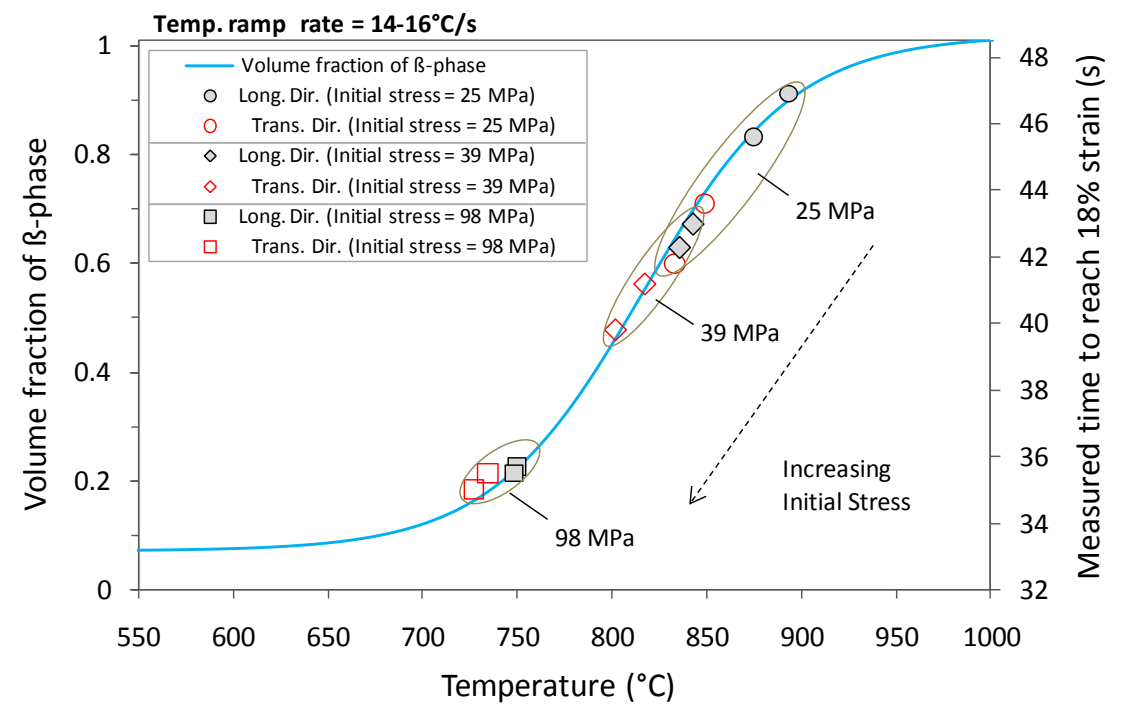

Figure 5.14 A superimposed plot of temperature and time data at $18 \%$ strain for $14-16^{\circ} \mathrm{C} / \mathrm{s}$ heating rate with the volume fraction of $\beta$ phase in $\mathrm{Zr}-2.5 \mathrm{Nb}$ pressure tube 


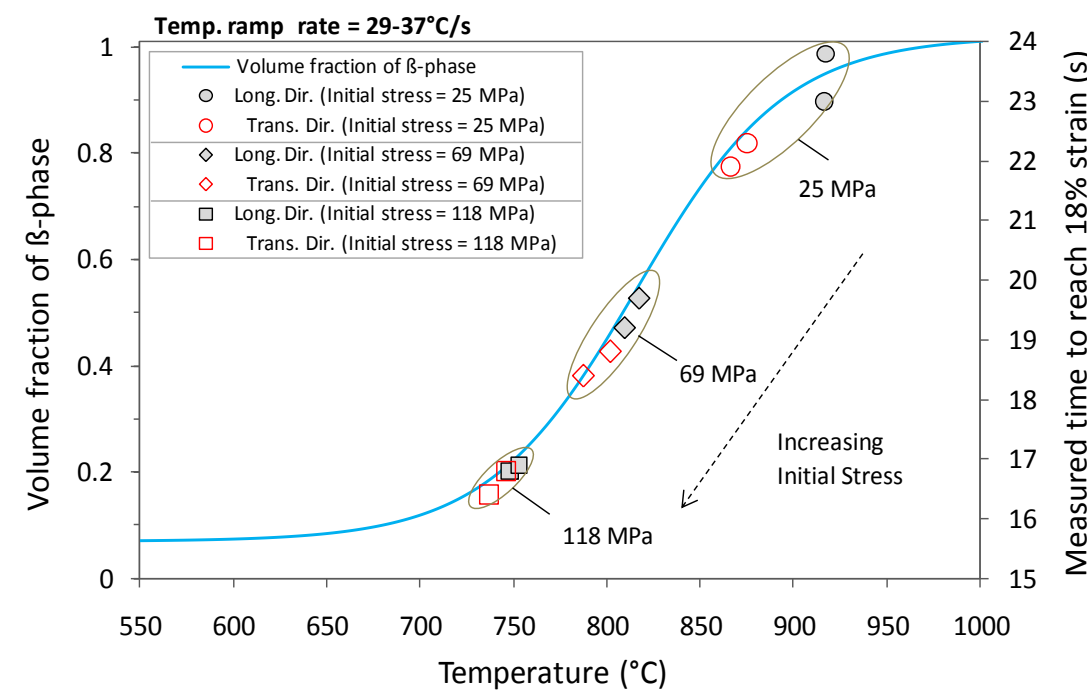

Figure 5.15 A superimposed plot of temperature and time data at $18 \%$ strain for $29-37^{\circ} \mathrm{C} / \mathrm{s}$ heating rate with the volume fraction of $\beta$ phase in $\mathrm{Zr}-2.5 \mathrm{Nb}$ pressure tube

\subsection{Discussion}

During a constant-load, rapid-temperature-ramp deformation test with a heating rate of $14-16^{\circ} \mathrm{C} / \mathrm{s}$ and $25 \mathrm{MPa}$ initial stress, the transverse specimen when heated to $780^{\circ} \mathrm{C}$ gave a value for contractile strain ratio (CSR) of 3.0 at $4 \%$ axial strain, indicating that more contraction occurs in the specimen-width (or tube-longitudinal) direction than in the specimen-thickness (or tube-radial) direction (Figure 5.9 and Figure 5.11).

At this "moderate"elevated temperature, most of the hcp $\alpha-\mathrm{Zr}$ grains still have their basal poles primarily oriented in the tube-transverse direction (Figure 5.5). As illustrated in Figure 5.16a, the transverse specimen has the hcp $\alpha$-Zr grains with their basal poles ("hard" directions, $\mathrm{C} 1$ to $\mathrm{C} 2$ ) mostly aligned parallel to the specimen tensile 
(tube-transverse) direction with a minor spread (C2) towards the specimen-thickness (tube-radial) direction. With such orientations of crystals in the transverse specimen, the anisotropic deformation occurs primarily by pyramidal and prismatic slip (i.e., along the specimen-width direction) than by basal slip (along the specimen-thickness direction). At this elevated temperature, deformation by twinning is unlikely and therefore does not contribute to the deformation anisotropy. However, at lower temperatures, twinned materials are expected to form and contribute to a higher strength in the transverse direction than for the longitudinal direction. In most hep metals, deformation occurs by slip and twinning; the easiest mechanism is by slip on prism planes, followed by slip on the pyramidal planes, then by more difficult slip on basal planes, and finally by twinning (Figure 5.17).

For the longitudinal specimen when it was heated to $780^{\circ} \mathrm{C}$ (same temperature) with same heating rate and initial stress, the CSR reached a value of 1.7 at just below $1 \%$ axial strain (Figure 5.10 and Figure 5.11). A lower CSR value for the longitudinal specimen indicates that there is relatively less contraction occurring in the specimenwidth (or tube-transverse) direction than in the specimen-thickness (or tube-radial) direction, at the lower value of axial strain. At $4 \%$ axial strain, the CSR value of 1.6 is obtained at $830^{\circ} \mathrm{C}$. As illustrated in Figure 5.16b, the longitudinal specimen has the hcp $\alpha-\mathrm{Zr}$ grains with their basal poles ("hard" directions, C1 to C2) mostly aligned perpendicular to the specimen tensile (tube-longitudinal) direction with a majority parallel to the specimen-width (tube-transverse) direction and a minor spread of basal poles (C2) towards the specimen-thickness (tube-radial) direction. In this case, the 
anisotropic deformation occurs primarily by pyramidal slip (i.e., along the specimenwidth direction) than by basal slip (along the specimen-thickness direction). The observed lesser anisotropic deformation in the longitudinal specimen could be also due in part to grain-boundary sliding at this "moderate" elevated temperature of $780^{\circ} \mathrm{C}$, which has been shown to exhibit a peak in superplasticity properties in $\mathrm{Zr}-2.5 \mathrm{Nb}$ pressure tube materials [5.5],[5.14],[5.15]. As a result of the large difference in anisotropic deformation at $780^{\circ} \mathrm{C}$ between the transverse and longitudinal specimens, the tensile axial strain in the transverse specimen was $4 \%$ compared to $1 \%$ for the longitudinal specimen (Figure 5.9 and Figure 5.10), indicating that the tensile deformation rate for the transverse specimen is faster than for the longitudinal specimen. These (non-isothermal) results agree with the faster creep rates seen in transverse specimens compared to longitudinal specimens from the constant-stress, constant-temperature tests at $700^{\circ} \mathrm{C}$ previously obtained by Shewfelt et al. [5.5]. In their isothermal creep tests at $700^{\circ} \mathrm{C}$ and $10 \mathrm{MPa}$ stress, they found the creep rates to differ by a factor of 8 [5.5]; however, their tests are limited to temperatures up to $700^{\circ} \mathrm{C}$ for both longitudinal and transverse specimens.

For both the transverse and longitudinal specimens tested at a low initial stress and heating rate (25 $\mathrm{MPa}$ and $\left.14-16^{\circ} \mathrm{C} / \mathrm{s}\right)$, the CSR (mechanical anisotropy) is seen to vary with increasing tensile axial strains at the low strain level (1.5\%), as seen in Figure 5.11 At $1.5 \%$ axial strain, these two types of specimens showed the same extent of mechanical anisotropy $(\mathrm{CSR}=1.8)$. This means that at $1.5 \%$ axial strain, the deformation rates for both specimens should be the same; however the longitudinal 
specimen required a much higher temperature than the transverse specimen to achieve the same deformation rate.

The effect of heating rate on both types of specimens is evaluated with the results showing that at the same initial stress, the effect of a faster heating rate is to decrease the time and increase the temperature for the specimen to reach $18 \%$ axial strain (Figure 5.12, Figure 5.13 and Figure 5.14). This could imply that increasing the heating rate can generate an increase in the deformation rate in the specimen.
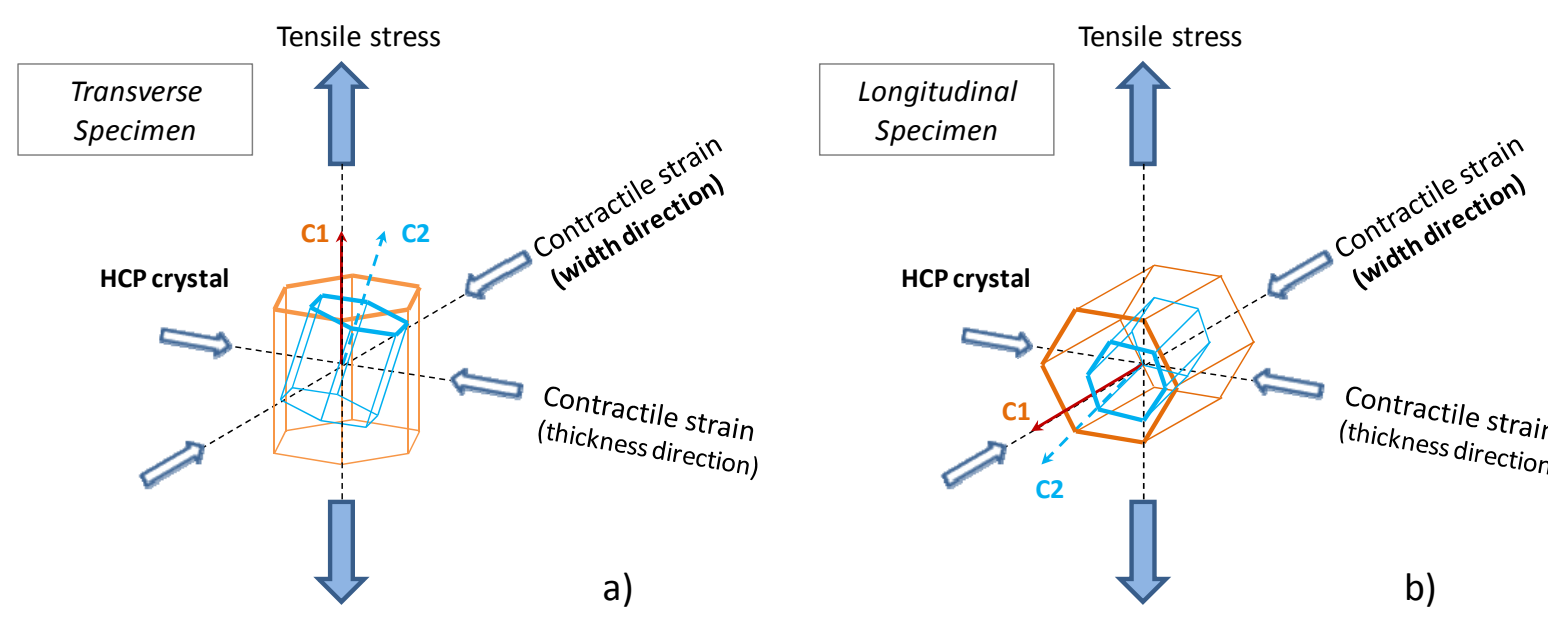

Figure 5.16 Illustration of the orientations of (hcp) $\alpha$-Zr crystals relative to the tensile axis in (a) transverse specimen, and (b) longitudinal specimen in $\mathrm{Zr}-2.5 \mathrm{Nb}$ pressure tube. 


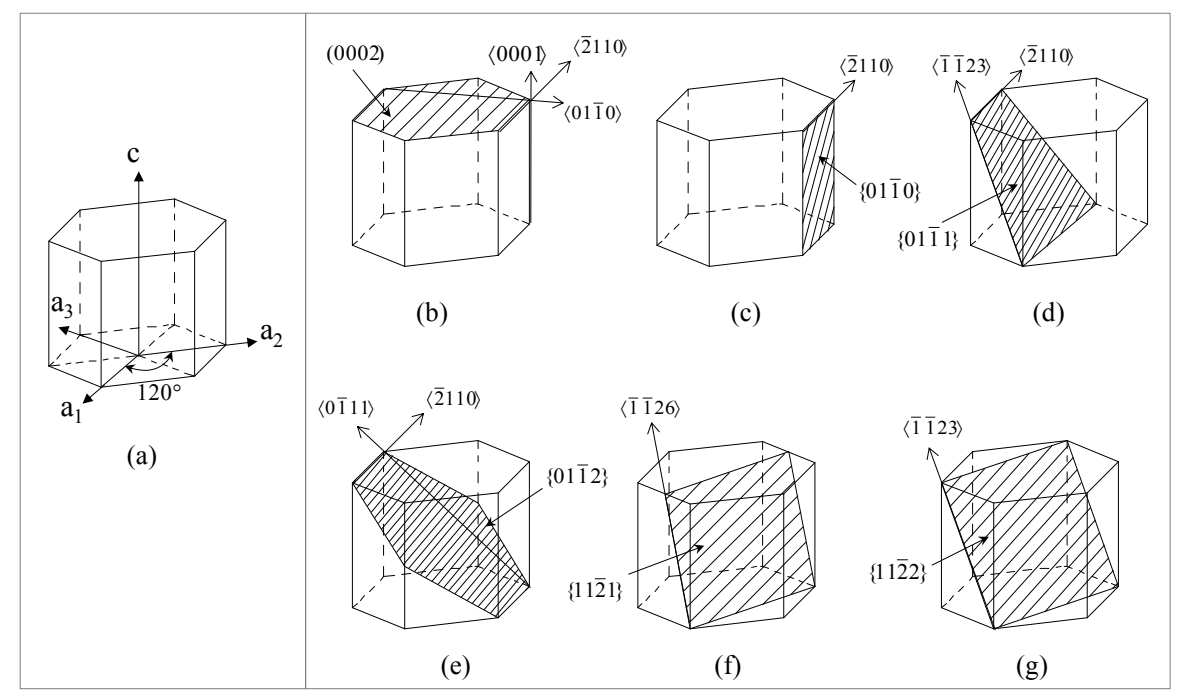

Figure 5.17 HCP lattice and axes (a) and planes and directions in HCP lattice for deformation by basal $<\mathrm{a}>\operatorname{slip}(\mathrm{b})$, prism $<\mathrm{a}>\operatorname{slip}(\mathrm{c})$, compressive pyramidal $<\mathrm{c}+\mathrm{a}>\operatorname{slip}(\mathrm{d})$, tensile pyramidal $<\mathrm{c}+\mathrm{a}>$ twin (e and f), compressive pyramidal $<\mathrm{c}+\mathrm{a}>$ twin $(\mathrm{g})[5.16]$.

With increasing temperatures, the material's strength decreases and the elongation increases, and for $\mathrm{Zr}-2.5 \mathrm{Nb}$ pressure tube materials with typical room-temperature crystallographic textures (Figure 5.3), the maximum value for elongation $(>100 \%)$ occurs at temperatures close to 700 to $750^{\circ} \mathrm{C}[5.5],[5.14],[5.15]$. As the specimen is heated from below $610^{\circ} \mathrm{C}$ (i.e., $\alpha /(\alpha+\beta)$ transus) to much higher temperatures into the two-phase $(\alpha+\beta)$ region (below the $(\alpha+\beta) / \beta$ transus at $\sim 960^{\circ} \mathrm{C}$ ), phase transformations occur. When the specimen temperature starts to exceed $610^{\circ} \mathrm{C}$, the low-temperature stable phase of hcp $\alpha$ $\mathrm{Zr}$ becomes unstable and transforms into the high-temperature stable phase of bcc $\beta-\mathrm{Zr}$, with a proportionate increase in the amount of $\beta$-phase material and reduction of the $\alpha$ phase material in the specimen. The results for the temperature and time at $18 \%$ strain for both the longitudinal and transverse specimens appear to show a correspondence with the volume fraction of $\beta$-phase material in the specimens at different temperatures. For 
both the low and high range of heating rates, it appears that increasing the initial stress levels tends to reduce the mechanical anisotropy as indicated by the increasing closeness of the data points for both types of specimens (Figure 5.14 and Figure 5.15). The correspondence of the two different sets of results suggests that there could be an effect of the $\beta$-phase material contributing to the anisotropic deformation behaviour, via grainboundary sliding mechanisms in the longitudinal and transverse specimens. The $\beta$-phase material is essentially a bcc $\beta-\mathrm{Zr}$ which is softer and more ductile than the hep $\alpha-\mathrm{Zr}$ because there are many more slip systems than in the hcp $\alpha$-phase material. During heating to high temperatures $\left(>600^{\circ} \mathrm{C}\right)$, progressively increasing proportion of the hcp $\alpha-\mathrm{Zr}$ phase transforms into a bcc $\beta-\mathrm{Zr}$ phase. The transformed $\beta-\mathrm{Zr}$ at the high temperatures would not be enriched with $\mathrm{Nb}$ (i.e., $<<20 \% \mathrm{Nb}$ ) and therefore making it a much softer material for grain boundary sliding to occur. The maximum superplasticity has been observed at temperatures where there is a large fraction of the relatively stronger $\alpha$-phase coexisting with a small fraction of the softer $\beta$-phase which is present as a layer at the $\alpha-\mathrm{Zr}$ grain boundaries. Since cubic crystalline materials such as bcc $\beta-\mathrm{Zr}$ phase mostly show isotropic properties, an increasing amount of $\beta$-phase material that is present in the specimen when it is being heated to much higher temperatures $\left(>750^{\circ} \mathrm{C}\right)$ would be expected to have only little or no effect on the mechanical anisotropy of the specimen during tensile deformation since the contribution from grain-boundary sliding would be largely diminished.

The mechanical anisotropy at $18 \%$ axial strain appears to persist at high temperatures from $800^{\circ} \mathrm{C}$ to $900^{\circ} \mathrm{C}$ for the transverse specimen as shown in Figure 5.11. 
This is probably due to the stable texture of the hep $\alpha-Z r$ phase present that remained essentially unchanged (Figure 5.5) even at a reduced quantity (Figure 5.6). At 18\% strain and with temperatures above $800^{\circ} \mathrm{C}$, the transverse specimen had a CSR value of 2.9. In comparison, the longitudinal specimen had a CSR value of 1.0, meaning that the deformation is nearly isotropic. As these results are discussed for tests at low initial stress and heating rate $\left(25 \mathrm{MPa}\right.$ and $\left.14-16^{\circ} \mathrm{C} / \mathrm{s}\right)$, a similar behaviour is expected for the results from higher initial stress and heating rate, although individual tests are not presented here for discussion. The difference in values for CSR between the transverse and longitudinal specimens is close to a factor of 3 , suggesting that the deformation rate in transverse specimen should still be faster than in the longitudinal specimen.

It should be noted that at $900^{\circ} \mathrm{C}$, in addition to the stable texture of the hep $\alpha-\mathrm{Zr}$ phase that is diminishing in quantity due to its transformation to the bec $\beta$-phase material on heating to $900^{\circ} \mathrm{C}$, there is a previously unobserved $\alpha$-phase texture component that has become more prominent due to coarsening of the prior 'primary' $\alpha$-grains (Figure 5.5). This different texture of 'primary' $\alpha$-phase can also be expected to affect the anisotropic deformation behaviour in the two types of specimens.

On evaluating irradiation effect on tensile deformation in rapid-temperature-ramp tests (Figure 5.13), an earlier analysis using transverse specimens taken from irradiated pressure tubes and their unirradiated pressure tubes materials concluded that there is little or no effect of irradiation on the temperature and time data at $18 \%$ axial strain [5.10]. This is a direct consequence of heating to the high temperatures $\left(>700^{\circ} \mathrm{C}\right)$ because any irradiation damage will be annealed from the pressure tube material [5.13] and thus the 
discussions and results for the un-irradiated material presented in this paper are also applicable to irradiated pressure tube materials.

A further consideration is the consistent difference in uniaxial deformation behaviour between the transverse and longitudinal specimens (Figure 5.12). This anisotropic deformation behaviour is expected to occur also during ballooning (biaxial) deformation of an overheated pressure tube. Under a low residual internal pressure, biaxial stressing of a pressure tube occurs, as illustrated in Figure 5.18, where the contractile straining in the pressure tube is mainly confined to the tube-radial (thickness) direction, since the material in the tube-transverse and tube-longitudinal directions are being axially strained (elongated) under tensile stresses generated by the internal pressure. With the crystal orientations of the hcp $\alpha$-phase grains in the pressure tube having their basal poles ( $\mathrm{C} 1$ to $\mathrm{C} 2)$ mostly aligned parallel to the tube-transverse direction (Figure 5.18) the contractile (thickness) strain occurs primarily by slip on prism planes of the hcp $\alpha-Z r$ grains. Elongation tensile strains occur in both the tube-transverse and tube-longitudinal directions of the pressure tube due to their tensile stress state in material. Through conservation of volume of the material, the contractile strain equals the sum of the two elongation tensile strains. Since the tensile stress in the tubetransverse direction is much higher than in the tube-longitudinal direction (in a general case, 2:1), the tensile elongation strain for the transverse direction would also be higher than for the longitudinal direction.

At low temperatures $\left(<500^{\circ} \mathrm{C}\right)$, the pressure tube material is stronger in the transverse direction than in the longitudinal direction due to its crystallographic texture 
(Figure 5.5), since there is a higher magnitude of critical resolved shear stress (CRSS) on the hcp crystals that has to be exceeded before plastic yielding in the material can occur. In uniaxial tensile tests results on transverse and longitudinal specimens, the transverse specimen showed there is mechanical anisotropy in the specimen that persisted for the $18 \%$ axial strain at high temperatures from $800^{\circ} \mathrm{C}$ to $900^{\circ} \mathrm{C}$, and near isotropic behaviour for the longitudinal specimen. A difference in deformation between the transverse and longitudinal specimens in uniaxial deformation tests can also be expected in biaxial deformation tests of pressure tube sections in closed-end or opened-end constraints. Thus, when the pressure tube is rapidly heated up to $1000^{\circ} \mathrm{C}$, as postulated in some LOCA scenarios, the elongation in the tube's transverse direction may also be consistently result in higher tensile straining than in the tube's elongation in the longitudinal direction.

Figure 5.18 Illustration of biaxial stressing of pressure tube and the contractile straining of the material being confined to the tube-radial direction.

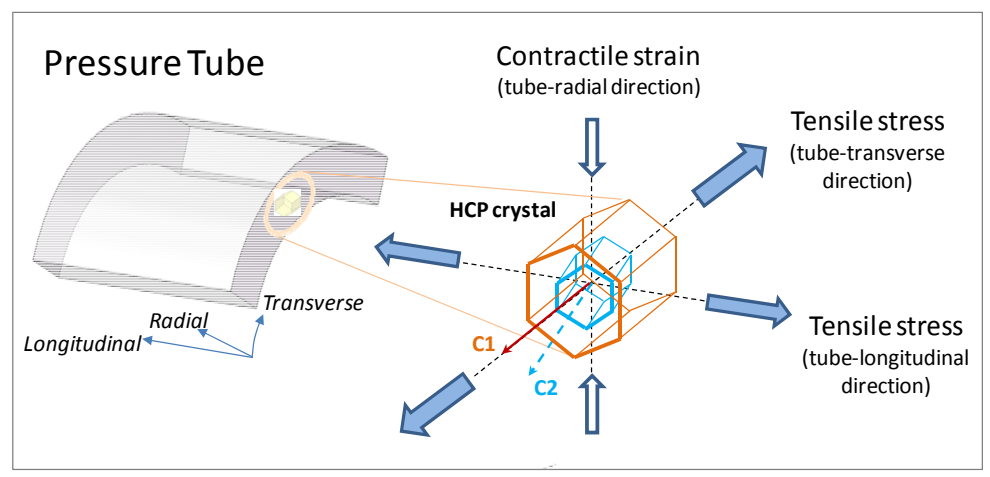

\subsection{Concluding Remarks}

The anisotropic deformation behaviour in transverse and longitudinal specimens evaluated in constant-load, rapid-temperature-ramp tests has been related to the stable 
crystallographic textures observed at high temperatures during heating of the pressure tube material. The following conclusions are drawn from this study.

1. The response of mechanical anisotropy, as defined by the contractile strain ratio (CSR) of the width-strain to thickness-strain (i.e., $\mathrm{e}_{\mathrm{W}} / \mathrm{e}_{\mathrm{T}}$ ), for both the transverse and longitudinal specimens was used to evaluate the difference in anisotropic deformation in the uniaxial tensile specimens.

2. At a low initial stress and heating rate, the transverse specimens continued to show anisotropic deformation characteristics for $18 \%$ tensile axial strain when the specimen was heated to $900^{\circ} \mathrm{C}$. In comparison, the longitudinal specimen showed near isotropy when subjected to the same initial stress and heating rate.

3. There appears to be a correspondence between the temperature-time data at $18 \%$ tensile strain and the volume fraction of $\beta$-phase at the different temperatures, suggesting that there could also be an effect of $\beta$-phase material on the anisotropic deformation behaviour in both the transverse and longitudinal specimens.

4. The comparison of earlier tests on irradiated pressure tubes with their unirradiated pressure tube materials evaluated previously indicate that there is little or no effect of irradiation on the high-temperature deformation behaviour of $\mathrm{Zr}-2.5 \mathrm{Nb}$ pressure tube materials.

5. The deformation at high-temperatures in $\mathrm{Zr}-2.5 \mathrm{Nb}$ pressure tube materials have been ascribed to occurring primarily by slips on prism and prismatic planes in the hep $\alpha-\mathrm{Zr}$ grains. Deformation at temperatures around $700-750^{\circ} \mathrm{C}$ by grain boundary sliding could also contribute to the mechanical anisotropy. 


\section{References}

[5.1] P.A. Ross-Ross, J. Eng. Inst. Can.,53 (10) 13, 1970

[5.2] B.A. Cheadle, The Development of $\mathrm{Zr}-2.5 \mathrm{Nb}$ Pressure Tubes for CANDU Reactors, J. ASTM Int., Vol. 7 (8), pp. 1-15, 2010

[5.3] M. Griffiths, J.E. Winegar, and A. Buyers, The transformation behaviour of the $\beta$-phase in $\mathrm{Zr}-2.5 \mathrm{Nb}$ pressure tubes, J. Nucl. Mater., Vol. 383, pp. 28-33, 2008

[5.4] S.A. Aldridge and B.A. Cheadle, Age Hardening of $\mathrm{Zr}-2.5 \mathrm{wt} \% \mathrm{Nb}$ Slowly Cooled from the $(\alpha+\beta)$ Phase Field, J. Nucl. Mater., Vol. 42, pp. 32-42, 1972

[5.5] R.S.W. Shewfelt, The Anisotropic Deformation of Zr-2.5 wt\% Nb CANDU Pressure Tubes between 20 and $700^{\circ}$ C, Can. Metall. Q., Vol. 23 (4), pp. 441-445, 1984

[5.6] N. Christodoulou, P.A. Turner, E.T.C. Ho, C.K. Chow and M. Resta Levi, Anisotropy of Yielding in a Zr-2.5Nb Pressure Tube Material, Metall. Mater. Trans A, Vol. 31A, pp. 409-420, 2000

[5.7]] P. Gangli, J. Root and R. Fong, Investigation of Texture and Interfaces in a $\mathrm{Zr}-2.5 \mathrm{Nb}$ Alloy with Zirconium Hydrides, Can. Metall. Q., Vol. 34, pp. 211-218, 1995

[5.8] R.S.W. Shewfelt, L.W. Lyall and D.P. Godin, A High Temperature Creep Model for Zr2.5Nb Pressure Tubes, J. Nucl. Mater., Vol. 125, pp. 228-235, 1984

[5.9] Z.L. Pan, S. St.Lawrence, P.H. Davies, M. Griffiths and S. Sagat, Effect of Irradiation on the Fracture Properties of $\mathrm{Zr}-2.5 \mathrm{Nb}$ Pressure Tubes at the End of Design Life, J. ASTM Int., Vol. 2 (9), pp. 1-22, 2005

[5.10] R.W.L. Fong and C.K. Chow, High-Temperature Transient Creep Properties of CANDU

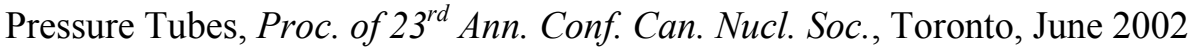

[5.11] R.W.L. Fong, R. Miller, H.J. Saari and S.C. Vogel, Crystallographic Texture and Volume Fraction of $\alpha$ and $\beta$ Phases in $\mathrm{Zr}-2.5 \mathrm{Nb}$ Pressure Tube Material During Heating and Cooling, Metall. Mater. Trans A, Vol. 43 (3), pp. 806-821, 2012

[5.12] J.P. Abriata and J.C. Bolcich: Bull. Alloy Phase Diagrams, Vol. 3 (1), pp. 34-44, 1982

[5.13] C.E. Coleman, P.C. Chow, C.E. Ells, M. Griffiths, E.F. Ibrahim, and S. Sagat, Rejuvenation of Fracture Properties of Irradiated Zr-2.5 Nb by Heat Treatment, Effects of Radiation on Materials: $15^{\text {th }}$ Int. Symp., ASTM STP 1125, pp. 318-336, 1992 
[5.14] H.E. Rosinger and A.E. Unger, Superplastic and Strain Rate Dependent Plastic Flow of $\mathrm{Zr}-2.5 \mathrm{wt} \% \mathrm{Nb}$ between 873 and $1373 \mathrm{~K}$, Atomic Energy of Canada Ltd. Report, AECL-6418, 1979

[5.15] B.S. Rodchenkov and A.N. Semenov, High Temperature Mechanical Behaviour of Zr-2.5\% Nb Alloy, Nucl. Engr. Design, Vol. 235, pp. 2009-2018, 2005

[5.16] P.G. Partridge, The Crystallography and Deformation Modes of Hexagonal Close-Packed Metals, Metall. Rev., Vol. 12, pp. 169-194, 1967 


\section{Chapter 6}

\section{Anisotropy Factors from Texture and Mechanical Strain in Zircaloy-4 Fuel Sheaths}

(Manuscript accepted for publication in J. Nucl. Mater., 2013)

http://dx.doi.org/10.1016/j.jnucmat.2013.04.089

Cover introduction: This manuscript presents the results of neutron diffraction measurements of crystallographic textures in three CANDU-type Zircaloy-4 fuel sheath materials with different starting microstructures. The textures measurements were obtained at near room temperature and during heating up to $1000^{\circ} \mathrm{C}$ to obtain the orientation distribution function (ODF) of the $\alpha-Z r$ and $\beta-Z r$ phases for studying the texture evolution and stability during heating. The ODF (texture) data were used to calculate the Kearns numbers (i.e., indicating the fractions $\left(f_{\mathrm{T}}, f_{\mathrm{R}}\right.$, and $\left.f_{\mathrm{L}}\right)$ of the resolved fraction of basal plane normals in the three principal directions (i.e., transverse, radial and longitudinal) of the tubing). The ODF data were also used to calculate the Hill's anisotropy factors $(F, G$, and $H)$ values using a self-consistent polycrystalline model, SELFPOLY, that have been used to calculate steady-state thermal creep anisotropy of CANDU $\mathrm{Zr}-2.5 \mathrm{Nb}$ pressure tube materials. The results from this study show that the derivation and use of a texture-based (variable) parameter, in place of a prefixed-value for the stress-exponent, $n$, that is used in the SELFPOLY polycrystalline model, yielded some reasonable good agreement between the calculated anisotropy factors and those previously obtained from mechanical strain tests on CANDU-type fuel sheath materials. This paper brings an interesting in-situ approach to determine Kearns factors and Hill's anisotropy factors. 


\begin{abstract}
$\underline{\text { Abstract }}$
The crystallographic textures in Zircaloy-4 fuel sheathing in the as-manufactured condition and with simulated braze zones microstructures have been characterized by neutron diffraction at several different temperatures $\left(100^{\circ} \mathrm{C}\right.$ to $\left.1000^{\circ} \mathrm{C}\right)$. The texture (ODF) data measured at $100^{\circ} \mathrm{C}$ for these three sets of samples are used to calculate the Kearns numbers and the Hill's anisotropy factors using SELFPOLY (a self-consistent polycrystalline model) to compare and correlate with previously obtained values from X-ray diffraction and mechanical strain tests on similar type of Zircaloy-4 fuel sheath materials. The results from SELFPOLY calculations showed the values for Kearns numbers to be similar to earlier data. It is found that the SELFPOLY calculated values for the Hill's anisotropy factors showed some reasonable agreement with those from mechanical strain tests, when a texture-based parameter replacing the numerical value for the "stress-exponent, n" parameter and a pre-fixed set of values for the critical resolved shear stress (CRSS) for the three different slips systems (prism, basal, and pyramidal) are used in the calculations.
\end{abstract}

\title{
6.1 Introduction
}

Zircaloy-4 is used as a sheathing material for fuel elements in nuclear reactors. A typical fuel sheathing fabrication schedule involves several hot and cold working steps as shown in Figure 6.1 [6.1]. The microstructure of as-manufactured fuel sheath material is in a cold-worked and stress-relieved state (Figure 6.2a). In a CANDU (a registered trademark of Atomic Energy of Canada Limited) fuel bundle, bearing and spacer pads 
(appendages) are attached to the fuel elements to maintain appropriate spacing between the elements. End plates are welded on to the ends of the elements to form the bundle. The microstructures of the fuel cladding are modified locally by the welding and brazing processes used to assemble the fuel bundle. The brazing of appendages involves heating to $1050^{\circ} \mathrm{C}$ for $40-60 \mathrm{~s}$, in argon atmosphere, and results in a $\beta$-transformed microstructure (Figure 6.2b). In the region of "heat-affected-zone" (HAZ), where the sheath material had experienced a lower heating peak temperature (e.g. $815^{\circ} \mathrm{C}$ ), an $\alpha$-annealed (equiaxed structure) is obtained, Figure 6.2c. As a result, the locally modified microstructures are expected to show distinct crystallographic textures, and a difference in their mechanical response to deformation.

For Zircaloys at low temperatures (below $\approx 875^{\circ} \mathrm{C}$ ), the microstructure consists of hexagonal close-packed (hcp) $\alpha$ phase zirconium with second phase particles [6.2],[6.3],[6.4]. The hcp crystallites of $\alpha-\mathrm{Zr}$ have anisotropic properties (e.g., elastic properties, diffusion characteristics, thermal conductivity). During a hypothetical hightemperature transient, the microstructure of the alloy will change accordingly with the changes in temperature and time. At high temperatures, the material will evolve with different volume fractions of the $\alpha$ - and $\beta$-phases. Within the dual-phase $(\alpha+\beta)$ region, zirconium alloys exhibit superplastic deformation behaviour [6.5],[6.6]. It is important to characterize the changes in phase transformation and to relate them and model their hightemperature deformation behaviour. Earlier studies on Zircaloy-4 fuel sheathing provided knowledge of the $\alpha-\beta$ phase transformation kinetics that has been used as one of 


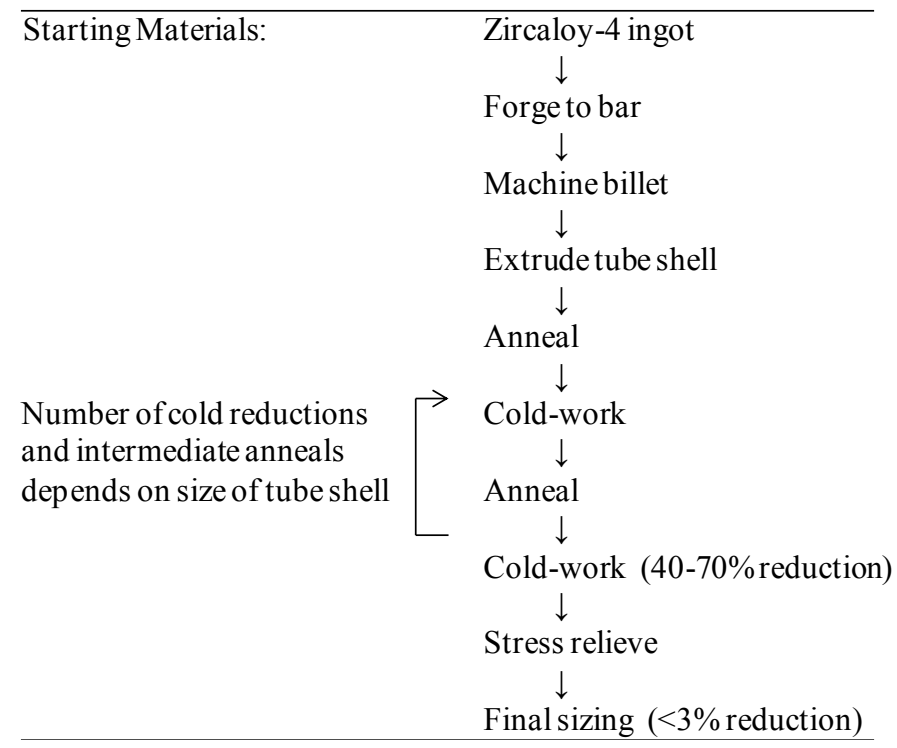

Figure 6.1 Typical fuel sheathing fabrication schedule [6.1].

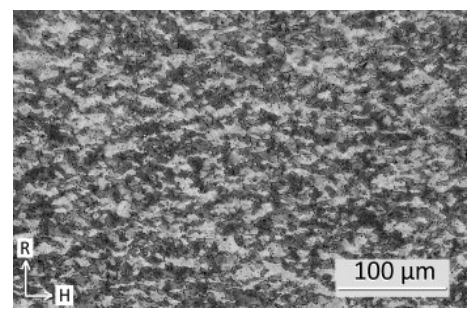

a)

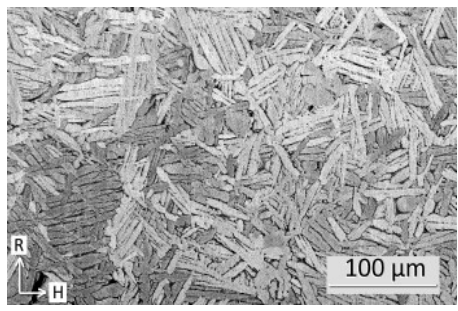

b)

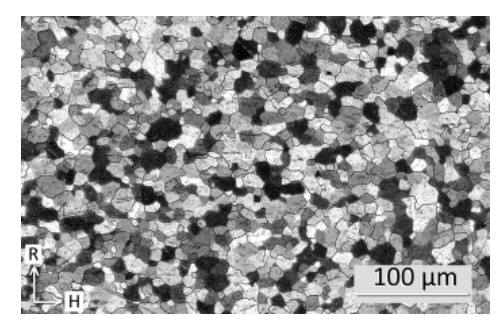

c)

Figure 6.2 Optical micrographs showing starting microstructures of Zircaloy-4 fuel sheathing used in neutron texture measurements: (a) as-manufactured, (b) transformed- $\beta$ in simulated braze zone, and (c) simulated heat-affected-zone.

(This figure first appeared in Figure 1.9) 
the modelling parameters for describing the thermo-mechanical behaviour of the sheath under loss-of-coolant accident conditions [6.7],[6.8],[6.9]. These investigations were primarily performed using dilatometry and calorimetry techniques. Other studies of phase transformation in different alloys include monitoring changes in electrical resistivity [6.10], and metallographic examinations of 'transformed' microstructures at room temperature [6.11]. In-situ studies using Scanning Electron Microscopy Electron Backscattered Diffraction (SEM-EBSD) have also provided insights into the nucleation and growth stages in $\mathrm{Ti}$ during the phase transformation process [6.12]. Hightemperature X-ray diffraction has also been used to study phase transformation in titanium alloys [6.13],[6.14] and also in zirconium alloys [6.15],[6.16]. Neutron diffraction has also been applied to study the kinetics of phase transformation in titanium alloys [6.17] and also in-situ texture changes in $\mathrm{hcp} \rightarrow \mathrm{bcc} \rightarrow \mathrm{hcp}$ transformation in a hotrolled Zircaloy-4 plate [6.18].

In this study, neutron diffraction experiments have been performed at Los Alamos Neutron Science Center to characterize the texture evolution of the two phases during heating to high temperatures (up to $1000^{\circ} \mathrm{C}$ ) and cooling under thermal equilibrium conditions. As the kinetics of phase transformations occurs much too fast at high temperatures, neutron measurements were not conducted during transient heating for texture analysis. A CANDU-type fuel sheathing was used in the texture characterization for an as-manufactured sheath and those that had been modified by subjecting the 
material of an as-manufactured sheath to a simulated-production brazing cycle $\left(1050^{\circ} \mathrm{C}\right.$ for 40-60 s, in vacuum).

The texture data are used to determine the Kearns numbers [6.19] (i.e., resolved volume fraction of basal poles in the principal directions of the sample) and the anisotropy factors that correlate with previously determined values obtained from mechanical strain tests [6.20],[6.21]. The Kearns numbers and the anisotropy factors are both calculated using a self-consistent polycrystalline model, SELFPOLY [6.22],[6.23] that has been used to calculate steady-state thermal creep anisotropy of CANDU $\mathrm{Zr}-2.5 \mathrm{Nb}$ pressure tube materials. The results evaluated in this study are shown to agree with earlier values for the Kearns numbers and the anisotropy factors measured by strain tests on similar type of fuel sheathing materials.

\subsection{Experimental}

\subsubsection{Materials and microstructures}

A CANDU-type Zircaloy-4 fuel sheathing material was used in this study to characterize the texture evolution during heating to high temperatures $\left(100^{\circ} \mathrm{C}\right.$ to $\left.1050^{\circ} \mathrm{C}\right)$. The sheathing dimensions were $11.5 \mathrm{~mm}$ outside diameter and $0.41 \mathrm{~mm}$ wall thickness. Three sets of samples were used for the neutron diffraction measurements. The first sample set consisted of as-manufactured (i.e., as-received) fuel sheath materials, with microstructures is shown in Figure 6.2a. The second sample set consisted of simulated braze-zone fuel sheath materials with transformed- $\beta$ with microstructures shown in 
Figure 6.2b. The third sample corresponding to the heat-affected-zone (HAZ) for the fuel sheathing with $\alpha$-annealed equiaxed microstructures as shown in Figure 6.2c.

To increase the sampling volume and thus improve the neutron measurements the texture sample was prepared by stacking together 18 plates that were cut from the fuel sheath (Figure 6.3). The overall dimension of the stacked sample is about $10 \mathrm{~mm}$ tall $\mathrm{x} 8$ mm wide x $9 \mathrm{~mm}$ thickness. To obtain the 18 plates, a slit ring was first cut from the fuel sheath and then reverse bent to obtain a flat strip that was cut into plates with the desired dimensions. The reverse bending of the strip is expected to introduce residual stresses and dislocations in the sample. Other than the residual stresses, it is expected that the reverse bending process would not induce any major change in the bulk texture of the specimen. On heating at elevated temperatures (e.g., at $500^{\circ} \mathrm{C}$ and higher) the sample would then be stress relieved. To improve thermal conduction between the plates, the stacked plates were held tightly together by spot welding two vanadium straps at each end.

\subsubsection{Simulated brazing cycle}

The samples with the simulated braze zone microstructures (Figure 6.2b and Figure $6.2 \mathrm{c}$ ) were produced using a production brazing cycle that involves induction heating of the sheathing under argon atmosphere to $1050^{\circ} \mathrm{C}$ for $40-60 \mathrm{~s}$ followed by a rapid cooling with argon to room temperature. It should be noted that for the simulated braze zone samples examined in this study, the fuel sheathing materials used to obtain these samples do not contain the Be-containing brazing alloy (filler material) that is normally used in production brazing of CANDU fuel sheath elements. This was done to 
obtain a homogeneous microstructure in the specimen for this study, without the presence of an additional $\mathrm{Zr}$-Be microstructure that could affect the resulting texture of the specimen.

Figure 6.3 Diagram

showing a stacked

sample consisting of

18 plates from a

Zircaloy-4 fuel sheath

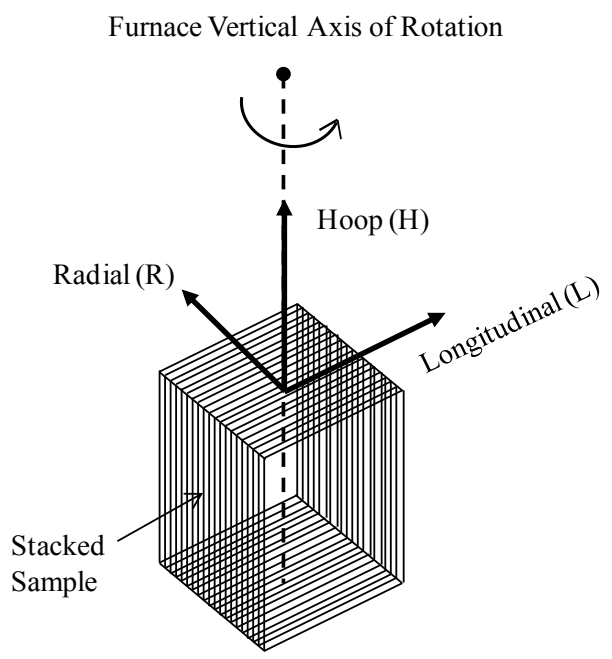

\subsubsection{Texture measurements}

Neutron diffraction measurements for texture were made on the three sets of samples of Zircaloy-4 fuel sheath materials. The texture measurements were performed on the time-of-flight (TOF) high-pressure preferred orientation (HIPPO) diffractometer at the Los Alamos Neutron Science Center. The details for such TOF textures measurements are found in [6.24].

To perform the HIPPO texture measurements, the sample is placed in a vanadium basket inside a vacuum furnace with vanadium heating elements and heat shields. An incident beam of polychromatic thermal neutrons collimated to $10 \mathrm{~mm}$ in beam diameter was directed at the sample. Two thermocouples, located in the furnace with one at about 
$70 \mathrm{~mm}$ above the sample within the $200-\mathrm{mm}$ high hot zone, were used to control and record the temperature of the sample. The second thermocouple was also located in the hot zone at about the same position as the first thermocouple. The uncertainty in the sample temperature for the furnace used in this study is estimated to be less than $\pm 5^{\circ} \mathrm{C}$, based on prior temperature calibrations performed on this furnace.

The pole figures of $\alpha$ and $\beta$ phases were measured during heating of the sample at several different temperatures $\left(100^{\circ} \mathrm{C}\right.$ to $\left.1000^{\circ} \mathrm{C}\right)$ and also on cooling to near room temperature. At each temperature, the sample was rotated around the furnace axis in three different rotations (-45 deg., 0 deg., and 45 deg., Figure 6.3). After the sample temperature had stabilized, diffraction data were collected for a period of 18 minutes, which was deemed sufficient to obtain the ODF (orientation distribution function) to reconstruct pole figures for many different planes. The ODF gives a complete map of the distribution of orientations of crystallites ( $\alpha$ or $\beta$ phase) in the sample. The total time for each temperature interval was about 1 hour (including time for data readout and rotation).

The pole intensities measured were used to extract texture information using the Rietveld method, as implemented in the MAUD (Material Analysis Using Diffraction) program [6.25] for analyzing HIPPO diffraction data.

The ODF and pole figures were used to evaluate the anisotropy factors for the three sets of samples of Zircaloy-4 fuel sheath materials. 


\subsection{Kearns numbers [6.19]}

The Kearns numbers for the three principal directions in the sample $\left(f_{R}, f_{T}\right.$, and $\left.f_{L}\right)$, defined as a weighted average of the intensity of the basal plane normals oriented with respect to the sample's principal direction, are calculated using eqn. (6.1).

$$
\begin{array}{r}
f_{d}=\left[\sum_{\alpha_{d}} V_{f}\left(\alpha_{d}, \beta\right) \sin \alpha_{d} \cos ^{2} \alpha_{d}\right] \\
/\left[\sum_{\alpha_{d}} V_{f}\left(\alpha_{d}, \beta\right) \sin \alpha_{d}\right]
\end{array}
$$

Here $d$ stands for R (radial), $\mathrm{T}$ (transverse) and L (longitudinal) direction of the original tube sample. $V_{f}\left(\alpha_{d}, \beta\right)$ is the volume fraction of grains with basal poles oriented at a given polar and azimuthal angles $\alpha_{d}$ and $\beta$ in the pole figure for the sample, respectively. Normally, the sum of the three Kearns numbers must equal to 1 (eqn. 6.2).

The Kearns numbers provide a useful 'first cut' for the evaluation of basal pole texture in the material. However, they are limited to crystallites directions only normal to their basal planes and therefore do not give a complete description of the texture. A complete description of all orientations of crystallites is given by the orientation description function (ODF), where all the crystallites directions, including the prism plane normals directions are also determined.

$$
f_{R}+f_{T}+f_{L}=1
$$


The texture (ODF) data from the sample are used to calculate the Kearns numbers $\left(f_{R}, f_{T}\right.$, and $\left.f_{L}\right)$ using SELFPOLY [6.22],[6.23]. The results for the three sets of samples are compared with previous results for similar CANDU fuel sheath materials [6.26].

\subsection{Anisotropy factors}

\subsubsection{Hill's anisotropy factors derived from mechanical strain data}

A theory of yielding of anisotropic metals was first proposed by Hill [6.27]. Hill proposed three tensile anisotropic factors designated as $F, G$, and $H$. In Cartesian co-ordinates $(\mathrm{r}=$ radial, $\theta=$ transverse, and $\mathrm{z}=$ longitudinal $)$ and for loading only in the principal directions of a tubing where the three shear stress terms are zero, the Hill's yield criterion is defined, in terms of the Huber-von Mises equivalent stress, as

$$
\begin{array}{r}
\bar{\sigma}=\left[F\left(\sigma_{\theta}-\sigma_{z}\right)^{2}+G\left(\sigma_{z}-\sigma_{r}\right)^{2}\right. \\
\left.+H\left(\sigma_{r}-\sigma_{\theta}\right)^{2}\right]^{1 / 2}
\end{array}
$$

The onset of yielding occurs when $\bar{\sigma}=Y$. For isotropic materials, the yield function $Y$ is the same as the yield stress in simple tension. The equivalent strain increment (Levy-von Mises) equations are related to the components of principal stresses, through

$$
\begin{aligned}
& d \varepsilon_{r}=d \lambda\left[H\left(\sigma_{r}-\sigma_{\theta}\right)+G\left(\sigma_{r}-\sigma_{z}\right)\right] \\
& d \varepsilon_{\theta}=d \lambda\left[F\left(\sigma_{\theta}-\sigma_{z}\right)+H\left(\sigma_{\theta}-\sigma_{r}\right)\right] \\
& d \varepsilon_{z}=d \lambda\left[G\left(\sigma_{z}-\sigma_{r}\right)+F\left(\sigma_{z}-\sigma_{\theta}\right)\right]
\end{aligned}
$$

where $d \lambda$ is a proportionality constant defined by following equation [6.28].

$$
\begin{aligned}
& \overline{d \varepsilon}=\bar{\sigma} d \lambda \\
& =\left[H\left(F d \varepsilon_{r}-G d \varepsilon_{\theta}\right)^{2}+F\left(G d \varepsilon_{\theta}-H d \varepsilon_{z}\right)^{2}\right. \\
& \left.\quad+G\left(H d \varepsilon_{z}-F d \varepsilon_{r}\right)^{2}\right]^{1 / 2} /[H F+F G+G H]
\end{aligned}
$$


For isotropic material, $F=G=H=1 / 2$.

From mechanical tests on tubes loaded in the principal directions of the tube, the $F, G$ and $H$ parameters can be determined using longitudinal tensile, open end burst, and closed end burst tests.

In uniaxial tensile test, $\sigma_{r}=\sigma_{\theta}=0$,

$$
\left(\frac{d \varepsilon_{\theta}}{d \varepsilon_{z}}\right)=-\frac{F}{G+H}
$$

In open end burst test, $\sigma_{r}=\sigma_{z}=0$,

$$
\left(\frac{d \varepsilon_{\theta}}{d \varepsilon_{z}}\right)=-\frac{F+H}{H}
$$

In closed end burst test, $\sigma_{r}=0, \sigma_{\theta}=2 \sigma_{z}$,

$$
\left(\frac{d \varepsilon_{\theta}}{d \varepsilon_{z}}\right)=-\frac{F+2 H}{G-F}
$$

As only two equations are independent, a third independent equation is needed to solve for the three unknown parameters, $F, G$, and $H$. Ross-Ross et al. [6.29] suggested that since for isotropic materials, $F=G=H=1 / 2$, the third condition was arbitrary set as $F+G+H=1.5$. In Duncombe's work [6.30], the third condition was also arbitrary set as $F+G=1$. In this work, the third condition suggested by Ross-Ross et al. [6.29] is used in the evaluation of anisotropy factors for the three sets of samples of Zircaloy-4 fuel sheath materials that were measured for texture by neutron diffraction. As discussed in the next section, the texture data are used to derive the anisotropy factors that match with the mechanical anisotropy factors $(F, G$, and $H$ parameters $)$ that have been determined earlier by Hunt [6.20] and Hunt and Newell [6.21] using the above equations (6.5), (6.6), and (6.7) for CANDU fuel sheaths. Their results are shown in Table 6.1. 
Also included for comparison in Table 6.1 are some previous results for the Kearns' texture numbers reported by Coleman et al. [6.26] for two differently fabricated Zircaloy-4 fuel sheaths.

\subsubsection{Modified Hill's criterion}

In a modified criterion, Backofen et al. [6.31],[6.32] reduced the three Hill's anisotropy factors $(F, G$, and $H$ ) to two anisotropy parameters called $R$ and $P$. These two parameters are defined as

$$
R=\frac{F}{H} ; \quad P=\frac{F}{G}
$$

The Hill's yield criterion eqn. (6.3) can be written in terms of $R$ and $P$, as

$$
\bar{\sigma}^{2}=\left[R P\left(\sigma_{\theta}-\sigma_{z}\right)^{2}+R\left(\sigma_{z}-\sigma_{r}\right)^{2}+P\left(\sigma_{r}-\sigma_{\theta}\right)^{2}\right] / P(R+1)
$$

Merkle [6.28] has shown using Prandtl-Reuss energy balance in conjunction with Hill's yield criterion (eqn. 6.3) that the strain increments or strain rates along the principal directions are related, in terms of $R$ and $P$, through

$$
\left[\begin{array}{l}
d \varepsilon_{r} \\
d \varepsilon_{\theta} \\
d \varepsilon_{z}
\end{array}\right]=\frac{\overline{d \varepsilon}}{P(R+1) \bar{\sigma}}\left[\begin{array}{ccc}
(R+P) & -R & -P \\
-R & R(P+1) & -R P \\
-P & -R P & P(R+1)
\end{array}\right]\left[\begin{array}{c}
\sigma_{r} \\
\sigma_{\theta} \\
\sigma_{z}
\end{array}\right]
$$

In a uniaxial tensile test in the longitudinal direction, $\sigma_{r}=\sigma_{\theta}=0$,

$$
R=\left(\frac{d \varepsilon_{\theta}}{d \varepsilon_{r}}\right)
$$

In a uniaxial tensile test in the transverse direction, $\sigma_{r}=\sigma_{z}=0$,

$$
P=\left(\frac{d \varepsilon_{z}}{d \varepsilon_{r}}\right)
$$


The two anisotropy parameters $R$ and $P$ are obtained from the contractile strain (rate) ratios in uniaxial tests. In cases where the $R$ and $P$ values are available for Zircaloy-2 calandria tube materials and with known Kearns numbers [6.33], the Hill's anisotropy factors are calculated using eqn. (6.9) for comparison in this study.

\subsubsection{Hill's anisotropy factors derived from texture data}

The Hill's anisotropy factors $(F, G$ and $H)$ for the fuel sheath materials evaluated in this work are calculated using SELFPOLY with the measured texture (ODF) data as input for the calculations. The SELFPOLY calculated values for anisotropy factors were determined to obtain an imposed reasonable agreement with the Hill's anisotropy factors previously obtained by Hunt [6.20],[6.21] based on mechanical strain tests (Table 6.1.)

The SELFPOLY model is a self-consistent polycrystalline model that has been developed to predict the deformation of polycrystals by averaging the behaviour of individual crystals and by assuming a certain deformation mechanism at the single crystal level [6.22]. Later, Turner et al [6.23] included a model for thermal creep by adopting Hutchinson's slip [6.34] models for power-law steady state creep of polycrystals. Christodoulou et al. [6.35] has employed the model to derive the CRSS (critical resolved shear stress) values that describe plastic yielding. In the SELFPOLY model [6.23], the single-crystal deformation rate is given by

$$
\dot{\varepsilon}_{i j}=\sum_{s} \dot{\gamma}_{0}^{s}\left(\frac{m^{s}: \sigma}{\tau^{s}}\right)^{n} m_{i j}^{s}
$$

Here, $\sigma$ is the deviatoric stress acting on the crystal, the index $s$ stands for the slip system (e.g., prismatic slip $\left(\tau^{p r}\right)$, basal slip $\left(\tau^{b a s}\right)$ or pyramidal slip $\left(\tau^{p y r}\right)$ ), the tensor $m_{i j}^{s}$ is the 
Schmid tensor corresponding to the slip system $s$, and, for each slip system, $\tau^{s}$ and $\dot{\gamma}_{0}^{s}$ are the CRSS and the reference shear strain rate, respectively. The stress-exponent $(n)$ is the inverse of the strain-rate sensitivity, i.e., $n=1 / m$. Details for this formulation are described in [6.35].

From eqn (6.14), the CRSS for prismatic slip $\left(\tau^{p r}\right)$ is set equal to $1 \mathrm{MPa}$ and the magnitude of $\dot{\varepsilon}$ is determined by the constant $\dot{\gamma}_{0}^{s}$. The model has been used in earlier work to derive CRSS values by matching the predicted anisotropy with that observed experimentally, by using a fixed value for the stress-exponent $n$, and adjusting the constant $\dot{\gamma}_{0}^{s}$ (which is considered equivalent to adjusting the absolute values of the CRSS with temperature and keeping the $\dot{\gamma}_{0}^{s}$ constant). The matching of results between predictions and experiments normally yields the ratio of CRSS values for prismatic, basal, and pyramidal glide. For plastic deformation of $\mathrm{Zr}-2.5 \mathrm{Nb}$ pressure tube material, Christodoulou et al. [6.35] found the CRSS ratio to be 1:1.6:2.5 (i.e., $\tau^{p r}: \tau^{b a s}: \tau^{p y r}$ ). In a similar analysis by Pang et al. [6.36] who fitted the tensile loading curves for Zircaloy-2 material under uniaxial deformation to determine suitable parameters for the three slip modes $(\mathrm{PR}=$ prismatic, $\mathrm{BAS}=$ basal, and $\mathrm{PYR}=$ pyramidal $)$, they found that the CRSS values were $90 \mathrm{MPa}$ for PR, $160 \mathrm{MPa}$ for BAS and $240 \mathrm{MPa}$ for PYR, giving a CRSS ratio of 1:1.8:2.7. This CRSS ratio is close to those of Christodoulou et al. [6.35].

In this present analysis, SELFPOLY is used to calculate the Hill's anisotropy factors using a fixed value for the CRSS ratio from Pang et al. [6.36] and the value for the stress-exponent $n$ is obtained through use of a texture-based parameter, $\zeta$ given as 


$$
\zeta=n=\frac{f_{T}}{f_{L}}+\left(f_{R}-f_{L}\right)^{2}+\left(f_{R}-f_{T}\right)^{2}+\left(f_{T}-f_{L}\right)^{2}
$$

where $n$ is the stress-exponent parameter used in SELFPOLY (eqn. (6.14), and $f_{R}, f_{T}, f_{L}$, are the Kearns numbers defined in eqn. (6.1). In this present analysis, eqn. (6.15) has been derived for the texture-based parameter $(\zeta)$ as a variable parameter to be substituted for the value of the stress-exponent, $n$, rather than using an arbitrarily assigned fixed value (i.e., a constant parameter), such as the stress-exponent value from a power-law creep rate equation. The derivation of eqn. (6.15) is obtained by imposing a reasonable agreement of the calculated values for Hill's anisotropy factors with those measured by Hunt [6.20] and Hunt and Newell [6.21] from mechanical strain tests on Zircaloy-4 fuel sheaths having very similar microstructures. Although the fitted value for $\zeta$ is based on texture parameters may be considered empirical, its physical justification may be related to the distance for mobile dislocations to slip and reach the grain boundaries or sinks.

The summarized results are presented in Table 6.1. In this SELFPOLY calculation, the Hill's anisotropy factors were determined using a fixed set of CRSS values based on Pang et al. [6.36] evaluation on Zircaloy-4 rod material and a variable value for the stress-exponent to be that of the texture-based parameter.

The mechanical anisotropy in fuel sheaths with different microstructures under biaxial stressing are also compared (in Section 6.3.2) with yield loci (normalized) as described by the Hill's yield criterion (eqn. (6.3)). As shown in this analysis, the anisotropy factors calculated for a range of zirconium-alloy materials such as $\mathrm{Zr}-2.5 \mathrm{Nb}$ pressure tube, Zircaloy-2 calandria tubes and Zircaloy-4 fuel sheaths, appear to vary in a 
systematic manner as a function of the Kearns numbers, $\left[\left(f_{R}-f_{L}\right)^{2}+\left(f_{R}-f_{T}\right)^{2}+\right.$ $\left.\left(f_{T}-f_{L}\right)^{2}\right]$.

\subsection{Results and Discussion}

\subsubsection{Textures of Zircaloy-4 fuel sheaths at $100^{\circ} \mathrm{C}$}

Figure 6.4 shows the basal and prism pole figures of $\alpha-\mathrm{Zr}$ phase in the three sets of samples of Zircaloy-4 fuel sheath materials measured at $100^{\circ} \mathrm{C}$. One set of samples consists of the as-manufactured fuel sheath material. The other two sets are from the same as-manufactured fuel sheath materials that had been processed with a simulated brazing cycle. One simulated braze at $1050^{\circ} \mathrm{C}$ for $50 \mathrm{~s}$ resulting in a $\beta$-transformed structure (Figure $6.2 \mathrm{~b}$ ), and the other heated at $815^{\circ} \mathrm{C}$ for $50 \mathrm{~s}$ simulating the heataffected-zone (HAZ) (Figure 6.2c) material in the region near the brazed appendages in a CANDU fuel sheathing element. All the pole figures are shown in a non-symmetrized representation.

As shown in Figure 6.4a, the as-manufactured fuel sheath has a predominant radial texture, as most of the (0002) basal plane normals are concentrated in the tube's radial direction. The prism $(11 \overline{2} 0)$ poles are aligned parallel to the tube's longitudinal direction. The strong radial texure in this tubing is not quite similar to the expected $\pm 30^{\circ}$ orientation for the basal poles seen in similar fuel cladding materials. The reason for such differences in texture features could be due to the manufacturing processes used to fabricate the sheaths and cladding materials. 
For the fuel sheath containing $\alpha$-annealed HAZ material the radial texture as shown in Figure $6.4 \mathrm{~b}$ is also similar to that for the as-manufactured fuel sheath. The simulated brazing at $815^{\circ} \mathrm{C}$ for $50 \mathrm{~s}$ did not appear to change much of its initial texture apart from producing an equiaxed grain structure (Figure 6.2c) indicating a fully annealed treatment despite given such a short time at the elevated temperature. It is also shown in Figure $6.4 \mathrm{~b}$ that there is little or no rotation of grains about its c-axis since the prism poles appeared to be still aligned parallel to the tube's longitudinal direction. This non-alignment implies that there was no recrystallization of the cold-worked (deformed) grains (Figure 6.2a) in the as-manufactured fuel sheath material to result in formation of an equiaxed shape grain structure. The equiaxed grain structure of the $\alpha$-annealed HAZ material is a result of grain growth, which would have little or no effect on the texture of the original grains.

In simulated brazing of the as-manufactured fuel sheath material at $1050^{\circ} \mathrm{C}$ for $50 \mathrm{~s}$, there is a change in texture from a predominantly radial to one that is mixed (i.e., radial and non-radial) or almost random texture (Figure 6.4c). This high-temperature brazing cycle produced a basketweave structure (Figure 6.2b) as a result of the phase transformation on cooling from being heated in the full $\beta$-phase field.

\subsubsection{Textures of Zircaloy-4 fuel sheaths at high temperatures $\left(500^{\circ} \mathrm{C}-1000^{\circ} \mathrm{C}\right)$ and on cooling}

Figure 6.5 shows the textures of $\alpha$ and $\beta$ phases in the three sets of samples of Zircaloy-4 fuel sheath materials evaluated in this study. The textures on heating from 
$500^{\circ} \mathrm{C}$ to $800^{\circ} \mathrm{C}$ are shown in Figure $6.5 \mathrm{a}$. On heating at $750^{\circ} \mathrm{C}$, only $\alpha$ phase was present in all the three sets of samples. Heating at $800^{\circ} \mathrm{C}$ to $950^{\circ} \mathrm{C}$, resulted in two phases ( $\beta$ and $\alpha$ ) being present (Figure 6.5a and Figure 6.5b) due to the transformation of some of the hep $\alpha-Z r$ grains to the bcc $\beta-Z r$ grain structure, which is more stable at the higher temperatures. For as-manufactured fuel sheath, heating was completed up to $850^{\circ} \mathrm{C}$.

On further heating to $950-1000^{\circ} \mathrm{C}$ (Figure $6.5 \mathrm{~b}$ ), only the $\alpha$-annealed sample was investigated where it is shown that only the $\beta$ phase was present as all of the $\alpha-\mathrm{Zr}$ was completely transformed to the $\beta$-Zr phase. Texture data for the $\beta$-transformed sample were only available on heating at $950^{\circ} \mathrm{C}$, and not at $1000^{\circ} \mathrm{C}$. For the $\alpha$-annealed and $\beta$-transformed samples on cool-down to near room temperatures (Figure 6.5c), the textures shown do not fully resemble its initial textures as produced from the simulated brazing cycle (Figure 6.4). The cool-down texture of the $\beta$-transformed material appears to be more randomized than its initial texture. In comparison, the $\alpha$-annealed sample showed a 90 deg. rotation of its initial radial texture on cool-down after being heated to 


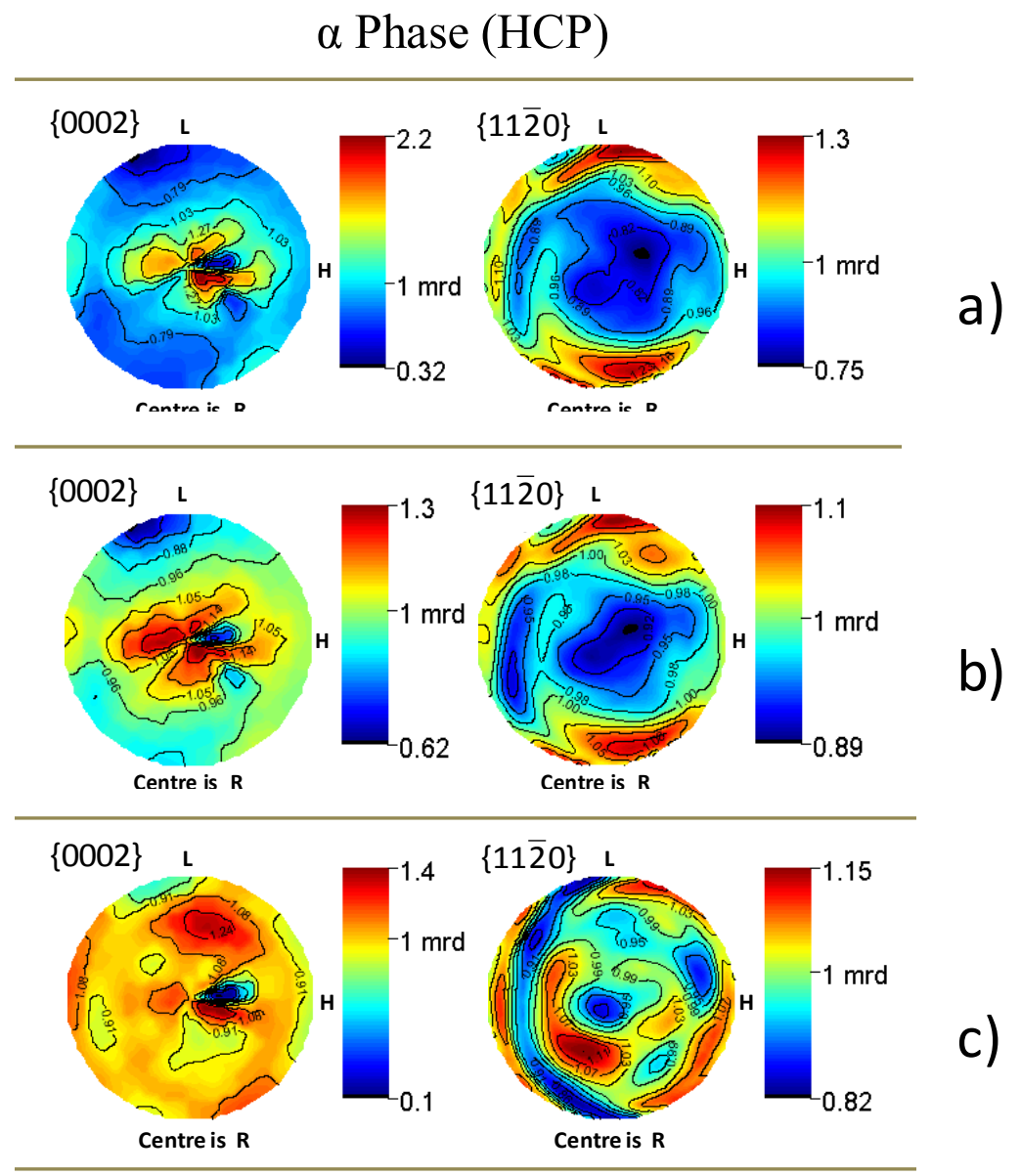

Figure 6.4 Basal (0002) and prism (11200) pole figures of $\alpha-Z r$ phase in Zircaloy-4 fuel sheaths measured at $100^{\circ} \mathrm{C}$ : a) as-manufactured, b) $\alpha$-annealed (HAZ), and c) $\beta$-transformed structure

$1000^{\circ} \mathrm{C}$, without any indication of a randomized texture that is obtained from simulated brazing at $1050^{\circ} \mathrm{C}$ for $50 \mathrm{~s}$ (Figure $6.2 \mathrm{~b}$ and Figure 6.4). As the texture measurements at $1000^{\circ} \mathrm{C}$ took $\sim 1 \mathrm{~h}$ to complete, in comparison to the short time $(50 \mathrm{~s})$ in the simulated brazing cycle at a slightly higher temperature $\left(1050^{\circ} \mathrm{C}\right)$, the longer time allows the $\beta-\mathrm{Zr}$ grains to grow much bigger than it would have otherwise been for the much shorter time 
at high temperature. It is well known [6.2],[6.3] that larger prior- $\beta$ grains tend to result in a parallel-plate type of Widmanstätten structure, such that the resulting texture is usually also randomized as compared with a basketweave structure which usually results from an abundance of second phase particles and smaller-sized prior- $\beta$ grains

\subsubsection{Comparison of Hill's anisotropy factors derived from texture and mechanical strain tests}

A comparison of the Kearns numbers and Hill's anisotropy factors for a range of differently-processed Zircaloy-4 fuel sheaths is given in Table 6.1. Some data from earlier work ([6.20],[6.21],[6.26]) are included in this table to show a typical range of values for these material parameters.

\subsubsection{Kearns numbers}

In the work of Coleman et al. [6.26], Table 6.1, only the Kearns numbers are available for as-manufactured (i.e., as-received) Zircaloy-4 fuel sheaths. These numbers were obtained from X-ray diffraction. However, the Hill's anisotropy factors were not available for those fuel sheath materials. Therefore, the Kearns numbers as determined from this study using the neutron diffraction texture data obtained for the asmanufactured Zircaloy-4 fuel sheaths can be compared in the same material condition (i.e., as-manufactured production tubing). It can be seen in Table 6.1 that the Kearns numbers for as-received (i.e., not braze) fuel sheath obtained from this study $\left(f_{R}=0.54\right.$, $\left.f_{T}=0.28, f_{L}=0.18\right)$ are almost the same as those for Atucha fuel sheath materials $\left(f_{R}=0.56\right.$, $\left.f_{T}=0.29, f_{L}=0.15\right)$. The Kearns numbers are also similar to those of Zircatec fuel sheaths 
$\left(f_{R}=0.65, f_{T}=0.30, f_{L}=0.05\right)$. The results from this study suggest that the texture (ODF) data obtained at $100^{\circ} \mathrm{C}$ from neutron diffraction measurements and used in calculating the Kearns numbers using SELFPOLY gave agreement with the X-ray data from earlier work.

Table 6.1 Kearns numbers and Hill's anisotropy factors for differently-processed Zircaloy-4 fuel sheath materials.

\begin{tabular}{|c|c|c|c|c|c|c|c|c|}
\hline \multirow{3}{*}{$\begin{array}{l}\text { Material } \\
\text { Parameters }\end{array}$} & \multicolumn{3}{|c|}{ Fong (This study) } & \multirow{2}{*}{\multicolumn{2}{|c|}{ Coleman et al. [6.26] }} & \multirow{2}{*}{\multicolumn{3}{|c|}{$\begin{array}{c}\text { Hunt [6.20], } \\
\text { Hunt and Newell [6.21] }\end{array}$}} \\
\hline & \multirow{2}{*}{$\begin{array}{c}\text { Not } \\
\text { Braze } \\
\text { (As- } \\
\text { mfg'd) }\end{array}$} & \multicolumn{2}{|c|}{ Simulated Braze } & & & & & \\
\hline & & $\begin{array}{c}\alpha \text {-ann. } \\
(\mathrm{HAZ}) \\
\left(815^{\circ} \mathrm{C},\right. \\
50 \mathrm{~s})\end{array}$ & $\begin{array}{c}\beta- \\
\text { transformed } \\
\left(1050^{\circ} \mathrm{C}\right. \\
50 \mathrm{~s})\end{array}$ & $\begin{array}{c}\text { Zircatec } \\
\text { As-Rec'd } \\
\text { (Lot } \\
\text { 226289) }\end{array}$ & $\begin{array}{l}\text { Atucha } \\
\text { As- } \\
\text { Rec'd } \\
\text { (Lot } \\
\text { MA-61) }\end{array}$ & $\begin{array}{c}\text { As- } \\
\text { Rec'd }\end{array}$ & $\begin{array}{c}\alpha- \\
\text { annealed } \\
\left(800^{\circ} \mathrm{C},\right. \\
1 \mathrm{~h})\end{array}$ & $\begin{array}{c}\beta \text {-treated } \\
\left(1060^{\circ} \mathrm{C},\right. \\
40-60 \mathrm{~s})\end{array}$ \\
\hline \multicolumn{9}{|c|}{ Kearns numbers ( $R=$ radial; $T=$ transverse; $L=$ longitudinal; direction of principal axis of the tube): } \\
\hline$f_{R}$ & 0.54 & 0.53 & 0.51 & 0.65 & 0.56 & - & - & - \\
\hline$f_{T}$ & 0.28 & 0.28 & 0.26 & 0.30 & 0.29 & - & - & - \\
\hline$f_{L}$ & 0.18 & 0.19 & 0.24 & 0.05 & 0.15 & - & - & - \\
\hline \multicolumn{9}{|c|}{ Hill's Anisotropy Factors: } \\
\hline$F$ & 0.76 & 0.73 & 0.58 & - & - & 0.76 & 0.96 & 0.57 \\
\hline$G$ & 0.54 & 0.56 & 0.54 & - & - & 0.56 & 0.32 & 0.42 \\
\hline$H$ & 0.20 & 0.21 & 0.38 & - & - & 0.18 & 0.22 & 0.51 \\
\hline
\end{tabular}




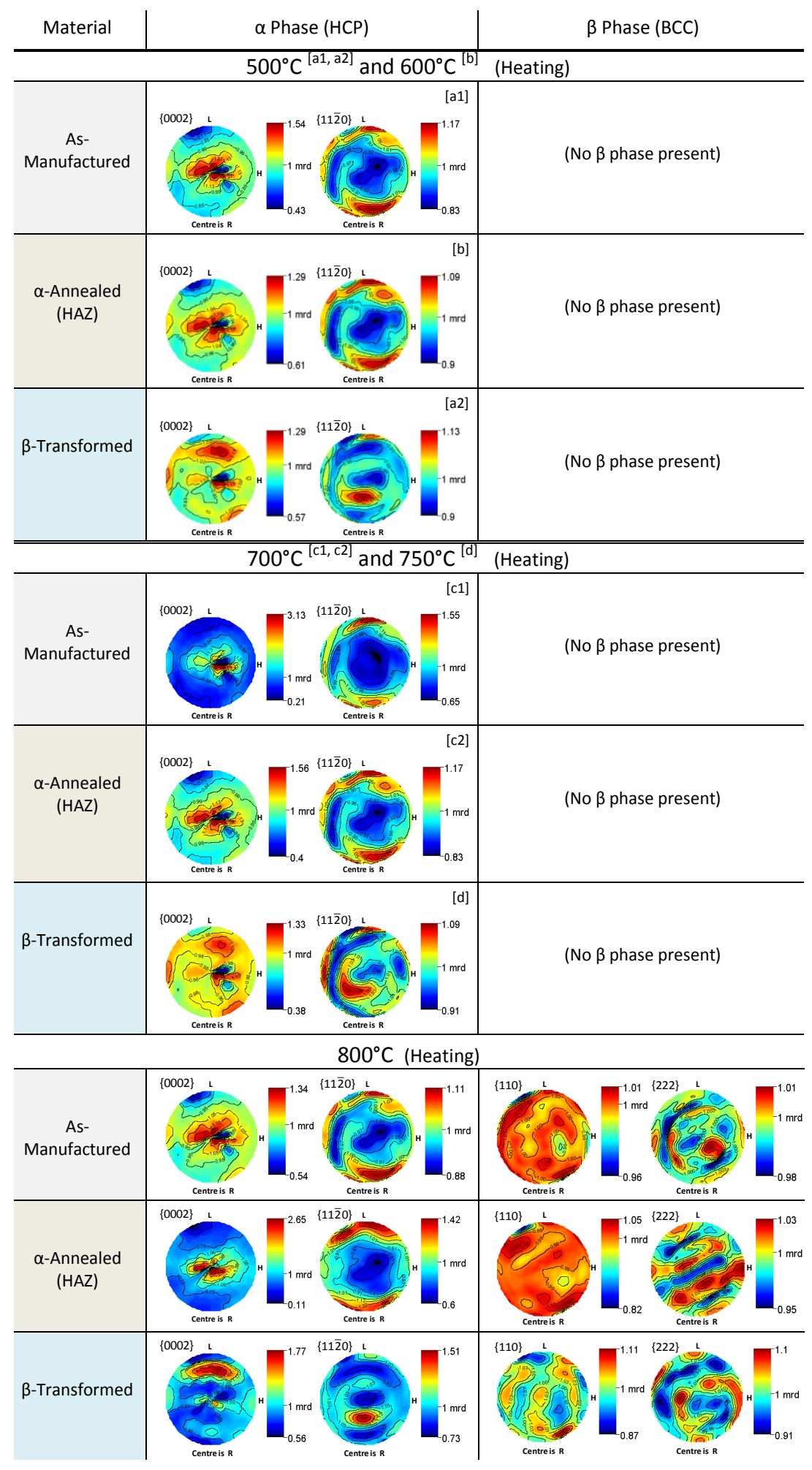

Figure 6.5 Pole figures of Zircaloy-4 fuel sheaths measured on heating at $500^{\circ} \mathrm{C}$ to $800^{\circ} \mathrm{C}$ 


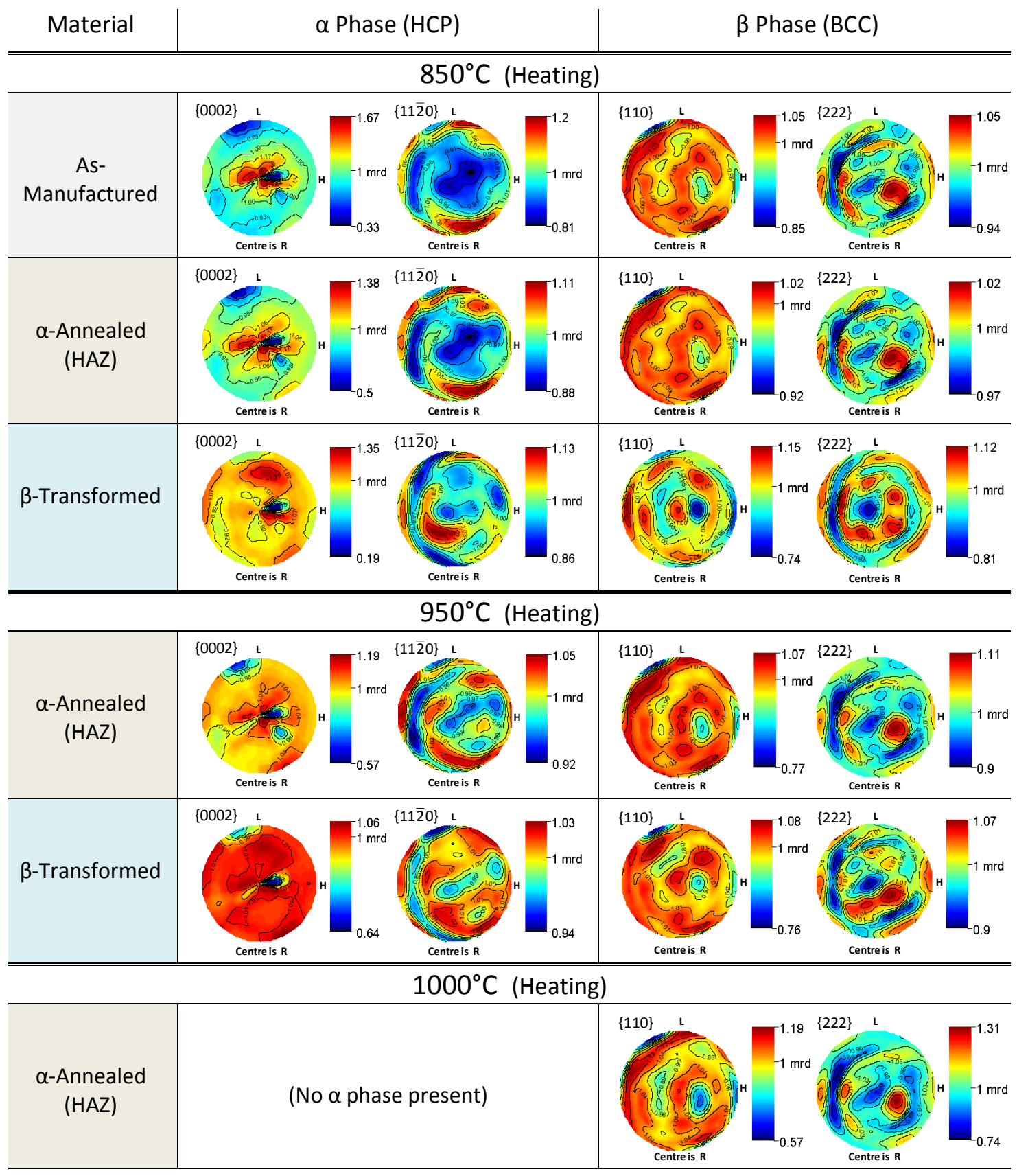

Figure 6.6 Pole figuresof Zircaloy-4 fuel sheaths measured on heating at $850^{\circ} \mathrm{C}$ to $1000^{\circ} \mathrm{C}$ 


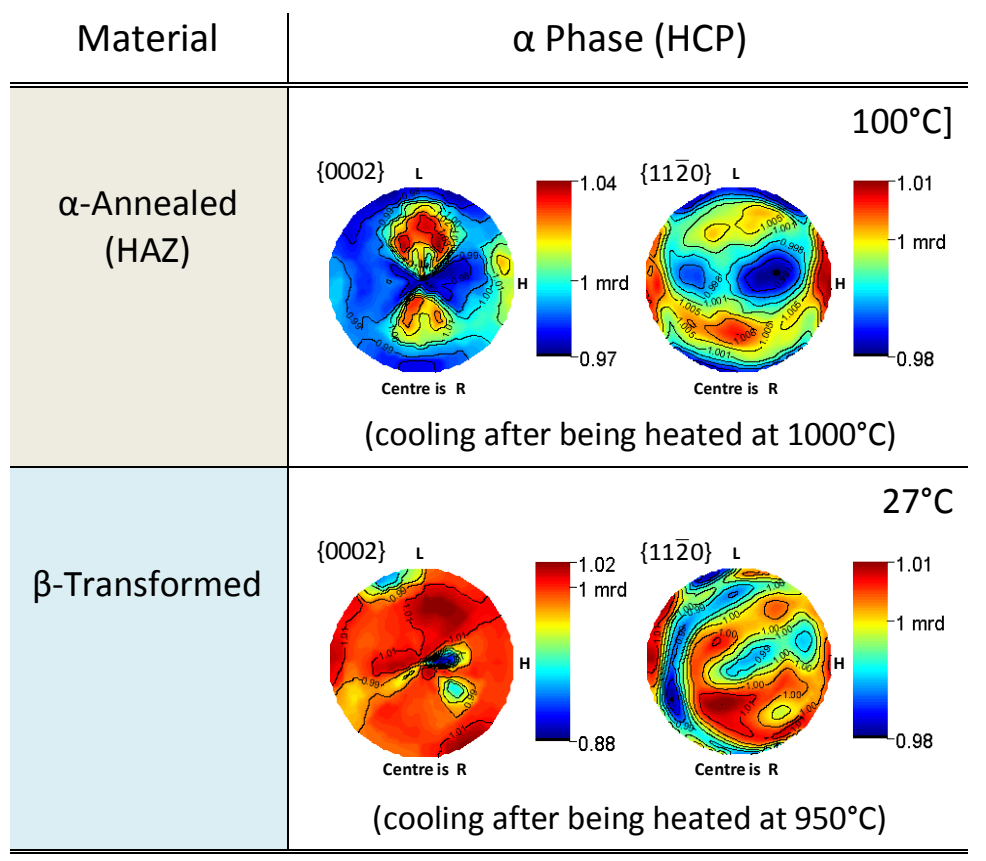

Figure 6.7 Pole figures of Zircaloy-4 fuel sheaths measured on cooling to near room temperature

In the work of Hunt et al. [6.20],[6.21], there is no information for the Kearns numbers for the three different conditions of the Zircaloy-4 fuel sheath materials (Table 6.1). Although no definite comparison can be made, the Kearns numbers for Hunt's as-received fuel sheath (i.e., as-manufactured production tubing) are expected to be similar to those of Coleman's [6.26], and thus would therefore be similar to the Kearns numbers for the as-received (i.e., not braze) fuel sheath materials used in this study. On the basis of their similar Kearns numbers, it would be justified to assume that textures for all the as-manufactured fuel sheaths indicted in Table 6.1 to have much the same type of texture (i.e., basal poles aligned along the radial direction of the tube). 


\subsubsection{Anisotropy factors}

As discussed above, since the Kearns numbers are similar for the as-manufactured fuel sheaths (Table 6.1) it can be expected that these tubes would also show similar mechanical anisotropy. However, only the work of Hunt et al. [6.20],[6.21] has determined the values for the Hill's anisotropy factors $F, G$, and $H$, using mechanical strain tests on fuel sheath materials and deriving them using eqn. (6.6), eqn. (6.7) and eqn. (6.8). In comparison, the anisotropy factors derived in this study used the texture (ODF) data analysed by the SELFPOLY model with a fixed set of CRSS values and a texture-based (variable) numerical value, $\zeta$, that replaces the fixed (preset) value for the stress-exponent $n$ required for the SELFPOLY calculations.

Table 6.1 lists the SELFPOLY calculated values for the anisotropy factors obtained from this analysis as compared to those obtained from mechanical strain tests. For as-received (i.e., not braze) fuel sheath used in this study, the calculated values for anisotropy factors $(F=0.76, G=0.54, H=0.20)$ are almost the same as those measured by mechanical strain $(F=0.76, G=0.56, H=0.18)$. These results are in good agreement as they were imposed to be in good agreement. In comparing the calculated anisotropy factors for the $\beta$-transformed fuel sheath with those from mechanical strain tests for $\beta$-treated fuel sheath material, the values for $F, G$, and $H$ are also in good agreement. Finally, a similar trend is observed for the $\alpha$-annealed fuel sheath materials; however the results cannot be compared directly because of the difference in annealing times $(50 \mathrm{~s}$ compared to $1 \mathrm{~h}$ ) at similar temperatures. As discussed earlier, a longer exposure time promotes grain growth and thus changes the cool-down texture from phase 
transformation of $\beta-\mathrm{Zr}$ to $\alpha-\mathrm{Zr}$ with mixed grain structure consisting of parallel-type platelets rather than a basketweave-type.

In this analysis of the texture (ODF) data using SELPOLY to calculate the anisotropy factors, it was found that the use of a fixed value assigned to the "stressexponent, $n$ " that is same as that for the stress exponent in a creep rate equation, there is no possible set of values for the CRSS that can be used to arrive at matching the $F, G$, and $H$ values with those from mechanical strain experiments.

The results presented in this study demonstrate that the use of a texture-based (variable) parameter (eqn. 6.15) in place of a prefixed-value for the stress-exponent, $n$, yielded some reasonable agreement between the calculated anisotropy factors and those obtained from experiments. Figure 6.8 summarizes the results and comparison in a plot of a normalized yield surface using Hill's yield criterion (eqn. (6.3)) for biaxial stressing in thin-walled tubing such as the fuel sheathing materials evaluated in this study. Since the textures appeared to be stable at higher heating temperatures, it can be expected that the high-temperature anisotropy factors would also be stable.

Using a texture-based parameter substituted for the stress-exponent value used in SELFPOLY calculation, the anisotropy factors for a $\mathrm{Zr}-2.5 \mathrm{Nb}$ CANDU pressure tube material were also calculated using the texture (ODF) data at $100^{\circ} \mathrm{C}$ that were previously measured by neutron diffraction [6.24]. The calculated values $(F=1.03, G=0.34$, $H=0.13)$ disagreed in some order with the experimental values $(F=0.32, G=0.28, H$ $=0.90$; mat 4 in Table VI [6.29]). However, it is possible that the values for $F, G$ and $H$ could be in a different order as it depends on how the Hill's yield criterion is defined. 
In addition to the above analysis using texture (ODF) data to calculate for anisotropy factors, the experimental $R$ and $P$ parameters (eqn. (6.12) and eqn. (6.13)) measured on two types of Zircaloy-2 seamless calandria tubes [6.33] were also used to determine the anisotropy factors as defined by eqn. (6.9).

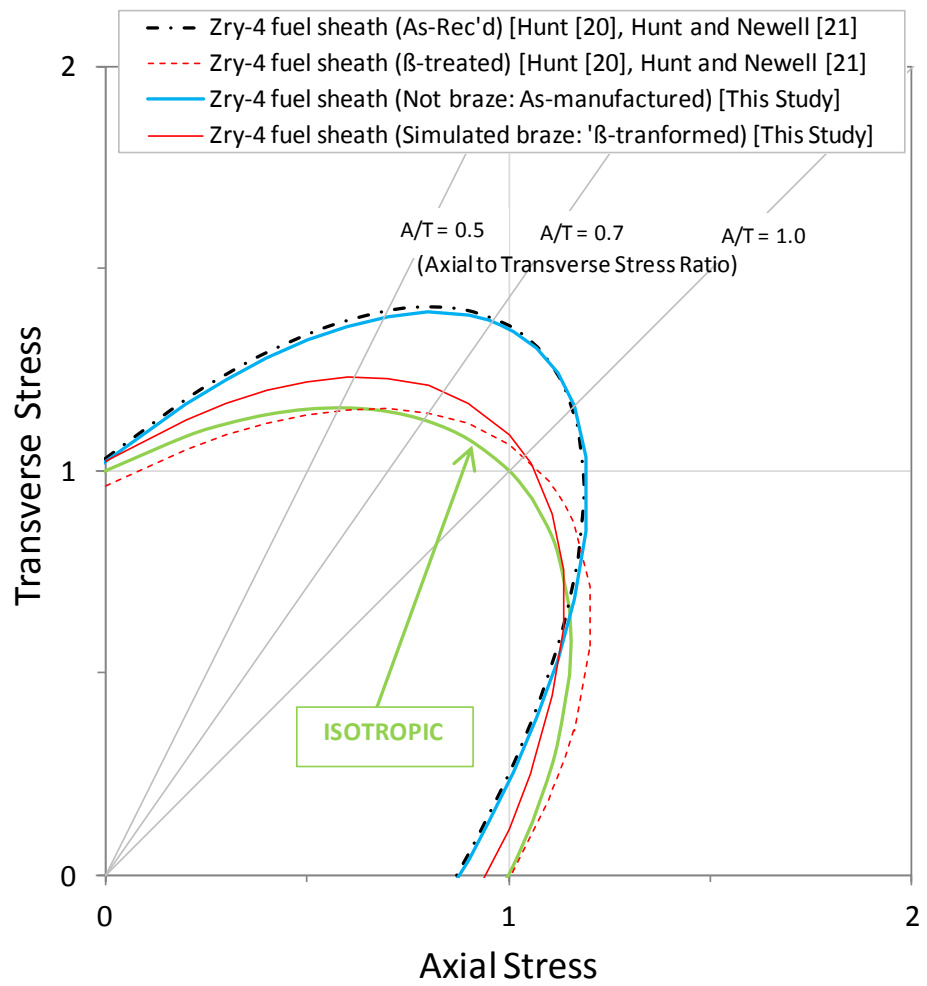

Figure 6.8 Yield loci for differently processed Zircaloy-4 fuel sheath materials 
Figure 6.9 shows a plot of the anisotropy factors as a function of the Kearns numbers $\left(\left[\left(f_{R}-f_{L}\right)^{2}+\left(f_{R}-f_{T}\right)^{2}+\left(f_{T}-f_{L}\right)^{2}\right]\right)$ for those calculated using texture (ODF) data and analyzed by SELFPOLY model and those determined using the $R$ and $P$ parameters. These results show a clear effect of texture on mechanical anisotropy of zirconium alloys materials. As shown in the plot, the material would respond in a isotropic manner (i.e., $F$ $=G=H=0.5)$ if the values of the Kearns numbers fall within the range from zero to about 0.1 since in this range the values for texture parameters $\left(f_{R}, f_{T}\right.$ and $\left.f_{L}\right)$ would be approximately equal. This means that there is about an equal distribution of the 'hard' direction (c-axis) of Zr-grains in the three principal directions (axial, transverse and radial) of the sample material. As the value for the Kearns numbers increases above 0.1 to about 0.2 , there is a sharp increase in the mechanical anisotropy of the material. This means that the distribution of the c-axis of the $\mathrm{Zr}$-grains is uneven. Between the values of 0.2 and 0.5 , there is little change in the anisotropy behaviour. Finally, for values beyond 0.5 , the mechanical anisotropy steadily becomes more pronounced. The trend in the mechanical anisotropy is a direct result of the texture in the material and consequently different deformation modes (different slip systems or twinning) can become more operative than others to produce the deformation strain behaviour when the material being stressed, biaxially. 


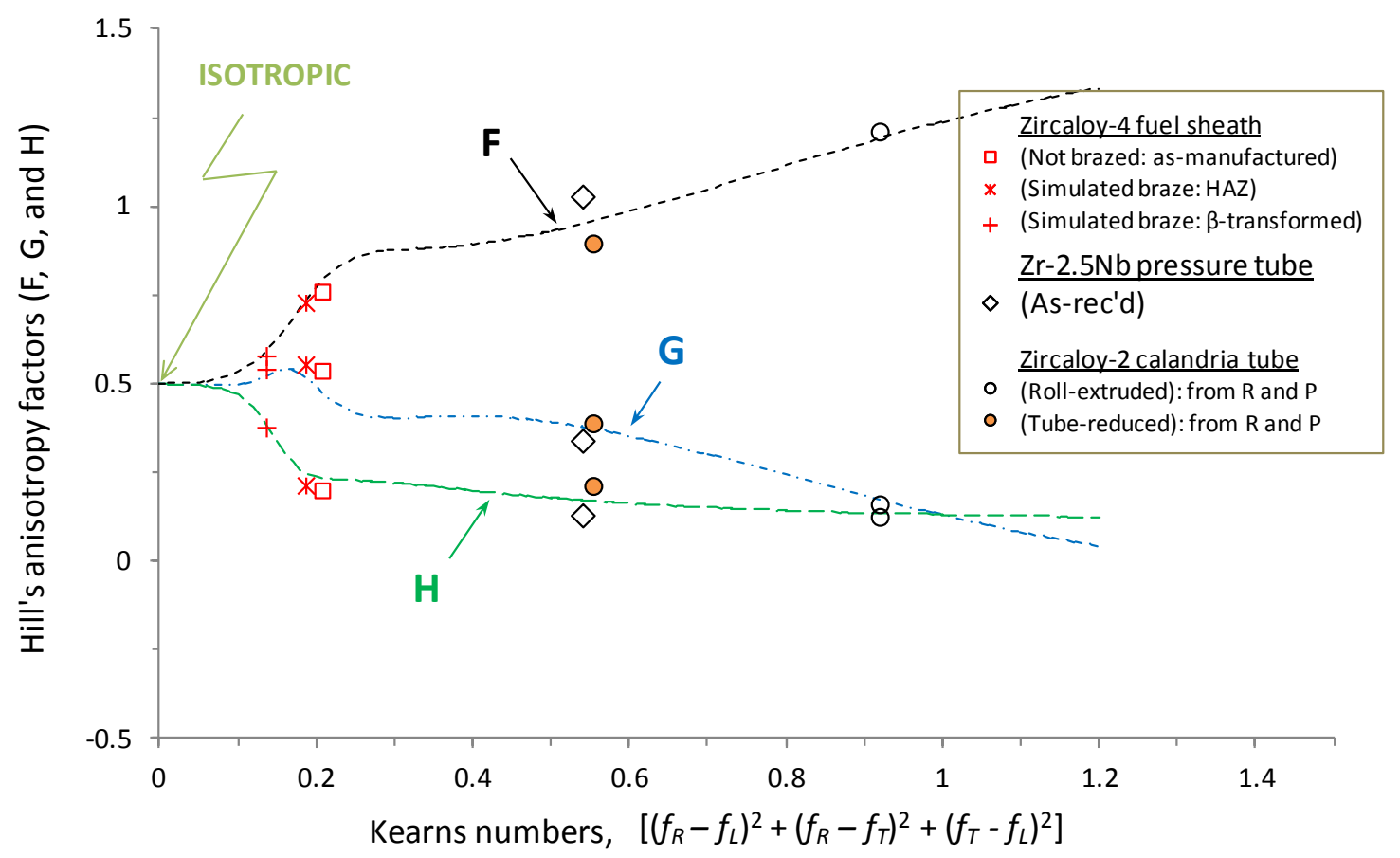

Figure 6.9 Plot of anisotropy factors as a function of Kearns numbers, $\left[\left(f_{R}-f_{L}\right)^{2}+\left(f_{R}-f_{T}\right)^{2}+\left(f_{T}-f_{L}\right)^{2}\right]$, for Zircaloy-4 fuel sheaths, Zr-2.5Nb pressure tube and Zircaloy-2 seamless calandria tubes.

\subsection{Conclusions}

The crystallographic textures in three sets of samples taken from: (i) asmanufactured (i.e., as-received) production Zircaloy-4 fuel sheaths, (ii) $\alpha$-annealed material (i.e., taken from the same as-received fuel sheath after given a simulated brazing cycle $\left(1050^{\circ} \mathrm{C}, 50 \mathrm{~s}\right)$, and (iii) $\beta$-transformed material (i.e., taken from the same as-received fuel sheath material after given a simulated brazing cycle $\left(815^{\circ} \mathrm{C}, 50 \mathrm{~s}\right)$ have been characterized on heating at $100^{\circ} \mathrm{C}$ and up to $1000^{\circ} \mathrm{C}$. The textures on cool-down to near room temperatures have also been evaluated. The following conclusions are drawn from this study. 
1. During heating to $750^{\circ} \mathrm{C}$, the three sets of samples showed only the $\alpha$-phase present and their textures to be quite stable, with little change in the $\{0002\}$ basal and $\{11 \overline{2} 0\}$ prism pole figures. On heating at $800^{\circ} \mathrm{C}$, the $\beta$-phase material was detected in the presence of the $\alpha$-phase material in all three sets of samples. At $800^{\circ} \mathrm{C}$, only the sample with $\beta$-transformed material showed its $\alpha$-phase texture had evolved slightly, and on further heating at $850^{\circ} \mathrm{C}$ and $950^{\circ} \mathrm{C}$ this texture had evolved again to resemble its initial texture observed at $100^{\circ} \mathrm{C}$. In comparison, the textures in the other two sets of samples did not show any texture evolution during heating to $950^{\circ} \mathrm{C}$. On cool-down, the textures of the $\alpha$-annealed and $\beta$-transformed samples do not fully resemble its initial textures as produced from the simulated brazing cycle. This difference in texture is a result of grain growth that occurs during the much longer times (hours) at the high temperatures when the texture measurements were made on the samples as compared to the short-time brazing cycle $(<60 \mathrm{~s})$ used to prepare the samples initially.

2. Heating at $1000^{\circ} \mathrm{C}$ indicated only $\beta$-phase material was present in the $\alpha$-annealed sample material.

3. Using the texture data measured at $100^{\circ} \mathrm{C}$ for the three sets of samples, the orientation distribution function (ODF) of all the $\alpha-\mathrm{Zr}$ crystallites in the sample was analyzed using SELFPOLY (a self-consistent, polycrystalline model) to calculate (i) the Kearns number (one form of texture parameter) and (ii) the Hill's anisotropy factors using an $\alpha$-phase texture-based parameter (e.g., the Kearns numbers replacing the value for the stress-exponent, $n$ ) and a pre-fixed set of values (ratios) for CRSS 
(critical resolved shear stress) from Pang et al. [6.36] for three slip systems in hcp $\alpha-\mathrm{Zr}$ crystals.

4. The SELFPOLY calculated values for the Kearns numbers showed good agreement with previously obtained values from X-ray diffraction on similar type of Zircaloy-4 fuel sheathing materials. The calculated values for the Hill's anisotropy factors showed some reasonable imposed agreement with previously obtained values from mechanical strain tests on similar type of Zircaloy-4 fuel sheaths.

5. The results from this study clearly show the effect of textures on mechanical anisotropy factors for a range of zirconium-alloy tubes such as fuel sheathing, pressure tube and calandria tubes with different starting textures and microstructures. A randomized texture (i.e., (with the Kearns numbers, $f_{R}, f_{T}$ and $f_{L}$ being approximately equal) results in no mechanical anisotropy (i.e., isotropic, with the Hill's factors, $F=G=H=0.5$ ). As the texture becomes less randomized (i.e., the texture becomes sharper as the values for the Kearns numbers become more different between each other), the mechanical anisotropy increases (i.e., $F \neq G \neq H$ ).

\section{References}

[6.1] R.A. Holt, W. Evans and B.A Cheadle, The role of zirconium alloy metallurgy in the fabrication of CANDU fuel, Atomic Energy of Canada Ltd. Report AECL-5107, 1975

[6.2] D.O. Northwood and W.L. Fong, Effect of brazing on the mechanical anisotropy of Zircaloy-4 nuclear fuel cladding, Can. Met. Quart., Vol. 22 (3), pp. 411-419, 1982

[6.3] W.L. Fong and D.O. Northwood, Identification of second-phase particles in Zircaloy-4 nuclear fuel sheathing, Metallography, Vol. 15, pp. 27-41, 1982 
[6.4] VO Quach and D.O. Northwood, Influence of the phosphorus impurity content on the microstructure of Zircaloy-4 air cooled from the high temperature beta phase region, Metallography, Vol. 17, pp. 191-201, 1984

[6.5] J.J. Kearns, J.E. McCauley and F.A. Nichols, Effect of alpha/beta phase constitution on superplasticity and strength of Zircaloy-4, J. Nucl. Mater., Vol. 61, pp. 169-184, 1976

[6.6] H.E. Rosinger and A.E. Unger, The superplastic and strain-rate dependent plastic flow of zirconium-2.5 wt\% niobium in the 873 to $1373 \mathrm{~K}$ temperature range, Atomic Energy of Canada Ltd. Report AECL-6418, 1979

[6.7] H.E. Sills and R.A. Holt, Predicting high-temperature transient deformation from microstructural models, Zirconium in the nuclear Industry: $4^{\text {th }}$ Conf. ASTM STP 681, pp. 325-341, 1979

[6.8] H.E. Sills and R.A. Holt, NIRVANA, a high-temperature creep model for Zircaloy fuel sheathing, Atomic Energy of Canada Ltd. Report AECL-6412, 1979

[6.9] T. Forgeron, J.C. Brachet, F. Barcelo, A. Castaing, J. Hivroz, J.P. Mardon, and C. Bernaudat, Experiment and modeling of advanced fuel rod cladding behaviour under LOCA conditions: alpha-beta phase transformation kinetics and EDGAR methodology, Zirconium in the nuclear Industry: $12^{\text {th }}$ Int. Symp.ASTM STP 1354, pp. 256-278, 2000

[6.10] S. Malinov, P. Markovsky, W. Sha, and Z. Guo, Resistivity study and computer modelling of the isothermal transformation kinetics of Ti-6Al-4V and Ti-6Al-2Sn-4Zr2Mo-0.08Si alloys, J. Alloys and Compounds, Vol. 314, pp. 181-192, 2001

[6.11] I.T. Bethune and C.D. Williams, The $\alpha /(\alpha+\beta)$ boundary in the Zr-Nb system, J. Nucl. Mater. Vol. 29, pp. 129-132, 1968

[6.12] G.G. Seward, S. Celotto, D.J. Prior, J. Wheeler, and R.C. Pond, In situ SEM-EBSD observations of the hep to bcc phase transformation in commercially pure titanium, Acta Mater., Vol. 52, pp. 821-832, 2004

[6.13] Z.S. Zhu, J.L. Gu, R.Y. Liu, N.P. Chen and M.G. Yan, Variant selection and its effect on phase transformation textures in cold rolled titanium sheet, Mat. Sci. \& Engr., Vol. A280, pp. 199-203, 2000

[6.14] J.W. Elmer, T.A. Palmer, S.S. Babu and E.D. Specht, In situ observations of lattice expansion and transformation rates of $\alpha$ and $\beta$ phases in Ti-6Al-4V, Mater. Sci., Vol. A391, pp. 104-113, 2005 
[6.15] J. Romero, M. Preuss, J. Quinta da Fonseca, Texture memory and variant selection during phase transformation of a zirconium alloy, Acta Mater., Vol. 57, pp. 5501-5511, 2009

[6.16] J. Romero, M. Preuss, J. Quinta da Fonseca, R.J. Comstock, M. Dahlback, and L. Hallstadius, Texture evolution of Zircaloy-2 during beta-quenching: effect of process variables, J. ASTM Inter., Vol. 7, No. 9, 2010

[6.17] B.K. Damkroger, D. Juul Jensen and G.R. Edwards, In-situ measurement of phase transformation kinetics using neutron diffraction, Scripta Mater., Vol. 22, pp. 287-291, 1988

[6.18] H-R Wenk, I. Lonardelli and D. Williams, Texture changes in the hcp $\rightarrow$ bcc $\rightarrow h c p$ transformation of zirconium studied in situ by neutron diffraction, Acta Mater. Vol. 52, pp. 1899-1907, 2004

[6.19] J.J. Kearns, Thermal expansion and preferred orientation in Zircaloy, WAPD-TM-472, 1965

[6.20] C.E.L. Hunt, Anisotropic theory and the measurement and use of the anisotropic factors for Zircaloy-4 fuel sheaths, Transactions, $3^{\text {rd }}$ Int. Conf. on Structural Mechanics in Reactor Technology, London, U.K., Vol. 1, Paper C 2/9, 1-5 Sept., 1975

[6.21] C.E.L. Hunt and W.G. Newell, Effect of $\beta$-Phase heat treatment on the subsequent $\alpha$ phase ballooning behavior of Zircaloy-4 fuel sheaths, Zirconium in the Nuclear Industry ( ${ }^{\text {th }}$ Conf.), ASTM STP 681, pp. 447-464, 1979

[6.22] C.N. Tomé, C.B. So, and C.H. Woo, Self-consistent calculation of steady-state creep and growth in textured zirconium, Phil. Mag. A 67, pp. 917-930, 1993

[6.23] P.A. Turner, C.N Tomé, N. Christodoulou, C.H. Woo, A self-consistent model for polycrystals undergoing simultaneous irradiation and thermal creep, Phil. Mag. A, vol. 79(10), pp. 2505-2524, 1999

[6.24] R.W.L. Fong, R. Miller, H.J. Saari, and S.C. Vogel, Crystallographic texture and volume fraction of $\alpha$ and $\beta$ phases in $\mathrm{Zr}-2.5 \mathrm{Nb}$ pressure tube material during heating and cooling, Metall. Mater. Trans. A, Vol. 43A, pp. 806-821, 2012

[6.25] H.R. Wenk, L. Lutterotti, and S.C. Vogel, Rietveld texture analysis from TOF neutron diffraction data, J. Powder Diffraction, Vol. 25(3), pp. 283-296, 2010 
[6.26] C.E. Coleman, V. Grigoriev, V. Inozemtsev, V. Markelov, M. Roth, V. Makarevicius, Y.S. Kim, K.L. Ali, J.K. Chakravarrty, R. Mizrahi, and R. Lalgudi, The effect of microstructure on delayed hydride cracking behavior of Zircaloy-4 fuel cladding-An International Atomic Energy Agency Coordinated Research Program, J. ASTM Inter., Vol. 7, No. 5, 2010

[6.27] R. Hill, A theory of the yielding and plastic flow of anisotropic metals, Proc. Roy. Soc. A, 193, London, 281, 1948

[6.28] J.G. Merkle, An engineering approach to multiaxial plasticity, ORNL-4138, July 1967

[6.29] P.A. Ross-Ross, V. Fidleris, and D.E. Fraser, Anisotropic creep behaviour of zirconium alloys in a fast neutron flux, Can. Met. Quart., vol. 11 (1), p. 101, 1972

[6.30] E. Duncombe, Improved first order analysis of the plastic stability of diffuse patches in tubes and sheets, WAPD-TM-984, 1973

[6.31] W.A. Backofen, W.F. Hosford, Jr., and J.J. Burke, Texture hardening, Trans. ASM, vol. 55, pp. 264-267, 1962

[6.32] W.A. Backofen, Deformation processing, Addison Wesley Publishing Co., Reading, Massachusetts, 1972

[6.33] C.E. Coleman and R.W.L. Fong, Strengthening CANDU calandria tubes by crystallographic texture, Can. Metall. Conf., Ottawa, Canada, August 20-23, 2000. Available as RC-2461 from the Information Centre, Atomic Energy of Canada Limited, Chalk River Laboratories, Chalk River, Ontario Canada.

[6.34] J.W. Hutchinson, Bounds and self-consistent estimates for creep of polycrystalline materials, Proc. Roy. Soc., Lond., A348, pp. 101-127, 1976

[6.35] N. Christodoulou, P.A. Turner, E.T.C. Ho, C.K. Chow, and M. Resta Levi, Anisotropy of yielding in $\mathrm{Zr}-2.5 \mathrm{Nb}$ pressure tube material, Metall. Mater. Trans. A, vol. 31A, pp. 409-420, 2000

[6.36] J.W.L. Pang, T.M. Holden, P.A. Turner, and T.E. Mason, Intergranular stresses in Zircaloy-2 with rod texture, Acta Mater., vol. 47 (2), pp. 373-383, 1999 


\title{
Chapter 7
}

\section{Characterization of the Crystallographic Textures and Mechanical Anisotropy Factors in Two Modifications of Zr-2.5Nb Pressure Tube Materials}

(Manuscript submitted to PRICM-8 Conference, 2013)

Cover Introduction: This manuscript presents the results of neutron diffraction measurements of crystallographic textures in two modified $\mathrm{Zr}$-2.5 Nb pressure tube materials. Using the in-situ approach to obtain the Kearns (texture) numbers and Hill's anisotropy factors (Chapter 6), the measured texture (ODF) data obtained on the two modified materials were used to calculate the Kearns numbers and Hill's anisotropy factors. The calculated anisotropy factors and the stable texture evolution observed in these two modified materials were discussed in relation to the mechanical anisotropy that can be expected in these materials during a postulated high temperature transient in a hypothetical loss-of-coolant accident (LOCA) scenario.

\begin{abstract}
$\underline{\text { Abstract }}$
$\mathrm{Zr}-2.5 \mathrm{Nb}$ alloy is used for the pressure tubes in CANDU reactors. Current as-manufactured tubes are produced in a cold-worked and stress-relieved metallurgical condition. The tubes installed in reactors normally operate at $\sim 300^{\circ} \mathrm{C}$. In a hypothetical loss-of-coolant-accident, the pressure tube may be overheated to $1000^{\circ} \mathrm{C}$. During the
\end{abstract}


temperature transient, a phase transformation occurs that changes the microstructure which affects the material's high-temperature deformation behaviour.

In this study, improvements to enhance the performance of pressure-tube materials are being explored by modifying the texture and microstructure of as-manufactured pressure tubes. Two modifications were carried out by hightemperature annealing, with or without subsequent cold-working. This paper presents the resulting modified textures as measured by neutron diffraction and their texture evolution during heating. The anisotropy factors for the modified $\mathrm{Zr}-2.5 \mathrm{Nb}$ pressure-tube materials were calculated using measured texture data and their mechanical anisotropy are compared with those previously characterized for Zircaloy-4 fuel cladding.

\subsection{Introduction}

The $\mathrm{Zr}-2.5 \mathrm{Nb}$ alloy is used for pressure tube materials in CANDU ${ }^{\circledR}$ reactors. The manufactured tubes are installed in-reactor in a cold-worked and stress-relieved condition. The tubes installed in reactors normally operate at $\sim 300^{\circ} \mathrm{C}$. In a hypothetical loss-of-coolant-accident (LOCA), the pressure tube material may be overheated to $1000^{\circ} \mathrm{C}$. During the temperature transient, a phase transformation occurs that changes the microstructure which affects the material's high-temperature deformation behaviour.

The pressure tubes are fabricated by the following steps: quadruple melt ingot, forge to bar, machine hollow billets, preheat billets to $815^{\circ} \mathrm{C}$ and extrude into tubes, cold-draw 25 to $30 \%$ (in two wall thickness reductions), and stress relief in steam

$\mathrm{CANDU}^{\circledR}$ is a registered trademark of Atomic Energy of Canada Limited (AECL). 
autoclave for 24 hours at $400^{\circ} \mathrm{C}$ (which also introduces a protective oxide layer on the inside and outside surfaces of the tube) [7.1]. The microstructure of as-manufactured pressure tubes typically consists of elongated hexagonal close-packed (hcp) $\alpha$-Zr grains containing a high dislocation density and a thin layer of body-centered cubic (bcc) $\beta$ phase at the $\alpha$-grain boundaries (Figure 7.1). At low temperatures $\left(<610^{\circ} \mathrm{C}\right)$, the pressure tubes exhibit a strong transverse crystallographic texture, Figure 7.2. During heating to $1050^{\circ} \mathrm{C}$, the texture evolution observed in-situ by neutron diffraction was found to be stable [7.2]. The observed anisotropic deformation of the as-manufactured pressure tube material at high temperatures has been related to the stable evolution of texture during heating. The material's response to the mechanical anisotropy at high temperatures has been ascribed to slips on prism and pyramidal planes in the hep a- $\mathrm{Zr}$ grains, with the deformation at temperatures around $700-750^{\circ} \mathrm{C}$ being attributed to grain boundary sliding [7.3].

Improvements on pressure tube materials are constantly being investigated to enhance their property performance in-reactor. For example, the performance of TMT-2 pressure tubes developed for Russian RBMK reactors showed improved crack tolerance after irradiation, and also in-reactor creep which was controlled mostly by texture and its initial microstructure [7.4]. The research work used alloy powders as starting materials to make the tubes for evaluation [7.4]. Improvement in delayed hydride cracking is also obtained with radial texture through texture modifications [7.5]-[7.7]. Other evaluations involved pressure tubes made from melted ingots and various thermo-mechanical and cold-working processes [7.8], including recovery and recrystallization annealing [7.9]. 
The evaluations are mostly for low temperature $\left(<500^{\circ} \mathrm{C}\right)$ applications of the pressure tube materials. For applications in high temperature deformation, there is little information or evaluation being made on improving the $\mathrm{Zr}-2.5 \mathrm{Nb}$ pressure tube materials. In this study, two simple modifications ('A' and 'B') have been made using an asmanufactured $\mathrm{Zr}-2.5 \mathrm{Nb}$ CANDU pressure tube material, to evaluate the modifications of texture and microstructure for improving the high temperature deformation characteristics of the material. The texture of the modified materials and its evolution during heating to $1050^{\circ} \mathrm{C}$ were evaluated by neutron diffraction at Los Alamos Neutron Science Center. The texture data were used as input in SELFPOLY (polycrystalline model) to calculate the Kearns (texture) numbers and anisotropy factors to evaluate the material's high-temperature response to mechanical anisotropy, for some hypothetical LOCA scenarios. Modification ' $A$ ' material was obtained by applying a hightemperature annealing $\left(875^{\circ} \mathrm{C}\right.$ for 17 days $)$ on an as-manufactured pressure tube material. Modification 'B' was obtained by applying cold-rolling on the Modification 'A' material with about $60 \%$ cold-work. This paper presents the texture obtained in the two modifications. The texture evolution during high-temperatures heating was found to be stable, similar to the texture evolution observed in as-manufactured pressure tube material [7.2]. The anisotropy factors calculated are discussed in comparison with those previously determined for Zircaloy-4 fuel sheaths materials [7.10]. 


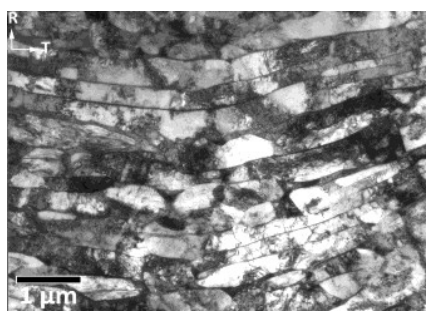

a)

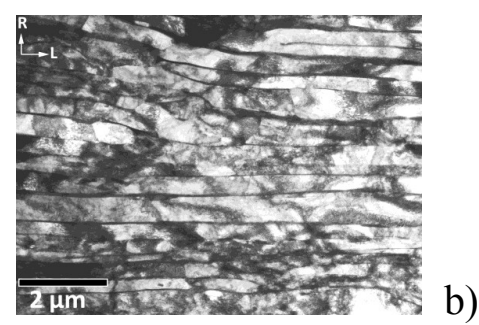

Figure 7.1 Elongated grain structures in as-manufactured pressure-tube (a) longitudinal, and (b) transverse direction. (This figure first appeared in Figure 3.1)

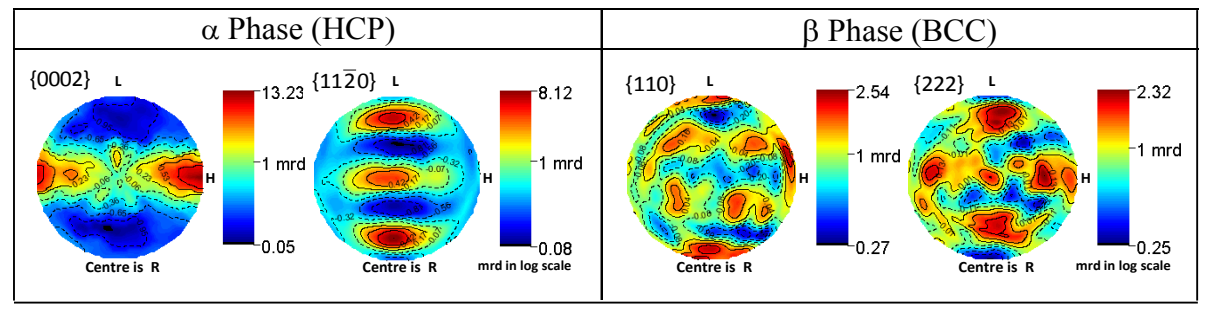

Figure 7.2 Pole figures of $\alpha$ - and $\beta$-phase in as-manufactured pressure tube at $100^{\circ} \mathrm{C}[7.2]$. (This figure first appeared in Figure 4.9)

\subsection{Experimental}

\subsubsection{Material modifications and sample preparation}

Two modifications were performed using an as-manufactured $\mathrm{Zr}-2.5 \mathrm{Nb}$ pressure tube material. The modifications were made using the same pressure-tube material in which the changes in texture and phase transformation during heating to high temperatures and cooling has been previously studied in-situ by neutron diffraction [7.2]. To prepare the modified materials, two slit rings each about $25 \mathrm{~mm}$ wide were cut from the as-manufactured pressure tube. The slit rings were reverse bent obtain a flat strip. After cleaning the flat strip with acetone, each strip was then encapsulated in a quartz tube under vacuum. The two strip materials were then modified, outlined as follows. 
- Modification ' $\mathrm{A}$ ' was performed by a high-temperature annealing at $875^{\circ} \mathrm{C}$ for 17 days and then cooling slowly. The microstructure of the modified material consists of large equiaxed grains of primary $\alpha-\mathrm{Zr}$ within a matrix of Widmanstätten $\alpha$-Zr platelets that were transformed from the prior $\beta$-phase, Figure 7.3a.

- Modification 'B' was performed by cold rolling the Modification ' $\mathrm{A}$ ' material in multi-passes in the same direction along the tube's transverse direction. A total wall thickness reduction of about $60 \%$ was achieved using the rolling mill at CANMET Materials Technology Laboratory. Figure 7.3b shows the microstructure of Modification 'B' material with elongated grains of primary $\alpha-\mathrm{Zr}$ and deformed $\alpha-Z r$ platelets

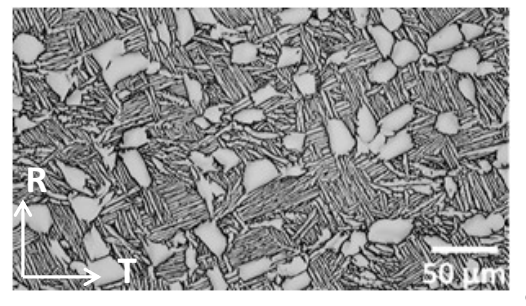

a)

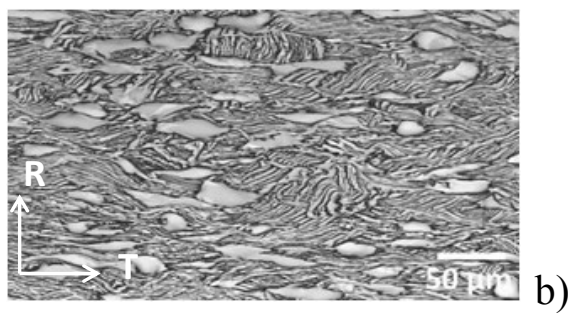

Figure 7.3 Optical micrographs showing microstructures of two modified pressure-tube materials (a) 'A' and (b) 'B'. (This figure first appeared in Figures 3.4 and 3.5)

These two modified pressure tube materials were characterized for their texture and evolution during heating to high temperatures up to $1050^{\circ} \mathrm{C}$ using neutron diffraction. A suitably-sized sample was prepared from each of the two modified materials (Modification 'A' and 'B'). 
To increase the sampling volume and thus improve the neutron measurement, the sample was prepared by stacking together two or more plates that were cut from the flat strip of the material (Figure 7.4). The overall dimension of the stacked sample is approximately $10 \mathrm{~mm}$ tall $\times 8 \mathrm{~mm}$ wide $\times 8 \mathrm{~mm}$ thick. To improve thermal conduction between the two plates, the small curvature and the oxide layer on the surfaces of the two plates were mechanically polished, then cleaned with acetone and the plates held tightly stacked together by spot-welding on a thin Zr-foil on both sides of the stacked sample. The neutron scattering from the thin $\mathrm{Zr}$ foils is expected to be minor since the volume of the stacked sample (volume being probed) is much larger than that of the foil, and hence they would not significantly alter the diffraction profile obtained from the stacked sample.

Figure 7.4 Diagram showing a stacked sample of pressure tube material. (This figure first appeared in Figure 3.11)

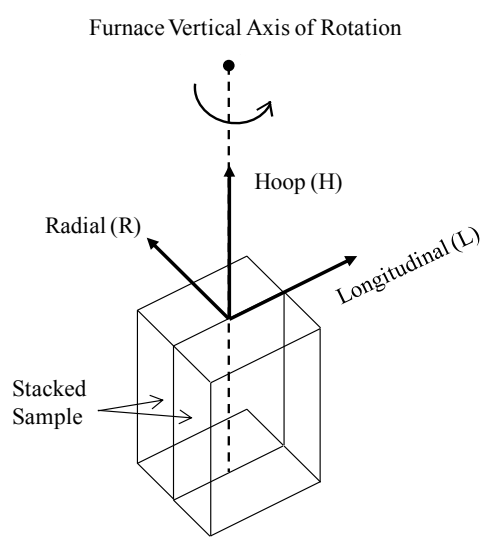

\subsubsection{Neutron diffraction measurements}

Neutron diffraction measurements for texture were made on the two modifications (' $\mathrm{A}$ ' and ' $\mathrm{B}$ ') of $\mathrm{Zr}-2.5 \mathrm{Nb}$ pressure tube materials. The texture measurements were performed on the time-of-flight (TOF) high-pressure preferred orientation (HIPPO) 
diffractometer at LANSCE. The details for such TOF texture measurements can be found in [7.2]. To perform the measurements, the sample is placed in a vanadium basket inside a vacuum furnace with vanadium heating elements and heat shields. An incident beam of polychromatic thermal neutrons collimated to $10 \mathrm{~mm}$ beam diameter was directed at the sample. Two thermocouples are located in the furnace at about $70 \mathrm{~mm}$ above the sample within the $200-\mathrm{mm}$ high hot zone, with one used to control and record the temperature of the sample. The uncertainty in the sample temperature for the furnace used in this study is estimated to be less than $\pm 5^{\circ} \mathrm{C}$.

The pole figures of $\alpha$ and $\beta$ phases were measured during heating of the sample at eight different temperatures $\left(100^{\circ} \mathrm{C}\right.$ to $\left.1050^{\circ} \mathrm{C}\right)$, traversing across the two solvus lines along the $\mathrm{Zr}-2.5 \mathrm{Nb}$ composition [7.11]. At each temperature, the sample was rotated around the furnace axis in three different rotations $\left(0^{\circ}, 45^{\circ}\right.$ and $\left.90^{\circ}\right)$. Diffraction data were collected at each of the three rotations for a period of 18 minutes which was deemed sufficient to obtain the ODF (orientation distribution function) of the crystallites in the sample to reconstruct pole figures for many different planes. The total time for each temperature interval was about $1 \mathrm{~h}$. The pole intensities measured with three panels of detectors were used to extract texture information using the Rietveld method, as implemented in the MAUD program [7.12] for analyzing HIPPO diffraction data. The ODF is calculated using the EWIMV algorithm, as implemented in MAUD that allows data to be entered at arbitrary pole figure positions [7.13]-[7.15]. A $10^{\circ} \times 10^{\circ} \times 10^{\circ}$ grid was used for calculating the ODF in the sample for each test temperature. No sample symmetry was imposed on the calculations. The complete pole figures for both $\alpha$ and $\beta$ 
phases were reconstructed using the calculated ODFs. In this paper, all the reconstructed pole figures are represented on a Lambert equal-area projection [7.16], and the ODF plots are only presented for heating at $100^{\circ} \mathrm{C}$ and $900^{\circ} \mathrm{C}$ to provide clarity for discussion. The ODF data were used as input in SELFPOLY [7.17]-[7.18], to calculate the Kearns (texture) numbers [7.19] and Hill's anisotropy factors [7.20].

\subsubsection{Kearns numbers [7.19] and Hill's anisotropy factors [7.20]}

\subsubsection{Kearns numbers [7.19]}

The Kearns numbers for the three principal directions in the sample $\left(f_{R}, f_{T}\right.$, and $\left.f_{L}\right)$, defined as a weighted average of the intensity of the basal plane normals oriented with respect to the sample's principal direction, are calculated using eqn. (7.1).

$$
f_{d}=\left[\sum_{\alpha_{d}} V_{f}\left(\alpha_{d}, \beta\right) \sin \alpha_{d} \cos ^{2} \alpha_{d}\right] /\left[\sum_{\alpha_{d}} V_{f}\left(\alpha_{d}, \beta\right) \sin \alpha_{d}\right]
$$

Here $d$ stands for $\mathrm{R}$ (radial), $\mathrm{T}$ (transverse) or L (longitudinal) direction of the original tube sample. $V_{f}\left(\alpha_{d}, \beta\right)$ is the volume fraction of grains with basal poles oriented at a given polar and azimuthal angles $\alpha_{d}$ and $\beta$ in the pole figure for the sample, respectively. Normally, the sum of the three Kearns numbers must equal to 1 (eqn. 7.2).

$$
f_{R}+f_{T}+f_{L}=1
$$

The calculated Kearns numbers for the modified ('A' and 'B') materials are compared with those of as-manufactured pressure tube [7.16], summarized in Table 7.1. 


\subsubsection{Hill's anisotropy factors [7.20]}

Hill [7.20] first proposed a theory of yielding of anisotropic metals by modification of the Huber-Hencky von Mises isotropic yielding with three tensile anisotropic factors designated as $F, G$, and $H$. In Cartesian co-ordinates ( $\theta=$ transverse, $\mathrm{z}=$ longitudinal, and $\mathrm{r}=$ radial), and for loading only in the principal directions of a tube, the Hill's yield criterion is defined, in terms of the Huber-Henky von Mises equivalent stress, as

$$
\bar{\sigma}=\left[F\left(\sigma_{\theta}-\sigma_{z}\right)^{2}+G\left(\sigma_{z}-\sigma_{r}\right)^{2}+H\left(\sigma_{r}-\sigma_{\theta}\right)^{2}\right]^{1 / 2}
$$

The onset of yielding occurs when $\bar{\sigma}=Y$. The Hill's anisotropy factors for the two modified pressure tube materials were calculated using SELFPOLY model [7.18] with the measured texture (ODF) data as input for the calculations. The SELFPOLY model is a self-consistent polycrystalline model that has been developed to predict the deformation of polycrystals by averaging the behaviour of individual crystals and by assuming a certain deformation mechanism at the single crystal level [7.17]. Later, Turner el al [7.18] included a model for thermal creep by adopting Hutchinson's slip [7.23] models for power-law steady state creep of polycrystals. In the SELFPOLY model [7.18], the single-crystal deformation rate is given by

$$
\dot{\varepsilon}_{i j}=\sum_{s} \dot{\gamma}_{0}^{s}\left(\frac{m^{s}: \sigma}{\tau^{s}}\right)^{n} m_{i j}^{s}
$$

Here, $\sigma$ is the deviatoric stress acting on the crystal, the index $s$ stands for the slip system (e.g., prismatic slip $\left(\tau^{p r}\right)$, basal slip $\left(\tau^{\text {bas }}\right)$ or pyramidal slip $\left.\left(\tau^{p y r}\right)\right)$, the tensor $m_{i j}^{S}$ is the 
Schmid tensor corresponding to the slip system $s$, and, for each slip system, $\tau^{s}$ and $\dot{\gamma}_{0}^{s}$ are the CRSS and the reference shear strain rate, respectively. The stress exponent $(n)$ is the inverse of the strain-rate sensitivity, i.e., $n=1 / m$. Details for this formulation are described in [7.24]. Pang et al. [7.25] fitted the tensile loading curves for Zircaloy-2 material under uniaxial deformation and determined suitable parameters for the three slip modes $(\mathrm{PR}=$ prismatic, $\mathrm{BAS}=$ basal, and $\mathrm{PYR}=$ pyramidal $)$, and they found that the CRSS (critical resolved shear stress) values were $90 \mathrm{MPa}$ for PR, $160 \mathrm{MPa}$ for BAS and $240 \mathrm{MPa}$ for PYR, giving a CRSS ratio of 1:1.8:2.7 (a ratio of prismatic to basal to pyramidal).

In this analysis, SELFPOLY is used to calculate the Hill's anisotropy factors using the fixed value for the CRSS ratio from Pang et al. [7.25] and the value for the stress-exponent $n$ is obtained through use of a texture-based parameter, $\zeta$ given as

$$
\zeta=n=\frac{f_{T}}{f_{L}}+\left(+\left(f_{R}-f_{T}\right)^{2}+\left(f_{T}-f_{L}\right)^{2} f_{R}-f_{L}\right)^{2}
$$

where $n$ is the stress exponent parameter used in SELFPOLY (eqn. (8.4)), and $f_{R}, f_{T}, f_{L}$, are the Kearns numbers defined in eqn. (7.1). The method of analysis used in this work is essentially the same as that used previously to calculate the anisotropy factors of fuel sheaths using measured texture data [7.10]. The anisotropy factors calculated for the modified ('A' and 'B') materials are compared with those of as-manufactured pressure tube [7.16] material, and are summarized as shown in Table 7.1. 
Table 7.1 Kearns numbers and Hill's anisotropy factors calculated using ODF data

\begin{tabular}{|c|c|c|c|c|c|c|}
\hline \multirow{2}{*}{$\begin{array}{c}\text { Zr-2.5Nb } \\
\text { pressure-tube } \\
\text { material }\end{array}$} & \multicolumn{3}{|c|}{ Kearns numbers } & \multicolumn{2}{c|}{ Hill's anisotropy factors } \\
\cline { 2 - 7 } & $f_{\mathrm{R}}$ & $f_{\mathrm{T}}$ & $f_{\mathrm{L}}$ & $F$ & $G$ & $H$ \\
\hline $\begin{array}{c}\text { As- } \\
\text { manufactured }\end{array}$ & 0.26 & 0.61 & 0.13 & 1.03 & 0.34 & 0.13 \\
\hline Modification 'A' & 0.18 & 0.38 & 0.45 & 0.53 & 0.44 & 0.53 \\
\hline Modification 'B' & 0.21 & 0.13 & 0.66 & 0.83 & 0.18 & 0.49 \\
\hline
\end{tabular}

\subsection{Results and Discussion}

\subsubsection{Pole figures of modifications (' $A$ ' and ' $B$ ') of $Z r-2.5 N b$ pressure tube materials}

Figure 7.5 shows a comparison of the pole figures of hep $\alpha$-phase and bcc $\beta$-phase for the Modification 'A' and 'B' materials measured during heating up to $1050^{\circ} \mathrm{C}$. The pole figures measured at intermediate heating temperatures between 100 and $800^{\circ} \mathrm{C}$ are not shown since they are the same as those at $800^{\circ} \mathrm{C}$. Examination of the pole figures for the $\alpha$-phase in the two modified materials suggests that the texture on heating to $800^{\circ} \mathrm{C}$ remained unchanged, thus the texture evolution is deemed to be stable. This observation of stable texture evolution is consistent with that previously observed in as-manufactured $\mathrm{Zr}-2.5 \mathrm{Nb}$ pressure tube materials [7.2]. With a stable texture evolution, the response to mechanical anisotropy during high temperature deformation can be expected to remain unchanged since the $\alpha$-phase material would be responsible for most of the deformation. As shown in a previous study [7.3], the anisotropy in high-temperature deformation is also influenced by grain boundary sliding, as a result of different volume fractions of $\beta$-phase present in the material during the $\alpha \rightarrow \beta$ phase transformation that occur on heating. 
On further heating to $900^{\circ} \mathrm{C}$, a new $\alpha$-phase texture component appears distinctly (indicated by the red arrows shown in Figure 7.5 for the Modification ' $A$ ' material). In comparison, the Modification 'B' material also shows the same $\alpha$-texture component appearing but with a lower intensity. The appearance of this texture component is due to coarsening of the prior "primary" $\alpha-Z r$ grains that were initially present in the two modified materials (Figure 7.3). This has also been previously observed in as-manufactured pressure tube [7.2]. The evolution of $\alpha$-phase texture resulting from the transformation of Widmanstätten $\alpha$-platelets to $\beta$-phase material, and the coarsening of the prior primary $\alpha-\mathrm{Zr}$ grains during heating, are clearly revealed in the ODF plots shown in Figure 7.6, and discussed in Section 7.3.2.

Examination of the transformed $\beta$-phase in Modification ' $A$ ' material on heating up to $1050^{\circ} \mathrm{C}$ (full $\beta$-phase field), Figure 7.5, shows that the $\beta$-phase texture remained unchanged throughout the entire heat-up schedule. This $\beta$-phase texture evolution is deemed to be a stable transformation process. In comparison, the texture evolution of transformed $\beta$-phase in Modification 'B' material remained unchanged on heating only up to $900^{\circ} \mathrm{C}$ (Figure 7.5). However, on further heating to $1050^{\circ} \mathrm{C}$ the $\beta$-phase texture had evolved to be different from that observed at $900^{\circ} \mathrm{C}$.

\subsubsection{ODF plots of hcp $\alpha$-phase in measured samples at $100^{\circ} \mathrm{C}$ and $900^{\circ} \mathrm{C}$}

Figure 7.6 shows the ODFs of hep $\alpha$-phase in the as-manufactured and two modifications ('A' and ' $\mathrm{B}$ ') of $\mathrm{Zr}-2.5 \mathrm{Nb}$ pressure tube materials that were measured at $100^{\circ} \mathrm{C}$ and $900^{\circ} \mathrm{C}$ on heating. Examination of the ODFs at $100^{\circ} \mathrm{C}$, shows that the 


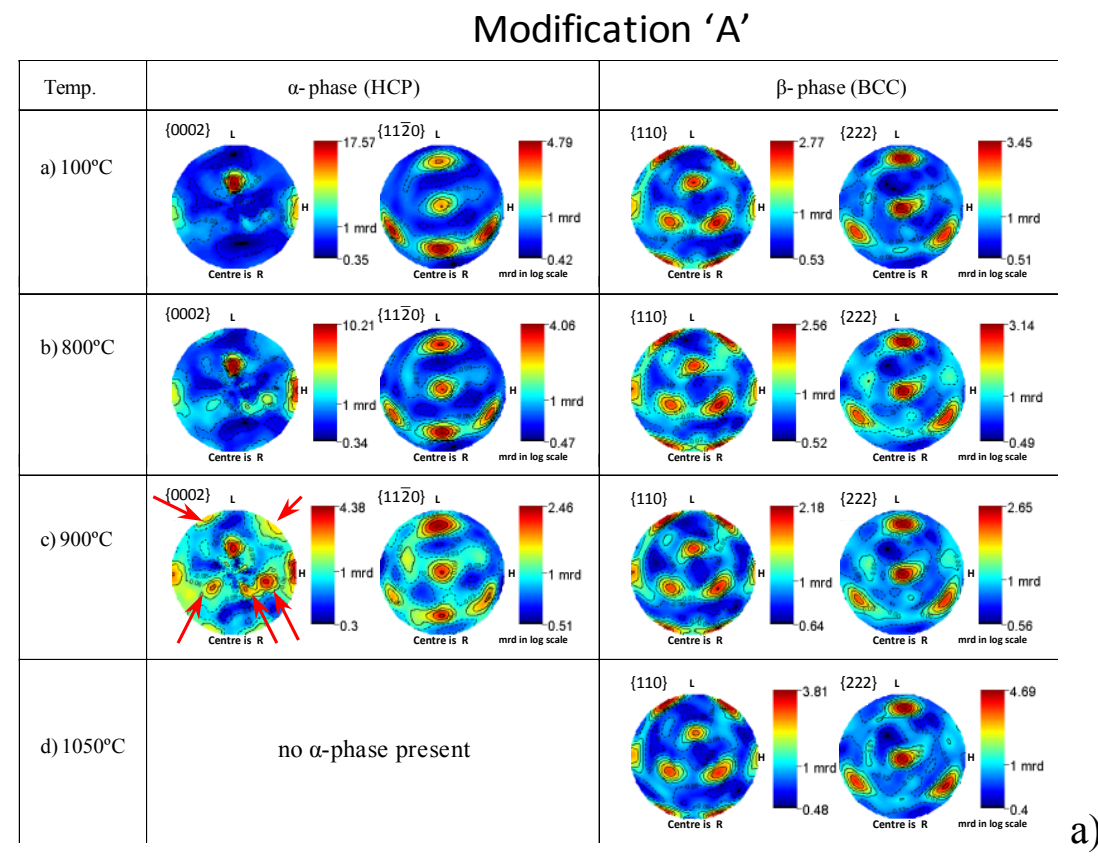

a)

Figure 7.5 Pole figures of (a) Modification 'A' and (b) Modification 'B' of pressure tube material 
as-manufactured material initially has three different texture components (labelled A, B, and $\mathrm{C}$ in the figure) with a pronounced transverse texture (label B). By applying a hightemperature annealing treatment to obtain the Modification ' $\mathrm{A}$ ' material, the phase transformation processes that occurred during heating to $875^{\circ} \mathrm{C}$ for 17 days and slowly cooling back to room temperature have resulted in two almost equally pronounced texture components (labelled C and D). Using the diagram (Figure 7.6) as a guide to illustrate the crystal orientations in relation to the sample axes, it is shown that the basal poles for the two texture components discussed earlier, are basically aligned with the transverse and close to the longitudinal direction of the tube. Modification ' $\mathrm{B}$ ' material is produced by applying cold rolling on the Modification "A" material. The process of cold rolling applied along the tube's transverse direction can produce twinning in the grains to generate the two visibly new texture components (labelled E and F) with basal poles aligned along the tube's longitudinal and radial direction. In the ODF plot, there is a relocation of texture component from one of the initial two texture components (labelled C) to two new locations (labelled $\mathrm{E}$ and F), resulting in reducing the ODF intensity of that particular texture component (labelled $\mathrm{H}$ ). This observation suggests that cold rolling along the transverse direction of the tube induces twinning to be produced only in grains with the prior transverse texture component. 


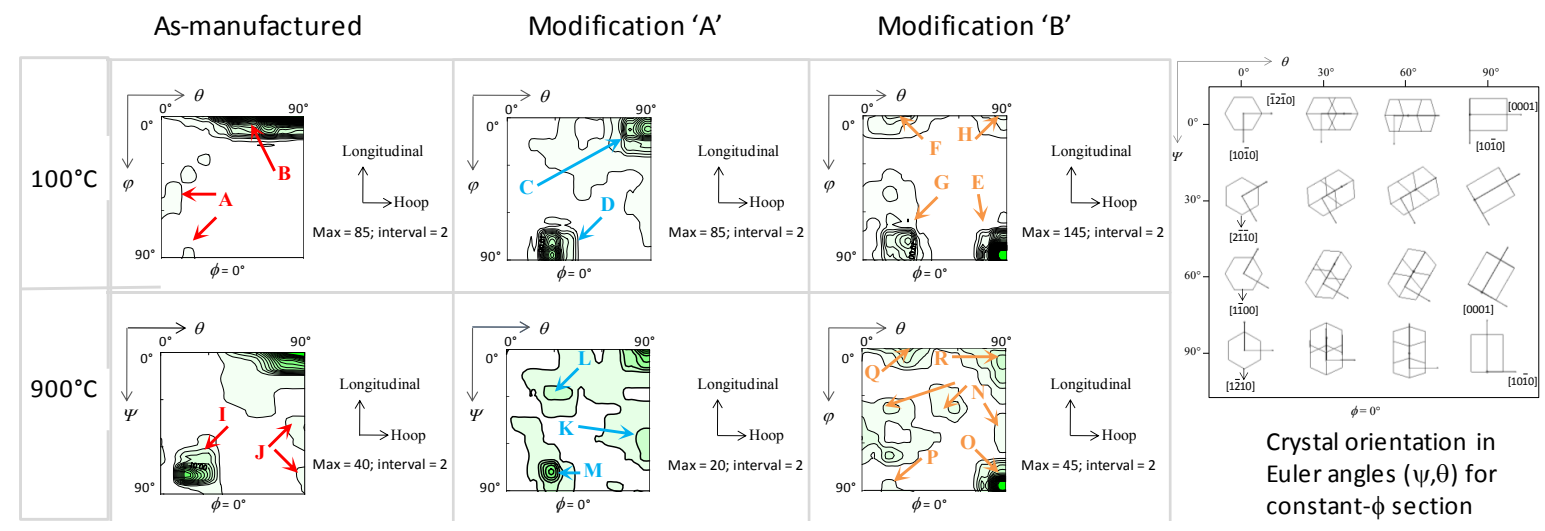

Figure 7.6 ODF plots (for $\phi=0^{\circ}$ ) of $\alpha$-phase in as-manufactured pressure tube and two modifications ('A' and 'B') materials. (Insert on right shows the crystal orientations).

(The insert for crystal orientation in the figure first appeared in Figure 2.11)

At $900^{\circ} \mathrm{C}$ on heating, previously unobserved $\alpha$-phase texture components appeared for all the three materials. As previously reported for as-manufactured pressure tube [7.2], the appearance of these texture components (labelled I and J) was a result of the coarsening of the prior 'primary' $\alpha-\mathrm{Zr}$ grains. The coarsening process is also responsible for the additional texture components observed in Modification 'A' material (labelled K and L). Similarly, additional texture components were also observed in Modification 'B' material (labelled O). 


\subsubsection{Comparison of yield loci using Hill's criterion}

Using the calculated Hill's anisotropy factors $(F, G$ and $H$ values listed inTable 7.1), a yield locus is generated using Hill's criterion (eqn. (7.3)) for a biaxial tensile stress state for the pressure tube materials, as shown in Figure 7.7. For comparison, the yield loci previously produced for Zircaloy-4 fuel sheath materials [7.10] are also included in the same figure. A larger size of an ellipse (i.e., yield locus) indicates a stronger anisotropy in yielding behaviour that can be expected when the tubing material is stressed biaxially.

Figure 7.7 Yield loci of Zr-

$2.5 \mathrm{Nb}$ pressure tube materials and Zircaloy-4 fuel sheaths

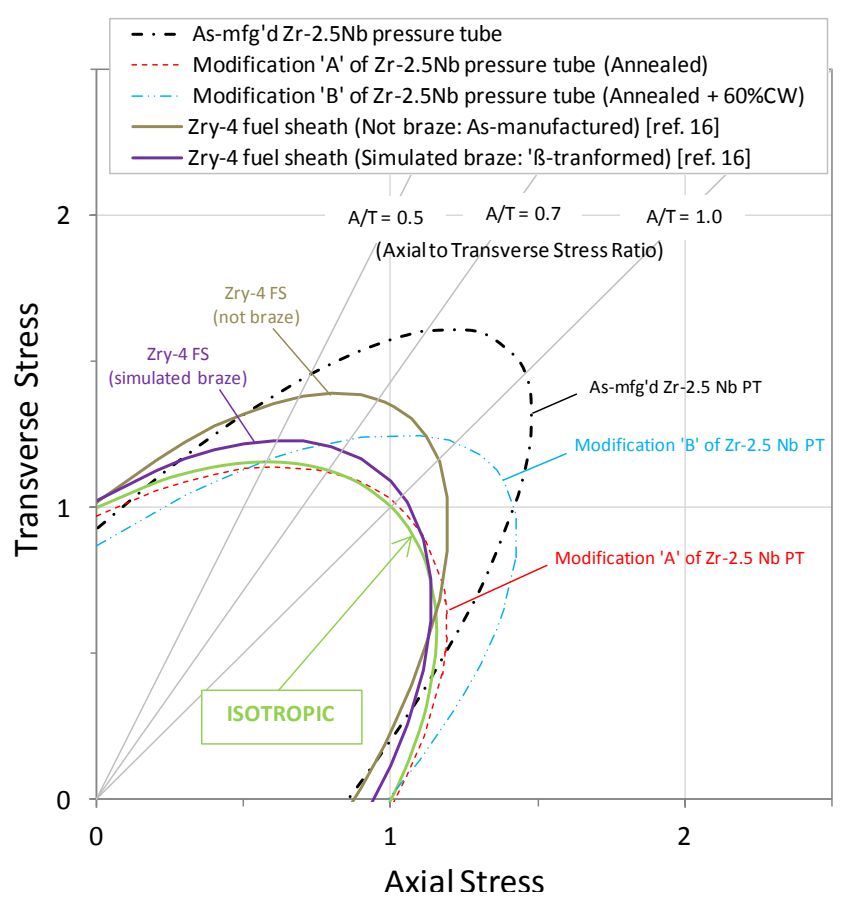

In Figure 7.7, for pressure tube materials, the mechanical anisotropy is strongest in an as-manufactured pressure tube, compared to the two modified materials (' $A$ ' and 'B'). Annealing in Modification 'A' gave almost isotropic property, and the cold rolling 
made on Modification ' $\mathrm{A}$ ' material increased the size of the ellipse, making it more anisotropic but not as anisotropic as the as-manufactured pressure tube. The transverse rolling generated a stronger axial (longitudinal) direction for yielding.

In comparison, the Zircaloy-4 fuel sheath with un-brazed material shows a yield anisotropy response similar in size to the Modification ' $\mathrm{B}$ ' material (their ellipses are about the same size), but has a stronger transverse direction. The simulated brazed fuel sheath [7.10] shows similar isotropy as that in Modification 'A' material since both these materials had gone through a high-temperature anneal.

\subsection{Conclusions}

The following conclusions are drawn from this study:

1. Modification 'A', a high-temperature annealing process applied on as-manufactured $\mathrm{Zr}-2.5 \mathrm{Nb}$ pressure tube, has been shown to modify its initial pronounced transverse texture and to produce a dual-textured material with basal poles aligned in the transverse and longitudinal directions of the tube. Although being dual-textured, the material shows an isotropic property.

2. Modification 'B', an application of cold-rolling process on a dual-textured material (Modification 'A"), is shown to produce further texture modifications, resulting in a quad-textured material with an anisotropic property stronger in the axial (i.e., longitudinal) direction of the tube.

3. The texture evolution in the two modified materials appeared to be stable during heating up to $900^{\circ} \mathrm{C}$. 


\section{References}

[7.1] B.A. Cheadle, The development of $\mathrm{Zr}-2.5 \mathrm{Nb}$ pressure tubes for CANDU reactors, J. ASTM International, Vol. 7, No. 8, Paper ID JAI103057, 2010

[7.2] R.W.L. Fong, R. Miller, H.J. Saari and S.C. Vogel, Crystallographic texture and volume fraction of $\alpha$ and $\beta$ Phases in $\mathrm{Zr}-2.5 \mathrm{Nb}$ pressure tube material during heating and cooling, Metall. Mater. Trans A, Vol. 43A, pp. 806-821, 2012

[7.3] R.W.L. Fong, Anisotropic deformation of $\mathrm{Zr}-2.5 \mathrm{Nb}$ pressure tube material at high temperatures, J. Nucl. Mater., Vol. 440, pp. 467-476, 2013

[7.4] C. Coleman,M. Griffiths,V. Grigoriev, V. Kiseliov, B. Rodchenkov, and V.Markelov, Mechanical properties of $\mathrm{Zr}-2.5 \mathrm{Nb}$ pressure tubes made from electrolytic powder, J. ASTM International, Vol. 4, No. 10, Paper ID JAI1101111, 2007

[7.5] S.S. Kim and Y.S. Kim, $K_{1 \mathrm{H}}$ in radial textured $\mathrm{Zr}-2.5 \% \mathrm{Nb}$ pressure tube, J. Nucl. Mater., Vol. 279, pp. 286-292, 2000

[7.6] C.E. Coleman, S. Sagat and K.F. Amouzouvi, Control of microstructure to increase the tolerance of zirconium alloys to hydride cracking, 26th Annual Conference of Metallurgist Canadian Institute of Mining and Metallurgy, Winnipeg, Manitoba, August 23-26, 1987

[7.7] C.E. Coleman, B.A. Cheadle, C.D. Cann, and J.R. Theaker, Development of pressure tubes with service life greater than 30 years, Garmisch-Partenkirchen, Germany, September 11-14, 1995, Zirconium in the Nuclear Industry-Eleventh International Symposium, ASTM STP 1295, pp. 884-898, 1996

[7.8] N. Saibaba, S. K. Jha, S. Tonpe, K. Vaibhaw, V. Deshmukh, S. V. Ramana Rao, K. V. Mani Krishna, S. Neogy, D. Srivastava, G. K. Dey, R. V. Kulkarni, B. B. Rath, E. Ramadasan, and S. A. Anantharaman, Microstructural studies of heat treated $\mathrm{Zr}-2.5 \mathrm{Nb}$ alloy for pressure tube applications, J. ASTM International, Vol. 8, No. 6, Paper ID JAI103213, 2011

[7.9] V.D. Hiwarkar, S.K. Sahoo, I. Samajdar, K. Narasimhan, K.V. Mani Krishna, G.K. Dey, D. Srivastava, R. Tewari, S. Banerjee, Annealing of cold worked two-phase $\mathrm{Zr}-2.5 \mathrm{Nb}-$ associated microstructural developments, J. Nucl. Mater., Vol. 384, pp. 30-37, 2009 
[7.10] R.W.L. Fong, Anisotropy factors from texture and mechanical strain in Zircaloy-4 fuel sheaths, J. Nucl. Mater., Vol. 440, pp. 288-297, 2013

[7.11] J.P. Abriata and J.C. Bolcich, The Nb-Zr system, Bull. Alloy Phase Diagrams, Vol. 3, No. 1, pp. 34-44, 1982

[7.12] H.R. Wenk, L. Lutterotti and S.C. Vogel, Rietveld texture analysis from TOF neutron diffraction data, J. Powder Diffraction, Vol. 25, No. 3 (14 pp.), 2010

[7.13] S. Matthies, L. Lutterotti and H.R. Wenk, Advances in Texture Analysis from Diffraction Spectra, J. Appl. Crystallogr. 30: 31-42, 1997

[7.14] S. Matthies, J. Pehl, H.R. Wenk and S. Vogel, Quantitative texture analysis with the HIPPO neutron TOF diffractometer, J. Appl. Crystallogr. 38:462-475, 2005

[7.15] L. Lutterotti, D. Chateigner, S. Ferrari and J. Ricote, Thin Solid Films, 450:34, 2004

[7.16] H.R. Wenk (1985), Preferred Orientation in Metals and Rocks, H.-R. Wenk, ed., Academic Press, pp.11-14, 1985

[7.17] C.N. Tomé, C.B. So, and C.H. Woo, Self-consistent calculation of steady-state creep and growth in textured zirconium, Phil. Mag. A 67, pp. 917-930, 1993

[7.18] P.A. Turner, C.N Tomé, N. Christodoulou, C.H. Woo, A self-consistent model for polycrystals undergoing simultaneous irradiation and thermal creep, Phil. Mag. A, vol. 79(10), pp. 2505-2524, 1999

[7.19] J.J. Kearns, Thermal expansion and preferred orientation in Zircaloy, WAPD-TM-472, 1965

[7.20] R. Hill, A theory of the yielding and plastic flow of anisotropic metals, Proc. Roy. Soc. A, 193, London, p. 281, 1948

[7.21] C.E.L. Hunt, Anisotropic theory and the measurement and use of the anisotropic factors for Zircaloy-4 fuel sheaths, Transactions, $3^{\text {rd }}$ Int. Conf. on Structural Mechanics in Reactor Technology, London, U.K., Vol. 1, Paper C 2/9, 1-5 Sept., 1975

[7.22] C.E.L. Hunt and W.G. Newell, Effect of $\beta$-Phase heat treatment on the subsequent $\alpha-$ phase ballooning behavior of Zircaloy-4 fuel sheaths, Zirconium in the Nuclear Industry ( ${ }^{\text {th }}$ Conf.), ASTM STP 681, pp. 447-464, 1979

[7.23] J.W. Hutchinson, Bounds and self-consistent estimates for creep of polycrystalline materials, Proc. Roy. Soc., Lond., A348, pp. 101-127 (1976). 
[7.24] N. Christodoulou, P.A. Turner, E.T.C. Ho, C.K. Chow, and M. Resta Levi, Anisotropy of yielding in $\mathrm{Zr}-2.5 \mathrm{Nb}$ pressure tube material, Metall. Mater. Trans. A, vol. 31A, pp. 409-420, 2000

[7.25] J.W.L. Pang, T.M. Holden, P.A. Turner, and T.E. Mason, Intergranular stresses in Zircaloy-2 with rod texture, Acta Mater., vol. 47 (2), pp. 373-383, 1999 


\section{Chapter 8}

\section{General Discussion and Conclusions}

The results reported in Chapter 4 showed a detailed neutron diffraction study on the evolution of texture in an as-manufactured $\mathrm{Zr}-2.5 \mathrm{Nb}$ pressure tube material during heating up to $1050^{\circ} \mathrm{C}$ and also on cooling. This study has provided the first set of detailed data, showing the $\alpha$-phase and $\beta$-phase textures that evolved during the $\alpha \rightarrow \beta \rightarrow \alpha$ phase transformations with the characteristics of lattice transformation that obeyed the Burgers orientation relationship (i.e., $\{110\}_{B C C} / /\{0001\}_{H C P} ;<111>_{B C C} / /<11 \overline{2} 0>_{H C P}$ ). It was found that the texture evolution of the $\alpha$-phase was stable during heating to $900^{\circ} \mathrm{C}$, and also identified a previously unobserved $\alpha-Z r$ texture component that appeared to be distinctly pronounced during heating at $900^{\circ} \mathrm{C}$ due to the coarsening of the prior 'primary' $\alpha-Z r$ grains that were initially present in the starting material. This observation suggests that the 'primary' $\alpha-\mathrm{Zr}$ grains are the last ones to transform into $\beta-\mathrm{Zr}$ phase as was discussed in Chapter 4 that it has been known that the 'primary' $\alpha-\mathrm{Zr}$ grains would be enriched with soluble oxygen at the high temperatures. This study also provided a measure of the change in volume fraction of the $\beta$-phase in the material as it was heated to $1050^{\circ} \mathrm{C}$ and also on cooling. The results and details of this work have been published in a peer-reviewed Journal [8.1]. It can be concluded that this study has provided a detailed benchmark on texture and microstructural parameters for as-manufactured CANDU Zr-2.5Nb pressure tube material. Such information can be used to improve polycrystalline models for evaluating mechanical deformation behaviour of the materials. 
The neutron diffraction investigation on the $\alpha \rightarrow \beta \rightarrow \alpha$ phase transformations provided a direct identification of the phase constituents and a quantification of volume fraction of the $\beta$-phase during heating and cooling. Using information on the texture and phase transformation during heating and cooling (Chapter 4 manuscript published in [8.1]), this knowledge has provided a further understanding of the anisotropic deformation behaviour in as-manufactured $\mathrm{Zr}-2.5 \mathrm{Nb}$ pressure tube materials that have been observed at high temperatures. Tensile deformation data previously obtained on transverse and longitudinal directions of the tube using high-temperature ramped tests showed anisotropic properties at temperatures up to $1000^{\circ} \mathrm{C}$. The anisotropic deformation behaviour of the as-manufactured pressure tube materials has been attributed to the stable evolution of the $\alpha-\mathrm{Zr}$ phase texture as determined in the neutron diffraction study during heating of the as-manufactured pressure tube material to high temperatures. With the stable texture evolution, the deformation mechanisms due to prismatic slips were identified to be responsible for the anisotropic deformation behaviour during the high temperature transient. The anisotropic deformation has also been attributed to grain boundary sliding due to the evolution of the phase transformations involving changes in volume fraction of the $\beta$-phase material with temperature changes. The use of this texture and phase transformation data obtained from the neutron diffraction study to help further understand the anisotropic high-temperature deformation behaviour has been discussed at the NUMAT-2012 conference, and this work has been published in a peerreviewed journal [8.2]. 
As it is well known that the mechanical anisotropy of zirconium alloy tubes is inherently dependent on the texture in the materials, the results reported in Chapter 6 have provided a relationship between these two parameters using neutron diffraction texture measurements obtained on CANDU type Zircaloy-4 fuel sheaths and known anisotropy factors previously measured using strain tests on fuel sheath materials with different simulated braze zone microstructures. This study has produced fuel sheaths samples with simulated braze zone microstructures using production brazing cycle (i.e., samples with $\beta$-transformed microstructure simulating the material in the brazed space location, and samples with $\alpha$-annealed microstructure simulating the heat-affected-zone (HAZ) material). The texture (ODF) data of these simulated braze sample materials and also as-fabricated fuel sheath samples were obtained by neutron diffraction during heating at eight different temperatures $\left(100^{\circ} \mathrm{C}\right.$ to $\left.1000^{\circ} \mathrm{C}\right)$. Using the texture ODF data, the Kearns (texture) numbers $\left(f_{\mathrm{R}}, f_{\mathrm{T}}\right.$, and $\left.f_{\mathrm{L}}\right)$ and the Hill's anisotropy factors $(F, G$, and $H$ ) were calculated using a polycrystalline model called SELFPOLY. The results of this study have been accepted for publication in a peer-reviewed journal [8.3] As noted in the journal review, this study brings an interesting in-situ approach to determine Kearns factors and Hill's anisotropy factors. Further research work is proposed to obtain ballooning test data on fuel sheaths with different simulated braze microstructures to obtain the Hill's anisotropy factors for validation of this in-situ approach using texture (ODF) data to predict the anisotropy factors.

With the in-situ approach developed in the above study (Chapter 6) to determine Kearns (texture) numbers Hill's anisotropy factors, the mechanical anisotropy behaviour 
was predicted for two modifications ('A' and 'B') of $\mathrm{Zr}-2.5 \mathrm{Nb}$ pressure tube materials. The results of this study are reported in Chapter 7. These two modifications had produced differently textured microstructure in the modified materials as characterized in detail by neutron diffraction during heating to $1050^{\circ} \mathrm{C}$. Modification 'A' material was produced using an as-manufactured $\mathrm{Zr}-2.5 \mathrm{Nb}$ pressure tube with a pronounced transverse texture and elongated $\alpha-\mathrm{Zr}$ grains, and modifying it by subjecting the pressure tube material with a high-temperature anneal $\left(875^{\circ} \mathrm{C}\right.$ for 17 days and slowly cooled). The texture obtained from this modification is a direct product of the phase transformation processes involved during the heating and cooling schedule that produced a material with two texture components (i.e., basal poles aligned in the transverse and close to longitudinal direction of the tube). The Modification ' $\mathrm{A}$ ' material has a dual microstructure consisting of equaixed primary $\alpha-\mathrm{Zr}$ grains in a matrix of Widmanstätten $\alpha$-Zr platelets. The Modification 'B' material was produced by cold-rolling of Modification 'A" material in the tube's transverse direction with about $60 \%$ reduction in wall thickness. The texture obtained from this modification is a direct product of the twinning processes involved with compression straining of the $\alpha-Z r$ grains that produced a material with four texture components (i.e., two different radial texture components, one transverse and one longitudinal texture component). The cold rolling process essentially 'sharpened' the longitudinal texture component and twinned the grains to produce two different radial-textured components. The texture changes are clearly shown in the texture ODF data. The previously unobserved $\alpha$-phase texture component that appeared during heating at $900^{\circ} \mathrm{C}$ in these two modified materials were also found in this 
study (Chapter 7), as it was first noted in the neutron study of the as-manufactured $\mathrm{Zr}-2.5 \mathrm{Nb}$ pressure tube [8.1]. The results for the Kearns (texture) numbers and the Hill's anisotropy factors for the two modifications ('A' and 'B') of $\mathrm{Zr}-2.5 \mathrm{Nb}$ pressure tube materials obtained in this study has been prepared to be presented and discussed at the PRICM-8 conference, and the manuscript is to be published in the proceedings [8.4]. Further investigations are proposed to obtain high temperature-ramped data that can be used to validate the mechanical anisotropy factors calculated using the texture (ODF) data.

\section{References}

[8.1] R.W.L. Fong, R. Miller, H. Saari, and S.C. Vogel, Crystallographic texture and volume fraction of $\alpha$ and $\beta$ phase in as-received $\mathrm{Zr}-2.5 \mathrm{Nb}$ pressure tube material during heating and cooling, Metall. Mater. Trans.A, Vol. 43A, pp. 806-821, 2012

http://dx.doi.org/10.1007/s11661-011-0914-6

[8.2] R.W.L. Fong, "Anisotropic deformation of $\mathrm{Zr}-2.5 \mathrm{Nb}$ pressure tube material at high temperatures, Paper presented at NUMAT 2012, Osaka, Japan, October 2012

Manuscript published in J. Nucl. Mater., Vol. 440, pp. 467-476, 2013

http://dx.doi.org/10.1016/j.jnucmat.2013.01.308

[8.3] R.W.L. Fong, Anisotropy factors from texture and mechanical strain in Zircaloy-4 fuel sheaths, J. Nucl. Mater., Vol. 440, pp. 288-297, 2013

http://dx.doi.org/10.1016/j.jnucmat.2013.04.089

[8.4] R.W.L. Fong, S. Vogel, R. Miller, and H. Saari, Characterization of the crystallographic textures and mechanical anisotropy factors in two modifications of $\mathrm{Zr}-2.5 \mathrm{Nb}$ pressure-tube materials, Paper to be presented at the $8^{\text {th }}$ Pacific Rim International Conference on Advanced Materials and Processing (PRICM-8), Waikoloa, Hawaii, USA, August 4-9, 2013, Manuscript to be published in Conference proceedings (2013) 


\section{Chapter 9}

\section{Future Research}

The following investigations are proposed for future research that relate to how detailed texture (ODF) information could be applied to help solve industrial technical problems. The future research proposed could also be used to provide a further understanding on the interactions between texture parameters and second phase constituents (e.g., zirconium hydride particles distributed in a textured zirconium matrix).

The following 7 proposals for future research are outlined, and discussed in a general and conceptualized way.

1) To evaluate the mechanical anisotropy response due to the two differently modified textures of $\mathrm{Zr}-2.5 \mathrm{Nb}$ pressure tube materials ('A' and ' $\mathrm{B}$ '), conduct uniaxial tensile deformation tests using longitudinal and transverse specimens at high temperatures using a temperature ramped test method, as used previously [9.1][9.2]. The data from the temperature ramped tests can be used to compare with those previously obtained on as-manufactured $\mathrm{Zr}-2.5 \mathrm{Nb}$ pressure tube materials [9.2]. The conclusion of this research should help furthering the understanding of texture effects on high-temperature anisotropic deformation behaviour. The research data could be used to develop a high-temperature deformation model with physics-based parameters.

2) Develop an analysis method for determining the values for the anisotropy factors $(F, G$ and $H)$ using Knoop hardness test data such as those reported in [9.3]. Then, use the determined anisotropy factors to predict the Kearns (texture) 
numbers and compare them to texture measurements. If such an analysis works, then one may not need to measure texture to get the ODF data on highly irradiated material. One would first use a pressure tube material that has been well characterized for its texture for this investigation.

3) Perform tensile and Knoop hardness tests on differently textured zirconium alloy materials that have been either embrittled with hydride particles, or have high soluble oxygen content, to determine how the mechanical anisotropy of the material may be affected. The material embrittlement using increased soluble oxygen level could be used to simulate hardening of material from exposure to neutron irradiation. The effect of irradiation on Zircaloy-2 materials has been previously reported to produce an isotropic mechanical behaviour in tensile tests on irradiated Zircaloy-2 calandria tube material [9.4] and also in Knoop hardness tests on Zircaloy-2 fuel cladding [9.3]. The anisotropy factors could then be used to develop an understanding of the interactions between textured grains and the second phase particles (e.g., hydrides) or interstitial solutes (e.g., oxygen or hydrogen in the lattice). Such an understanding could be used for modeling purposes to predict the effect of hardening with irradiation.

4) Conduct fuel sheath ballooning testing using simulated braze and as-manufactured sheathing materials which have been characterized for their texture data (Chapter 6) to obtain the data on creep deformation. This data can then be used to validate creep predictions using the calculated values for the 
anisotropy factors that were obtained using only the texture data. For this research, both uniaxial and biaxial tests with different stress ratios (axial-to-hoop stress) can provide the mechanical anisotropy factors for $F, G$ and $H$ values that can then be used to validate the calculated values obtained with texture data.

5) Propose a methodology to predict hydride reorientation propensity using known ODF texture data and applied stress on cooldown. Investigate whether texture data can be applied to predict the effect of texture and direction of applied stress for uniaxial and also biaxial stress state on hydride dissolution and precipitation

6) Investigate the possible use of a hydride distribution (HD) map to first determine the Hydride Orientation Parameter (HOP) using a digital autocorrelation function and then, using the HOP, build a correlation with the bulk texture parameter (say Kearns numbers for now, and use it to get the anisotropy factors) for the pre-hydrided materials. One may have to use additional parameters based on known hydride crystallographic orientation relationships with hcp $\alpha$-Zr lattice. This is an experimental program that would require using a test material with a known ODF (for the bulk texture) for $\alpha$-Zr phase. Then, hydride the material to get a range of maps for $\mathrm{HD}$ on the material (including tests with reoriented HD) to provide a range of $\mathrm{HD}$ maps for $\mathrm{HOP}$ characterization that can then be used to set up a correlation model to relate the bulk texture (ODF) with HOP. If this can be accomplished, then such a model could be used in predicting fracture toughness parameters and DHC velocity or $K_{1 \mathrm{H}}$ values. In addition, the same 
material should be investigated using Small Angle Neutron Scattering (SANS) technique to determine the size and orientation of hydride precipitates, as previously demonstrated [9.5]. A further extension of the SANS investigations is to study the nucleation and precipitation of hydrides to determine the nucleating shape of the hydride particles during cooling, and also during hydrogen charging into the metal matrix to simulate hydrogen pickup in-reactor. A further SANS study can also investigate the re-orientation of precipitated hydrides during cooling under applied stress. The direction quantification of HOP provided by SANS can then be used to calibrate the metallographic digital autocorrelation method.

7) Use EBSD and XRD to obtain texture data on the Modification 'A' and 'B' materials. Develop a way to calculate the ODF and used it for comparison with the ODF measured by neutron diffraction (Chapter 7). This will then allow for cross referencing and checking for consistencies between the three diffraction methods using electrons, X-rays and neutrons.

In summary, all of the above mentioned proposed work can be constituted for several thesis investigations, as future research into furthering the understanding of how crystallographic texture affects the mechanical behaviour of different zirconium alloys materials and for application to model deformation behaviour. 


\section{References}

[9.1] R.W.L. Fong and C.K. Chow, High-Temperature Transient Creep Properties of CANDU Pressure Tubes, Proc. of $23^{\text {rd }}$ Ann. Conf. Can. Nucl. Soc., Toronto, June 2002

[9.2] R.W.L. Fong, Anisotropic deformation of $\mathrm{Zr}-2.5 \mathrm{Nb}$ pressure tube material at high temperatures, J. Nucl. Mater., Vol. 440 pp. 467-476, 2013

http://dx.doi.org/10.1016/j.jnucmat.2013.01.308

[9.3] M. Nakatsuka and M. Nagai, Reduction of plastic anisotropy of Zircaloy cladding by neutron irradiation, (I) Yield loci obtained from Knoop hardness", J. Nucl. Sci. Technol., Vol. 24 [10], pp. 832-838, 1987

[9.4] X. Wei, J. R. Theaker, and M. Griffiths, Deformation anisotropy of annealed Zircaloy-2 as a function of fast neutron fluence, J. ASTM International, Vol. 5, No. 1, pp. 11, 2008

[9.5] R.W.L. Fong and S. Spooner, Investigation of zirconium hydrides and hydrogen solubility limit in Zr-2.5Nb alloy by small angle neutron scattering, Scripta Metall., Vol. 30, pp. 649-654, 1994 


\section{Appendix A}

An example of MAUD analysis using the Rietveld method and EWIMV algorithm used to calculate the orientation distribution function of crystallites using measured pole figures.

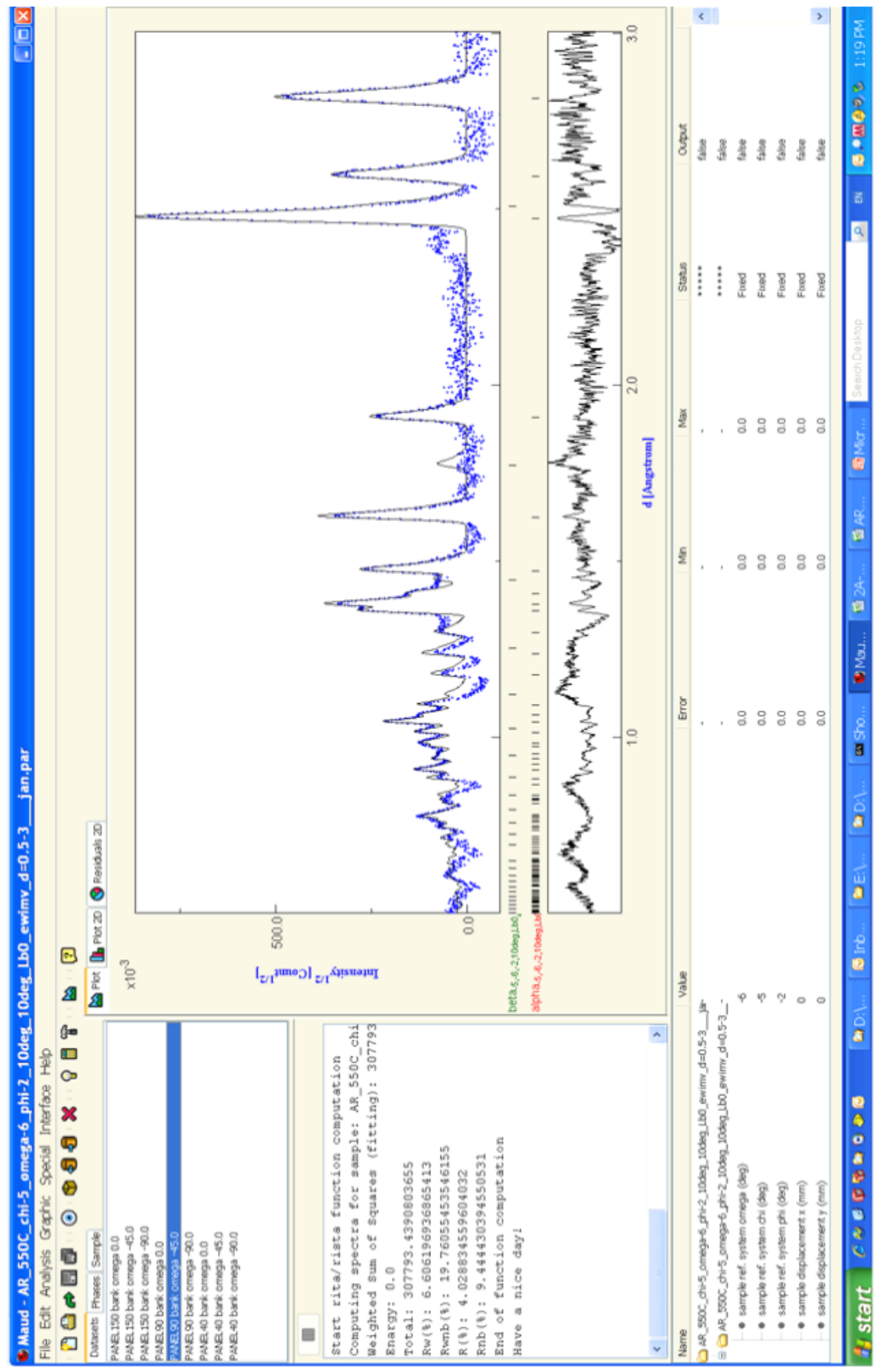

